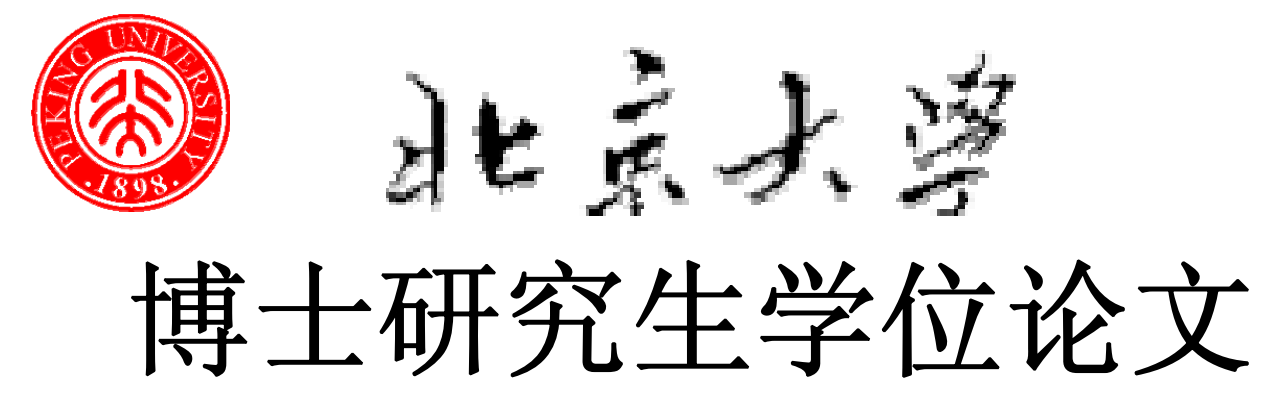

题目：北京大学 ERL-FEL 束线设计 和束流动力学研究

姓名: 王 桂 梅

学 号: 10304867

院系: 物理学院

专 业: 核技术及应用

研究方向: 粒子加速器的原理与技术

导师姓名：赵咅教授 $\mathrm{Yu}-\mathrm{Chiu}$ CHAO（美国)

$$
\text { 二 } 00 \text { 八年六月 }
$$





\section{版权声明}

任何收存和保管本论文各种版本的单位和个人, 未经本论文作者同意, 不得 将本论文转借他人, 亦不得随意复制、抄录、拍照或以任何方式传播。否则, 引 起有碍作者著作权之问题, 将可能承担法律责任。 



\section{摘 要}

能量回收直线加速器 (ERL) 不仅能够像储存环一样加速高流强电子束, 而 且还能像直线加速器一样保持束流的高品质, 可以获得超短电子束团, 束流流强 不受功率源限制, 并且降低垃圾靶辐射。ERL 的优点以及在高平均功率自由电 子激光上的成功实验引起了各国科学家和军方关注, 成为目前加速器领域发展的 热点和重要方向。北京大学超导实验室在建 “基于超导加速器的 SASE 自由电 子激光” 装置采用全超导技术, 为能量回收提供很好的试验和发展平台。

根据实验室发展规划, 结合北京大学在建设备, 论文进行能量回收自由电子 激光装置 (ERL-FEL) 理论和设计研究, 使它能在 $\mathrm{CW}$ 模式下运行, 产生高平均 功率自由电子激光, 达到掌握 ERL 的物理和关键技术, 为以后能量回收应用到 第三代同步辐射的升级和实现 MW 级高功率 FEL 研究等奠定基础。

论文主要工作是研究了 ERL-FEL 有关的物理问题, 完成了能量回收束线设 计和束流动力学研究。ERL-FEL 的束线设计需要满足两个方面的要求, 即 FEL 和能量回收的要求, 以实现高功率 FEL 输出和节约功率源功率的目标。论文的 工作主要有以下几个方面: 优化系统总体参数, 分析和计算对比能量回收和非能 量回收下所需射频功率; 详细研究了光阴极注入器的束流动力学, 并给出了最优 运行加速梯度; 比较各种并束段结构的特点, 对北大 ERL-FEL 实验室的并束段 进行优化设计; 系统分析了返航束线束流相空间调控和匹配要求, 在此基础上设 计了北大 ERL-FEL 的返航束线; 采用粒子追踪对束线的束流动力学进行研究, 包括短束团下的相干同步辐射效应和大能散下高阶相差的影响等。

论文考虑各种误差对束线传输的影响, 运用数学分析方法对返航束线轨道校 正系统进行优化设计, 在此基础上, 研究了束线结构各种误差的敏感性, 给出相 应的容差范围，验证了所设计系统的可靠性和稳定性。

此外, 还对 ERL 中多圈、多束团引起的束流不稳定性（BBU 效应）进行深 入研究, 得出该系统的阈值平均电流, 并找出最危险的高阶模, 为 PKU-FEL 实 现高平均功率 FEL 提供了理论依据。

论文的工作是紧密结合北京大学实验室的特点和 ERL-FEL 的要求进行优化 设计, 提出了工作在 ERL-FEL 模式下注入器中避免过聚焦的方案和运行要求, 
对将来注入器的调试具有指导意义; 通过研究, 提出了 $\mathrm{R}_{56}$ 独立可调的对称消色 散 $\operatorname{arc}$ 结构, 其中各磁铁功能独立, 可简化束流调试过程。

关键词: 能量回收, 自由电子激光, 空间电荷效应, 束流崩溃效应, 轨道校正 


\title{
Beam line design and beam physics study of Energy Recovery Linac Free Electron Laser at Peking University
}

\author{
Guimei WANG (Nuclear Technology and application) \\ Directed by Prof. Zhao Kui and Dr. Yu-Chiu CHAO
}

\begin{abstract}
Energy recovering linac (ERL) offers an attractive alternative for generating intense beams of charged particles by approaching the operational efficiency of a storage ring while maintaining the superior beam quality typical of a linear accelerator. In ERLs, the decelerated beam cancels the beam loading effects of the accelerated beam with high repetition rate. Therefore, ERLs can, in principle, accelerate very high average currents with only modest amounts of RF power. So the efficiency of RF power to beam is much higher. Furthermore, the energy of beam to dump is lower, so it will reduce dump radiation. With the successful experiments in large maximum-to-injection energy ratio up to $51: 1$ and high power FEL up to $14 \mathrm{~kW}$, the use of ERL, especially combining with superconducting RF technology, provides a potentially powerful new paradigm for generation of the charged particle beams used in MW FEL, synchrotron radiation sources, high-energy electron cooling devices and so on. The 3+1/2 DC-SC photo injector and two 9cell TESLA superconducting cavity for IR SASE FEL in PKU provides a good platform to achieve high average FEL with Energy Recovery.

The work of this thesis is on Beam line design and Beam dynamics study of Energy Recovery Linac Free Electron Laser for Peking University. It is the upgrade of PKU facility, which is under construction. With ERL, this facility can work in CW mode, so it can operate high average beam current without RF power constraint in main linac and generate high average FEL power. Moreover, it provides a test facility to study the key technology in ERL.

System parameters are optimized for PKU ERL-FEL. The oscillation FEL output power is studied with different bunch charge, transverse emittance, bunch length and energy spread. The theory of optimal RF power and $Q_{\text {ext }}$ with ERL and without ERL
\end{abstract}


is analyzed and applied to PKU injector and linac including microphonic effect.

Space charge effect in the injector and merger is studied for beam energy at $\sim 5 \mathrm{MeV}$. Simulation shows that in the $3+1 / 2$ DC-SC injector, there is a region the beam could be over focused by RF electromagnetic field and the transverse emittance in the transport line up to linac will increase instantly due to over focusing. In order to eliminate this effect on beam emittance, several solutions are investigated to avoid over focusing. This result is very important for beam loading experiment for low bunch charge operation. Meanwhile, different merger structures are compared in terms of error sensitivity and emittance increase with space charge effect.

In recirculation beam line, a new symmetric $180^{\circ}$ arc structure is designed. It fulfills the achromatic condition and adjustable bunch compression. These two parameters are controlled by different Quads knob. With this novel structure, the recirculation lattice can achieve path length adjustment, bunch compression and decompression in a large range.

With beamline error, the beam central orbit will deviate from the designed trajectory. An orbit correction system is optimized, which balances between cost and performance of orbit after correction at design level. Different methods are used to estimate its robustness. The BBU instability, especially multi-pass BBU imposed a potentially severe limitation to the average current that can be accelerated in an ERL. Simulation gives the harmful HOMs and predicts that the threshold average current in this machine is much higher than the possible operation current.

This work is based on the existing facility in PKU, so it provides guidelines for the facility operation and upgrade in the future. The theoretical analysis of ERL requirement and FEL requirement on beam transport line and beam property paves the way for future ERL research.

Key Words: Energy Recovery Linac, FEL, Space Charge effect, Multi-pass BBU, Beam orbit correction 


\section{目录}

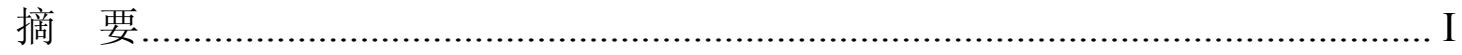

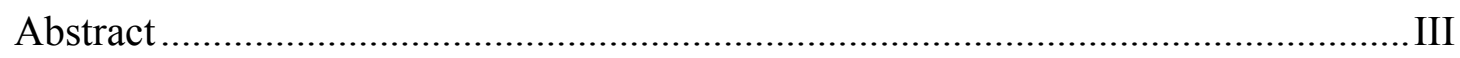

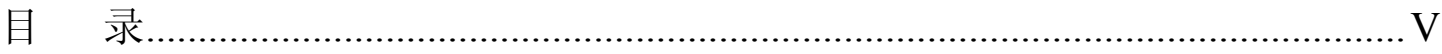

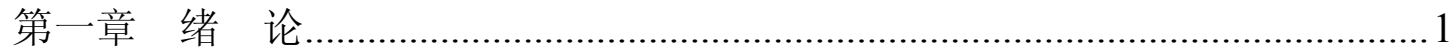

1.1 能量回收的概念和优点..............................................................................

1.2 能量回收直线加速器的发展历史和现状……………………………………...

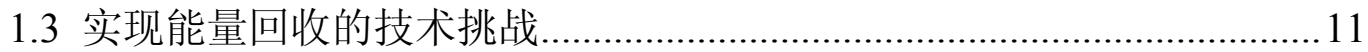

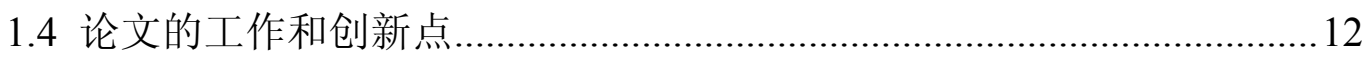

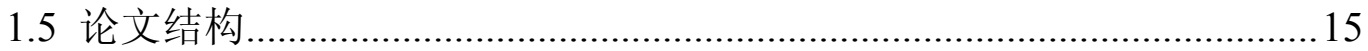

第二章 北京大学 ERL-FEL 装置总体介绍...…………………………………………17

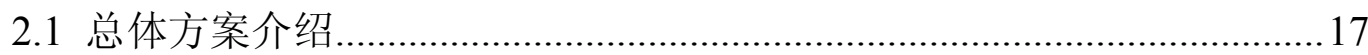

2.2 PKU 腔镜式高平均功率 FEL 设计的初步考虑 …………………………....18

2.2.1 腔镜式 FEL 工作过程 …………………………………………….... 18

2.2.2 FEL 的基本关系 ………………………………………………......... 19

2.2.3 高平均功率 FEL 主要物理和技术挑战及解决途径 ………………22

2.3 北京大学 FEL 增益和输出功率研究 ………………………………………2. 23

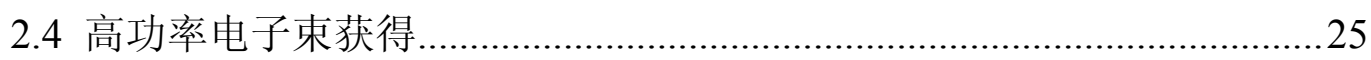

2.4.1 超导腔基本参数和束载分析…………………………………………....26

2.4.2 北京大学超导腔运行参数分析.............................................................34

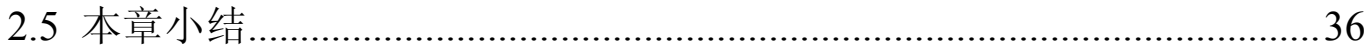

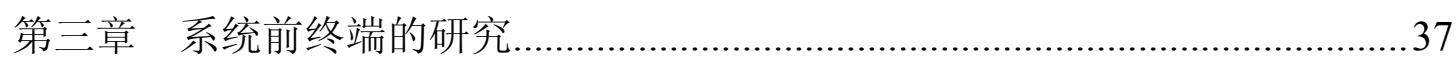

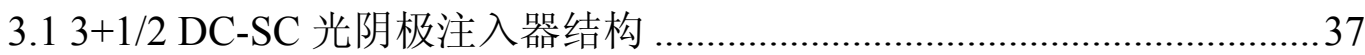

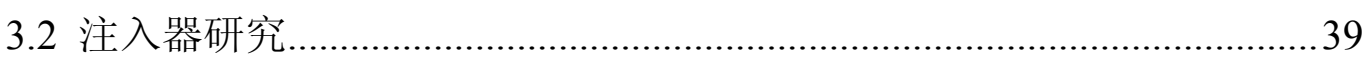

3.2.1 注入器束流动力学研究....................................................................39

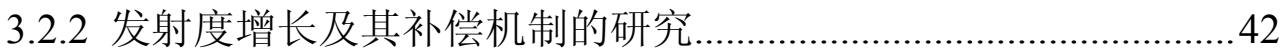

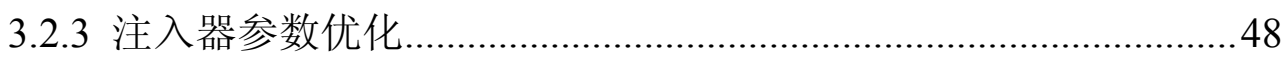

3.3 merger 结构研究 …………………………………………………………........

3.3.1 不同消色散 merger 结构研究 ……………………………………....5 
3.3.2 三块磁铁 merger 结构优化设计 58

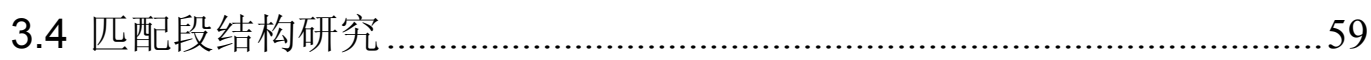

3.4.1 匹配段结构方案一 ......................................................................6 63

3.4 .2 匹配段结构方案二 ……………………........................................65

3.5 前终端束线结构和束流动力学模拟 ……................................................6 67

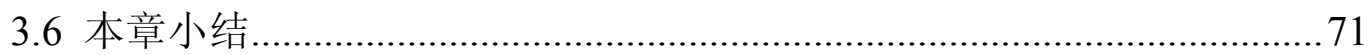

第四章 返航装置设计 ......................................................................................... 73

4.1 返航束线总体要求............................................................................................. 73

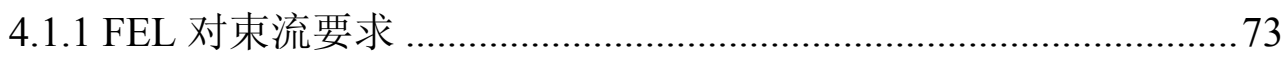

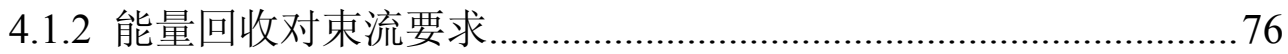

4.2 束流纵向相空间调控 .............................................................................. 78

4.2.1 束流纵向相空间调控条件 ................................................................. 78

4.2.2 ERL-FEL 中束团长度和能散调控理论…………………………..... 81

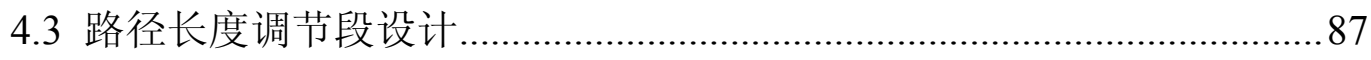

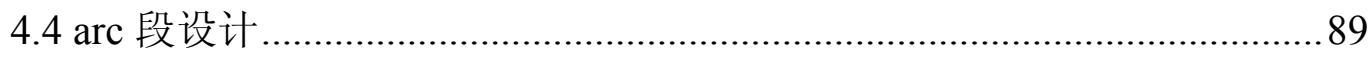

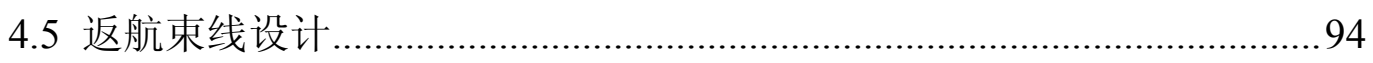

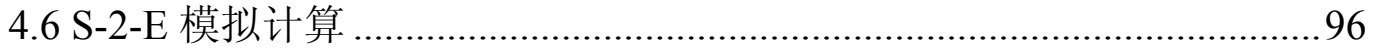

4.6.1 主加速器到扭摆器入口的模拟计算................................................. 96

4.6.2 扭摆器出口到主加速器的模拟计算................................................ 99

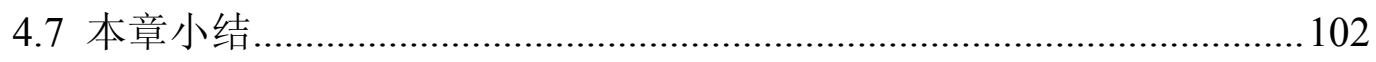

第五章 轨道校正系统优化设计和系统稳健性研究............................................. 105

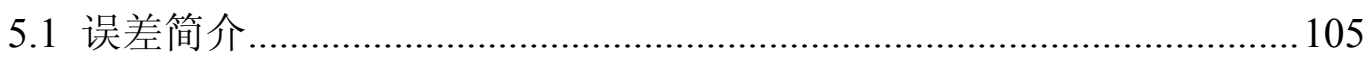

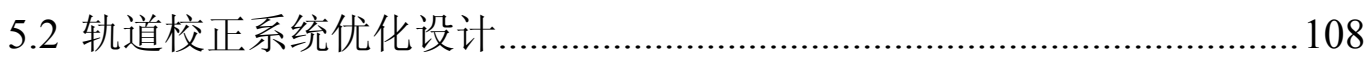

5.2.1 解析计算方法及轨道校正系统优化设计 ........................................109

5.2.2 粒子追踪研究轨道校正系统..........................................................113

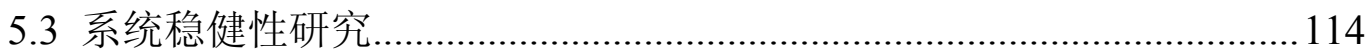

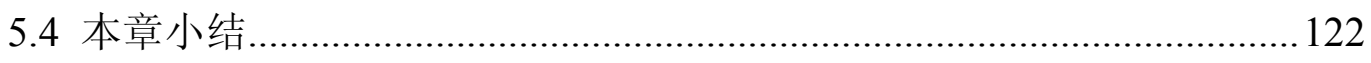

第六章 多圈束流崩溃效应理论与模拟计算......................................................... 123

6.1 多圈束流崩溃效应及单模阈值电流理论推导 ........................................... 124

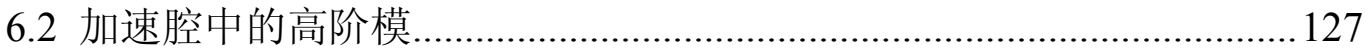




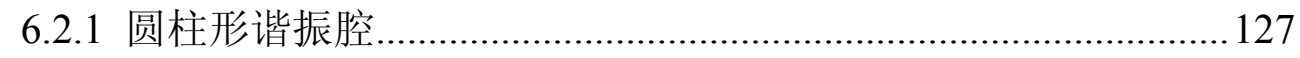

6.2.2 圆柱形波导的截止频率………………….................................... 129

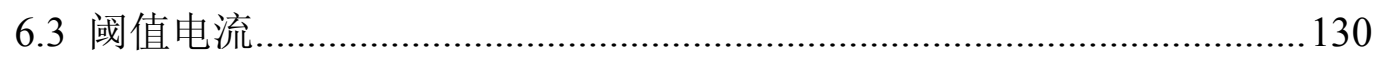

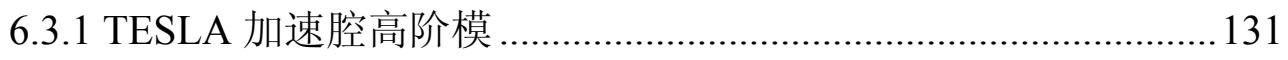

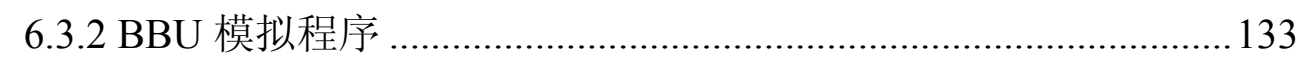

6.3 .3 阈值电流计算 .......................................................................... 133

6.4 阈值电流测量和提高阈值电流的方法 .................................................... 137

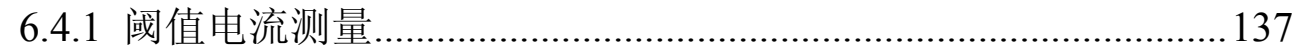

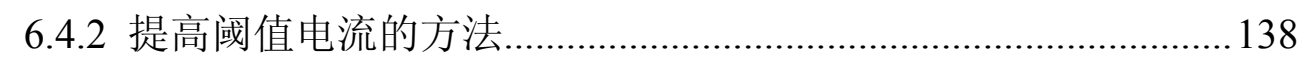

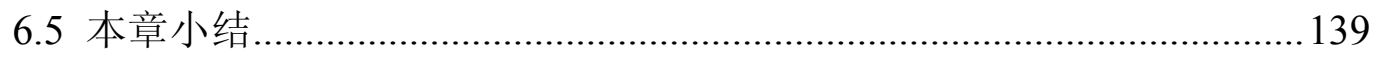

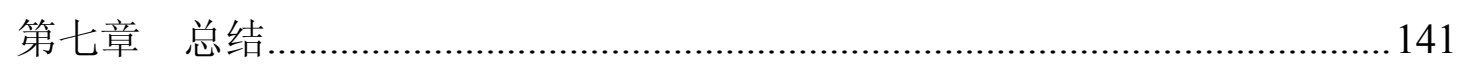

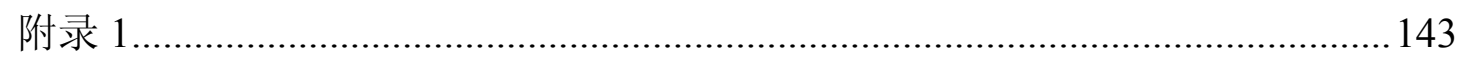

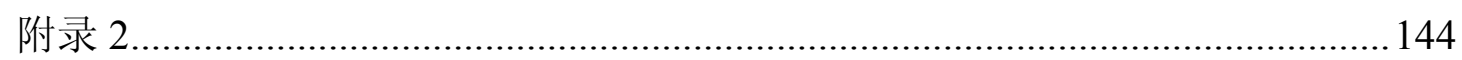

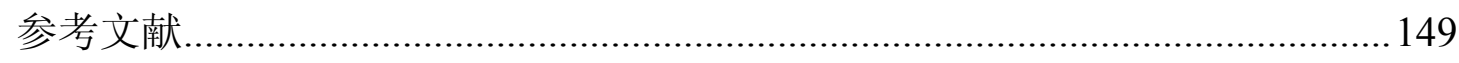

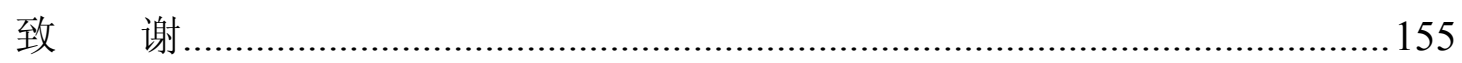





\section{第一章 绪 论}

随着新光源及各种应用的高能加速器装置的发展, 对电子束流品质的要求不 断提高（高亮度、高束团电荷量、低能散、超短束团长度和高平均流强）。最常 用的储存环装置受到辐射平衡条件的限制, 目前电子束品质 (特别是束团长度) 在储存环上的发展已经接近理论极限, 很难有大的新突破。另一类是直线加速器, 它能够很好的加速传输并基本保持电子源所能提供的高品质束流, 但这种直线加 速器对功率源要求很高, 受速调管技术、供电和运行成本的限制, 很难获得高平 均功率的电子束。

如何获得和保持高品质的高平均功率束流成为当今加速器领域的发展热点。 能量回收直线加速器 (Energy Recovery Linac, ERL) 是用直线加速器加速电子 束, 经应用后, 使用过高能电子束再通过束传输装置以减速相位返回到主加速器 中, 把高能电子束的功率转换为微波加速场功率, 用于加速注入器新注入的电子 束, 达到充分利用 “废” 束流能量的目标, 不需要大功率微波源就能实现大平均 流强电子束的加速, 节省了微波功率源规模和造价以及功率源的运行费用, 同时 也大幅度地降低进入垃圾靶 “废” 电子束的功率, 降低辐射污染水平。ERL 不 仅能够像储存环一样加速高流强电子束, 而且由于电子束是单次通过包括直线加 速器的输运环, 它还能像直线加速器一样保持束流的高品质, 获得超短电子束团。 它提供的高流强、高品质电子束在实现高平均功率自由电子激光、产生超短的同 步辐射光并进一步提高其亮度、电子束冷却以及电子-离子对撞等领域具有广阔 的应用前景, 成为目前加速器领域发展的热点和重要方向。

本章将综述 ERL 发展中的重要理论和实验进展, 分析 ERL 在加速器领域发 展中的历史、发展现状和趋势, 以及 ERL 中的关键技术。然后介绍本论文的选 题和特点。

\section{1 能量回收的概念和优点}

加速器中, 带电粒子在 $\mathrm{RF}$ 加速场中能量改变是 $d \varepsilon / d t=q \vec{v} \cdot \vec{E}_{c}$, 其中 $\vec{v}$ 是粒 子的速度, $\vec{E}_{c}$ 是加速腔中的电场, 合理选择带电粒子相对 RF 电场的相位, 粒子 得到加速, 加速场的能量转换给粒子, 类似的, 选择合适的相对相位, 粒子的能 
量也会转换给 RF 场。加速腔中的电磁场来源有两个: 微波功率源通过功率耦合 器在加速腔中建立电磁场; 运动束团通过有边界加速腔时, 它是一个电流源, 根 据 Maxwell 方程, 束团会在加速腔内产生电磁场。后续粒子在加速腔中感受的电 场 $\vec{E}_{c}$ 是它们叠加后的电磁场。

由于腔壁损耗、束流负载等, 加速腔内的电场 $\overrightarrow{E_{c}}$ 随时间衰减, 衰减常数 $\tau_{L}=Q_{L} / 2 \omega_{0}$, 即取决于加速腔的有载品质因子及工作频率。电子束是与腔内稳 定微波场作用以获得预期的性能。

能量回收时, 加速腔中的电磁场来源有微波功率源、加速束流和减速束流。 当加速束团和减速束团之间的时间间隔远小于加速结构的建场时间常数 $\tau_{L}$ 时, 减 速束团所激励的电磁场将补充加速束流所带走的功率, 从而节约了微波功率源功 率, 或者可进一步提高加速电子束的流强, 直到发生束流崩溃。

能量回收光源原理示意图 1.1 所示, 其工作过程是电子源提供的高品质电子 束通过 merger 注入到主加速器加速到预期的高能区, 高能电子束在插入件（如 扭摆器或波荡器）中辐射光, 作用过的电子束通过束流传输装置返回, 以减速相 位注入主加速器, 经主加速器减速后电子能量等于注入电子能量, 沉积到垃圾靶, 完成能量回收和发光过程。减速的高能电子束能量交还给 RF 电磁场的功率与加 速新注入的电子束所需功率基本相等, 因此, 功率源需要补充的功率主要用于加 速腔壁上热损耗和束线上辐射引起的电子能量丢失，与电子束的流强基本无关。

图 1.2 显示 JLAB FEL 实验测量结果, 表示各个加速腔在不同流强下功率源 馈入到加速腔的微波功率, 实验结果表明能量回收时加速器所需要的 RF 功率与 空载时所需要的功率基本相等, 与流强无关。

为了描述能量回收系统的效率, 引入功率倍增因子 ${ }^{[1]} \kappa \equiv P_{\text {beam }} / P_{R F}$, 它是机 器的束流功率 $P_{b e a m}$ 与用于加速束流所需要的 $\mathrm{RF}$ 功率 $P_{R F}$ 之比, 它表示微波功率 源的利用效率, $\kappa$ 越大, 效率越高。对于能量为 $E_{i n j}$ 、平均流强为 $I_{b}$ 的束流注入 到能量回收加速系统, 经加速后能量增加到 $E_{f}$, 则倍增因子可以表示为

$$
\kappa=\frac{P_{\text {beam }}}{P_{R F}} \approx \frac{I_{b} E_{f} / e}{I_{b} E_{\text {inj }} / e+P_{r f, \text { linac }}}
$$

其中, 系统所需要的微波功率分两部分: 注入器加速束流能量到 $E_{i n j}$ 时, 束流带 
走的功率 $I_{b} E_{i n j}$; 为了保持加速器中的电磁场, 补充腔壁热损耗、辐射损失、加 速束流带走的功率与减速束流返回的功率差等所需要的微波功率 $P_{r f, \text { linac }}$ 。

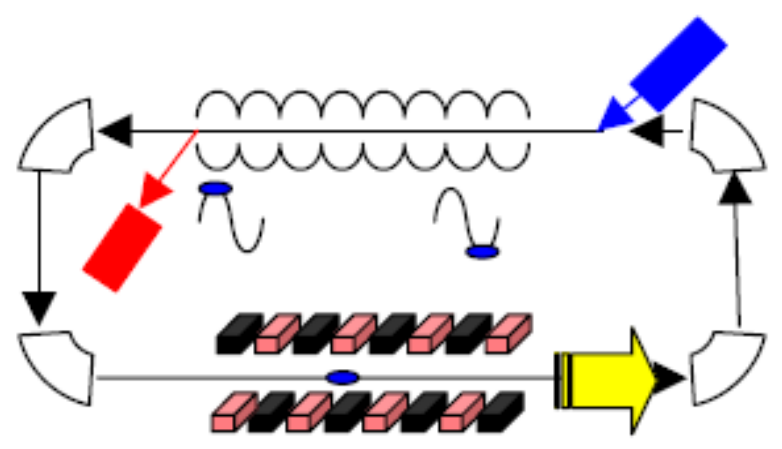

图 1.1 能量回收光源示意图

从表达式 (1.1) 可以看出:（1）注入能量越低, 功率倍增因子就越大。

束流强度越大, 功率倍增因子越大。当 $P_{r f, \text { linac }}$ 远小于注入束流功率, 倍增因子的 极限值是 $E_{f} / E_{i n j}$, 与电子束的流强无关。(3) 功率倍增因子随着微波功率 $P_{r f, \text { linac }}$ 的减小而增大。因此, 能量回收加速系统运行在高平均流强和高能量下更有优势, 并且 $P_{r f \text {, linac }}$ 尽可能小。

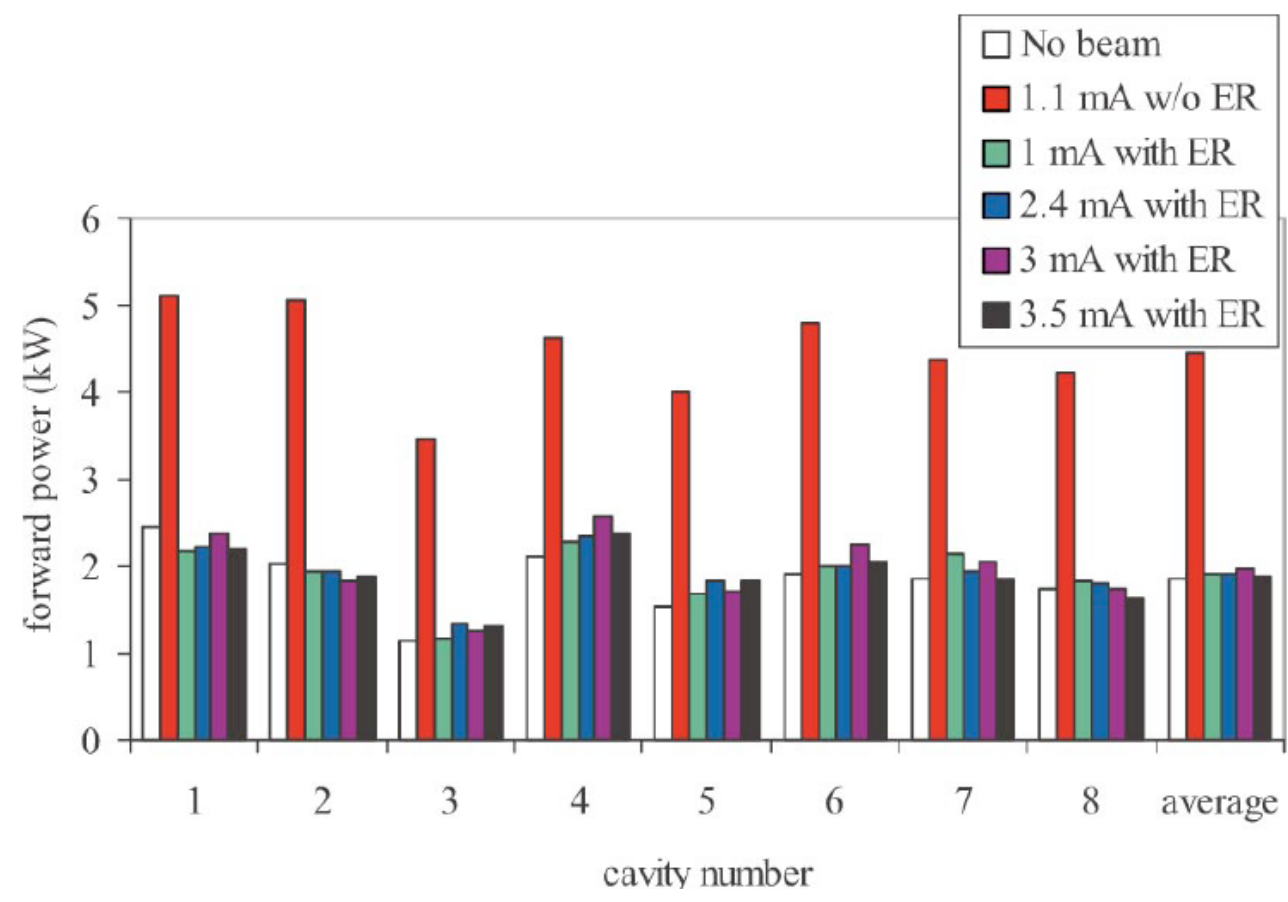

图 1.2 不同工作模式、不同流强下, 加速腔所需要的 RF 功率

连续波 $(\mathrm{CW})$ 模式下, 加速腔壁的热损耗 $P_{\text {diss }}=\frac{V_{c}^{2}}{(R / Q) Q_{0}}$, 其中, $V_{c}=E_{a c c} \cdot d$, $\mathrm{d}$ 是加速场长度, $R / Q$ 是只与腔形有关的参数, $Q_{0}$ 是腔品质因子。常用的加速 
器分两类: 常温加速器和超导加速器。常温腔和超导腔除了要求的运行温度差别 很大外, $Q_{0}$ 差别很大, 约 $10^{5}$ 量级。表 1.1 列出常温加速器和超导加速器典型参 数以及相应的腔壁热损耗, 计算结果表明: 在 $\mathrm{CW}$ 下, 加速场梯度为 $1 \mathrm{MV} / \mathrm{m}$ 时, 常温加速器腔壁热损耗在 $10 \mathrm{~kW}$ 以上, 并且随着加速场梯度增大, 腔壁热损耗随 场梯度呈平方增长, 而超导加速器的腔壁热损耗约 $1 \mathrm{~W}$, 增大梯度 10 20 倍, 热 损耗功率增大到百瓦量级, 仍远小于常温加速器的腔壁热损耗。 $\mathrm{CW}$ 加速场模式 下，腔壁热损耗限制了常温腔运行场梯度，加速场梯度一般低于 $1.75 \mathrm{MV} / \mathrm{m}$, 而 超导加速器 CW 模式下运行场梯度在 10 20MV/m。

表 1.1 常温加速器和超导加速器对照表

\begin{tabular}{|c|c|c|}
\hline 加速器类型 & 超导加速器 & 常温加速器 \\
\hline$Q_{0}$ & $2 \times 10^{9}$ & $2 \times 10^{4}$ \\
\hline $\mathrm{R} / \mathrm{Q}(\Omega / \mathrm{m}) @ 500 \mathrm{MHz}$ & 330 & 900 \\
\hline $\mathrm{P}_{\text {beam }} / \mathrm{L}_{\mathrm{c}}(\mathrm{W} / \mathrm{m}) @ \mathrm{E}_{\mathrm{acc}}=1 \mathrm{MV} / \mathrm{m}$ & 1.5 & 56000 \\
\hline $\mathrm{AC} \quad$ Power $(\mathrm{kW} / \mathrm{m})$ & 0.54 & 112 \\
\hline
\end{tabular}

虽然原理上常温加速器和超导加速器都可以实现能量回收, 但从 $\kappa$ 的定义可 以看到, 常温加速器的热负载效应巨大, 其 $P_{r f, \text {,inac }}$ 远大于超导加速器的 $P_{r f, \text {,inac }}$, 因此, 超导加速器的能量回收装置是实现能量回收最有效的途径。基于超导加速 器的能量回收, 可运行在 $\mathrm{CW}$ 模式下, 平均加速流强范围从几 $\mathrm{mA}$ 到上百 $\mathrm{mA}$, $\kappa$ 从十几到几百。

能量回收装置中, 电子束团是单次通过返航输运线, 束团时间结构可以很方 便的控制和改变, 束团长度可以压缩达到 $100 \mathrm{fs}$ 量级; 束流品质不受储存环上辐 射平衡的限制, 它主要由注入束流决定, 束流横向发射度相比储存环可以减小两 个量级, 或者亮度提高两个量级。因此, ERL 目前被认为第三代光源的升级一 3.5 代光源, 如康奈尔大学的光源和阿贡实验室 APS 光源升级。

超导直线加速器结合能量回收系统节约了 $\mathrm{RF}$ 微波功率, 实现高平均流强运 行, 能够提供目前直线加速器或储存环所不能实现的高品质、高功率束流。如 储存环上流强 $100 \mathrm{~mA}$, 束流能量 $5 \mathrm{GeV}$, 采用直线加速器, 束流带走的功率是 $500 \mathrm{MW}$, 若不采用能量回收, 巨大的功率消耗将很难承受; 储存环是目前无法 实现束团长度到 $100 \mathrm{fs}$ 量级; 而采用能量回收可以实现短束团、高流强运行, 并 且束流发射度进一步提高。 
此外, 回收后束流能量降到几 $\mathrm{MeV}$, 减少了高能粒子在垃圾靶处引起的中子 活化辐射, 避免了中子辐射屏蔽的困难; 降低了垃圾靶上所沉积的电子束功率 (降 为原来的 $E_{i n j} / E_{f}$ )。图1.3给出粒子不同能量范围辐射剂量沉积, 可以看出能量 在 $10 \mathrm{MeV}$ 以上开始有中子活化, 这部分很难屏蔽, 而能量回收装置可以避免中子 活化。

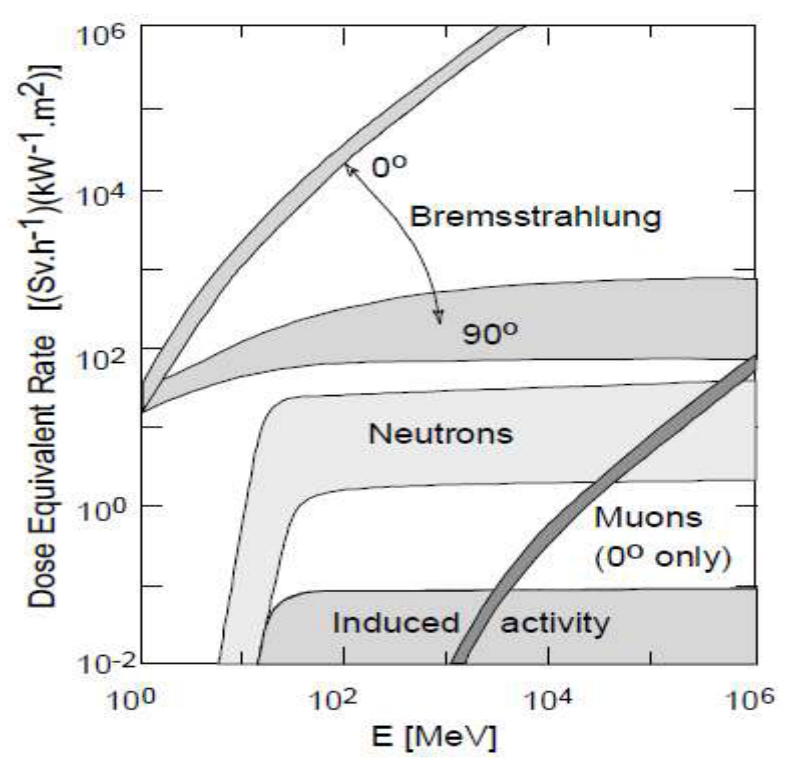

图 1.3 辐射剂量随束流能量变化曲线

因此, 结合超导加速器技术, 能量回收的优势总结如下。

（1）节能: 所需用的 RF 功率基本不依赖于束流流强, 加速平均流强不受 $\mathrm{RF}$ 功率源限制, 可实现束流 $\mathrm{CW}$ 或高占空因子模式加速, 解决了常温加速器在 高流强、高能量下加速所需要的巨大功率问题。

(2) 环保: 减少电子束沉积在垃圾靶上的辐射功率, 降低辐射能量, 减小 垃圾靶体积; 回收后束流能量将到 $10 \mathrm{MeV}$ 以下时, 避免中子活化辐射。

（3）束流品质高: 可以产生超短脉冲、高亮度的电子束。

(4) 系统效率高: RF 功率转化到可以利用的束流功率大大提高, 增加系统 的总体效率。

\section{2 能量回收直线加速器的发展历史和现状}

为实现对撞机高功率束流的要求, 1965 年, M. Tigner 第一次提出能量回收 概念 ${ }^{[2]}$, 他描绘出两种可能的能量回收装置方案, 分别是同一个加速器上回收能 量和不同加速器之间回收能量。它的基本思想是电子束可以从 RF 电磁场中获得 
能量, 同样通过合适选择加速后的高能电子束到达 RF 场的相位, 电子束能量也 会转移给加速腔中的电磁场。第一种方案是由同一个功率源控制的两台完全相同 的加速器分别加速相同流强的束流, 如图 1.4 所示, 加速后的两束束流经过传输 到达另一个加速器时都处于减速相位, 这样两个加速器分别从束流得到能量并加 速后续束流, 如此循环, 只需要对束流提供一次加速就能维持两台加速器运行。 但是此装置的缺点就是对两束束流完全相同要求很高, 并且需要两台加速器。

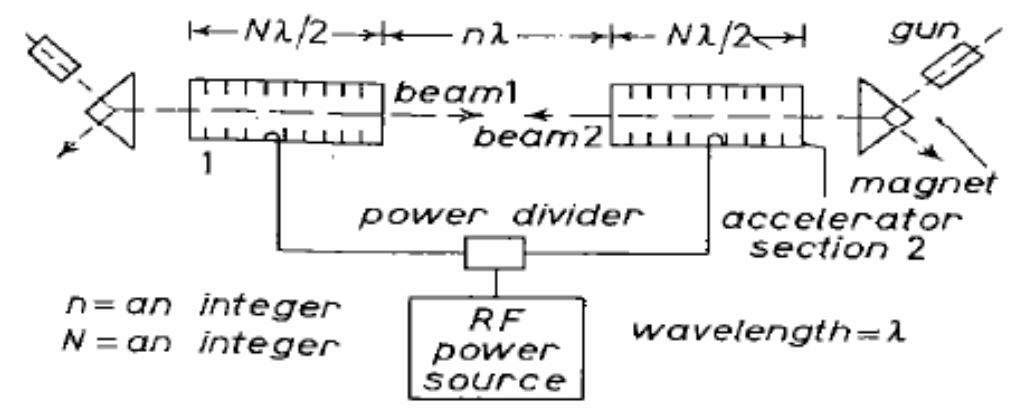

图 1.4 能量回收方案一

第二种方案如图 1.5 所示, 加速后的束流经传输后, 以合适的相位返回到同 一个加速器中, 把能量交换给加速场。这种结构需要加入带有磁铁结构的传输段 把束流传输方向改变 180 度返回到加速器, 它只需要一台加速器来维持机器运 行。

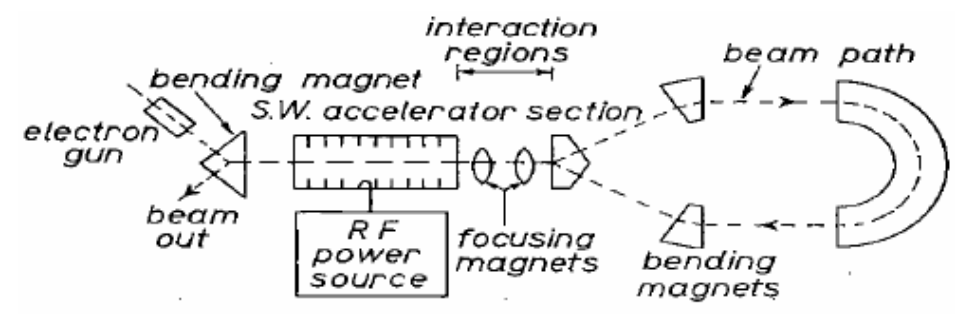

图 1.5 能量回收方案二

M.Tigner 提出能量回收方案在对撞机上至今没有实现, 然而他的两种构想 维形在不同的加速器装置上得以发展并实现。

1977 年, 加拿大的 Chalk River Nuclear Laboratories 在 reflextron 装置上第一 次实现能量回收 ${ }^{[3]}$ 。电子束通过常温加速器加速后, 由 180 度弯转磁铁改变电子 束传输方向返回到同一加速结构, 通过改变弯转磁铁到加速结构的距离, 电子束 再次通过加速器的相对加速场相位改变, 可以再次加速或减速电子, 输出的电子 能量范围在 $5 \mathrm{MeV}$ (能量回收) 和 $25 \mathrm{MeV}$ (再加速) 之间。

1985 年, MIT-Bates ${ }^{[4]}$ 加速器中心在同步再循环系统上通过改变电子束的路 
径长度, 使得返回的电子束相对加速场相位为 180 度, $400 \mathrm{MeV}$ 的电子束能量减 速到 $23 \mathrm{MeV}$ 。在这台系统上他们还做了返回的电子束相对加速场相位 90 度和 0 度的返航实验。当相对相位为 90 度时, 电子束通过加速器共三次, 第二次通过 加速器时电子能量保持不变, 因此该电子束第三次通过加速器, 相对加速场相位 是 180 度, 电子束能量被减少。相对相位为 0 度时, 电子束返回加速器时再次被 加速, 输出电子束能量从 $250 \mathrm{MeV}$ 到 $480 \mathrm{MeV}$ 。

1986 年 7 月, Stanford University's Superconducting Accelerator (SCA, Same Cell Energy Recovery）实现 $55 \mathrm{MeV}$ 电子束平均流强 $150 \mu \mathrm{A}$ 的能量回收实验, 回 收后束流到 $5 \mathrm{MeV}$, 它是能量回收在射频超导加速器上第一次得到验证。基于当 时射频超导腔的发展情况, 多电子倍增效应限制了加速场梯度和加速能量; 为了 得到更高的能量, 束流通过加速器多圈加速, 但由于高阶模未能充分衰减, 束流 平均流强受到多圈束流崩溃 (Beam BreakUp, BBU) 的限制, 射频超导直线加 速器结合能量回收加速高平均流强的优势当时并没有得到体现。

同时期, Los Alamos National Laboratory 的自由电子激光装置上也实现了能 量回收, 电子束能量从 $21 \mathrm{MeV}$ 降低到 $5 \mathrm{MeV}$, 该装置的特点是有两台加速器, FEL 后电子束传输到另一加速器, 能量交还给另一加速器。虽然不同加速器之间 的能量回收实验得到验证, 但是这种方式迄今为止没有再被采用。

从 1990 年到 2007 年, Jefferson Lab 分别在四台不同装置上实现了电子束能 量回收, 并取得巨大进展: 能量在百 $\mathrm{MeV}$ 时加速流强约 $10 \mathrm{~mA}$, 能量在 $1 \mathrm{GeV}$ 时返航能量和注入能量比最大到 51: 1, 这是目前 ERL 所达到的流强和能量比 最高纪录。 ERL 实验在 Jefferson Lab 取得的巨大成就与射频超导技术的发展密 不可分。1985 年, Jefferson Lab 提出建造基于射频超导技术的 $4 \mathrm{GeV}$ 电子加速器 装置做核物理实验, Cornell University 针对超导腔多电子倍增效应和消除 HOM 专门设计了椭圆超导腔结构。在 CEBAF 初期建造时, 为专门研究 BBU 问题, 在注入器后连接单圈返航束线, 注入器能够加速 $5.5 \mathrm{MeV}$ 平均流强 $200 \mu \mathrm{A}$ (重 复频率 $1497 \mathrm{MHz}$, 电荷量 $0.12 \mathrm{pC}$ ) 的电子束, 返航束线上带有两个 cryomodule, 加速束流能量到 $43 \mathrm{MeV}$, 此返航束线可以再次加速束流到 $80 \mathrm{MeV}$ 或者能量回收 (由于第二圈传输时束流丢失严重, 最高平均流强运行在 $30 \mu \mathrm{A}$ ) 束流减速到 $5.5 \mathrm{MeV}$ 。

同时, JLAB 还提出建造 SRF 直线加速器驱动的 FEL 装置, 并采用能量回 
收技术，该装置运行在 CW、中等束团电荷量下，它一方面保持高平均流强、高 束流品质, 同时还降低 RF 功率源的要求, 产生高平均功率的束流, 提高系统功 率转换到光功率的效率。1991 年, 基于 ERL 的 FEL 初步设计被提出- IR FEL Demo, 1998 年, 这台红外 FEL 装置成功运行, 注入能量是 $10 \mathrm{MeV}$, 平均流强 $5 \mathrm{~mA}$, 经主加速器能量增大到 $48 \mathrm{MeV}$, 至 2001 年, 该装置输出红外 CW FEL, 平均功率到 $2 \mathrm{~kW}$ 。

随着 IR FEL Demo 的运行成功, SRF 结合能量回收（ERL）的优势得到认 定。ERL 技术开始受到关注, 并推广到可能的应用领域, 它们对束流的要求包 括高流强和高能量。

2001 年, Jefferson Lab 在高能 CEBAF 装置进一步研究能量回收技术, 它在 很长的直线加速器上实现了多圈加速和多圈减速。通过在返航束线上加入 chicane 结构, 改变束流路径长度, 装置由设计的能量再加速模式 (energy recirculating) 改造为能量回收模式, 2003 年, $56 \mathrm{MeV}$ 的注入能量加速到 $1056 \mathrm{MeV}$ 并成功回收束流, 流强为 $80 \mu \mathrm{A}$; 当 $20 \mathrm{MeV}$ 能量注入时, 返航能量与注入能量 比最大到 51: 1, 是目前所达到的最大能量比实验, 也是目前 ERL 运行的最高 能量, 加速器长度达 $1.3 \mathrm{~km}$ 。高能下的能量回收的主要限制是当加速段很长时, 主加速中低能和高能束流所受聚焦力差别很大, 进而限制返航能量和注入能量的 最大比值。

IR FEL Demo 运行成功后, 该设备进一步升级 ${ }^{[5]}$, 主加速器部分加入两个 cryomodule, 束流能量到 $145 \mathrm{MeV}$, 注入束流可以输出平均流强到 $10 \mathrm{~mA}$, 由于 受束流崩溃效应（Beam Break Up）效应限制, 最高回收流强是 7.5mA, 束流功 率约 $1.1 \mathrm{MW} 。 2004$ 年 6 月, 该设备在 $\mathrm{CW}$ 模式下成功输出 $6 \mu \mathrm{m}$ 激光, 功率到 $10 \mathrm{~kW}$ 。2006 年 10 月, 该设备输出 $1.6 \mu \mathrm{m}$ 光 $14.2 \mathrm{~kW}$, 是 FEL 历史上所达到的 最高平均功率。目前, 他们正在推动 $\mathrm{FEL}$ 功率到 $100 \mathrm{~kW}$ 或更高到 $1 \mathrm{MW}$, 波长 拓宽到 UV, 也是对美国 80 年代提出的 “星球大战” 又一步推进。

继 JLAB FEL Demo 成功运行之后, 日本 JAERI 和俄罗斯的 BINP 也都在红 外 FEL 波段实现能量回收。

日本 JAERI 的 ERL-FEL ${ }^{[6,7]}$ 注入器运行 $5 \mathrm{~mA}, 2.5 \mathrm{MeV}$, 加速后能量 $17 \mathrm{MeV}$, 受制冷系统的限制, 它运行在宏脉冲模式下, 脉冲长 $1 \mathrm{~ms}$, 重复频率是 $10 \mathrm{~Hz}$ 。 正在向 $\mathrm{CW}$ 高平均流强升级。 
表 1.2 ERL-FEL 运行参数和升级参数

\begin{tabular}{|c|c|c|c|}
\hline & $\begin{array}{c}\text { JLAB } \\
10 \mathrm{~kW}\end{array}$ & $\begin{array}{c}\text { JAERI } \\
\text { Operating/Upgrade }\end{array}$ & $\begin{array}{c}\text { BINP } \\
\text { Operating/Upgrade }\end{array}$ \\
\hline $\mathrm{E}[\mathrm{MeV}]$ & 145 & 17 & $12 / 50$ \\
\hline $\mathrm{I}_{\text {ave }}[\mathrm{mA}]$ & 9 & $5 / 40$ & $20 / 50$ \\
\hline $\mathrm{Q}_{\text {bunch }}[\mathrm{pC}]$ & 135 & 500 & $900 / 2200$ \\
\hline$\varepsilon_{\mathrm{N}, \mathrm{rms}}[\mu \mathrm{m}]$ & 15 & 30 & 20 \\
\hline Rep rate $[\mathrm{MHz}]$ & 75 & $10 / 80$ & 22.5 \\
\hline Duty Factor[\%] & 100 & $1 / 100$ & 100 \\
\hline
\end{tabular}

俄罗斯 $\mathrm{BINP}^{[8]}$ 是在常温加速器上 (频率是 $180 \mathrm{MHz}$ ) 进行能量回收实验, 注 入能量是 $2 \mathrm{MeV}$, 最高能量到 $12 \mathrm{MeV}$ (主加速器采用单腔单 cell 结构), 输出 $0.2 \mathrm{~kW}$ 激光, 波长在 $0.12 \sim 0.18 \mathrm{~mm}$ 。他们计划把返航束线升级到四圈, 束流能量 到 $50 \mathrm{MeV}$, 平均流强到 $50 \mathrm{~mA}$, 输出的激光功率到 $10 \mathrm{~kW}$, 光波长在 $3 \sim 20 \mu \mathrm{m}$ 。 表 1.2 是已出光的三台 ERL-FEL 装置运行和升级参数。

ERL 实验的成功和发展潜力为它将来应用到各个领域奠定了坚实基础, 它 能实现高平均流强加速以及保持束流品质的特点受到广泛关注。最近几年, ERL 技术不断被提出应用到不同方面，可以划分到四个不同领域：高平均功率 FEL， ERL 光源、电子冷却装置和电子-离子对撞。光源和电子-离子对撞要求高能量, 束流能量到几个 $\mathrm{GeV}$; FEL 以及电子冷却离子更注重高流强, 平均流强到安培 量级, 束流能量要求是百 $\mathrm{MeV}$ 量级。

正在建造的基于能量回收装置的设备除了现有设备的升级外，还有 Daresbury ERLP ${ }^{[9]}(\sim 35 \mathrm{MeV}, 1.3 \mathrm{GHz}$, 平均流强大于 $0.8 \mathrm{~mA}$, 输出激光 $3 \sim 75 \mu \mathrm{m}$,

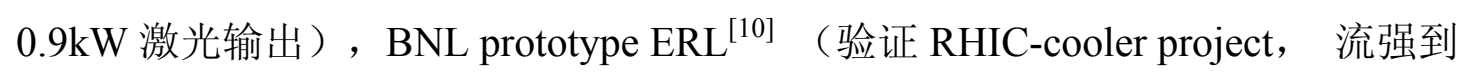

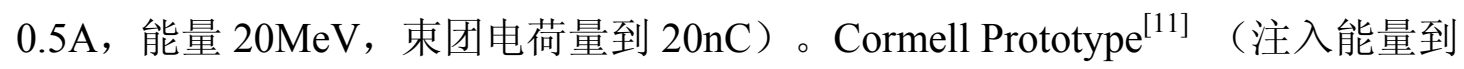
$15 \mathrm{MeV}$, 平均流强到 $100 \mathrm{~mA}$, 加速能量是 $100 \mathrm{MeV}$, 束团电荷量 $77 \mathrm{pC}$ ）, 目前 正在进行注入器试运行阶段。

基于 ERL 的高功率 FEL 装置新提出的主要有 KAERI FEL ${ }^{[12]}$ (电子束能量

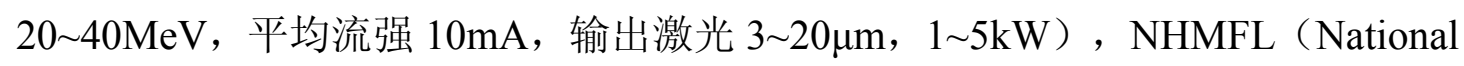
High Magnetic Field Laboratory, 电子能量到 $60 \mathrm{MeV}$, 束团电荷量 $135 \mathrm{pC}$, 平均 流强 $5 \mathrm{~mA}$, 束流功率 $300 \mathrm{~kW}$, 输出光波长 $2 \sim 100 \mu \mathrm{m}$, 激光功率 $1 \mathrm{~kW}, 37.5 \mathrm{MHz}$ )。 


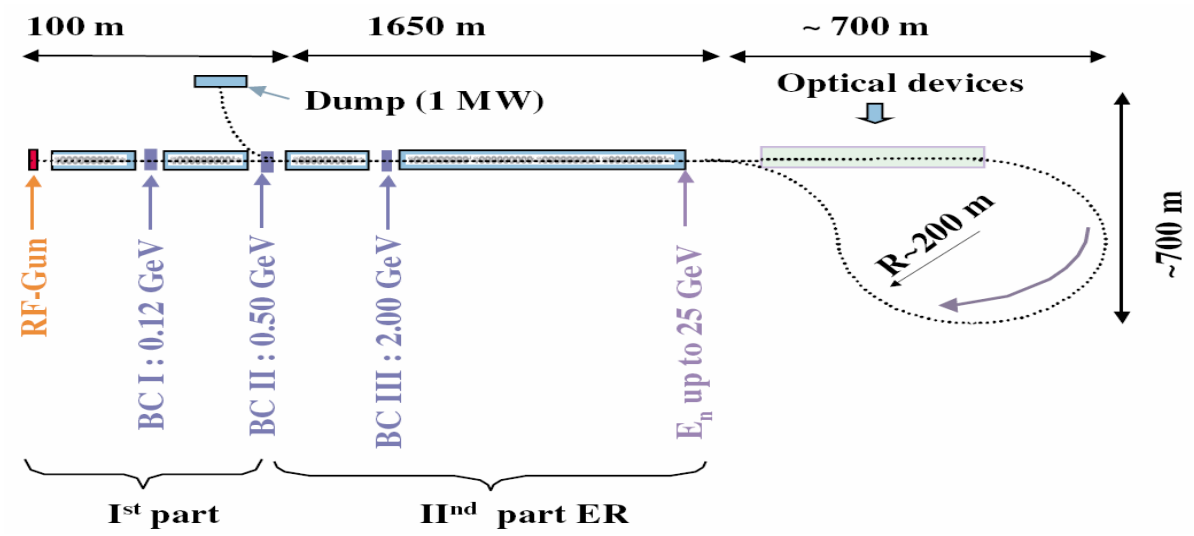

图 1.6 TESLA XFEL ERL 方案示意图

光源上计划采用 ERL 的有 Cornell ERL 光源 ${ }^{[13,14]}$, APS 第三代同步辐射光 源升级, Brookhaven ${ }^{[15]}$ 的 PERL, Daresbury 的 $4 \mathrm{GLS}^{[16,17]}$, Erlangen ${ }^{[18]}$ 大学的 ERLSYN, Lawrence Berkeley ${ }^{[19]}$ 实验室的 LUX 和日本的 $\mathrm{KEK}^{[20]}$ 。第四代光源上, 最新提出了能量回收结合 SASE XFEL 方案, 即 TESLA XFEL ERL ${ }^{[21]}$, 如图 1.6 所示, 电子能量最高加速到 $25 \mathrm{GeV}$, 输出光波长 $0.1 \sim 6.4 \mathrm{~nm}$, 不采用能量回收重 复频率是 $10 \mathrm{~Hz}$, 平均功率是 66 800W, 能量回收后它的重复频率到 $1 \mathrm{MHz}$, 光 平均功率和亮度提高 $10^{5}$ 。

BNL 的 RHIC ${ }^{[22,23]}$ 装置上计划采用电子束冷却技术, 要求电子束平均流强到 $200 \mathrm{~mA}$ ，束流能量 $55 \mathrm{MeV}$ ，束团电荷量约 $10 \mathrm{nC}$ 。

将 ERL 技术应用到电子离子对撞的概念装置有 $\mathrm{eRHIC}$ (基于 RHIC ${ }^{[24,25]}$ 装置)

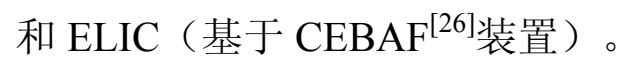

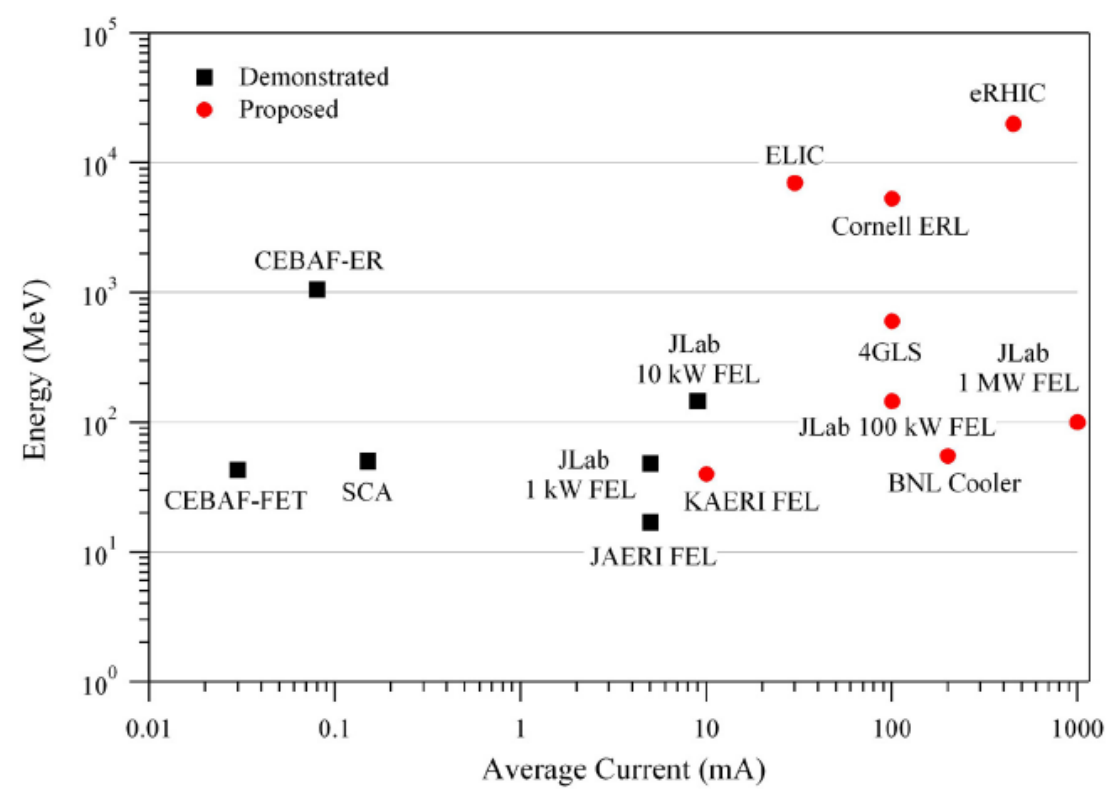

图 1.7 基于能量回收装置上能量与平均流强发展趋势 
图 1.7 给出 ERL 应用到各种装置上所运行的能量和平均流强, 可以看出, 光源上束流运行能量从几百 $\mathrm{MeV}$ 到几个 $\mathrm{GeV}$, 流强从 $10 \mathrm{~mA}$ （高相干模式）到 $100 \mathrm{~mA}$ （高通量模式），取决于运行模式。对撞机上， ERL 运行能量 $10 \mathrm{GeV}$ 范 围, 平均流强 $100 \mathrm{~mA}$ 。 ERL 未来发展方向是发展高功率束流——高平均流强和 高能量束流。

\section{3 实现能量回收的技术挑战}

能量回收推动加速器在发展高能量、高流强和保持电子束束流品质上显示出 巨大优势，它的挑战在于实现能量回收时束流和束线各相关参数达到预计的要 求, 使得 ERL 优势获得最大发挥, 系统效率达到最高。

从参数要求和束线结构上分析, 这些困难可以归结为三部分：注入器束线, 能量回收传输束线和超导加速器。

注入器束线: 它是从光阴极到主加速器入口的低能束线。ERL 的优势之一 就是束团单次通过能量回收传输束线和主超导加速器, 不受辐射平衡的限制, 束 流品质主要由注入束流决定, 换句话说, 注入器束线提供的束流品质决定了束线 上束流品质的上限。ERL 要求运行束流在高亮度、高平均流强和 $\mathrm{CW}$ 模式下。 为了得到最好的束流品质（高亮度），低能段要求产生低发射度束流，并控制传 输过程中空间电荷效应引起的发射度增长, 使它引起的发射度增长降到最小。空 间电荷引起发射度增长的控制是通过增大束流在非相对论段加速场梯度, 使束流 很快加速到高能。高平均流强要求束流高重复频率, 电子源热效应引起的发射度 增大将不可忽视。目前, 发展适合 ERL 要求的高亮度、高流强的注入器仍是国 际关注的热点之一。Cornell 优化设计的 DC gun, 束团电荷为 $0.1 \mathrm{nc}$ 时, 计算的 束流归一化发射度可以达到 $0.1 \mathrm{~mm}-\mathrm{mrad}$, 还有待实验验证。

并束段是能量回收装置的一个重要组成部分, 它的功能是把低能的注入束流 和高能的返航束流都传输到主加速器中, 它是由若干块磁铁组成, 束流横向和纵 向相空间的耦合, 非消色散时, 会引起束流发射度增大。这部分束线, 空间电荷 效应是束流品质变坏的一个重要主要因素。

能量回收传输束线: 束流加速到高能后, 能量回收传输束线对电子束发射度 的保持和相空间的调控是能量回收的另一挑战, 分为加速器和返航传输线两部 分。对不同能量的加速束流, 加速器横向聚集力不同, 对同向传输的加速和减速 
束流, 在加速器入口和出口, 两束流能量差别最大, 即 $E_{f} / E_{i n j}$, 聚焦力差别限 制了 $E_{f} / E_{i n j}$ 比值的极限, 也限制了系统的效率（ERL 系统的效率极限要求 $E_{f} / E_{i n j}$ 越大越好）。

返航束线除了需考虑同步辐射（SR）、相干同步辐射（CSR）以及空间电荷 力引起束流品质变坏外, 还要满足横向和纵向相空间匹配。束流应用不同, 对相 空间要求也不同。在振荡器式 ERL-FEL 中, 要求扭摆器中束流峰值电流高, 从 而增大 FEL 的增益; 经过 FEL 之后, 束流能散变大, 要求返航束线要能够传输 大能散束流到垃圾靶并保证束流不丢失, 这要求对纵向相空间匹配进行调控, 以 实现减速时加速器对束流能散的压缩。

超导加速器: 基于超导加速器能量回收最大优势是可以运行在高占空因子或 $\mathrm{CW}$ 模式下, 以获得高平均功率的电子束, 尤其是 $\mathrm{CW}$ 模式下, 它的潜力得到最 大发挥, 因此, ERL 在各个应用领域中都要求束流是 $\mathrm{CW}$ 、高流强运行。 $\mathrm{ERL}$ 中, 采用超导直线加速器加速束流到 $\mathrm{GeV}$ 时, 优化的加速场梯度约是 $20 \mathrm{MV} / \mathrm{m}$, 品质因子 $Q_{0}$ 约 $10^{10}$ 量级, 对应加速器成本 (取决于加速器长度, 与场梯度成反 比) 和制冷系统的功率消耗成本 (随场梯度平方增长) 之和最小化。目前, 加速 器运行在 $\mathrm{CW}$ 下的参数还没有达到以上的优化值, 还有待实验验证。此外, 高阶 模的衰减是超导加速器的另一挑战。高流强能量回收时, 束流通过加速器会激励 起高阶模, 当返航束流第二次通过加速器, 再次激励高阶模, 若与初次激励的高 阶模相互增强并形成正向反馈放大, 将引起的束流不稳定效应, 限制了最大加速 流强。

\section{4 论文的工作和创新点}

2005 年 3 月, 第 32 届 ICFA 会议在 Jefferson Lab 召开, 会议主题是 “能量 回收直线加速器” [27], 这是 ERL 第一次成为独立会议主题。此后, 能量回收直 线加速器会议每两年一次继续, 确定了 ERL 在加速器领域的发展地位。

另一方面, 2002 年 12 月, 北京大学的高增益自由电子激光项目“基于超导 加速器的 SASE 自由电子激光的关键物理和技术问题的研究”被列入国家重点基 础科研发展规划（973 项目）, 该 FEL 装置称为 PKU-FEL, 输出光在红外波段。 加速部分由 $3+1 / 2$ DC-SC 超导光阴极注入器、TESLA 型 $2 \times 9$ cell 超导直线加速 
器组成, 电子束重复频率是 $26 \mathrm{MHz}$, 它的工作模式是脉冲模式, 脉冲长度 $5 \mathrm{~ms}$, 重复频率是 $10 \mathrm{~Hz}$, 占空因子是 $5 \%$, 其限制之一来源于主加速器 RF 功率源。为 了进一步提高输出光功率, 实现高平均功率 FEL, 必须增大占空因子, 提高束流 平均流强。由于整台机器都是采用超导加速, 可以运行在 $\mathrm{CW}$ 模式下, 而不需要 考虑常温加速器高重复频率束载运行带来的巨大热损耗问题, 为能量回收提供最 好的试验和发展平台, 它将完全摆脱 RF 功率源的限制, 主加速器所需要的 RF 功率将取决于加速腔热损耗和麦克风效应。CW 模式下输出光平均功率可提高 20 倍, 它将是一台高重复频率、高功率红外用户装置。升级后的束流性能主要受制 于注入器。另外, 目前, 国内在能量回收上还没有任何实验装置, 这台装置将为 我国掌握能量回收技术提供最好的契机, 为以后能量回收应用到光源升级、MW 高功率 FEL 研究奠定基础。除此之外, 通过调制束流返回到加速器中的相位, 该设备还可以研究多圈加速。

在这个背景下, 作者结合北大现有设备, 集中研究能量回收模式下满足高功 率 FEL 要求的束线和束流动力学, 提出了系统升级设计, 主要包括以下几项工 作:

- RF加速腔运行参数优化。分析了能量回收和非能量回收模式下, RF腔与 束流相互作用时, 加速腔各参数之间的关系, 稳态下, 包括束载和麦克风 效应时, RF功率源所需要馈入的最小功率以及最佳运行参数 $Q_{\text {ext }}$ 的选择, 对系统实际运行有重要的参考价值。

- 系统前终端设计研究。在 $3+1 / 2$ cell DC-SC光阴极注入器结构基础上, 考虑 CW模式、大范围调变束团电荷量下, 使用PARMELA优化设计注入器参 数, 系统地研究各运行参数对束流品质的影响, 提出了在注入段传输线上 避免空间效应引起发射度增长的方案; 并运用程序ASTRA对比模拟结果, 确保模拟的正确性; 对不同的并束段结构误差的敏感度和空间电荷效应引 起发射度增长进行研究, 结合实际机器要求和限制, 确定最合适的并束段 结构; 完成前终端束线设计。

- 能量回收传输束线设计研究。理论分析优化束流纵向相空间参数; 使用磁 结构, 实现束流路径长度调变, 改变返航束流相对RF的相位, 改变机器 运行模式, 实现能量回收或再加速; 设计了对称消色散 $\operatorname{arc}$ 结构, 其 $R_{56}$ 大 范围可调; 完成满足FEL和能量回收的返航束线光学设计。 
- 轨道校正系统优化设计。论文分析和模拟计算了传输线上各种误差造成的 束流轨道偏离, 运用分析方法优化BPM和Corrector在传输线上的位置, 尽 量减少BPM和Corrector个数, 并使得校正后系统轨道偏离在可以接受范 围; 同时，使用粒子追踪的办法验证了优化后的校正系统的可靠性和稳定 性。

- 系统可靠性和稳定性研究。分析实际机器运行时, 考虑束流光学失配和电 源抖动等, 束流光学的敏感程度; 研究磁铁有系统安装误差时, 匹配段四 极铁和 $\operatorname{arc}$ 内部调控色散和 $R_{56}$ 的四极铁所需要调整的范围; 考虑非理想情 况下，系统所能容忍的磁铁准直误差和纵轴旋转误差。

- 束流不稳定性和CSR效应研究。理论分析并模拟计算多圈加速时束流崩溃 效应，给出相应的阈值加速电流，确定出有害高阶模; 模拟计算CSR效应 对束流品质的影响。

- S-2-E模拟计算。考虑空间电荷效应、同步辐射、相干同步辐射，使用程 序PARMELA和ELEGANT追踪粒子到FEL以及FEL之后到垃圾靶束流相 空间演变。

本论文工作具有下列特点和创新之处：

- 结合实验室发展规划, 理论研究注入器系统和主加速器系统在能量回收和 非能量回收模式下所运行的最优参数以及所需RF功率源功率。

- 根据实验室目前条件, 对运行的ERL的注入器运行参数进行优化, 使得前 端输运系统空间电荷效应引起的发射度增长通过注入器的SRF加速聚焦 结构补偿，发射度增长控制到最小，同时保证注入束流能量。

- 提出 $R_{56}$ 独立可调的消色散 $\mathrm{ARC}$ 结构, 并进行参数优化设计, 结构优点是 各磁铁功能独立, 避免机器运行中改变一个参数其他参数关联变化带来的 麻烦; 每个ARC除了满足束流传输方向 180 度改变外, 还能实现束线对束 流纵向相空间控制, 即FEL之前束团完全压缩和回收后能散压缩; 分析RF 场带来的二阶效应以及校正匹配条件。

- 运用数学分析方法优化轨道校正系统, 根据误差分布, 产生联系误差和测 量系统之间的响应矩阵（矩阵中包含corrector）, 通过SVD方法分析响应 矩阵, 清楚了解轨道的可观测性、误差的可校正性以及校正系统是否存在 
奇点。此方法的优点是能够清楚了解BPM和Corrector放置位置是否有效, 确保Corrector在一定范围内, 各个不同位置能够处理 $3 \sigma$ 以上的误差, 并 且BPM能够有效监测到束流轨道，避免BPM过少不能有效控制束流轨道 或过多而加大对Corrector的要求。

\section{5 论文结构}

论文第一章是绪论, 综述了能量回收的概念和优点, 能量回收的发展历史和 现状，以及实现能量回收存在的困难。

第二章介绍系统总体参数要求，包括 RF 系统和 FEL 参数。介绍 RF 功率源 运行参数之间的关系，考虑有束流负载和麦克风效应时，能量回收/非能量回收 下, 加速腔最佳运行参数和所需要的 RF 功率源功率。使用腔镜式 FEL 经验公式 估算输出光功率以及各束流参数对 FEL 功率的影响。

第三章是系统前终端的研究，是从光阴极到主加速器入口的传输线。使用 PARMELA 程序优化注入器参数和束流参数, 分析各个参数对束流品质的影响, 包括 DC 高压、束流相对 RF 相位、RF 平均加速场梯度、束团电荷量、束斑大小 和束团长度, 并使用 ASTRA 程序验证 PARMELA 模拟的正确性, 运用简单模型 分析不同注入情况下, 空间电荷效应对发射度变化趋势的影响, 提出前终端可能 避免发射度增长过快的方法。分析不同的 Merger 结构对误差的敏感程度, 并模 拟空间电荷效应引起的发射度增长范围，综合考虑各种因素，确定了适合北京大 学装置的前终端传输束线。

第四章是能量回收束线设计。优化路径调节装置（chicane 结构），使其涵 盖 FEL 开和关两种运行模式以及准直误差引起束流路径长度改变所需要调节的 $\mathrm{RF}$ 相位; 设计了对称消色散 $\operatorname{arc}$ 结构, 方便大范围调节 $R_{56}$, 满足 FEL 之前束团 完全压缩和 FEL 之后束团拉伸要求; 优化各匹配段, 使得束流横向光学匹配主 加速器、ARC 以及 FEL 的要求; 理论分析 RF 场引起束团纵向相空间弯曲效应, 给出消除二次项的最优匹配条件; 结合 PARMELA 跟踪结果, 运用 ELEGANT 跟踪粒子到 FEL 之前以及从 FEL 之后到垃圾靶束流相空间变化; 对 CSR 引起的 束流品质变化进行研究。

第五章是轨道校正系统优化和系统 robustness 研究。分析 corrector 对束流光 学的影响; 使用数学分析方法优化 BPM 和 Corrector 的位置和个数, 使得这部分 
花费最低, 并有效控制束流轨道在可接受范围; 应用 Elegant 程序追踪计算, 进 一步验证轨道校正系统的可行性; 运用 elegant 程序分析实际机器运行时, 束流 光学失配和电源抖动时, 束流光学的敏感程度; 研究磁铁有系统安装误差时, 匹 配段四极铁和 $\operatorname{arc}$ 内部调控色散和 $R_{56}$ 的四极铁所需要调整的范围; 考虑非理想 情况下, 系统所能容忍的磁铁准直误差和纵轴旋转误差。

第六章是能量回收束线上多圈加速束流崩溃效应。多圈加速时, 束流崩溃效 应是限制机器运行平均流强的主要机制, 这部分采用数值分析和模拟计算分析不 同高阶模所限制的最大平均流强, 确保机器运行流强在阈值电流之下。

第七章是总结。 


\section{第二章＼cjkstart北京大学 ERL-FEL 装置总体介绍}

北京大学自由电子激光装置是基于北京大学超导加速器平台, 其目标之一是 研究高平均功率自由电子激光的物理与关键技术问题。本实验平台运行能量较 低, 设备规模相对较小, 其注入器和主加速器均为超导运行, 为研究能量回收的 物理与关键技术提供很好的实验研究条件, 因此将能量回收技术应用于北京大学 自由电子激光装置是一个合理且恰当的选择。北京大学能量回收型自由电子激光 装置 (PKU-ERL-FEL) 可以为用户提供高平均功率、波长可调的自由电子激光。

本章研究的主要内容是: 在北京大学超导加速器平台现有条件下, 采用能量 回收方案, PKU-ERL-FEL 系统提供自由电子激光的能力以及相关的运行条件, 内容分两部分: 第一部分研究激光的品质, 对采用能量回收方案条件下的自由电 子激光工作参数进行优化设计, 包括电子束参数和扭摆器参数, 并研究输出光功 率与束流品质的关系; 第二部分研究了注入器和主加速器需要的微波功率以及加 速腔最优负载品质因子。

\section{1 总体方案介绍}

图 2.1 给出了 PKU-ERL-FEL 设计方案的示意图。它由 3+1/2cell DC-SC 光阴 极微波电子枪、主加速器、束团磁压缩装置、扭摆器和返航输运线等组成。 PKU-ERL-FEL 可采用两种 FEL 工作模式即 SASE-IR FEL 和振荡型的 IR FEL。

$3+1 / 2$ cell DC-SC 光阴极注入器提供的电子电子束能量增益约 $5 \mathrm{MeV}$, 工作频 率为 $1.3 \mathrm{GHz}$, 设计的最大运行场梯度约 $15 \mathrm{MV} / \mathrm{m}$ 。主加速器由两个 9-cell TESLA 型超导腔组成, 工作频率为 $1.3 \mathrm{GHz}$, 工作温度为 $2 \mathrm{~K}$, 主加速器在有束流负载下 的设计加速梯度是 $15 \mathrm{MV} / \mathrm{m}$, 通过主加速器, 电子束团可以获得 $20 \sim 35 \mathrm{MeV}$ 的能 量增益。

不采用能量回收时, 该装置用于 SASE 自由电子激光研究 ${ }^{[28]}$, 束流工作在宏 脉冲模式下, 束团微脉冲重复频率是 $26 \mathrm{MHz}$, 宏脉冲重复频率几十 $\mathrm{Hz}$, 单束团 电荷量到 $300 \mathrm{pC}$ 以上, 平均流强较低, 相应地输出的 $\mathrm{FEL}$ 平均功率也较低。采 用能量回收后, 要求束流工作在 $\mathrm{CW}$ 模式或长脉冲模式下, 若不改变单束团电荷 量, 则平均流强将达到 $8 \mathrm{~mA}$, 大大超过注入器的能力。按照北京大学 DC-SC 光 阴极注入器的现有设计, 在几十 $\mathrm{MHz}$ 重复频率下, 提供束团电荷量的能力从几 
十 $\mathrm{pC}$ 到上百 $\mathrm{pC}$, 在这样的条件下, 自由电子激光将是振荡器型工作模式。

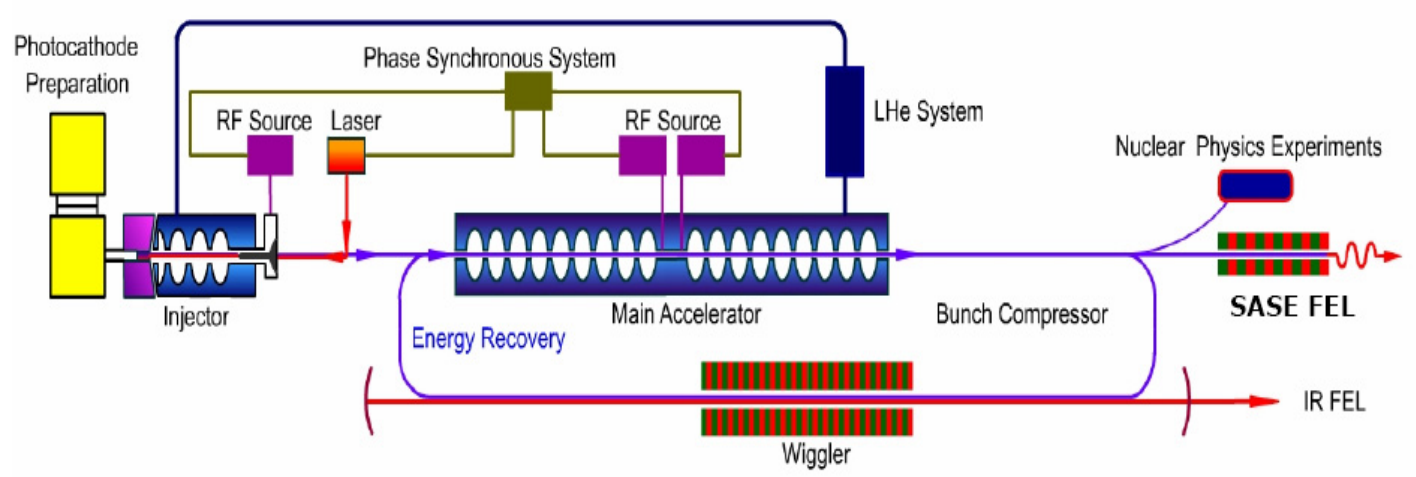

图 2.1 北京大学 ERL-FEL 设计方案示意图

\subsection{PKU 腔镜式高平均功率 FEL 设计的初步考虑}

腔镜式高平均功率 FEL 设计的主要要求有高平均功率、高品质电子束的获 得, 高效率的 FEL 和高抗辐射损伤的光腔等。由超导加速器组成的 ERL 是获得 高品质、高平均功率电子束的最有效途径, 它也是本论文的主要内容, 将在后面 几章讨论。

\subsection{1 腔镜式 FEL 工作过程}

腔镜式 FEL ${ }^{[29]}$ 工作过程如图 2.2 所示, 当相对论电子束通过处于光学谐振腔 内的扭摆器产生自发辐射, 而随着后续的新电子束团通过扭摆器器与经过端镜反 射的同向自发辐射的多次作用, 实现了光场对电子束团的能量调制向密度调整转 化, 从而产生受激辐射, 此时电子束与激光脉冲处于时空重叠状态, 随着激光场 的不断增强, 这种转换过程也加快, 束团的密集程度也越高, 最后达到稳定的饱 和状态, 这是 FEL 装置的主要工作过程。图 2.3 是腔镜式饱和时, 束流纵向相空 间沿扭摆器的演化过程。

对于高平均功率 FEL 光腔的要求除了需满足一般 FEL 的要求外, 主要困难 是由于腔内激光的功率非常高极易烧坏端镜。为此, 除了需要对腔镜进行冷却外, 主要是采用比较短的瑞利长度, 或者加大光腔长度, 以降低端镜所受的激光功率 密度。

在振荡腔中, 光束截面在 $\mathrm{z}$ 点的大小表示为

$$
w(z)=w_{0}\left(1+\left(\frac{z}{Z_{R}}\right)^{2}\right)^{1 / 2}
$$


$\mathrm{z}$ 表示离光束腰的距离, $w_{0}$ 表示束腰处的束斑直径, 瑞利长度 $Z_{R}=\frac{w_{0}^{2} \pi}{\lambda_{R}}$ 。减小 $Z_{R}$ 或增大 $\mathrm{z}$ 可以实现腔镜处的光斑增大, 降低端镜处的激光功率密度。

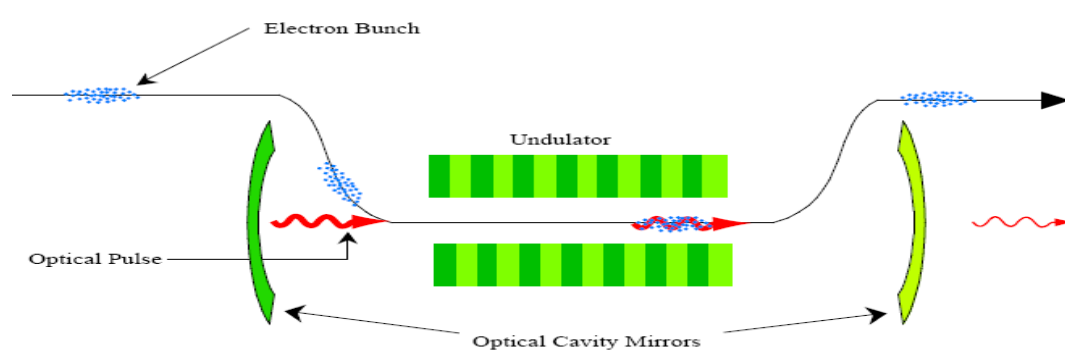

图 2.2 腔镜式自由电子激光示意图
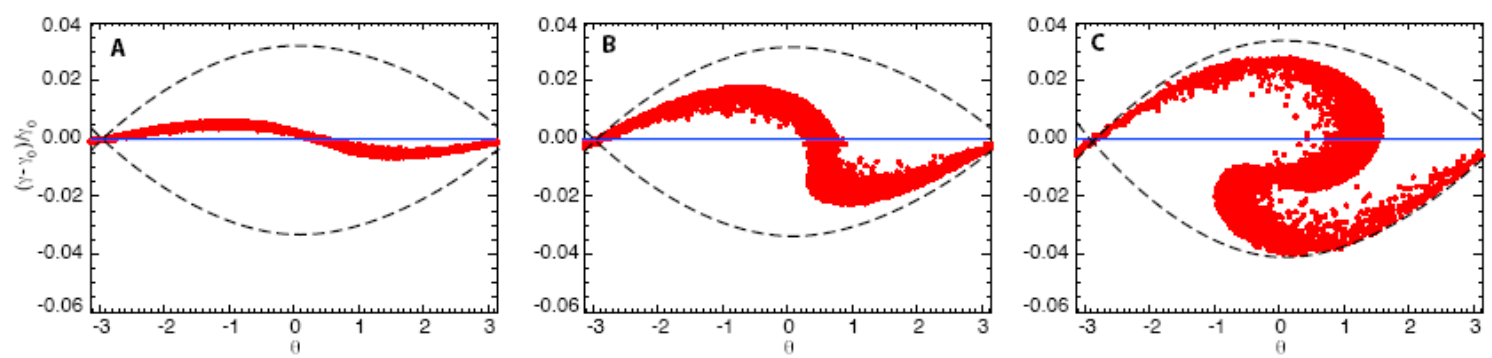

图 2.3 腔镜式饱和时, 束流纵向相空间沿扭摆器演化过程

( $\mathrm{A}-\mathrm{C}$ 为扭摆器入口到扭摆器末端)

从FEL理论可知, 对光腔的长度要求是:

$$
L_{c}=\frac{1}{2} n c \Delta T_{\mu}
$$

其中, $\Delta T_{\mu}=1 / f_{\text {beam }}$ 表示束团间的时间间隔, $L_{c}$ 是腔镜长度, $2 L_{c} / c$ 表示光 在光腔内来回一次所经历的时间, $n$ 是整数, 当 $n=1$, 表明光在腔镜来回一次所 经历的时间等于电子束团之间时间间隔, 腔内只有一个电子束团脉冲, 第一个束 团产生的光返回到扭摆器入口时遇到第二个电子束, 二者重叠并发生相互作用, 使光强得到增大; $m=2$, 表示腔内只有两个电子束团, 表明光在腔镜来回一次所 经历的时间是电子束团之间时间间隔的两倍, 第一个束团产生的光返回到扭摆器 入口时遇到第三个电子束等, 依次类推, 直到光的增益与腔内损耗相等, 即达到 所谓饱和状态。

\subsubsection{FEL 的基本关系}

表述FEL的基本参数有波长、增益和功率。

FEL基波共振波长是 


$$
\lambda_{r}=\frac{\lambda_{u}}{2 \gamma^{2}}\left(1+K^{2} / 2\right)
$$

其中, $\lambda_{u}$ 为扭摆器周期, $\gamma=E / m_{e} c^{2}$ 为相对论能量因子; 扭摆器磁场无量纲调 制参数 $K=\frac{e B \lambda_{u}}{2 \pi m_{e} c}=0.934 B[T] \lambda_{u}[\mathrm{~cm}]$, 式中, $e$ 为电子电荷量, $B$ 为扭摆器磁场 峰值磁感应强度, $m_{e}$ 为电子静止质量, $c$ 是真空光速。 $\lambda_{r}$ 是电子经过一个扭摆器 周期长度时光相对电子束滑移长度。由于 FEL 的增益函数 $g(x)$ 在共振波长为零, 其最大值对应的束流能量偏离共振能量, 因此, 输出波长偏离共振波长。

FEL 的增益 $G=-\Delta u / u$, 是电子束减少的能量与光的初始能量比, 表明光放 大的快慢程度。理想情况下, 电子束通过光腔中扭摆器的单次 FEL 小信号增益 ${ }^{[30]}$ 是

$$
g_{0}=-2 \pi^{2} \frac{I}{I_{A}} \frac{K^{2}[J J]^{2}}{\left(1+K^{2} / 2\right) \gamma} N_{u}^{2} g(x)
$$

$I$ 为电子束峰值流强, Gauss 分布束 $I=Q /\left(\sqrt{2 \pi} \tau_{\mu}\right), I_{A}=17045 A$ 是 Alven 电流, $[J J]=\left[J_{0}(\xi)-J_{1}(\xi)\right]^{2}$, 其中 $\xi=\frac{K^{2} / 2}{2\left(1+K^{2} / 2\right)}, g(x)=\frac{d}{d x}\left(\frac{\sin x}{x}\right)^{2}$, 对应的最大峰值 是 0.54 , 此时 $x=k_{u} L_{u}\left(\gamma_{0}-\gamma_{r}\right) / \gamma_{r}$ 是 1.3, 表明增益最大对应的能量偏离共振波长 对应的能量 $\gamma_{r}$ 。

实际上, 电子束有分布, 束团发射度、能散等因素会导致小信号增益减小。 考虑这些因素时, 激光小信号增益修正为 ${ }^{[31]}$

$$
G=0.85 \cdot 16 \pi \cdot 2.974 \frac{I}{I_{A}} \frac{N_{u}^{2}}{\gamma}[J J]^{2} \eta_{I} \eta_{f}
$$

$\eta_{I}$ 包含束流发射度和束流能散等因素造成的增益下降, $\eta_{f}$ 是填充因子, 表示光 和电子束有效作用强弱, 与光腔基膜和束包络函数有关。束团长度、能散、发射 度以及横向束包络分布都会影响增益。

（a）束流的能散与发射度对 FEL 增益的影响 考虑能散 $\sigma_{\gamma} / \gamma$ 和归一化发射度 $\varepsilon_{N}$, 增益减小系数

$$
\eta_{I}=\frac{2 \pi}{0.85} \int_{0}^{1} d \alpha \frac{\alpha(1-\alpha) \sin \psi e^{-\alpha^{2} \sigma^{2} / 2}}{\sqrt[4]{\left(1+a_{x}^{2} \alpha^{2}\right)\left(1+a_{y}^{2} \alpha^{2}\right)}}
$$




$$
\begin{gathered}
\psi=\alpha \nu-\frac{1}{2} \tan ^{-1}\left(a_{x} \alpha\right)-\frac{1}{2} \tan ^{-1}\left(a_{y} \alpha\right) \\
\sigma=4 \pi N_{u} \sigma_{\gamma} / \gamma, \quad a_{x}=\frac{2 \pi \varepsilon_{N} L_{u}}{\beta_{x 0} \gamma \lambda_{r}}, \quad a_{y}=\frac{2 \pi \varepsilon_{N} L_{u}}{\beta_{y 0} \gamma \lambda_{r}}
\end{gathered}
$$

$v$ 表示能量的失谐, $\beta_{x 0}$ 和 $\beta_{y 0}$ 表示扭摆器入口电子束包络, $L_{u}$ 是扭摆器长度, $\eta_{I}$ 最大时对应的最优 $v$ 近似为

$$
v_{\text {opt }} \cong 2.606 e^{-0.526 \sigma}+1.07 \sigma+(2+\sigma / 5)\left[\frac{a_{x}}{a_{x}+3}+\frac{a_{y}}{a_{y}+3}\right]
$$

填充因子

$$
\eta_{f}=\frac{4 \lambda_{r}}{2.974 \lambda} \frac{\alpha}{1+\alpha^{2} / 7} \int_{0}^{1} \frac{d x}{A_{e}(x)+1+\alpha^{2} x^{2}}
$$

其中: $A_{e}(x)=\frac{4 \pi \varepsilon_{N}}{\gamma \lambda Z_{R}} \sqrt{\beta_{x}(x) \beta_{y}(x)}, \quad \alpha=L_{u} / 2 Z_{R}, \quad x=2 z / L_{u}$

$$
\beta_{x}(x)=\beta_{x 0}\left(1+\left(\frac{Z_{R}}{\beta_{x 0}}\right)^{2} \alpha^{2} x^{2}\right), \quad \beta_{y}(x)=\frac{\gamma \lambda_{u}}{2 \pi K}
$$

对理想束流, 最优填充因子对应的瑞利长度 $Z_{R}=L_{u} / 2.96$ 。

(b) 束团长度对 FEL 增益的影响

前面提到当电子前进一个扭摆器周期时辐射场相对电子向前滑移一个波长。 若电子束团长度很短, 扭摆器中辐射光可能会向前滑移甚至离开电子束团。这将 影响增益。

定义滑移因子 $\eta_{\mu}=\left[1+\frac{N_{u} \lambda}{3 \sigma_{z}}\right]^{-1}, \quad \eta_{\mu}^{\prime}=\left[1+\frac{N_{u} \lambda}{2 \sigma_{z}}\right]^{-1}$, 其中, $\sigma_{z}$ 是电子束团 $\mathrm{rms}$ 长度。

激光增益由于滑移效应修正为:

$$
G^{\prime}=\eta_{\mu} G+0.265 \eta_{\mu}^{\prime} G^{2}
$$

束团越长，增益下降越厉害。

考虑腔镜耦合输出和传输损失时, 激光输出峰值功率为:

$$
P_{\text {out }}=\frac{(\Gamma-\delta) I_{s} \lambda L_{u} R_{A}}{2.97 \eta_{f}} \frac{G(1-\Gamma)}{\eta_{I} \Gamma}\left\{1-\exp \left[-\frac{1.8}{1+G / \eta_{I}}\left(\left(\frac{1}{\Gamma}-1\right)-1\right)\right]\right\}
$$


$\Gamma$ 是耦合输出系数, $\delta$ 是光传输损失系数, $I_{s}=\frac{m c^{3}}{16 \pi r_{e}} \frac{1+K^{2}}{[J J] N_{u}^{4} \lambda_{r}^{2}}, \frac{m c^{3}}{r_{e}}=8.71 G W$,

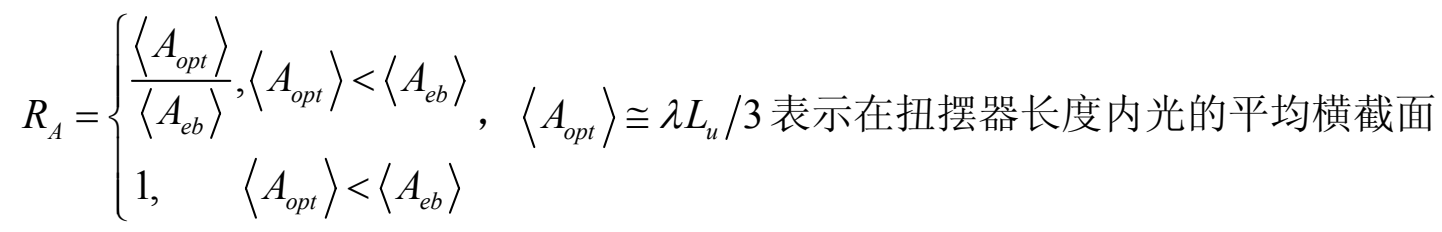
积, $\left\langle A_{e b}\right\rangle \cong(4 / 3)\left(\pi m c^{2} \varepsilon_{n} L_{u}\right) / E_{b}$ 是在扭摆器长度内束流平均横截面面积, $\varepsilon_{n}$ 是束 流横向归一化发射度。化简得到输出光功率与扭摆器周期数 $N_{u}$ 成反比。

理想情况下, 输出光功率和腔镜内饱和功率的关系是

$$
P_{\text {out }}=\Gamma P_{\text {sat }}
$$

平均光功率是 $P_{a v e}=2.35 P_{\text {out }} \tau f_{\text {bunch }}, \tau$ 是光脉冲长度, $f_{\text {bunch }}$ 是束团重复频率。 电子转换为激光的效率为:

$$
\xi \leq \frac{1}{2 N_{u}}
$$

$N_{u}$ 为波荡器的周期数。

\subsection{3 高平均功率 FEL 主要物理和技术挑战及解决途径}

高平均功率 $\mathrm{FEL}$ 主要指平均功率在 $1 \mathrm{~kW}$ 以上的 FEL。它在工业和国家安 全等方面有重大应用前景, 目前实验上已经实现 $14 \mathrm{~kW}$ 出光, 正在为平均功率达 兆瓦级的目标而努力。其主要物理和技术挑战是高平均功率、高品质、相对论电 子束的产生; 能承受高激光辐射的反射镜等光学器件; 以及通过 FEL 作用后的 高平均功率的废电子束对环境的辐射污染问题。解决这些技术问题最有效的途径 就是采用具有 ERL 的超导加速器和提高自由电子激光的能量转换效率。

高平均功率、高品质、相对论电子束的获得对于平均功率为千瓦级以上的 FEL 至关重要, 由于目前 FEL 的效率在 $1 \%$ 左右, 因此, 要求电子束的平均功 率达到十万瓦级。若实现军事上要求 MW 级 FEL 目标, 就要求电子束功率达到 100 兆瓦, 从目前常温加速器的效率, 就要求供电系统提供 200-300 兆瓦的电力, 相当于一座发电站的能量。因此只有采用超导加速和能量回收技术。超导 ERL 能耗包括超导所需的低温冷却系统和功率源的耗电, 其总能耗大约常温加速器的 三分之一。而提高自由电子激光的能量转换效率最有效的途径也是采用 ERL, 经 FEL 作用后的电子能量的大部分都转换为微波功率用于加速后续电子束, 废 
电子束的能量降到注入器水平, 它不但大幅度提高了 FEL 总体效率 (可提高几 十倍）, 而且解决了上述废弃电子束（其能量一般低于产生中子的能量）对环境 的辐射污染问题。

而从 FEL 本身, 为了解决腔镜损伤问题, 采用长腔镜以降低端镜的功率密 度, 同时对端镜采取泠却措施, 以保证光腔的正常工作。此外, 还可采用所谓 MOPA 的运行模式, 即 FEL 振荡器工作在低功率水平, 然后通过 FEL 放大达到 所需功率, 也是避开腔镜损伤问题的途径之一。

为了获得比较高的能量转换效率, 选取周期数比较少的扭摆器或所谓 taper 型扭摆器（零滑移运行模式）, 可使 FEL 的转换效率有明显甚至有成倍地提高。

综合考虑北大加速器束流设计指标和自由电子输出光波长波长范围 6 65 $\mu \mathrm{m}$, 扭摆器采用混合型永磁结构, PKU-FEL 扭摆器参数选择 $\lambda_{u}=4 \mathrm{~cm}$, $K=0.7 \sim 2$, 磁间隙在 $1.5 \sim 2.8 \mathrm{~cm}$ 之间。扭摆器周期数 $N_{u}$ 决定 FEL 辐射谱纯度主要 因素之一, 周期数越多, 谱纯度越高。由于高平均功率 FEL 追求的主要目标是 高功率和高效率, 因此, 采取牺牲一些谱纯度来获得高效率, 选取周期数为 25 。

为了解决腔镜损伤问题, 拟采用与短扭摆器相对应的短瑞利长度、长腔长的 光学腔结构, 以降低金属端镜表面的功率密度。此外, 还对金属端镜进行泠却, 加快端镜的热导, 以保证光腔的正常工作。选取光腔长度为 11.538 米, 对应端 镜上光斑尺寸约 $2 \mathrm{~cm}$ 。PKU-FEL 输出平均功率约 $800 \mathrm{~W}$, 饱和功率约 $40 \mathrm{~kW}$, 根 据目前实验经验, 加上泠却系统, 端镜是可承受这样大功率密度的。

\section{3 北京大学 FEL 增益和输出功率研究}

根据以上腔镜式 FEL 理论分析以及优化后的扭摆器参数, 用以上公式估算 了束团电荷量、横向归一化发射度、束团长度以及纵向归一化发射度 $\left(\varepsilon_{z}=\tau(\delta E / E) E\right.$, 改变纵向归一化发射度, 束团长度保持不变, 发射度变化对 应的是能散改变) 对输出光功率和光增益的影响, 如图 2.4-2.7。电子束、扭摆器 和腔镜基准参数以及输出光参数如表 2.1 。 
表 2.1 电子束和 FEL 参数表

\begin{tabular}{|c|c|c|}
\hline \multirow{8}{*}{ 电子束参数 } & 能量 & $35 \mathrm{MeV}$ \\
\hline & 束团电荷量 & $120 \mathrm{pC}$ \\
\hline & 重复频率 & $26 \mathrm{MHz}$ \\
\hline & rms 能散 & $0.4 \%$ \\
\hline & 束才长度 & $1 \mathrm{ps}$ \\
\hline & 纵向归一化发射度 & $80 \mathrm{keV}-\mathrm{ps}$ \\
\hline & 横向归一化发射度 & $10 \mathrm{~mm}-\mathrm{mrad}$ \\
\hline & 扭摆器中心的 BetaX & $33 \mathrm{~cm}$ \\
\hline \multirow{3}{*}{ 扭摆器参数 } & 扭摆器周期 & $4 \mathrm{~cm}$ \\
\hline & 扭摆器周期数 & 25 \\
\hline & 扭摆器参数 K & $0.7 \sim 2$ \\
\hline \multirow{3}{*}{ 腔镜 } & 瑞利长度 & $40 \mathrm{~cm}$ \\
\hline & 腔镜损耗系数 $\Gamma$ & $8 \%$ \\
\hline & 传输损耗系数 $\delta$ & $0.2 \%$ \\
\hline \multirow{3}{*}{ 光参数 } & 波长 (E:20 35MeV) & $6 \sim 65 \mu \mathrm{m}$ \\
\hline & 最大功率@120pC & $\sim 900 \mathrm{~W}$ \\
\hline & $\eta_{F E L}$ & $\sim 1 \%$ \\
\hline
\end{tabular}

束团电荷量从 $20 \mathrm{pC}$ 变化到 $120 \mathrm{pC}$ 时, 输出平均光功率从十几 $\mathrm{W}$ 到 $900 \mathrm{~W}$, 随电荷量增长。 $120 \mathrm{pC}$ 时, 横向归一化发射度从 $5 \mathrm{~mm}-\mathrm{mrad}$ 变化到 $20 \mathrm{~mm}-\mathrm{mrad}$ 时, 功率变化不超过 $6 \%$; 束团长度从 $0.5 \mathrm{ps}$ 变化到 $1.5 \mathrm{ps}$ 时, 功率变化最大到 $25 \%$; 纵向归一化发射度变化从 $70 \mathrm{ps}-\mathrm{keV}$ 到 $120 \mathrm{ps}-\mathrm{keV}$ 时, 功率变化不超过 $5 \%$ 。结果 表明, 横向发射度和能散对功率影响较小; 束团电荷量和束团长度对功率影响更 明显, 这两个参数都改变束流峰值流强。

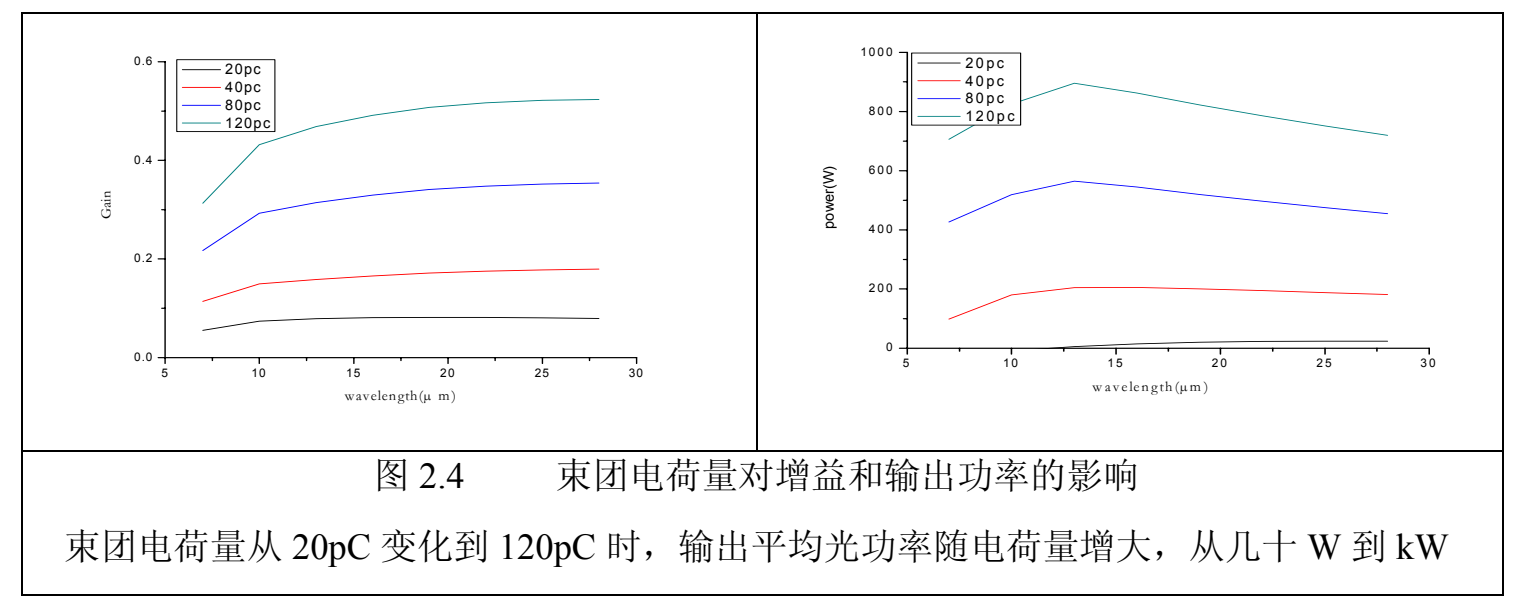




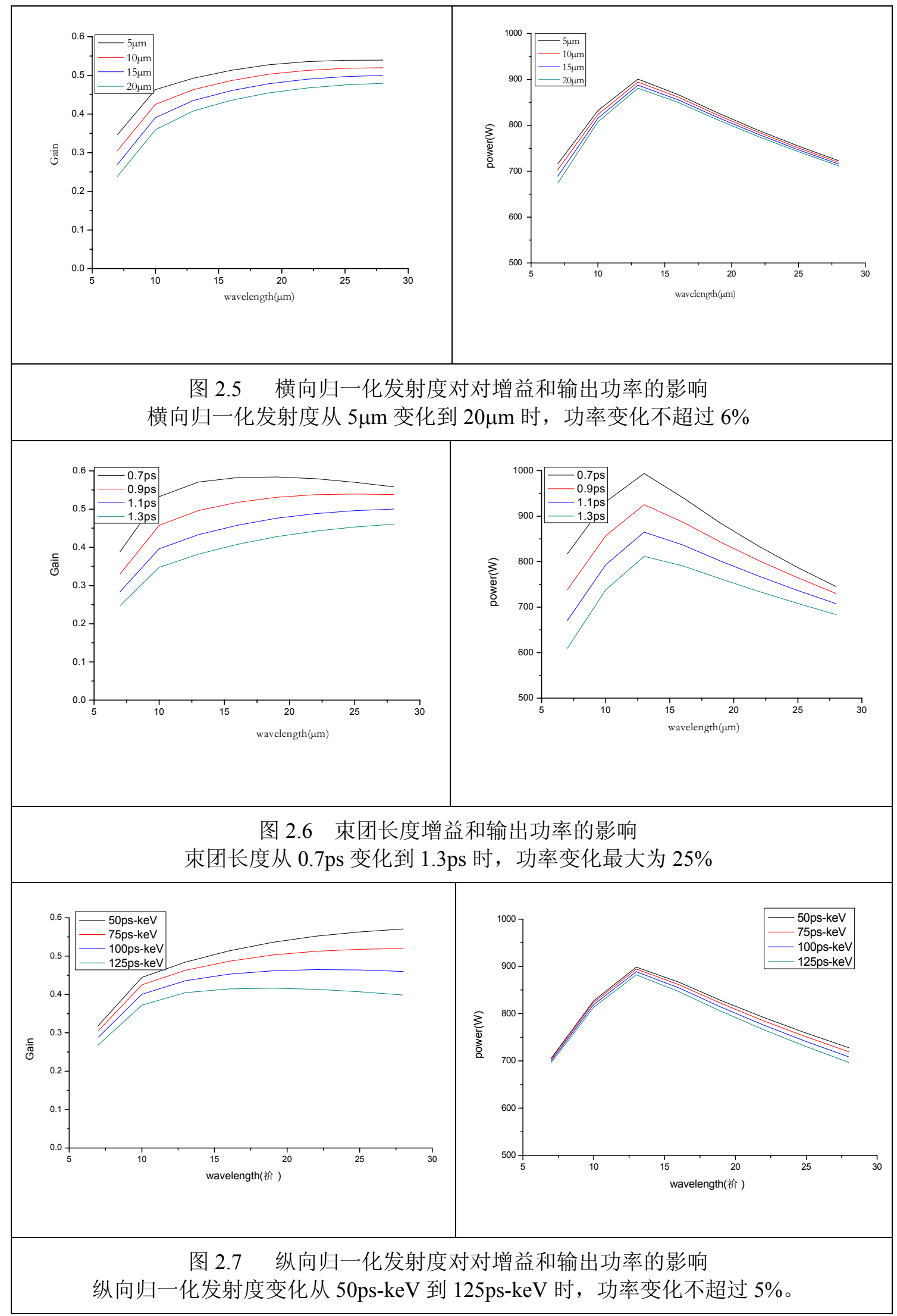

\section{4 高功率电子束获得}

高平均功率、高品质、相对论电子束的获得是实现高平均功率 FEL 的一个 
难点, 它的主要限制之一是加速器的功率源。加速腔建场所需要的微波功率主要 分为电子束带走的功率和腔壁热损耗功率, 电子束带走功率相比热损耗越大, 微 波功率转换到电子束的效率越高。

电子束的平均功率正比于平均电流和束流能量, 提高电子束功率的方法有增 大单束团电荷量、提高束团重复频率和增大能量。

增大单束团电荷量和提高束团重复频率都是为了增大平均流强, 它们取决于 驱动激光和电子源, 单束团电荷量取决于驱动激光峰值功率和电子源效率, 束团 重复频率最大到加速腔加速模频率。此外, 微波功率限制了加速器的加速能力, 加速器常运行在短脉冲模式, 平均流强低。

束流能量主要由加速器系统决定, 通过提高加速场梯度或增多加速腔个数来 增大束流能量, 为了控制加速器成本, 希望加速腔高梯度运行, 但加速场梯度与 腔壁热损耗相关。腔壁热损耗 $P_{\text {diss }} \propto E_{c}^{2} / Q_{0}$, 取决于腔内的加速场, 与束流流强 无关, 腔壁热损耗与加速场梯度的平方成正比, 与加速器 $Q_{0}$ 成反比, 场梯度越 高, 热损耗越大, 所需要的制冷系统越庞大。常温加速器 $Q_{0}$ 较低, 腔壁热损耗 是限制运行场梯度的最重要因素, 常温腔通常运行在高梯度短脉冲模式, 在长脉 冲或 CW 模式下, 运行梯度低, 腔壁损耗的功率占系统功率很大一部分, 降低了 总体效率; 超导加速器 $Q_{0}$ 很大, 腔壁热损耗较小, 运行梯度主要由加速腔本身 性能决定, 超导加速器常运行在十几 $M V / m$, 在高流强 (长脉冲或连续波运行模 式）下, 它的优势更为明显。若获得同样能量的高平均流强电子束, 使用的超导 加速腔比常温腔规模小十倍量级, 并且, 超导腔微波功率转换到电子功率的效率 更高。

北京大学加速器平台采用全超导技术, 具有加速高平均流强电子束的能力。 目前, 由于主加速器的微波功率的限制, 束流运行在宏脉冲模式下。在现有条件 下, 提高束流功率的办法是采用能量回收技术, 提高平均流强, 使束流运行在长 脉冲或 $\mathrm{CW}$ 模式下。

下面将研究采用能量回收和非能量回收时系统运行参数。

\subsection{1 超导腔基本参数和束载分析}

超导腔是一种 $\mathrm{RF}$ 加速结构, 用于加速电子的模式是基模 $\mathrm{TM}_{010}$, 这是谐振 腔中最低频率的模式, 粒子在加速相位进入这个驻波场, 就会受到轴向电场力的 
加速, 带走腔中的储能。反映它品质的最重要参数之一是加速梯度 $E_{a c c}=V_{c} / d$, $V_{c}$ 是电子在加速腔获得的加速电压, $d$ 是有效加速长度。对 Pill-box 的 $T M_{010}$ 加 速模, $E_{a c c}=2 E_{0} / \pi$, 其中, $E_{0}$ 是加速峰值电场。

腔壁热损耗

$$
\mathrm{P}_{\text {diss }}=\frac{1}{2} R_{s} \int_{s}|H|^{2} d s
$$

其中, $R_{s}=R_{B C S}(T)+R_{0}=A_{s} \omega^{2} \exp \left(-\frac{\Delta(0)}{k_{B} T}\right)+R_{\text {res }}+R_{\text {mag }}$ 是超导腔表面电阻, 一 般是10 20n $\Omega, \mathrm{R}_{\mathrm{BCS}}(\mathrm{T})$ 是理论表面电阻, 它正比于谐振频率的平方, 一般情 况下, $R_{B C S}(T)$ 是表面电阻的最主要的部分; $R_{r e s}$ 是残余表面电阻, 与腔壁的材 料有关; $\mathrm{R}_{\mathrm{mag}}$ 是超导转变过程中俘获的外部磁场引起的浴流损耗的等效电阻, 与 磁屏蔽效果有关; $H$ 是超导腔表面磁场。 $P_{\text {diss }}$ 随加速腔场梯度增大呈平方增长。

品质因子 $Q_{0}$ 定义是腔内储存的能量与腔壁上一个 $\mathrm{RF}$ 周期内消耗的能量比

$$
Q_{0} \equiv \frac{\omega_{0} W}{P_{\text {diss }}}=\frac{\text { Energy stored in cavity }}{\text { Energy dissipated in cavity walls per radian }}
$$

$W$ 是腔内储存的能量, $\omega_{0}$ 是加速腔的工作模式的角频率, $Q_{0}$ 越高, 腔壁消耗 的热功率越小。对超导铌腔, $Q_{0}$ 在 $10^{10}$ 量级。

分路阻抗定义是

$$
\mathrm{R}_{\mathrm{a}} \equiv \frac{\mathrm{V}_{\mathrm{c}}^{2}}{\mathrm{P}_{\text {diss }}}
$$

从 $R_{a}$ 和 $Q_{0}$ 的定义得到

$$
R_{a} / Q_{0}=V_{c}^{2} /\left(\omega_{0} W\right)
$$

$\mathrm{R}_{\mathrm{a}} / \mathrm{Q}_{0}$ 是几何分路阻抗, 只与谐振腔的形状相关。利用该关系式, 同样加速 腔结构、同样加速场梯度下, 腔壁热损耗与 $Q_{0}$ 成反比, 常温腔因为表面发热很 厉害和需要极强的射频微波功率源而不能运行在高梯度 $\mathrm{CW}$ 模式, 而超导腔壁上 损耗的功率比常温腔要小 5 个量级, 于是减少了对功率源的要求, 因此超导腔的 最大优势就是可以加速连续波 (CW) 或者是高占空比的束流。

超导腔中微波场建立是通过主耦合器（input coupler）将微波功率馈入到超 导腔, 通过提取探针 (pick-up) 测量腔内高频场信号。当馈入功率停止后, 加速 腔中储存的能量会逐步损耗, 损耗源有三个: 一是腔壁本身的热损耗, 二是经耦 
合器的损耗, 三是经 pick-up 的损耗。因此总损耗为: $P_{t o t}=P_{d i s s}+P_{e}+P_{t}, P_{d i s s}$ 是 腔壁消耗的功率、 $P_{e}$ 是漏回主耦合器的功率, $P_{t}$ 是探针提取功率, 通常 $P_{t}$ 相比 $P_{d i s s}$ 和 $P_{e}$ 很小, 可以忽略。超导腔内能量随时间改变是:

$$
\frac{d W}{d t}=-P_{t o t}
$$

$P_{t o t}=P_{d i s s}+P_{e}+P_{t}$, 类比 $Q_{0}$, 定义有载品质因子

$$
Q_{L} \equiv \frac{\omega_{0} W}{P_{\text {tot }}} \approx \frac{\omega_{0} W}{P_{\text {diss }}+P_{e}}=1 /\left(\frac{1}{Q_{0}}+\frac{1}{Q_{e}}\right)
$$

由 (2.16) 和 (2.17) 式可以得到 $\frac{d W}{d t}=-\frac{\omega_{0} W}{Q_{L}} \Rightarrow W=W_{0} e^{-\frac{\omega_{0} t}{Q_{L}}}$ 。

因此, 腔内的能量随时间衰减, 衰减时间常数是 $\tau_{L}=\frac{Q_{L}}{\omega_{0}}$, 它反映腔内电磁 场衰减（或建立）的快慢，另外， $1 / \tau_{L}$ 表示频域范围内加速场带宽。

定义耦合常数

$$
\beta \equiv \frac{Q_{0}}{Q_{e}}=\frac{P_{e}}{P_{\text {diss }}}
$$

它反映了耦合器与腔之间耦合的强弱。腔有载因子 $Q_{L} \approx Q_{0} /(1+\beta)$ 。

下面介绍超导腔加速束流的工作过程 ${ }^{[32]}$ 。考虑束流是 $\mathrm{CW}$ 模式, 时间结构 如图 2.8, 束团之间等间距, 时间间隔是 $T_{b}=1 / f_{\text {bun }}, f_{\text {bun }}$ 是束团重复频率, 单束 团时间结构呈高斯型分布, $\mathrm{rms}$ 长度是 $\sigma_{z}$ 。当束团满足以下条件时, 腔束相互作 用过程可以用等效电路模型分析:

(1) 束团以接近光速通过加速腔, 并且在加速腔中, 电子速度基本不变。 这样，束团可以等效为恒流源 $\widetilde{i_{b}}$ 。

（2）束团时间间隔 $T_{b}$ 是加速场周期 $1 / f_{r f}$ 的整数倍, 保证所有束团相对加速 场中的相位相同。

（3）束团时间间隔 $T_{b}$ 远小于加速场衰减时间 $\tau_{L}$, 保证腔总是工作在稳定状 态。

（4）束团等效电流 $I(t)=\sum_{m=1}^{\infty} \frac{Q_{b}}{\sqrt{2 \pi \sigma_{t}}} \exp \left[-\frac{\left(t-m T_{b}\right)^{2}}{2 \sigma_{t}^{2}}\right]$, 通过 Fourier 变换, 
频域内, 束流频谱带宽 $\sigma_{\omega}=c / \sigma_{z}$ 远大于加速场角频率, 即 $\sigma_{z}<<\lambda_{r f} / 2 \pi$ 。这样, 束流激励的电压与微波功率源产生的电压可以矢量叠加得到腔内加速场电压, $\widetilde{V}_{c}=\widetilde{V}_{g}+\widetilde{V}_{b}$ 。

（5）由束流激励的高阶模通过高阶模耦合器得到有效衰减，对束流影响可 以不考虑。

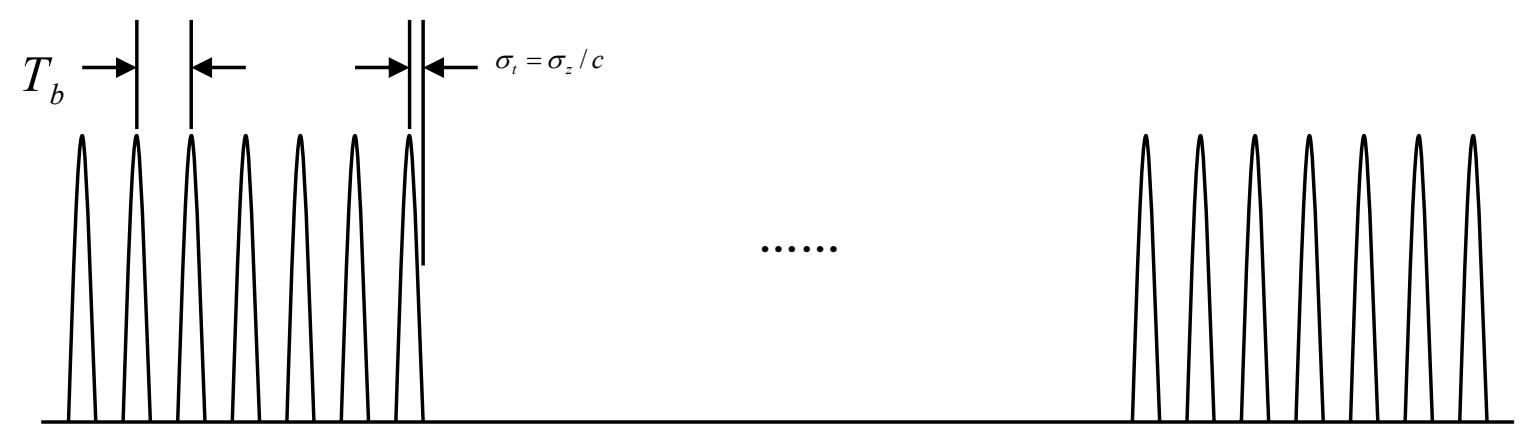

图 $2.8 \mathrm{CW}$ 束团时间结构

这些条件通常都能满足。对北京大学的主加速器, 超导加速腔频率是 $1.3 \mathrm{GHz}$, 束载品质因子 $Q_{L} \sim 10^{7}$, 加速场衰减时间常数 $\tau_{L} \sim 10^{-3} s$, 因此, 要求的 束团微脉冲重复频率远大于 $\mathrm{kHz}$ 。对 $\mathrm{MHz}$ 重复频率的束团, 经过时间 $T_{b}$, 电磁 场强度变化约 $1 / 1000$, 腔内加速场基本不变。束团重复频率 $f_{b u n}$ 的倍数是 $1.3 \mathrm{GHz}$, 如北京大学驱动激光频率是 $81.25 \mathrm{MHz}$ 和 $26 \mathrm{MHz}$ 。加速腔中的束团长度约 $8 \mathrm{ps}$ 或 $2.4 \mathrm{~mm}$, 加速场波长是 $23 \mathrm{~cm}$, 满足 $\sigma_{z}<<\lambda_{r f} / 2 \pi$ 。对 $\mathrm{CW}$ 模式下运行的束流, 可以用等效电路分析加速腔运行参数。

对宏脉冲模式运行的束流, 宏脉冲长度 $T_{\text {macro }}$ 与宏脉冲重复频率 $f_{\text {macro }}$ 决定了 束流占空因子 $D F, D F=T_{\text {macro }} f_{\text {macro }}$ ， 反映束团的时间结构。

在能量回收模式下，束团时间结构如图 2.9, 相邻加速和减速束团之间的时 间间隔是 $\delta T$, 从图中可以看出它小于束团之间的时间间隔 $T_{b}$, 因此, $\delta T$ 也远小 于加速场衰减时间 $\tau_{L}$, 有加速和减速束团时, 腔内工作场保持稳定状态, 加速束 流和减速束流在等效电路中看作两个电流源。在宏脉冲模式下, 头部加速的束流 返回加速腔所需要的时间 $T_{d}$ 由返航束线长度决定, 从图中看出, 头部束团在 $T_{d}$ 时 间内的功率是由微波功率供给, 尾部束团 $T_{d}$ 时间内回收的能量不能用来加速电 子, 这部分电子功率不能有效利用, 有用的电子束团时间长度是 $T_{\text {macro }}-T_{d}$, 为了 
提高能量回收的总体利用效率, 要求 $T_{d}$ 远小于宏脉冲长度 $T_{\text {macro }}$ 。对百米长返航 束线, $T_{d} \sim 10^{-5} \mathrm{~s}$, 如果宏脉冲长度在 $\mathrm{ms}$ 量级以上, 则 $99 \%$ 以上的束团功率都能 回收后利用。

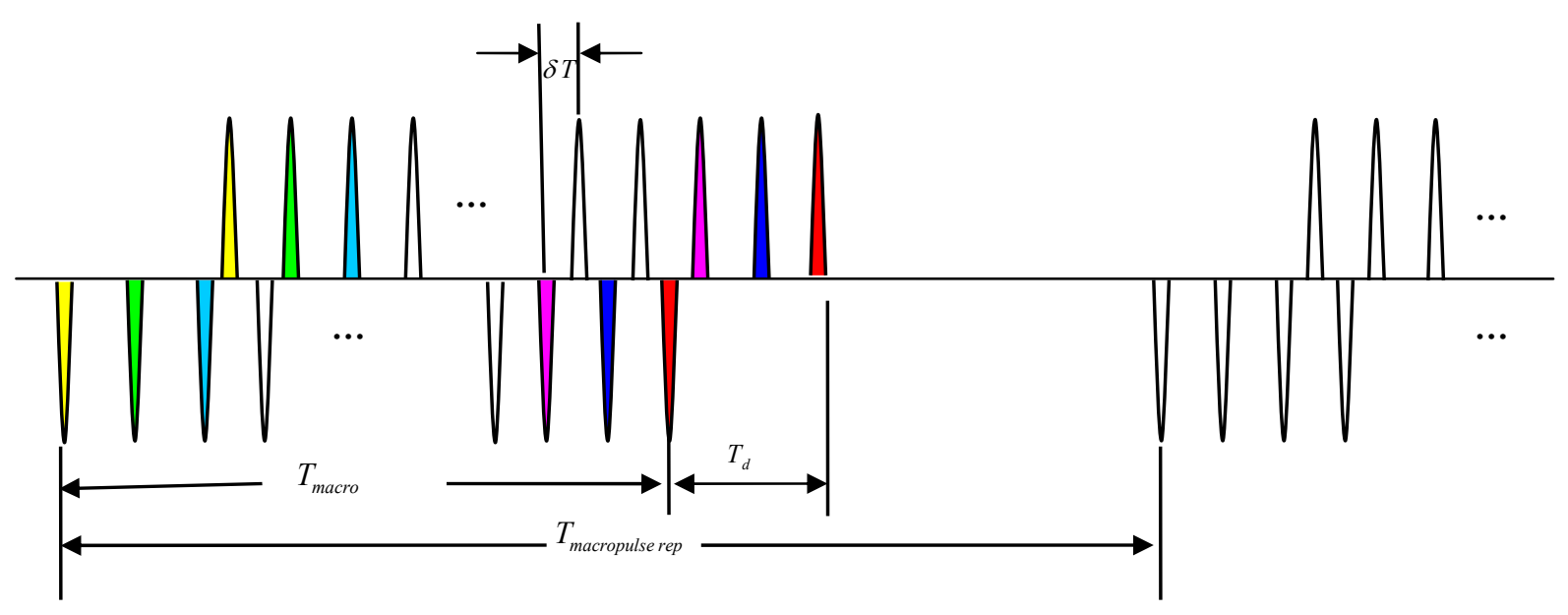

图 2.9 能量回收束团时间结构

下面用等效电路模型分析能量回收时, 超导加速腔工作参数。

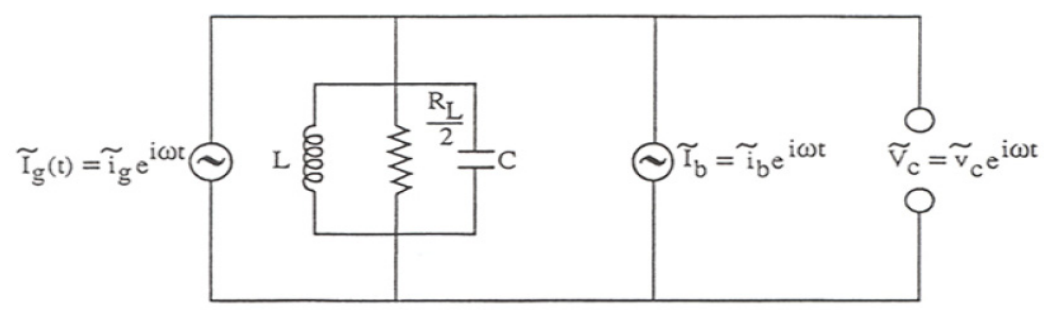

图 2.10 束载时加速腔等效电路

当束流通过加速腔时, 束流对腔的作用等效为电流源 $\vec{I}_{b}=\vec{i}_{b} e^{i \omega t}$, 对短束团, $\left|I_{b}\right|=2 I_{0}$, 其中, $I_{0}$ 是束流平均流强。束载等效电路如图2.10所示, 等效电阻 $R_{L} / 2=\frac{1}{\left(\frac{1}{Z_{g}}+\frac{1}{R}\right)}=\frac{R_{a}}{2(1+\beta)}$, 电阻上的电流是 $\vec{i}_{R}=\frac{v_{c}}{R_{L} / 2}$, 电容 $\mathrm{C}$ 的电流是 $\overrightarrow{i_{C}}=C \frac{d v_{c}}{d t}$, 电压 $v_{c}=L \frac{d \overrightarrow{i_{L}}}{d t}$ 。根据Kirchoff定律, $\overrightarrow{i_{L}}+\overrightarrow{i_{R}}+\overrightarrow{i_{C}}=\overrightarrow{i_{g}}-\overrightarrow{i_{b}}$, 两边对时间 微分, 得到

$$
C \frac{d^{2} v_{c}}{d t^{2}}+\frac{1}{R_{L} / 2} \frac{d v_{c}}{d t}+\frac{v_{c}}{L}=\frac{d\left(\overrightarrow{i_{g}}-\overrightarrow{i_{b}}\right)}{d t}
$$

进一步变形得到 


$$
\frac{d^{2} v_{c}}{d t^{2}}+\frac{\omega_{0}}{Q_{L}} \frac{d v_{c}}{d t}+\omega_{0}^{2} v_{c}=\frac{\omega_{0} R_{L}}{2 Q_{L}} \frac{d\left(\overrightarrow{i_{g}}-\overrightarrow{i_{b}}\right)}{d t}
$$

将 $v_{c} 、 \overrightarrow{i_{g}}$ 和 $\overrightarrow{i_{b}}$ 随时间的变化表示为两部分: 随 $\mathrm{RF}$ 功率源快速振荡项 $e^{i \omega t}$ 和 缓变量 $V_{c} 、 I_{g}$ 和 $I_{b}$, 分别表示为 $v_{c}=V_{c} e^{i \omega t} 、 \overrightarrow{i_{g}}=I_{g} e^{i \omega t}$ 和 $\overrightarrow{i_{b}}=I_{b} e^{i \omega t}$, 代入公式 (2.20)

$$
\frac{d^{2} V_{c}}{d t^{2}}+\left(2 i \omega+\frac{\omega_{0}}{Q_{L}}\right) \frac{d V_{c}}{d t}+\left(i \frac{\omega \omega_{0}}{Q_{L}}+\omega_{0}^{2}-\omega^{2}\right) V_{c}=\frac{\omega_{0} R_{L}}{2 Q_{L}} \frac{d\left(I_{g}-I_{b}\right)}{d t}+\frac{\omega_{0} R_{L}}{2 Q_{L}} i \omega\left(I_{g}-I_{b}\right)
$$

忽略小量 $\frac{d^{2} V_{c}}{d t^{2}} 、 \frac{1}{Q_{L}} \frac{d V_{c}}{d t} 、 \frac{d\left(I_{g}-I_{b}\right)}{d t}$, 进一步化简为

$$
\frac{d V_{c}}{d t}+\frac{\omega_{0}}{2 Q_{L}}(1-i \tan \psi) V_{c}=\frac{\omega_{0} R_{L}}{4 Q_{L}}\left(I_{g}-I_{b}\right)
$$

稳态时,

$$
V_{c}=\frac{R_{L} / 2}{(1-i \tan \psi)} I_{g}-\frac{R_{L} / 2}{(1-i \tan \psi)} I_{b}=\frac{R_{L}}{2} I_{g} \cos \psi e^{i \psi}-\frac{R_{L}}{2} I_{b} \cos \psi e^{i \psi}
$$

或

$$
V_{c}=V_{g r} \cos \psi e^{i \mu}+V_{b r} \cos \psi e^{i \mu}=V_{g}+V_{b}
$$

即腔电压 $V_{c}$ 是微波功率电压 $V_{g}$ 和束流电压 $V_{b}$ 的矢量叠加, $V_{g r}$ 和 $V_{b r}$ 分别对应着共 振时的微波功率电压和束流电压。 $V_{g} 、 V_{b}$ 与共振电压 $V_{g r} 、 V_{b r}$ 之间的关系如图2.11 所示, $\psi$ 越大, 工作电压越小。共振电压

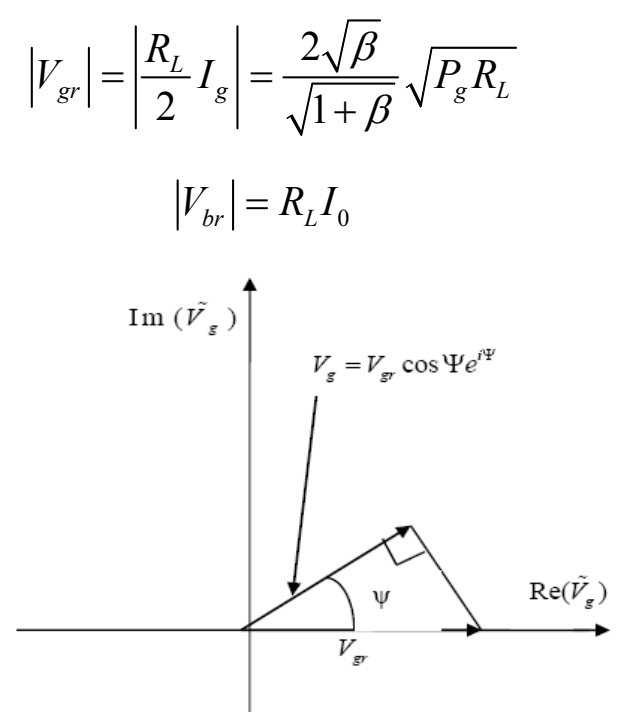

图 2.11 工作电压与共振电压关系 
对应的微波功率源电流

$$
I_{g}=\left(V_{c}+R_{L} I_{0}\right) /\left(R_{L} / 2\right)
$$

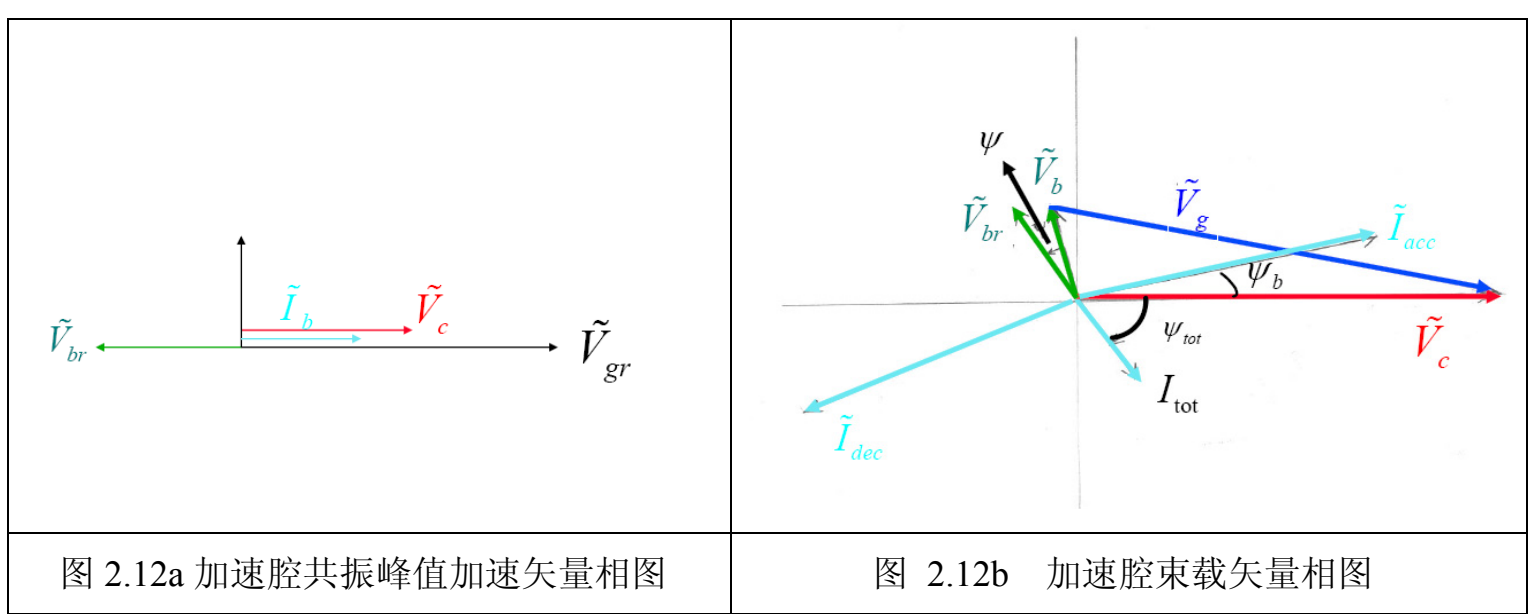

图 2.12a 显示束流处于峰值加速并且加速腔共振时, 加速电压和电流矢量叠 加相图, 加速电压 $V_{c}=V_{g r}-V_{b r}$ 。定义束载参数 $K=\frac{I_{0}}{2} \sqrt{R_{L} / P_{g}}$, 对应的电压、储 存能量、腔壁损耗功率、束流功率、反射功率、微波功率分别是

$$
\begin{gathered}
V_{c}=\sqrt{P_{g} R_{a}}\left[\frac{2 \sqrt{\beta}}{\sqrt{1+\beta}}\left(1-\frac{K}{\sqrt{\beta}}\right)\right] \\
W=\frac{4 \beta}{(1+\beta)^{2}} \frac{Q_{0}}{\omega_{0}} P_{g}\left(1-\frac{K}{\sqrt{\beta}}\right)^{2} \\
P_{\text {diss }}=\frac{4 \beta}{(1+\beta)^{2}} P_{g}\left(1-\frac{K}{\sqrt{\beta}}\right)^{2} \\
I_{0} V_{c}=I_{0} \sqrt{R_{a} P_{\text {diss }}} \\
P_{\text {refl }}=P_{g}-P_{\text {diss }}-I_{0} V_{c}=\frac{[(\beta-1)-2 K \sqrt{\beta}]}{(1+\beta)^{2}} P_{g} \\
P_{g} \equiv \frac{1}{16 \beta} R_{a} I_{g}^{2}=\frac{1}{16 \beta} R_{L}(1+\beta)\left(\frac{V_{c}+I_{0} R_{L}}{R_{L} / 2}\right)^{2}
\end{gathered}
$$

超导腔的 $\beta$ 通常远大于 1 时, $P_{g} \approx \frac{1}{4 R_{L}}\left(V_{c}+I_{0} R_{L}\right)^{2}$ 。匹配时, 加速腔不反射功率, $P_{\text {refl }}=0$, 此时, $R_{L} \approx R_{a} / \beta=V_{c} / I_{0}, \beta=I_{0} R_{a} / V_{c}$, 所需用的微波功率是 


$$
P_{g}=P_{\text {diss }}+P_{\text {beam }}=V_{c} I_{0} / \beta+V_{c} I_{0} \approx P_{\text {beam }}
$$

它基本上全部转化为束流功率。

以上分析了超导腔共振并且峰值加速时, 各个参数之间的关系。实际加速器 上, 加速腔有一定的工作带宽, 并且为了实现一定的目的, 如压缩束团长度, 束 流相对加速场相位通常选择偏离峰值加速。下面分析当束流偏离峰值、超导腔工 作频率偏离共振时多束团加速对应的超导腔工作性质。

图 $2.12 \mathrm{~b}$ 给出有两个束流 $I_{\mathrm{acc}}$ 和 $I_{\mathrm{dec}}$ 时 ${ }^{[33]}$, 微波功率源电压、加速腔电压、束 流电压和电流之间的矢量关系图。其中, $\psi_{b}$ 是束流 $I_{\mathrm{acc}}$ 相对加速场相位, $I_{\mathrm{tot}}$ 是 $I_{\mathrm{acc}}$ 和 $I_{\mathrm{dec}}$ 的矢量叠加, $\psi_{\mathrm{tot}}$ 是叠加后的电流相对加速场 $V_{c}$ 的相位, $\psi$ 是调谐角, 表 示加速腔偏离共振工作。类似共振时推导关系, 相对加速电压, 此时的电流表示 为 $I_{\mathrm{tot}}=2 I_{0} e^{i \psi_{\mathrm{tot}}}$, 微波功率变成

$$
P_{g}=\frac{V_{c}^{2}}{R_{L}} \frac{(1+\beta)}{4 \beta}\left\{\left[1+\frac{I_{0} R_{L}}{V_{c}} \cos \psi_{\text {tot }}\right]^{2}+\left[\tan \Psi-\frac{I_{0} R_{L}}{V_{c}} \sin \psi_{\text {tot }}\right]^{2}\right\}
$$

通常 $\mathrm{RF}$ 微波源频率偏离超导腔工作频率 $\delta \omega \quad\left(=\omega-\omega_{0}\right)$ 远小于 $\omega_{0}$, 调谐角度近 似表示 $\tan \Psi=-2 Q_{L} \frac{\delta f}{f_{0}}=-2 Q_{L} \frac{\delta f_{0} \pm \delta f_{m}}{f_{0}}=-2 \frac{Q_{0}}{1+\beta} \frac{\delta f_{0} \pm \delta f_{m}}{f_{0}}$, 由两部分组成: 可以控 制部分 $\delta f_{0}$ 和不可控制部分 $\delta f_{m}$ （如麦克风效应）。

根据表达式 (2.35) , 当耦合参数 $\beta$ 满足

$$
\beta_{\text {opt }}=\sqrt{(b+1)^{2}+\left[2 Q_{0} \frac{\delta f}{f_{0}}+b \tan \psi_{t o t}\right]^{2}}
$$

微波功率输出极小, 其中 $b \equiv \frac{I_{t o t} R_{a}}{V_{c}} \cos \psi_{t o t}$ 。

进一步优化调谐角度, 当调谐角 $\psi$ 满足关系式 $\tan \Psi=\frac{I_{0} R_{L}}{V_{c}} \sin \psi_{\text {tot }}$, 或

$$
\delta f_{0}^{o p t}=-\frac{f_{0}}{2 Q_{0}} b \tan \Psi_{t o t}
$$

功率源输出功率相对调谐角度的变化最小, 相应的微波功率是 


$$
P_{g}^{o p t}=\frac{V_{c}^{2}}{2 R_{a}}\left[b+1+\sqrt{(b+1)^{2}+\left(2 Q_{0} \frac{\delta f_{m}}{f_{0}}\right)^{2}}\right]
$$

对应的最优 $\beta$ 值

$$
\beta_{o p t}=\sqrt{(b+1)^{2}+\left(2 Q_{0} \frac{\delta f_{m}}{f_{0}}\right)^{2}}
$$

可以看出, 当束流偏离峰值加速时, 需要对加速腔频率进行调谐, 此时需要 的微波功率最小。

表 2.2 北京大学注入器和主加速器微波功率参数

\begin{tabular}{|c|c|c|c|}
\hline 参数 & 注入器 & $\begin{array}{c}\text { 主加速器 } \\
\text { (能量回收) }\end{array}$ & $\begin{array}{c}\text { 主加速器 } \\
\text { (非能量回收) }\end{array}$ \\
\hline$\Psi_{\text {tot }}$ & 0 & 0 & -10 \\
\hline$\delta f_{0}^{o p t}$ & 0 & 0 & $17.5 \mathrm{~Hz}(0)$ \\
\hline$\beta_{\text {opt }}$ & 2308 & 384 & $1579(1536)$ \\
\hline$Q_{L}$ & $4.33 \times 10^{6}$ & $2.6 \times 10^{7}$ & $6.33 \times 10^{6}\left(6.51 \times 10^{6}\right)$ \\
\hline$P_{g}^{\text {opt }}$ & $16.62 \mathrm{~kW}$ & $7.44 \mathrm{~kW}$ & $60.05 \mathrm{~kW}(61.82)$ \\
\hline$P_{\text {disp }}$ & $7.25 \mathrm{~W}$ & $38.6 \mathrm{~W}$ & $38.6 \mathrm{~W}$ \\
\hline$P_{\text {beam }}$ & $16.5 \mathrm{~kW}$ & $60 \mathrm{~kW}$ & $60 \mathrm{~kW}$ \\
\hline
\end{tabular}

\subsection{2 北京大学超导腔运行参数分析}

以下粗略估算北京大学注入器和主加速在最优条件下所需要的微波功率, 估 算的工作电流是 $3 \mathrm{~mA}$ 。注入器工作参数如下: $\delta f_{m}=25 \mathrm{~Hz}, Q_{0}=1 \times 10^{10}$, $f_{0}=1300 \mathrm{MHz}, I_{0}=3 \mathrm{~mA}, V_{c}=5.5 \mathrm{MV}, R_{a} / Q_{0}=417 \Omega$, 处于峰值加速。主加 速器工作参数如下: $\delta f_{m}=25 \mathrm{~Hz}, Q_{0}=1 \times 10^{10}, f_{0}=1300 \mathrm{MHz}, I_{0}=3 \mathrm{~mA}$, $V_{c}=20 M V, R_{a} / Q_{0}=1036 \Omega$, 加速相位是-10 度, 能量回收时减速相位 170 度。 计算各种情况下微波功率参数如表 2.2 , 注入器最优 $Q_{L}$ 是 $4.33 \times 10^{6}$, 所需要的功 率 $16.6 \mathrm{~kW}$, 其中束流带走的功率 $16.5 \mathrm{~kW}$, 剩余的主要是克服麦克风效应; 每个 9 cell 主加速腔能量回收时需要的功率是 $7.44 \mathrm{~kW}$, 主要克服麦克风效应, $Q_{L}$ 是 $2.6 \times 10^{7}$, 而束流功率是 $60 \mathrm{~kW}$; 非能量回收时, 主加速腔需要的微波功率是 
$60 \mathrm{~kW}, Q_{L}$ 约 $6.33 \times 10^{6}$, 表中最后一列两组值分别是考虑调谐匹配和不匹配两种 情况, 括号内的值是表示不考虑调谐频率, 与改变工作频率 $17.5 \mathrm{~Hz}$ 所需要的微

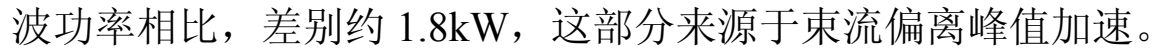

图 2.13 是注入器工作在不同流强下, 麦克风效应引起工作频率振荡从 $0 \mathrm{~Hz}$ 到 $100 \mathrm{~Hz}$ 时对应的最优微波功率和负载品质因子 $Q_{L}$, 在低流强下, 麦克风效应 对微波功率影响较大, 它带走的功率相对束流带走的功率较大, 尤其是电流为 $0 \mathrm{~A}$ 时, 微波功率主要是克服麦克风效应。高流强时, 功率和 $Q_{L}$ 渐渐趋于一致。
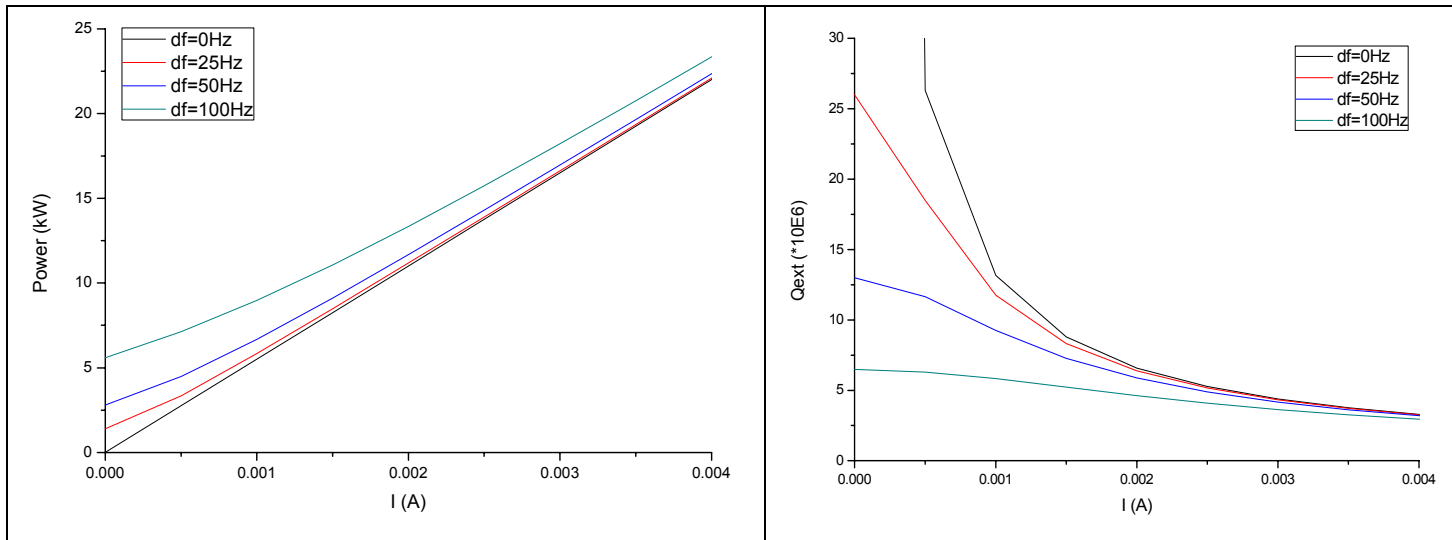

图 2.13 不同流强下, 麦克风效应对注入器功率源功率和负载品质因子的影响

主加速器部分非能量回收模式下运行参数变化曲线与注入器类似, 下面只研 究能量回收模式下麦克风效应的影响。束流注入相位是-10 度, 返回相位是 180 度时, 图 2.14 给出微波功率以及最优负载品质因子随平均流强变化, 可以看出, 能量回收时, 束流流强对微波功率以及负载品质因子影响很小, 它们主要由麦克 风效应的大小决定。

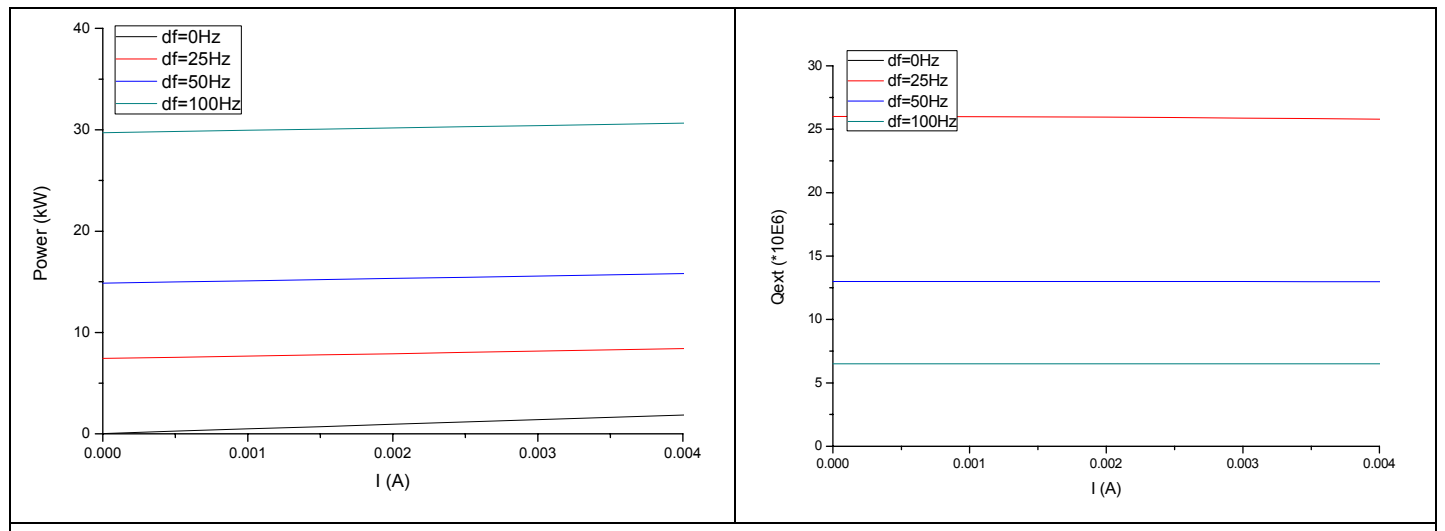

图 2.14 不同流强下, 麦克风效应对主加速器微波功率和负载品质因子的影响

以上考虑束流只激励加速模的理想情况, 实际束流在加速腔除了与受基模加 
速外, 还会激励高阶模。能量回收时, 束流激励高阶模带走束流部分功率, 从而 降低回收效率。高阶模中, 对束团能量影响最大的模式是单极模 $T M_{0 n p}$, 它的轴 线纵向电场非 0 。

连续束团下, 束流激励高阶单极模所需要的功率 ${ }^{[34]}$

$$
P_{b, n}=\frac{I_{0}^{2}(r / Q)_{n} Q_{0, n}}{\left(1+\beta_{n}\right)} F_{r}=\frac{P_{c, n}}{\left(1+\beta_{n}\right)}
$$

其中, $F_{r}=\frac{\frac{T_{b}}{T_{d}}\left[1-\exp \left(-2 \frac{T_{b}}{T_{d}}\right)\right]}{2\left[1-2 \exp \left(-\frac{T_{b}}{T_{d}}\right) \cos \left(\Delta \omega T_{b}\right)+\exp \left(-2 \frac{T_{b}}{T_{d}}\right)\right]}, \quad P_{c, n}$ 是高阶模对应的腔壁热

损耗, $\Delta \omega=\omega-\omega_{n}, \omega=\frac{2 \pi h}{T_{b}}, h$ 是整数, $\omega_{n}$ 是高阶模频率, $\beta_{n}$ 是耦合系数, 对 超导腔的高阶模, $\beta_{n} \sim 10^{4}-10^{5}$ 。TESLA 超导腔 ${ }^{[35]}$ 所有高阶模在腔壁上的热损 耗约 $\mathrm{mW}$ 量级, 因此, 束流用于激励高阶模所需要的功率约百瓦量级, 相比束 流功率，小于 $1 \%$ 。高阶模激励对能量回收效率影响较小。

\section{5 本章小结}

本章对北京大学 ERL-FEL 机器总体参数优化计算, 研究了 CW 模式下束团 电荷从 $20 \mathrm{pC}$ 变化到 $120 \mathrm{pC}$ 时激光平均输出功率的大小, 并研究束流品质如横向 归一化发射度、纵向归一化发射度以及束团长度对激光输出功率的影响。

此外, 介绍 $\mathrm{RF}$ 微波源运行参数之间的关系, 考虑有束流负载和麦克风效应 时, 能量回收/非能量回收下, 加速腔最优运行参数和所需要的 RF 微波功率。结 果表明, 注入器所需要的微波功率主要取决于束流流强, 主加速器在能量回收的 运行模式下, 其所需的微波功率主要受麦克风效应的大小决定, 与电子束流强基 本无关。 


\section{第三章 系统前终端的研究}

系统前终端是指从光阴极到主加速器之间的束线, 包括 $3+1 / 2$ cell DC-SC 光 阴极注入器、匹配段和并束段（merger）, 电子束能量在这部分较低, 空间电荷 效应是影响束流品质变坏的一个重要因素。

$3+1 / 2$ cell DC-SC 光阴极注入器是 $1+1 / 2$ cell DC-SC ${ }^{[36,37]}$ 光阴极注入器样机 的升级, 包括直流光阴极电子枪和 $3+1 / 2$ cell 射频超导腔, 当 $\mathrm{RF}$ 平均电场梯度 在 $13 \mathrm{MV} / \mathrm{m}$ 时, 电子束能量增益到 $5 \mathrm{MeV}$ 。电子束流品质主要由注入器决定, 因 此, 注入器参数优化目标是如何产生高品质电子束。merger 是传输低能注入束流 和高能返航束流到主加速器中, 它包含若干块弯转 $\mathrm{B}$ 铁, 从而实现两个束线的 束流合并到同一束线上。 $\mathrm{B}$ 铁传输束流时会引入色散, 增大束流有效发射度, 为 了控制发射度增长, merger 结构设计要求是消色散。对低能注入束, 空间电荷效 应使束团头部的电子得到能量而尾部的电子损失能量, 改变束流能散分布, merger 偏离消色散, 进而增大发射度, 这部分主要是控制束流品质变坏在可接受 范围内。匹配段由聚焦元件组成, 用来控制束包络和相空间形态, 使电子束匹配 地注入主加速器。

研究了注入器参数, 使用程序 PARMELA 对影响发射度增长的各个因素进 行优化, 给出注入器最优工作参数, 对原设计提出进一步改进发射度的方法; 研 究了四种不同 merger 结构, 包括误差敏感分析和空间电荷效应, 结合北京大学 实际情况, 设计了尺寸最小、磁铁个数最少的三块磁铁结构; 研究了注入器提供 的束流品质和主加速器的接受度, 根据这两个条件对匹配段提出要求, 设计了两 种束线方案, 考虑磁场屏蔽等因素, 选择只有四极铁组合的束线。

\subsection{3+1/2 DC-SC 光阴极注入器结构}

$3+1 / 2$ cell DC-SC 光阴极注入器是北京大学自主研发的新型光阴极注入器, 结构如图 3.1 所示, 光阴极产生的电子束首先经过 DC 段加速, 然后进入 $3+1 / 2$ cell 超导加速结构。相比常温加速腔, 该设计采用超导技术, 减少了工作过程中腔壁 的功率损耗, 可以在高占空因子或 $\mathrm{CW}$ 模式下运行, 能够提供高平均流强的电子 束流; 采用直流高压结构, 将光阴极移出超导腔, 避免光阴极材料和激光对超导 腔的污染, 以及 $\mathrm{RF}$ 周期场引起束流反向轰击光阴极表面, 解决了光阴极与超导 
腔的兼容性问题。

关于注入器结构, 这里直接采用朱风博士优化设计的结构 ${ }^{[38]}$, 其设计优化目 标是高束团电荷量，以下的模拟计算都是基于该优化结构。

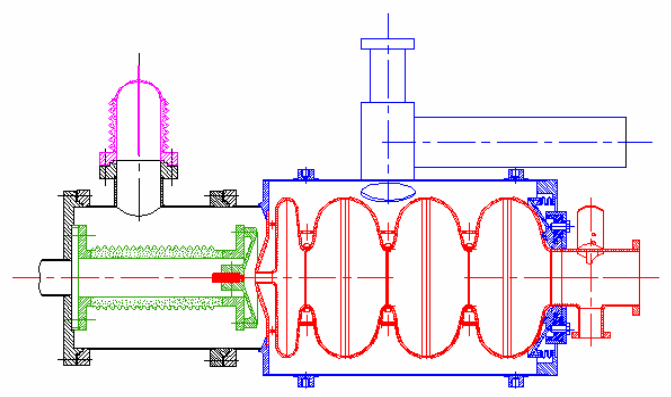

图 $3.13+1 / 2$ DC-SC 光阴极注入器结构

直流光电子枪是采用皮尔斯结构, 如图 3.2a, 主要包括阴极、聚焦电极、阳 极和束管，优化后的参数见表 3.1, DC 高压 $90 \mathrm{kV}$ ，极间距离 $14 \mathrm{~mm}$ ，加上 $2 \mathrm{~mm}$ 的鼻半径, 总长度是 $16 \mathrm{~mm}$ 。该结构下对应的电场分布如图 $3.2 \mathrm{~b}$, 红色是轴线上 纵向加速电场 $\mathrm{Ez}$ 分布, 绿色是 $\mathrm{r}=2 \mathrm{~mm}$ 处的径向电场 $\mathrm{Er}$ 分布, 阴极表面场梯度 约 $4.5 \mathrm{MV} / \mathrm{m}$ 。

表 3.1 直流光电子枪结构尺寸

\begin{tabular}{|c|c|c|c|c|c|}
\hline 阴极倾角 & 阳极倾角 & 极间距离 & 高压 & 束管半径 & 鼻半径 \\
\hline 16 度 & 21 度 & $14 \mathrm{~mm}$ & $90 \mathrm{kV}$ & $6 \mathrm{~mm}$ & $2 \mathrm{~mm}$ \\
\hline
\end{tabular}

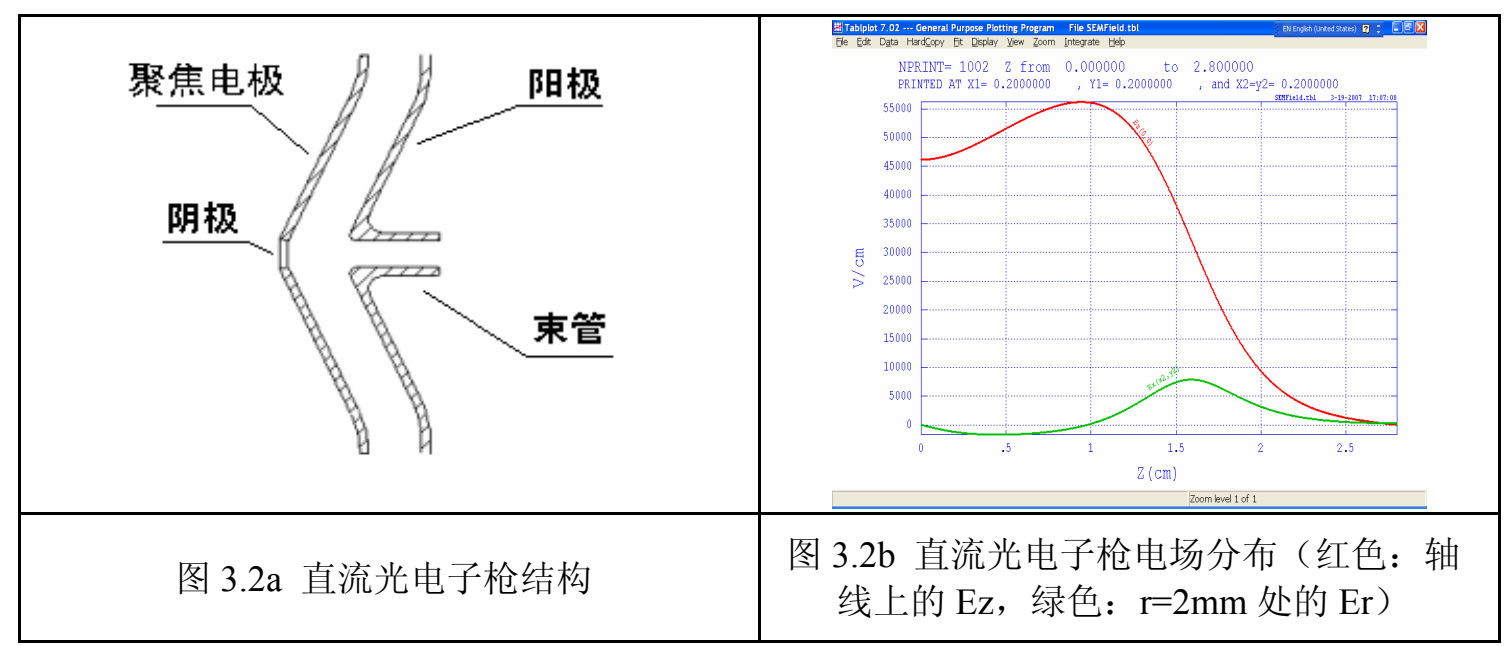

$3+1 / 2$ cell 超导腔的前半个腔设计较复杂, 为了保证和 DC 段很好的匹配, 其 结构设计如图 3.3a, 它不是普通的半腔结构, 为阻止微波漏到 DC 段, 前端孔径 
很小, 起点纵向电场为 0 ; 整腔结构是采用 TESLA $1.3 \mathrm{GHz}$ 超导腔的设计, 场分 布如图 3.3b。优化后 $3.5 \mathrm{cell}$ 结构总长度是 $57.4 \mathrm{~cm}, \mathrm{Ep} / \mathrm{Eacc}=2.12, \mathrm{Bp} / \mathrm{Eacc}=4.95$, 工作频率 $1.3 \mathrm{GHz}, \mathrm{R} / \mathrm{Q}=417.7 \Omega, 2 \mathrm{k}$ 下的 $\mathrm{Q}$ 值是 $1.44 * 10^{10}$, 运行的平均加速场 梯度约 $13 \mathrm{MV} / \mathrm{m}$ 。

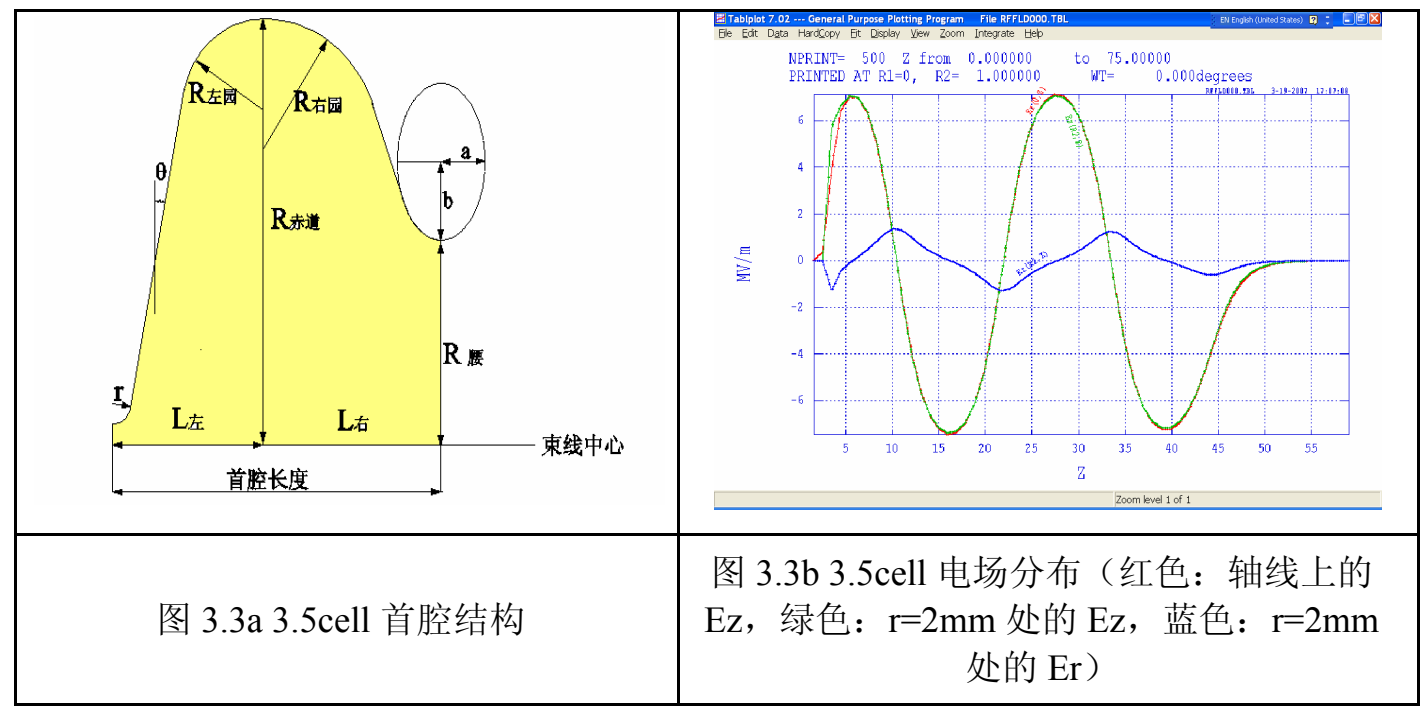

以上介绍了 $3+1 / 2$ DC-SC 光阴极几何结构以及优化后的运行参数, 该结构是 针对北京大学红外 SASE FEL ${ }^{[39]}$ 装置设计的, 束团电荷量约 $300 \mathrm{pC}$, 注入器出口 到主加速器是直线传输, 无偏转磁铁, 束线长度约 $3 \mathrm{~m}$ 。

\section{2 注入器研究}

SASE-FEL 对束流的要求和腔镜式 ERL-FEL 要求侧重点不同: SASE-FEL 要求束团电荷量很高, 从而得到很高的峰值流强; 能量回收下, 更强调高重复频 率, 对峰值流强的要求虽然越高越好, 但不如 SASE 那么苛刻, 最低要求是电子 束单次通过扭摆器, 光的增益大于光腔的总损耗。从实验室光阴极实际工作能力 和注入器的功率源考虑, ERL-FEL 装置上运行的束团电荷量考虑在 $20 \mathrm{pC}$ 到 $120 \mathrm{pC}$ 范围。另外, 能量回收装置中, 新增加了 merger 部分, 注入器出口到主 加速器的低能束线长度比以前更长, 约 $6 \mathrm{~m}$, 结构较复杂, 束流品质的保持更加 困难。输运线结构和束团电荷量都有较大变化, 因此, 注入器束流品质需要重新 研究, 这里主要用 PARMELA 程序计算, 也用 ASTRA 程序对模拟结果进行验证。

\subsection{1 注入器束流动力学研究}

首先采用模拟电荷量 $300 \mathrm{pC}$ 时对应的注入器结构、初始束团参数（假定为 
Gauss 分布) 以及机器运行参数, 即机器原期望运行的参数范围, 只改变束团电 荷到 $20 \mathrm{pC}$, 设置了两种平均场加速梯度: $13 \mathrm{MV} / \mathrm{m}$ 和 $8 \mathrm{MV} / \mathrm{m}$, 具体参数如表 3.2 , 为了与前终端束线长度类比, 注入器之后加了 $6 \mathrm{~m}$ 的直线漂移段 (3.2.2 节将解释 匹配段和 merger 段发射度变化与等长直线漂移段发射度变化趋势类似），RF 加 速相位选在能量增益最大值附近，此时对应的纵向相空间也满足 merger 段控制 发射度增长的要求, 模拟结果如图 3.4 所示。注入器具有轴对称性, $\mathrm{x}$ 和 $\mathrm{y}$ 方向 束流传输相同, 因此, 以下只给出 $\mathrm{x}$ 方向的束流品质。3.4a 显示横向归一化发射 度和纵向发射度变化曲线, 0 点对应光阴极位置, $59 \mathrm{~cm}$ 是注入器出口, 结果表 明两种情况下, 纵向发射度都保持得很好, 空间电荷效应影响不大, 相比较而言, 高梯度下, 注入器出口纵向发射度更大, 在 3.2.2 将会分析纵向发射度差别; 而 空间电荷效应引起的横向发射度变化差别很大, 在 $13 \mathrm{MV} / \mathrm{m}$ 下, 注入器出口的 横向发射度直线上升，而低梯度下，横向发射度在注入器后的变化曲线类似用常 用的螺线管补偿发射度 ${ }^{[40]}$ 效果。空间电荷力与能量平方成反比 ${ }^{[41]}$, 高加速梯度 下, 束流在注入器出口能量更高, 空间电荷效应引起的横向发射度增长应该更小。

表 3.2 模拟计算的初始条件

\begin{tabular}{|c|c|c|}
\hline \multirow{3}{*}{ 电子束团 } & 束团 FWHM 半径 $(\mathrm{mm})$ & 3 \\
\cline { 2 - 3 } & 束团 FWHM 长度 $(\mathrm{ps})$ & 8 \\
\cline { 2 - 3 } & 束团电荷量 $(\mathrm{pC})$ & 20 \\
\cline { 2 - 3 } & 初始电子能量 $(\mathrm{eV})$ & $13 / 8$ \\
\hline 超导腔 & 平均加速电场强度 $(\mathrm{MV} / \mathrm{m})$ & -90 \\
\hline \multirow{2}{*}{ 皮尔斯阴极 } & 阴极电位 $(\mathrm{kV})$ & 0 \\
\cline { 2 - 3 } & 阳极电位 $(\mathrm{kV})$ & 10 \\
\hline
\end{tabular}

为了更清楚研究两种情况下束流横向发射度变化差别很大的原因, 图 3.4b、 $3.4 \mathrm{c}$ 和 $3.4 \mathrm{~d}$ 从不同侧面反映粒子的信息，红色曲线对应 $13 \mathrm{MV} / \mathrm{m}$ 的加速梯度， 黑色曲线对应 $8 \mathrm{MV} / \mathrm{m}$ 的加速梯度, 由于注入器出口只有漂移段, 对束流分布影 响不大, 因此, 只显示从光阴极到注入器出口的一段距离束斑大小以及粒子横向 位移的变化。从 $3.4 \mathrm{~b}$ 得到, $13 \mathrm{MV} / \mathrm{m}$ 情况下, 加速腔内约 $30 \mathrm{~cm}$ 处, 束流被聚焦 很小, 因此电荷密度较大, 相应的空间电荷力也很大, ASTRA 程序模拟验证了 空间电荷力在该点附近的确很大。 $3.4 \mathrm{c}$ 是对其中几个粒子轨迹追踪, 表明在高梯 度下, 粒子轨迹在 $30 \mathrm{~cm}$ 交叉, 低梯度下粒子轨迹无交叉。图 $3.4 \mathrm{~d}$ 是对所有粒子 
横向坐标追踪, 横轴表示是 DC 出口粒子的坐标, 纵轴表示是注入器出口对应粒 子的坐标，低梯度下，粒子的坐标符号都保持不变，而 $13 \mathrm{MV} / \mathrm{m}$ 下，粒子的坐 标符号都发生改变, 从而表明所有粒子在 3.5cell 腔内轨迹交叉。束流轨道交叉 的主要原因是同样加速场下, 注入器对低电荷量束团过聚焦。

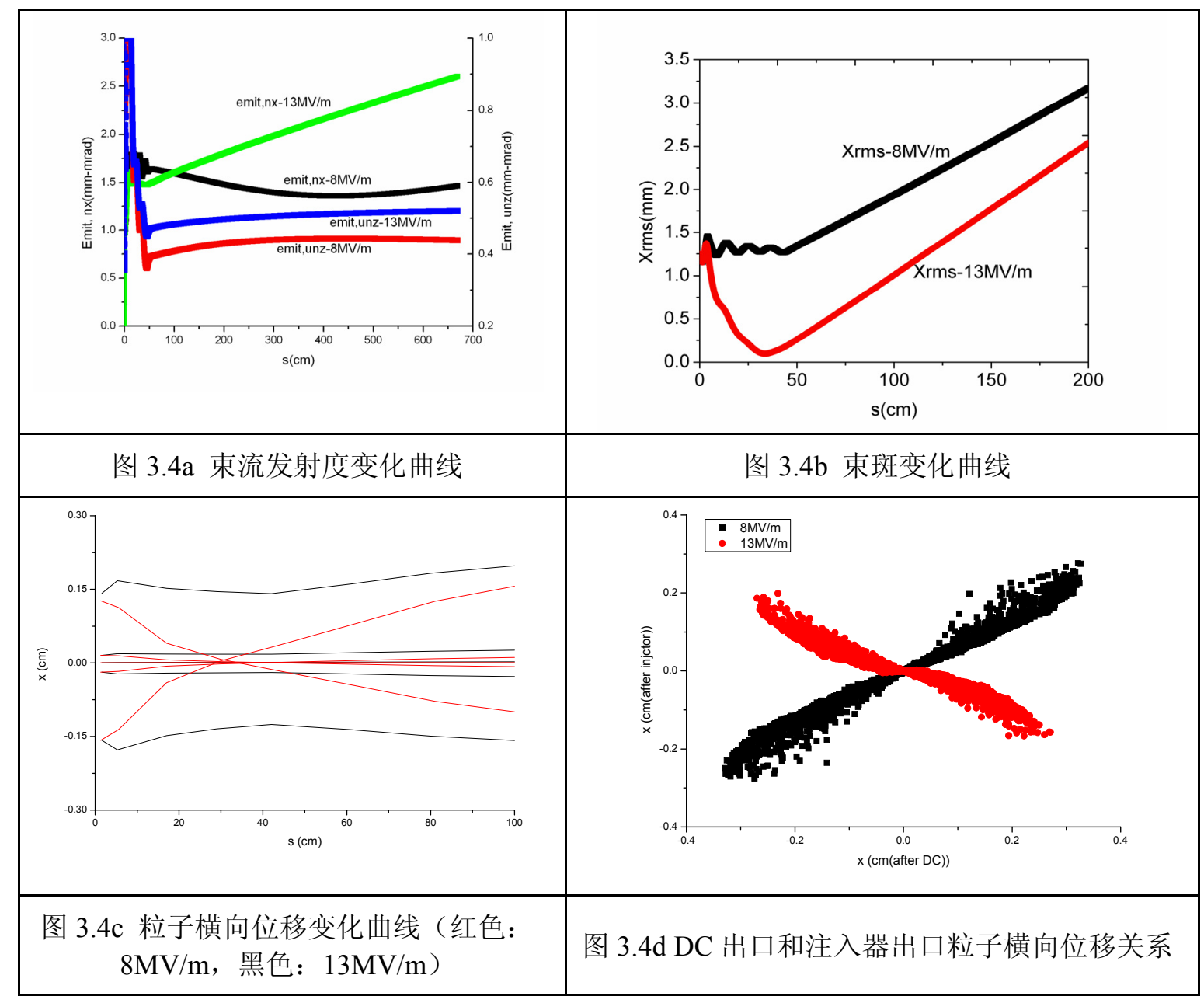

为了验证 PARMELA 模拟的正确性, 这里也用 ASTRA ${ }^{[42]}$ 程序计算, 结果发 射度变化趋势与 PARMELA 结果一致, 这里不再给出, 图 3.5 给出两种梯度下相 应的横向空间电荷力和纵向空间电荷力追踪曲线, 纵向电荷力变化较平滑, 横向 空间电荷力在 $13 \mathrm{MV} / \mathrm{m}$ 下有一个很高的尖峰, 力的大小约是 $8 \mathrm{MV} / \mathrm{m}$ 下力的 10 倍, 验证了 PARMELA 程序的结论。 


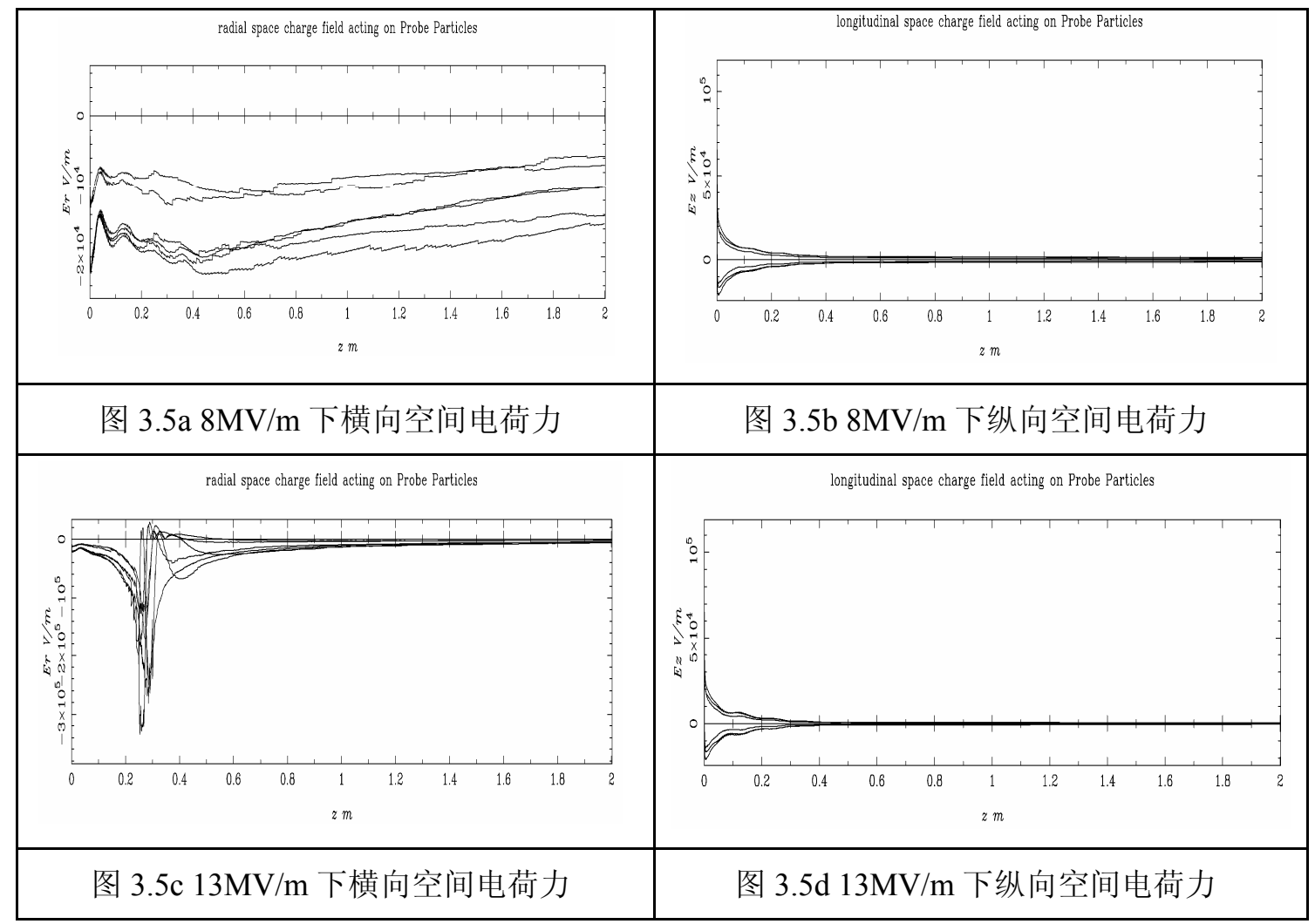

\subsection{2 发射度增长及其补偿机制的研究}

这里首先解释根据 Liouville 定理定义的归一化发射度和归一化 $\mathrm{rms}$ 发射度 区别，以及几何发射度定义。

根据 Liouville 定理, 当满足一定的条件 ${ }^{[43]}$ 时, 归一化发射度保持不变, 它 的定义是

$$
\varepsilon_{n x}=\frac{1}{m c} \int d x d p_{x}=\beta \gamma \int d x d x
$$

其中 $\beta$ 和 $\gamma$ 是粒子相对论因子, $\beta=v / c, \gamma=1 / \sqrt{1-\beta^{2}}, x^{\prime}=p_{x} / p_{z}$ 。它强 调的是束流相空间面积, 无法反映相空间畸变及密度分布情况 ${ }^{[44]}$ 。实际束流相空 间分布不均匀，中间密，边缘稀，因此有 $90 \%$ 发射度、100\%发射度等定义。

归一化 $\mathrm{rms}$ 发射度 ${ }^{[45]}$ 适用任何相空间分布, 最为常用, 是评价装置好坏的 一个重要参数, 其定义为:

$$
\varepsilon_{r m s, n, x}=\beta \gamma \sqrt{\left\langle x^{2}\right\rangle\left\langle x^{\prime 2}\right\rangle-\left\langle x x^{\prime}\right\rangle^{2}}
$$

它能更全面的反映粒子相空间分布的好坏, 如相空间畸变 ${ }^{[46]}$ 的情况下, 归一化 $\mathrm{rms}$ 发射度变大，而归一化发射度遵从Liouville定理，仍然保持不变，归一化 rms发 射度也被称为有效发射度。 
几何发射度在实际测量值, 在计算束斑大小中常用到 $\left(X=\sqrt{\beta_{x} \varepsilon_{x}}\right.$, 其中, $\beta_{x}$ 是束包络函数), 其定义是归一化发射度与 $\beta \gamma$ 的比值:

$$
\varepsilon=\varepsilon_{n} / \beta \gamma
$$

对密度均匀分布的束流, 发射度和 $\mathrm{rms}$ 发射度关系是 $\varepsilon=4 \varepsilon_{r m s}$, 相应的, 束 斑和 $\mathrm{rms}$ 束斑关系是 $X=2 X_{r m s}$ 。

归一化发射度定义中包含束流能量信息, 当束流能量变化时, 理想情况下, 归一化发射度保持不变, 相应得到几何发射度将随 $\beta \gamma$ 变化, 能量增大时, 束流 几何发射度变小。

关于发射度补偿技术, 最早是 80 年代末 Carlsten 提出的 ${ }^{[47]}$, 它是用一个螺 线管线圈聚焦束流实现, 补偿线性空间电荷力引起的发射度增长, 该理论中假设 空间电荷力与粒子所处的半径成线性关系, 即束流传输中, 类似流体传输, 可用 薄层近似（Laminar flow）理论 ${ }^{[48]}$, 因此, 粒子轨迹不会相互交叉, 粒子密度近 似不变。发射度补偿过程是束流首先经过直线段, 线性空间电荷力引起发射度增 大, 然后经过薄透镜聚焦, 最后再经过漂移段, 完成归一化 $\mathrm{rms}$ 发射度补偿。

对粒子轨迹交叉的情况, 以上发射度补偿技术不再适用。下面给出模型定性 分析两种情况下空间电荷力引起发射度变化的趋势 ${ }^{[49]}$ 。

电子束团初始分布如图 3.6a, 建立内部坐标系 $(\mathrm{x}, \mathrm{z})$, 为了简单, 只考虑 束团横向边缘的两个电子 $\mathrm{a}$ 和 $\mathrm{b}, \mathrm{a}$ 处于束团中间位置, $\mathrm{b}$ 处于束团头部, 电子 纵向位置不同, 所受空间电荷力有差别进而改变束流发射度。假设初始情况下, 电子束没有横向速度, 即 $\mathrm{x}=0$, 发射度最小; 电子束团沿 $\mathrm{z}$ 方向运动, 其过程 是先经过一段长度为 $\mathrm{z} 1$ 的漂浮管, 然后经过一个薄透镜 (焦距为 $\mathrm{f}$ ), 接着再经 过长度为 $\mathrm{z} 2$ 的漂浮段, 下图中相空间不同颜色对应经不同元件后的相空间分布。

对常见束流分布, 束团中间的密度大于两端的密度, 因此, a 点的空间电荷 力大于 $\mathrm{b}$ 点的空间电荷力, 空间电荷力对束流的作用类似散焦元件, 其区别在于 散焦元件中, 力的大小取决于横向位置, 与纵向位置无关, 不改变束流发射度, 而空间电荷力与纵向位置相关, 是引起发射度变大的根源。经过漂移段 $\mathrm{z} 1$ 后, 由于 $\mathrm{a}$ 点散焦力大于 $\mathrm{b}$ 点, 因此, $\mathrm{a}$ 点发射角更大, 对应的横向位移也更大, 如 图 3.6b 所示。 rms 发射度增大的过程可以如下理解: 把束团沿纵向划分若干片, 每一片都有相应的发射度, 束团总 rms 发射度取决于不同片之间相空间的倾斜方 
向（orientation）, 当倾斜方向差别变大时, 即便每片的发射度不变, 束团的 rms 发射度也将增大。经过第一个漂移段 $\mathrm{z} 1$, 由于空间电荷力差别, 片之间相空间 的倾斜方向随漂移距离增大不断增大，相同横向位置 $\mathrm{x}$, 束团中部的倾斜角大于 两端的倾斜角, 因此, 束团发射度在直线段随 $\mathrm{z} 1$ 一直增大。

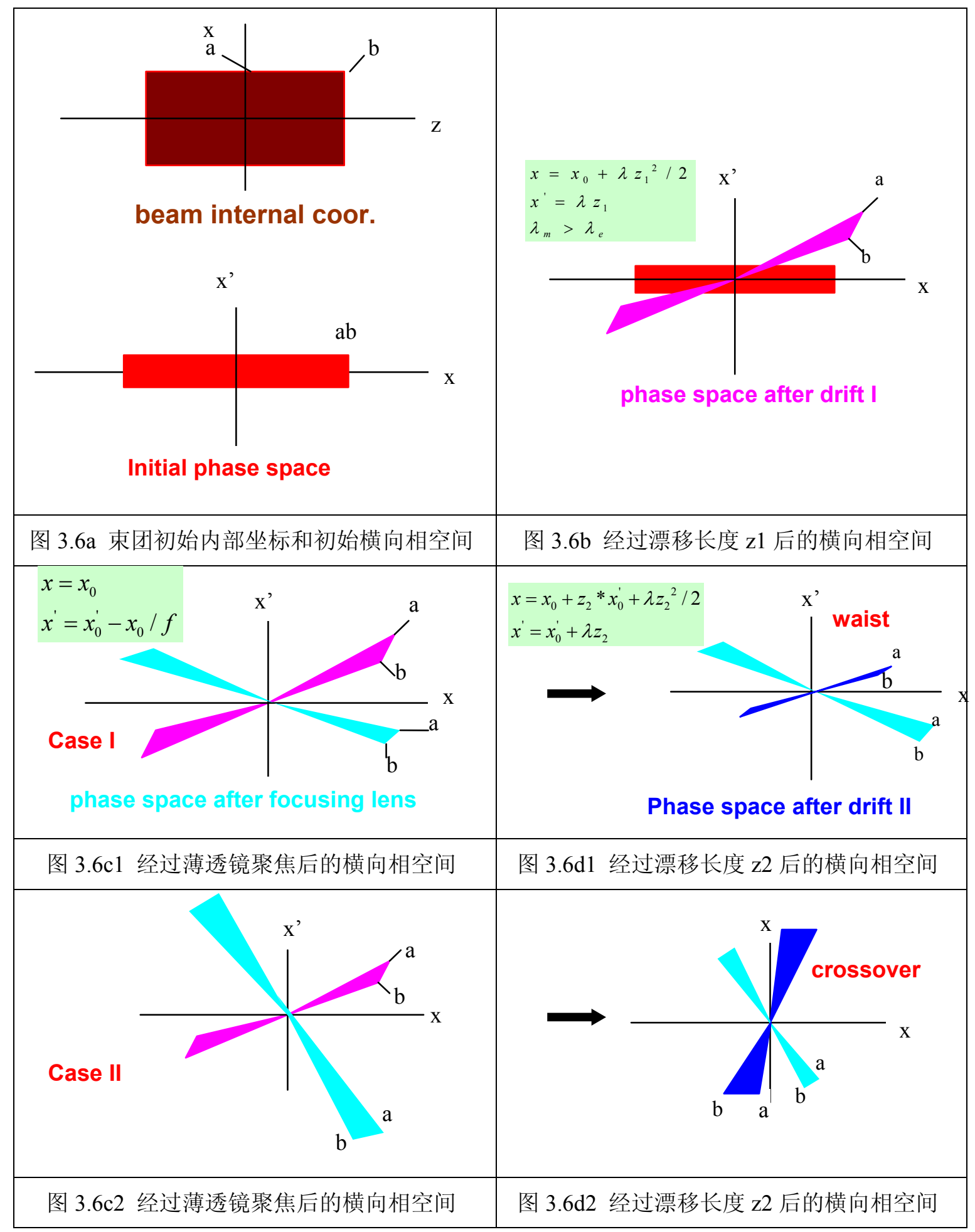


尔后，经过薄透镜聚焦元件，聚焦强度需要足够把束流从发散变成汇聚束， 如图 3.6c1 和图 3.6c2 所示, 聚焦的强弱对应两种的情况: 图 3.6c1 是聚焦强度合 适，在接下面的漂移段束流成腰，电子横向坐标不改变符号，处于相空间第一象 限的电子仍然回到第一象限, 如图 3.6d1; 图 3.6c2 是聚焦强度过强, 电子发散 角过大 (过聚焦), 以致下面的漂移段中, 电子横向坐标改变符号, 原来处于相 空间第一（三）象限的电子到第三（一）象限, 如图 3.6d2。聚焦过程是薄透镜 近似, 因此, 该过程中发射度不改变。

第一种情况如图3.6c1是经常采用的发射度补偿技术，经聚焦元件后，空间 电荷力是让不同薄片的相空间倾斜方向趋向一致, 聚焦前后空间电荷力引起的发 射度变化相互抵消, 达到发射度补偿目的。

在第二种情况如图 3.6c2, 电子的横向坐标改变符号, 因此, 束团内束流轨 迹交叉。同样由于空间电荷力差别，不同薄片的相空间倾斜方向差别变的更大, 聚焦前后空间电荷力引起的发射度变化贡献一致, 发射度一直增大, 因此, 这种 情况应该避免。

上面提到, 薄透镜聚焦强度要足够强, 对弱聚焦或散焦透镜, 束流相空间将 类似如图 3.6b 相空间, 空间电荷力引起的发射度增长在透镜前后贡献效果一致, 因此, 对有聚散焦元件组合的束线, 其发射度变化趋势与用漂移段的变化趋势类 似, 研究匹配段和 merger 段发射度变化可以先用漂移段代替。

总结以上过程，发射度补偿需要四个条件：

（1）粒子所受内部空间电荷力随它所在的纵向位置变化，这是与聚焦元件 的区别, 也是发射度变化的根源。

（2）聚焦元件之前，空间电荷力引起发射度变大。

（3）聚焦强度要足以把束流从发散变成汇聚，但又要避免束流交叉，过强 的聚焦只会使得 $\mathrm{rms}$ 发射度在原来的基础上继续增大。

（4）聚焦元件之后要有漂移段，使得空间电荷力继续改变发射度。

$3+1 / 2$ cell DC-SC光阴极注入器中, 情况比以上复杂, $\mathrm{DC}$ 静电场和 $3+1 / 2$ cell $\mathrm{RF}$ 场和空间电荷力同时存在，并伴随电子加速，但过程类似。

$\mathrm{DC}$ 段较短, 参见图 $3.2 \mathrm{~b}$, 横向静电场对束流先聚焦再散焦, 束流能量很低, 空间电荷效应严重, 模拟显示, $90 \mathrm{kV}$, 束流发射度增大, 这一段可以看成近 似3.6b过程。 
根据图3.3b所示的 $3+1 / 2$ cell RF加速腔场分布，先不考虑首腔左半部分场分 布, 其后的纵向电场 $E_{z}$ 可以近似为:

$$
E_{z}=E_{0} \cos k z \cos \left(\omega t+\phi_{0}\right)
$$

其中, $\phi_{0}$ 是参考电子相对首腔RF峰值点的相位, $\omega$ 是RF角频率, $k$ 是RF波 数, $z=v t, v$ 是电子速度。

定义参考粒子相位 $\phi_{R}$ :

$$
\phi_{R}=\omega t-k z+\phi_{0}
$$

电子的纵向运动方程:

$$
\frac{d \gamma}{d z}=\frac{e E_{z}}{m c^{2}}=\frac{e E_{0}}{2 m c^{2}}\left[\cos \left(\phi_{R}\right)+\cos \left(\phi_{R}+2 k z\right)\right]
$$

在相对论下, 即 $v \approx c$, 相位 $\phi_{R}$ 近似不变。方程（3.6）第二项表示方向传输 波, 对电子加速总贡献是 0 , 因此

$$
\frac{d \gamma}{d z}=\frac{e E_{0}}{2 m c^{2}} \cos \left(\phi_{R}\right)
$$

定义参考粒子看到 RF场的时间是 $t=0$ 时刻, 则束团头部相对参考粒子先看 到RF场, $t<0$, 束团尾部后看到 RF场, $t>0$ 。当参考相位 $\phi_{R}>0$, 即峰值后加 速, 如图3.7红色所示, 头部粒子能量高、尾部粒子能量低, 纵向散焦, $\mathrm{RF}$ 场把 束团拉长。当参考相位 $\phi_{R}<0$, 即峰值前加速, 如图3.7蓝色所示, 头部粒子能量 低、尾部粒子能量高, 纵向聚焦, RF场对束团有压缩效果。

对横向场, 解Maxwell方程, 可以得到

$$
\begin{gathered}
\frac{d P_{r}}{d t} \propto-r \sin (\phi) \\
B_{\theta}=\frac{r}{2 c^{2}} \frac{\partial E_{z}}{\partial t}
\end{gathered}
$$

径向电磁场力

$$
F_{r}=\frac{d P_{r}}{d t}=q E_{r}-q v B_{\theta}
$$

结合以上方程

$$
\frac{d P_{r}}{d t} \propto-r E_{0} \sin \left(\phi_{R}\right)
$$

横向力与 $r$ 和电场梯度 $E_{0}$ 成正比。当 $\phi_{R}>0$ 时, $\mathrm{RF}$ 场对束团横向聚焦; $\phi_{R}<0$ 
时, RF 场对束团横向散焦。与纵向受力效果相反。

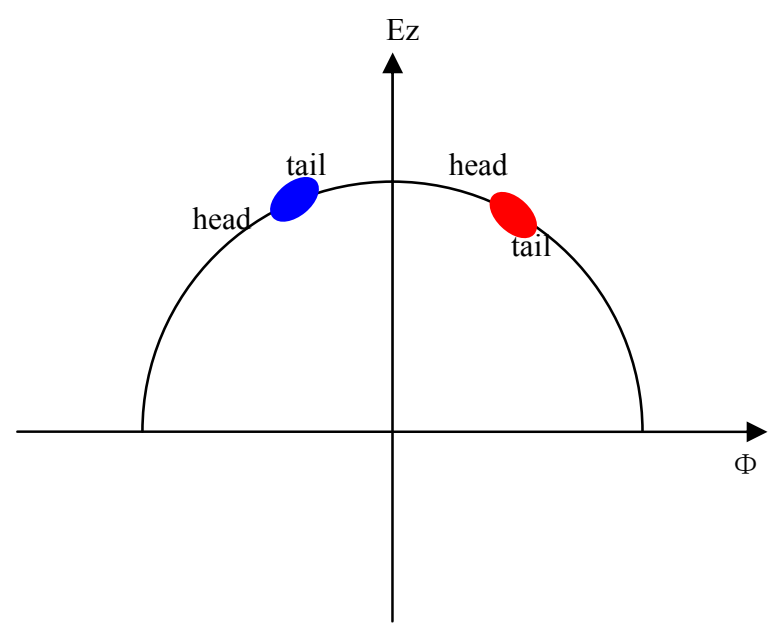

图 3.7 束团相对 RF 场相位

从 (3.11) 还可以得到, 电子所受的横向力与它处在束团中的位置 $\left(\phi_{R}\right)$ 有 关, 这点与空间电荷力类似 (空间电荷力沿 $\mathrm{z}$ 方向呈 Guass 变化, 而加速场范围 内，横向 RF 沿 $\mathrm{z}$ 方向单调变化），它将导致横向发射度改变。

以上是考虑场分布沿 $\mathrm{z}$ 变化满足正弦(余弦)变化的情况, $3+1 / 2$ cell 首腔左半 部分场不是标准的半腔, 但场变化趋势与半腔结构类似, 因此对束流的作用与前 面分析类似。

$3+1 / 2$ cell 注入器中, 束流动能从 $0.09 \mathrm{MeV}$ 增加到 $5 \mathrm{MeV}$, 因此, 需要考虑 低能下，束流相对 RF 场的相位滑移，根据（3.5）式，可以得到束流相对 RF 场 在 3.7 图是从右向左滑, 能量越低, 相位滑移越大。纵向上, 首先要求粒子尽可 能获得高能量, 其次, 要求纵向相空间分布较平, 即能散很小束团很长, 避免能 量和位置关联 $\left(\alpha=-\frac{\partial \beta}{2 \partial s}\right.$ 表示相空间倾斜程度, $\alpha$ 越小，相空间越平， $\beta=\frac{\sigma^{2}}{\varepsilon}$ 反 映束团长度/束斑的大小, 函数 $f=\alpha / \sqrt{\alpha^{2}+1}$, 反映束团可压缩/拉伸的程度, $\alpha$ 绝对值越小, $f$ 的绝对值也越小, 关联越弱, 束团可压缩/拉伸效果越小, 反之 相反。），在随后的匹配段和 merger 段, 就避免了束团变长或压缩, 控制空间 电荷力在 merger 段对发射度增长的影响, 因此, 3+1/2cell RF 腔内, 其初始相位 选在 $\phi_{R}>0$, 然后向峰值滑动, 到注入器出口时, 加速相位滑到 $\phi_{R}<0$, 满足纵 向相空间分布要求。分析横向电场力, 如上所述, $\phi_{R}>0$ 时, 电磁场对束团横向 聚焦, 首腔中, 加速相位一直处于 $\phi_{R}>0$, 因此, 对束团横向作用一直是聚焦效 
果。在 3.2.1 节模拟结果显示 $13 \mathrm{MV} / \mathrm{m}$ 下, 粒子轨迹在加速腔内交叉, 而降低梯 度, 粒子轨迹不交叉, 结合 (3.11) 式, 高梯度下, 电磁场聚焦更强, 束流过聚 焦, 结合图 3.4d 模拟结果和图 3.6d2 模型, 便不难解释图 3.4a 中 $13 \mathrm{MV} / \mathrm{m}$ 下发 射度增长现象。

\subsection{3 注入器参数优化}

以上定性解释了发射度变化趋势, 从能量增益考虑, 希望注入器运行在高梯 度下, 但在注入器内束流过聚焦, 造成后面发射度不断增大不是实验所希望的, 这节将研究哪些因素造成束流过聚焦, 找到过聚焦的区域, 研究避免过聚焦的办 法, 同时保证电子束获得能量最高。使用 PARMELA 程序计算。

注入器中, 影响电子束横向发射度变化的原因很复杂, 除了注入器结构外, 主要有以下几种机制 ${ }^{[50]}$ :

（1）空间电荷效应: 特别是在电子从光阴极出来时的低能段, 空间电荷力对 横向发射度增长的影响特别明显, 空间电荷力大小与束团电荷量、驱动激光光斑 大小以及驱动激光脉冲长度有关。

（2） DC 横向静电场: 束流在 DC 段动量很低, 从 0 到 $90 \mathrm{kV}$, 很容易受到 影响。横向电场力取决于 DC 电压。

（3）横向电磁场: 3.2.2 节分析了束团纵向不同位置, 所受电磁场力也不同, 从而增大横向发射度, 它引起横向发射度变化 $\varepsilon_{r} \sim E_{0} r^{2} \sigma_{z}, \mathrm{r}$ 是束团的半径, $\sigma_{z}$ 是束团长度。电磁场力取决于 RF 加速场梯度和电子束相对 RF 场的相位。

(4) 光阴极本身的热发射度: 模拟显示光阴极热发射度在该注入器中影响 可以忽略。

根据以上分析, 对影响横向发射度变化的机制对应参数分别进行模拟优化, 优化参数有 $\mathrm{DC}$ 电压、 $\mathrm{RF}$ 相位、 $\mathrm{RF}$ 场梯度、束团电荷量、驱动激光脉冲长度和 光斑尺寸。

$20 \mathrm{pC}$ 下, 图 3.8 研究横向相空间束流品质变化, 包括注入器出口横向 twiss 参数和注入器后 $6 \mathrm{~m}$ 处归一化 $\mathrm{rms}$ 发射度随 $\mathrm{DC}$ 高压、 $\mathrm{RF}$ 平均场加速梯度和 $\mathrm{RF}$ 相位变化, 黑色表示 $\beta$ 曲线, 绿色是 $\alpha$ 曲线, 红色是归一化 $\mathrm{rms}$ 发射度曲线, 束 团初始参数如表 3.2。改变 DC 高压和 RF 平均场加速梯度时, 为了满足 merger 段对束流纵向相空间要求, $\mathrm{RF}$ 相位做相应调整。从图 $3.8 \mathrm{a}$ 可以看出 $\mathrm{DC}$ 电压从 
$70 \mathrm{kV}$ 到 $120 \mathrm{kV}$ 变化中, 归一化 $\mathrm{rms}$ 发射度基本不变, 约 $1.5 \mathrm{~mm}-\mathrm{mrad}$, 发射度 随 DC 电压增大减小, 这是因为 DC 段总体效果是聚焦, 对初始段空间电荷力引 起的发射度增长有补偿效果, 电压越大, 聚焦力越强, 补偿效果越大, 从发射度 变化可以知道 $\mathrm{DC}$ 段聚焦强度还不足以造成粒子轨迹交叉。 $3.8 \mathrm{~b}$ 图 $\mathrm{RF}$ 场从 $7 \mathrm{MV} / \mathrm{m}$ 到 $12 \mathrm{MV} / \mathrm{m}$ 变化中, 红色曲线是注入器后 $6 \mathrm{~m}$ 处归一化 $\mathrm{rms}$ 发射度, 蓝 色曲线是注入器出口的归一化 $\mathrm{rms}$ 发射度, 发射度随场梯度变化较大, 加速梯度 在 $10 \mathrm{MV} / \mathrm{m}$ 以上, 束流发射度在注入器后增长很快, 从 $1.5 \mathrm{~mm}-\mathrm{mrad}$ 增长到 $3 \mathrm{~mm}-\mathrm{mrad}$, 此区域是过聚焦区, 应该避免; 同时还可以看到, 在过聚焦发生边 界处, 刚好对应 $\alpha \approx 0$, 表明注入器对束流聚焦强度刚好使得束流在注入器出口 成腰, 对应的 $\beta$ 值也很小, 因此束斑很小, 束流较容易控制, 在过聚焦边界之前, 随场梯度增大, 束流的 $\beta$ 值变小, 发散变弱, 在过聚焦边界之后, 场梯度增大, 束流的 $\beta$ 值变大, 发散更严重。图 $3.8 \mathrm{c}$ 和 $3.8 \mathrm{~d}$ 分别在 $8 \mathrm{MV} / \mathrm{m}$ 和 $13 \mathrm{MV} / \mathrm{m}$ 下 $\mathrm{RF}$ 相位扫描曲线, 扫描相位范围是最高能量增益对应的相位左右各 10 度, 可以看 出 $\mathrm{RF}$ 相位变化对发射度影响不大, $8 \mathrm{MV} / \mathrm{m}$ 时 twiss 参数变化趋势对应过聚焦边 界之前, 发射度得到补偿, $13 \mathrm{MV} / \mathrm{m}$ 时 twiss 参数变化趋势对应过聚焦边界之后, 发射度不断长大。

综合以上分析可以看出, 一定电荷下, DC 高压和 RF 相位对是否过聚焦影 响不大, $\mathrm{RF}$ 平均场加速梯度起决定作用, 除了直接测量发射度变化判断过聚焦 外, 还可以根据 twiss 参数变化来判断过聚焦区; 远离过聚焦边界, $\alpha$ 和 $\beta$ 值很 大，束流发散很厉害，不容易传输控制; 在发射度补偿区，束流在注入器出口能 量低; 而在过聚焦区, 束流能量虽然高, 但发射度也变坏。综合考虑, 最优工作 参数是 RF 加速场梯度在过聚焦边界对应的场梯度或稍微偏下区, 对 $20 \mathrm{pC}$ 束团 电荷量, 过聚焦边界对应的 RF 场梯度是 $10 \mathrm{MV} / \mathrm{m}$ 。 


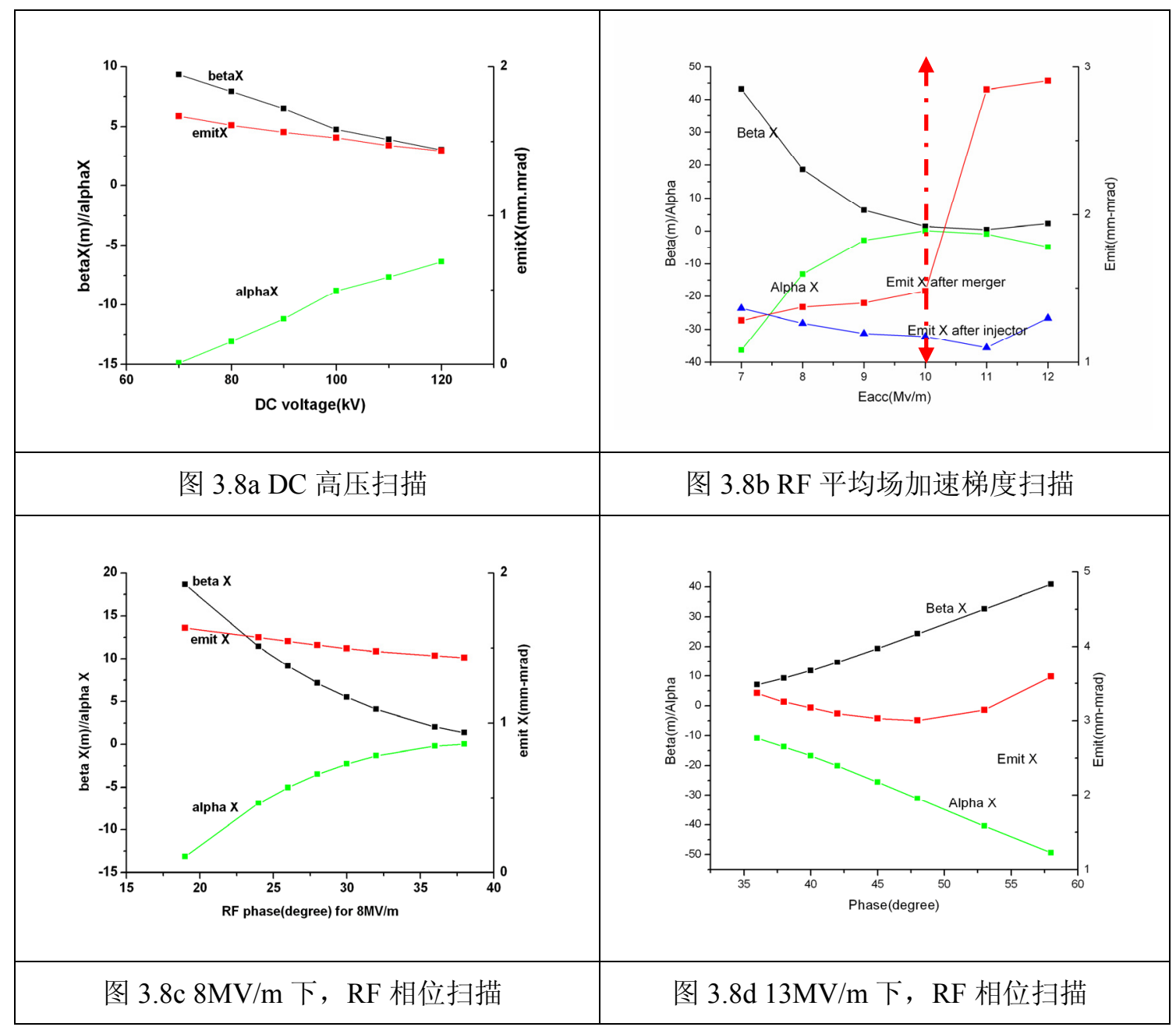

以上研究了注入器参数对横向束流品质的影响, 图 3.9 研究纵向相空间束流 品质, 包括纵向归一化 $\mathrm{rms}$ 发射度、束团长度、 $\mathrm{rms}$ 能散和动能, 所用束流初始 参数、 $\mathrm{RF}$ 相位选择以及扫描参数与图 3.8 相同, 黑色表示 $\mathrm{rms}$ 能散曲线, 绿色 是束团长度曲线, 红色是纵向归一化 $\mathrm{rms}$ 发射度曲线、蓝色是动能曲线。

从图 3.9a 得到, DC 高压对纵向束流品质影响不大, $\mathrm{RF}$ 场梯度 $13 \mathrm{MV} / \mathrm{m}$ 时, 束团能量 $5.5 \mathrm{MeV}$, 束团 $\mathrm{rms}$ 长度约 $3 \mathrm{ps}$, 纵向归一化 $\mathrm{rms}$ 发射度 $10 \mathrm{ps}-\mathrm{keV}$, 能 散 $0.25 \%$ 。扫描场梯度时, 为保证纵向相空间能量位置关联小, 随场梯度增加, 束团相对 RF 的初始相位偏离峰值更远, 对应图 3.7 峰值右侧区域。从图 $3.9 \mathrm{~b}$ 中 看出, 束团长度、能量以及纵向归一化 $\mathrm{rms}$ 发射度随场梯度增大, 相对能散 $(\delta E / E)$ 基本不变, 这是因为 $\mathrm{RF}$ 相位改变; 对能量随场梯度增加, 根据（3.7） 式不难理解。低能下束流相对 RF 相位滑移, 低梯度相比高梯度加速, 相位滑移 更严重, 低梯度对应的相位有更多时间工作在图 3.7 峰值左侧, 即束团压缩区, 
因此, 注入器出口的束团长度更短; 纵向归一化 $\mathrm{rms}$ 发射度定义类似 (3.2) 式 定义, $\varepsilon_{n z}=\frac{1}{m c} \int d z d p_{z}$, 取决于绝对能散 $\left(d E=E^{*}(\delta E / E)\right)$ 和束团长度, 当能 量位置关联很小时, 发射度近似为绝对能散和束团长度的乘积, 而绝对能散和束 团长度都随场梯度增大, 因此, 随着场梯度增大, 归一化 $\mathrm{rms}$ 发射度变大。对 $3.9 \mathrm{c}$ 和 $3.9 \mathrm{~d}$ 图中，不同场梯度下，纵向相空间参数随 $\mathrm{RF}$ 相位变化趋势相同，峰 值加速处能散最小; 根据上节分析, 峰值相位之前的区域是束团压缩区, 峰值之 后的区域是束团拉伸区, 解释了束团长度随相位变化曲线。

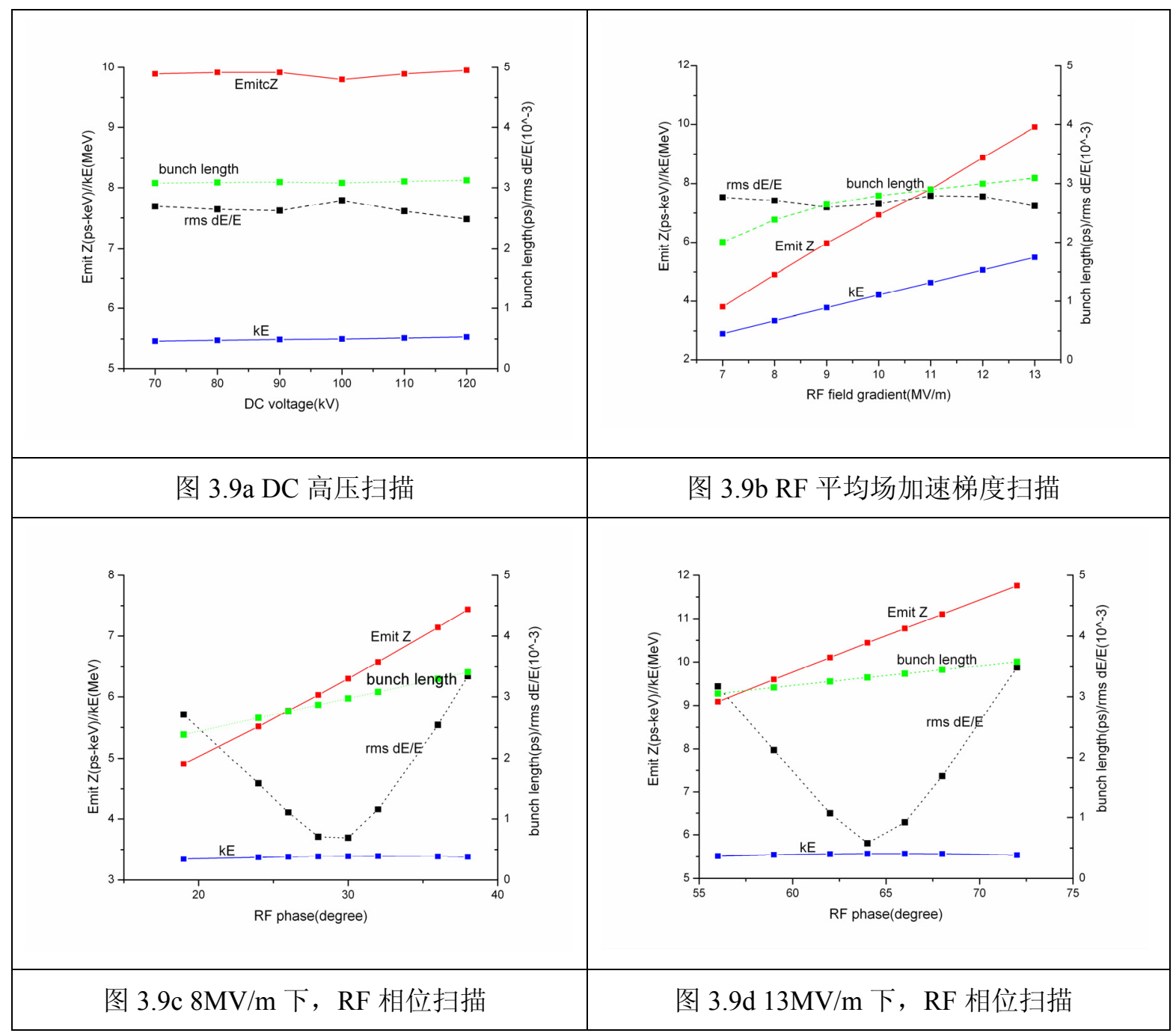




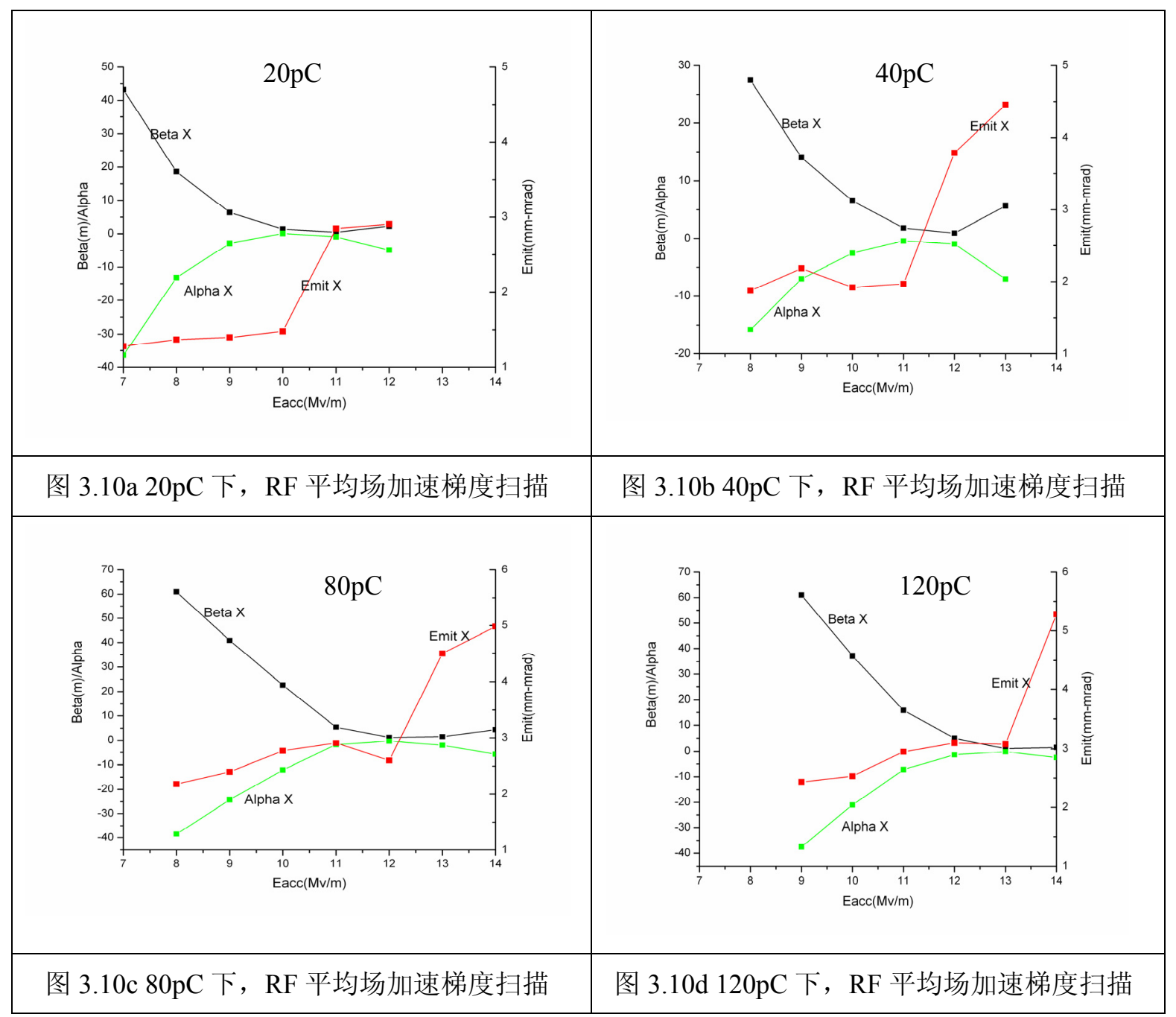

纵向相空间上, $\mathrm{DC}$ 高压对束流品质影响很小; 纵向束流品质主要取决于加 速场梯度和 RF 相位。

从注入器参数扫描结果得到: 一定电荷量下, 注入器可调参数中, RF 平均 场梯度是决定束流过聚焦最重要的因素。图 3.10 是改变束团电荷量, 研究过聚 焦边界对应的场梯度，扫描的电荷量分别是 $20 \mathrm{pC} 、 40 \mathrm{pC} 、 80 \mathrm{pC}$ 和 $120 \mathrm{pC}$, 分别 对应的过聚焦边界场梯度约是 $10 \mathrm{MV} / \mathrm{m} 、 11 \mathrm{MV} / \mathrm{m} 、 12 \mathrm{MV} / \mathrm{m}$ 和 $13 \mathrm{MV} / \mathrm{m}$, 随电 荷量增加而增大。电荷量越大, 空间电荷力越强, 从电子受力分析看, 过聚焦边 界对应的外力应该增强, 因此, 对应的边界场梯度增大。 


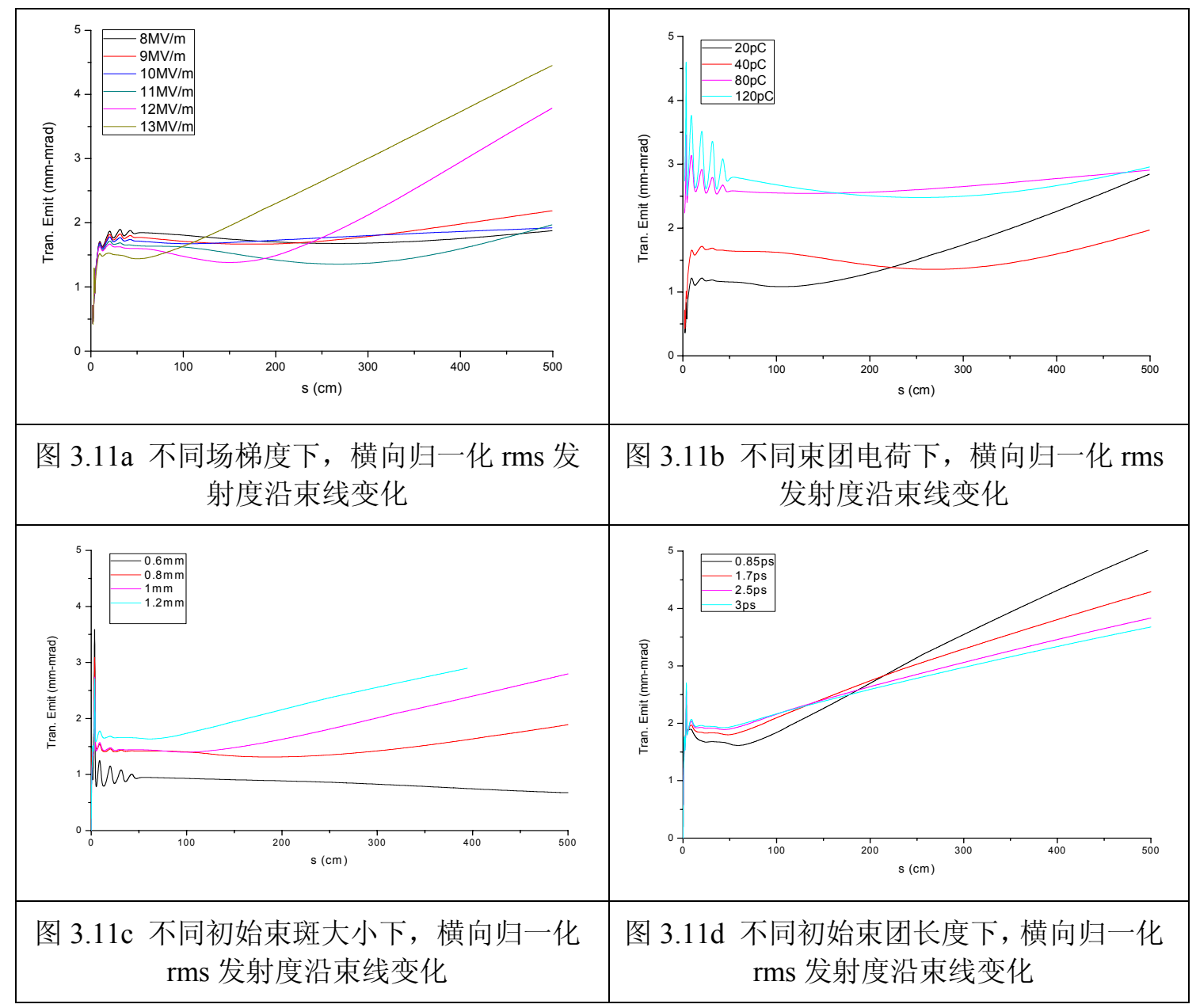

模拟结果表明, 低束团电荷下, 该注入器存在束流过聚焦区, 它将限制注入 器的加速能力。避免过聚焦的办法是减小粒子在注入器部分受到的聚焦力或增大 散焦力, 减小聚焦力是降低场梯度, 增大散焦力除了增大电荷量外还可以减小驱 动激光束斑和缩短激光脉冲长度, 另外, 就是改变注入器设计结构, 这里不再重 新设计。以上束流参数对应束线上某一点的值, 图 3.11 给出横向归一化 $\mathrm{rms}$ 发 射度沿束线变化情况, 研究了场梯度、电荷量、驱动激光束斑和激光脉冲长度对 发射度的影响, 结果表明降低场梯度、减小驱动激光束斑或增大束团电荷量可以 避免过聚焦, 但改变激光脉冲长度对过聚焦影响不大。

\section{3 merger 结构研究}

Merger 在输运线上是把不同能量的电子同时注入到主加速器, 因此, 它包 括若干 B 铁。束线传输中, B 铁会引入色散项, 横向和纵向相空间由于能散耦合, 横向发射度变化为 ${ }^{[51]}$ : 


$$
\varepsilon_{x}=\varepsilon_{x 0}\left[1+\frac{1}{\varepsilon_{x 0}}\left(\gamma_{x f} \eta^{2}+2 \alpha_{x f} \eta \eta^{\prime}+\beta_{x f} \eta^{\prime 2}\right)\left(\frac{\Delta p}{p}\right)^{2}\right]^{1 / 2}
$$

或

$$
\varepsilon_{x}=\varepsilon_{x 0}\left[1+\frac{\left(\alpha_{x f} \eta+\beta_{x f} \eta^{\prime}\right)^{2}+\eta^{2}}{\varepsilon_{x 0} \beta_{x f}}\left(\frac{\Delta p}{p}\right)^{2}\right]^{1 / 2}
$$

$\varepsilon_{x 0}$ 是色散为 0 时对应的发射度, $\eta$ 是色散函数, $\eta$ 是色散函数的导数, $\beta_{x f} 、 \alpha_{x f}$ 和 $\gamma_{x f}$ 是经色散段传输后的 twiss 参数, $\frac{\Delta p}{p}$ 是动量散度, 不考虑空间电荷效应时, $\frac{\Delta p}{p}$ 保持常数。从 (3.12) 可以知道, 当 $\eta=0$ 和 $\eta^{\prime}=0$ 同时满足, 即系统消色散, 色散项引起的发射度增长是 0 。因此, 消除由于色散引起的发射度增长, 要求 merger 段是消色散结构。

merger 结构设计中, 考虑国际上其他实验室现有的设备已经采用的结构, 介 绍了不同结构满足消色散的条件、各自的优缺点, 并分析了它们对误差敏感度以 及空间电荷效应。

\subsection{1 不同消色散 merger 结构研究}

现有装置采用的消色散 Merger 装置结构有: Jlab-FEL ${ }^{[52]}$ 三块磁铁结构, chicane 结构 (BINP 和 CEBAF) 和日本 dogleg 结构 ${ }^{[53]}$, 另外 BINP 最新提出的 zigzag 结构 ${ }^{[54,55]}$, 如图 3.12 所示, 红色是返航束线, 蓝色是注入束线, 为了设计 简单, 它们都是关于中心对称, 详细可分为两类: 对称消色散 (JLAB 和 BINP) 和反对称消色散（JAERI 和 BNL）。

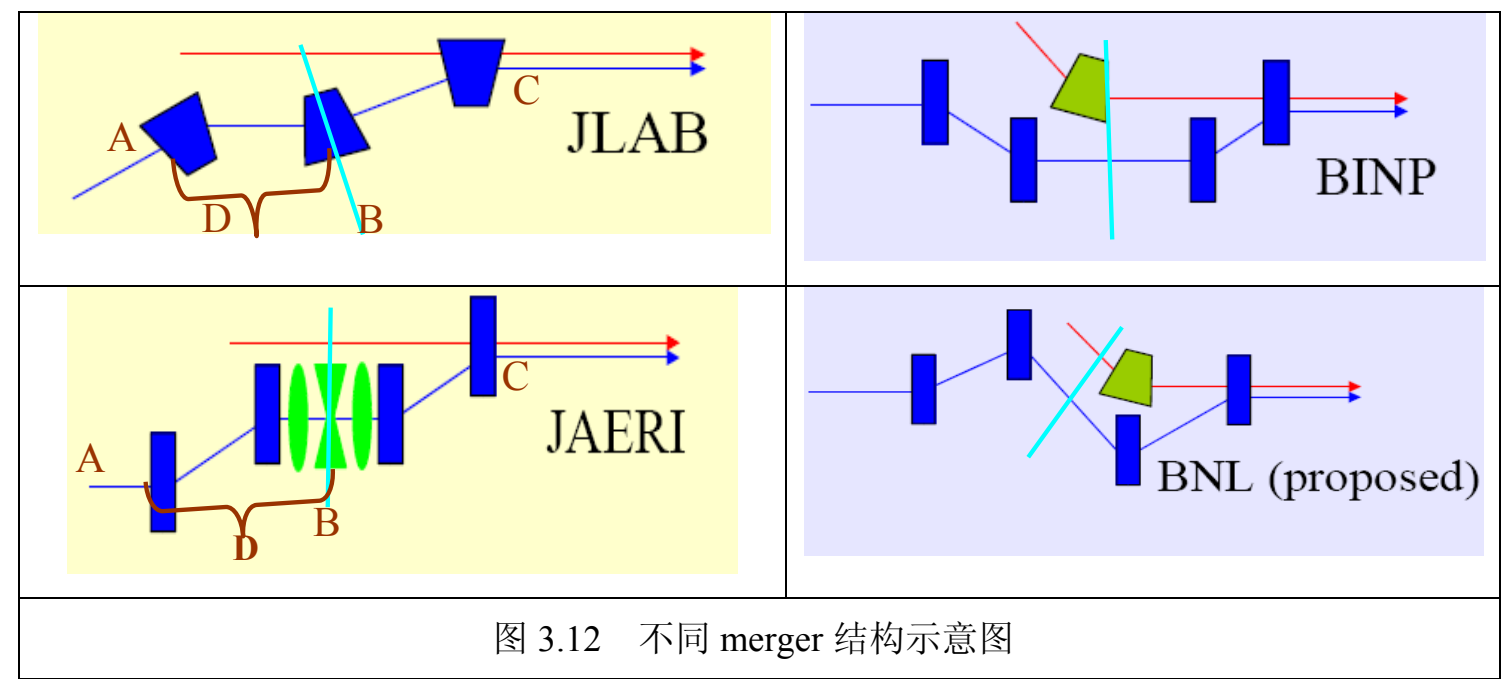


论文默认 $\mathrm{x}$ 平面是偏转平面。从 merger 起点 $\mathrm{A}$ 到终点 $\mathrm{C}$ 的传输矩阵 $\mathrm{M}$ 是

$$
\left(\begin{array}{c}
x \\
x^{\prime} \\
\Delta p / p
\end{array}\right)=\left(\begin{array}{ccc}
m_{11} & m_{12} & m_{16} \\
m_{21} & m_{22} & m_{26} \\
0 & 0 & 1
\end{array}\right)\left(\begin{array}{c}
x \\
x^{\prime} \\
(\Delta p / p)_{0}
\end{array}\right)
$$

从起点 $\mathrm{A}$ 到中心点 $\mathrm{B}$ 的传输矩阵 $\mathrm{D}$ 是

$$
\left(\begin{array}{ccc}
D_{11} & D_{12} & D_{16} \\
D_{21} & D_{22} & D_{26} \\
0 & 0 & 1
\end{array}\right)
$$

merger 消色散, 要求 $m_{16}$ 和 $m_{26}$ 都为 0 。根据对称性, 从 $\mathrm{A}$ 到 $\mathrm{B}$ 的传输矩阵 $\mathrm{D}^{[56]}$ 在对称系统中只要求 $D_{26}=0$, 而反对称系统, 要求 $D_{16}=0$, 消色散条件数 因对称性而降低, 简化了设计要求。

扇形磁铁边缘角是 0 , 在偏转平面是聚焦效果; 矩形磁铁入口和出口的边缘 角之和等于偏转角, 常用的入射边缘角是 0 或 $1 / 2$ 偏转角, 这两种情况, 边缘场 散焦和磁铁聚集使得偏转平面没有聚焦效果, 类似直线传输。

根据消色散要求, JLAB 的 merger 系统采用三块完全相同的扇形铁, 磁铁偏 转角是 $\theta,-\theta$ 和 $\theta$, 消色散条件 $D_{26}=0$ 对 merger 几何结构要求是

$$
d=R^{*}(2 \cos \theta-1) / \sin \theta
$$

其中, $d$ 是第一块磁铁到第二块磁铁之间的距离, $R$ 是磁铁偏转半径。因此, 当 磁铁偏转半径和偏转角确定后, 要调节磁铁之间的距离满足消色散。它采用磁铁 个数最少, 偏转平面束流聚焦, 非偏转平面是直线传输, 注入束线和返航束线互 不影响。

BINP 的 chicane 结构所用磁铁是矩形磁铁, 磁铁偏转角是 $\theta,-\theta,-\theta$ 和 $\theta$, 当入射边缘角是 0 或者 $1 / 2 \theta$ 时, 该结构自动满足 $D_{26}=0$, 磁铁之间距离自由可 调。偏转平面无聚焦, 类似直线传输, 非偏转平面有聚焦作用。消色散条件对它 的几何结构要求很低, 只要求磁铁边缘角合适即可, 但返航束线至少有一块磁铁 嵌在 merger 中, 因此 chicane 的横向和纵向尺寸要足够大。

JAERI 的 dog-leg 结构用四块矩形磁铁和三块 $\mathrm{Q}$ 铁, 磁铁偏转角是 $\theta,-\theta$, $\theta$ 和 $-\theta$, 消色散条件是通过调节 $\mathrm{Q}$ 铁强度实现, 第二块 $\mathrm{B}$ 铁后色散函数非 0 , 色散函数的导数是 0 , 为了满足对称中心处 $D_{16}=0$, 要求第一块 $\mathrm{Q}$ 铁聚焦强度 
很大。该结构返航束线和注入束线分离, 所用磁铁个数最多。

BNL 的 zig-zag 结构用四块矩形磁铁, 磁铁偏转角是 $\theta / 2,-\theta, \theta$ 和 $-\theta / 2$, 偏转平面类似直线传输, 非偏转平面束流聚焦, 第二块和第三块磁铁偏转角是第 一块和第四块的两倍, 消色散条件是

$$
d_{2} / 2-d_{1}=R(1-\cos \theta) / \tan \theta
$$

其中 $d_{1} 、 d_{2}$ 对应第一块磁铁到第二块磁铁的距离和第二块磁铁到第三块磁铁的 距离, $R$ 是磁铁偏转半径, $\theta$ 是第一块磁铁的偏转角, 因此, 磁体固定后, 磁体 之间的距离也相应确定。对返航束线的位置要求与 chicane 类似, merger 结构需 要有足够的空间容纳返航束线的磁铁。

根据以上理论分析, 并结合几何空间要求, 设定四种结构的磁铁偏转角相等, 都是 20 度（zig-zag 磁铁偏转角是 10 度和 20 度），第一块磁铁到第二块磁铁之 间的距离约 $1 \mathrm{~m}$, 偏转半径 $0.5 \mathrm{~m}$, 对应的 $M_{56} \sim-0.15 \mathrm{~m}$, 类 JLAB 的 merger 束线 长度是 $3.5 \mathrm{~m}$, 尺寸最小, 其他三种结构束线长度约 $5 \mathrm{~m}$ （包含 merger 后 $1 \mathrm{~m}$ 长漂 移段）。下面都是根据这些几何结构计算。

从 (3.13) 式可以看出, 若 merger 结构偏离消色散条件, 束流横向发射度将 增大。实际传输系统有各种技术误差, 图 3.13 用 DIMAD ${ }^{[57]}$ 程序研究了磁铁误差 $0.5 \%$ 、束流能散为 $\pm 1 \%$ 时对应的束流中心轨道, 最后一点对应 merger 后 $1 \mathrm{~m}$ 点, 从图中可以看出: 在 zigzag 结构 $\mathrm{x}$ 和 $\mathrm{y}$ 平面、 chicane 结构的 $\mathrm{x}$ 和 $\mathrm{y}$ 平面以及三 块磁铁结构的 $\mathrm{x}$ 平面中, 束流轨道能很好的控制, 而三块磁铁结构的 $\mathrm{y}$ 平面和 $\operatorname{dog} \operatorname{leg}$ 结构的 $\mathrm{x}$ 和 $\mathrm{y}$ 平面对误差较敏感。 dogleg 结构的 $\mathrm{x}$ 平面内, 束流中心轨道 偏离参考轨道很远, 达到 $1.5 \mathrm{~cm}$, 要求磁铁好场区很大, 加之, 该结构需要磁铁 数目最多, 因此首先舍弃掉 dogleg 结构。

低能下, 空间电荷效应不可忽略, 它改变束流内部的能散分布, 束团头部电 子得到能量, 尾部电子失去能量。以上设计的消色散结构是假设束流能散保持不 变, 包含空间电荷力时, 束流能散改变, 束流横向发射度将增大。

上面提到这四种结构都不是等时结构, $M_{56}$ 约 $-0.15 \mathrm{~m}$, 因此, 当束流能量位 置关联很好时, merger 结构将压缩束团, 空间电荷力更加显著, 造成的发射度增 长也更大, JLAB FEL 装置实际运行经验表明 ${ }^{[58,59,60]}$ 注入器出口束流纵向相空间 应具有低能散和长束团长度, 即能量位置关联很小, 从而避免 merger 中束团压 
缩。这个要求限制了注入器中 RF 场运行相位, 3.2.3 节注入器参数优化中 RF 运 行相位都满足这个要求。

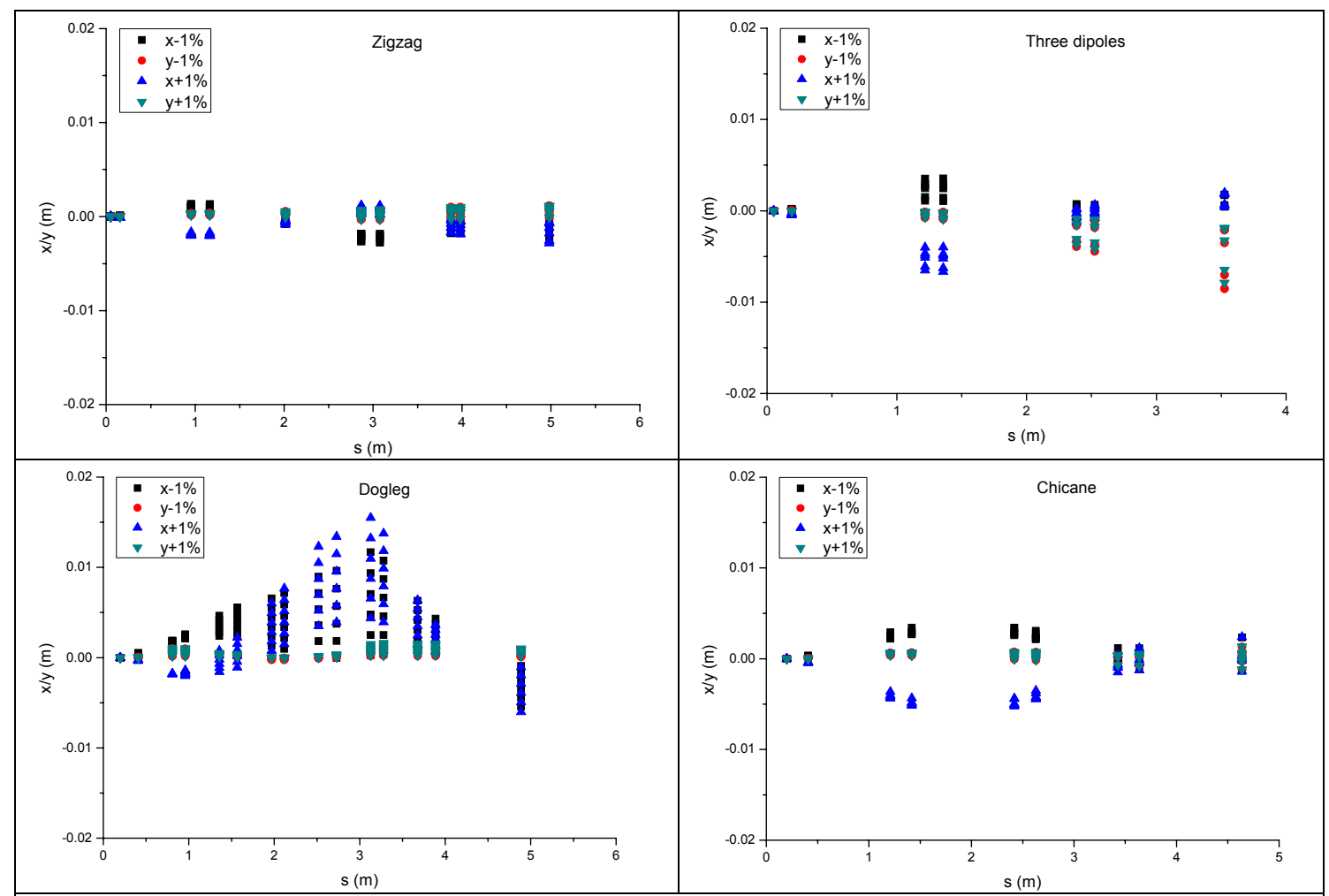

图 3.13 不同 merger 结构误差敏感度分析（能散士 $1 \%$ 时对应的中心轨道）

图 3.14 是用 PARMELA 程序模拟计算从光阴极到 merger 出口 $\mathrm{x}$ 和 $\mathrm{y}$ 平面归 一化 $\mathrm{rms}$ 发射度变化趋势, 对应三种 merger 结构, 所用电荷量是 $120 \mathrm{pC}$ 。结果 表明经 merger 后 chicane 的 $\mathrm{y}$ 平面、zigzag 的 $\mathrm{x}$ 和 $\mathrm{y}$ 平面归一化 $\mathrm{rms}$ 发射度都基 本保持不变, 与文献[61]模拟电荷量为 $1 \mathrm{nC}$ 的结论一致; chicane 的 $\mathrm{x}$ 平面和三 块磁铁结构发射度经 merger 后都变大, 但都小于 $6 \mathrm{~mm}-\mathrm{mrad} 。$

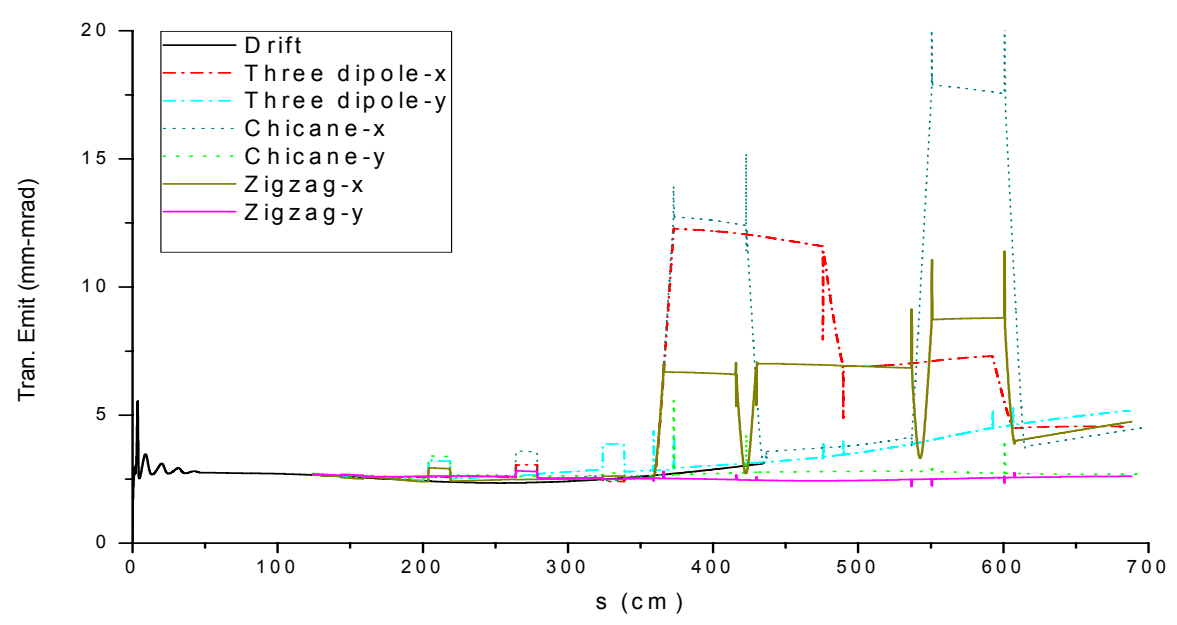

图 3.14 三种不同 merger 结构中，横向归一化 rms 发射度变化趋势 
总结以上分析, zigzag 结构在误差敏感分析和发射度增长上都给出最优结 果; 三种结构下模拟的最大发射度增长都满足 IR-FEL 系统的要求。另外, zigzag 结构目前在实际装置上还没有实现。结合北京大学实际空间限制和节约经费的原 则, 本论文设计中最终选用的 merger 结构是类似 JLAB 的三块磁铁结构。

\subsection{2 三块磁铁 merger 结构优化设计}

三块铁考虑的几何结构参数有偏转角 $\theta$ 、偏转半径 $\mathrm{R}$ 、电子在磁铁内所走路 程 $\mathrm{s} 、$ 磁铁的磁铁之间的距离 $\mathrm{d}$ 和束线之间的距离 $\mathrm{L}$, 它们之间的关系是

$$
\begin{gathered}
s=R \theta \\
L=d \sin (\theta) \\
d=R *(2 \cos \theta-1) / \sin \theta
\end{gathered}
$$

因此, 这五个参数中, 只要确定两个, 其它三个都相应确定。
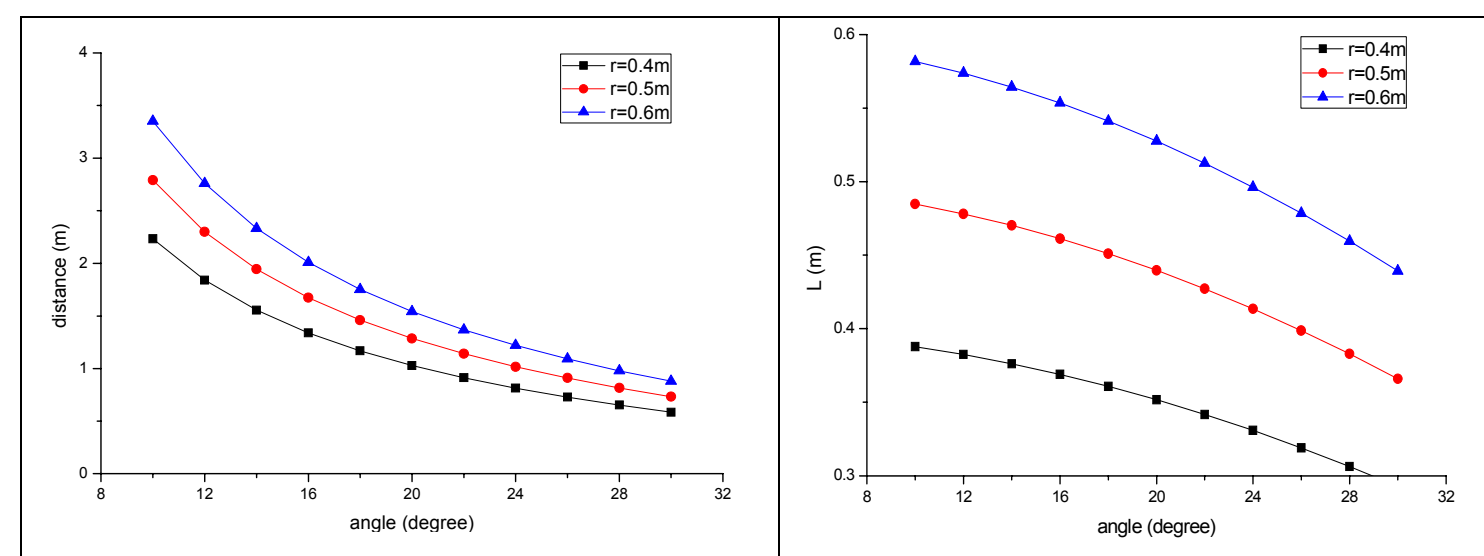

图 $3.15 \mathrm{r}=0.4 \mathrm{~m}, 0.5 \mathrm{~m}, 0.6 \mathrm{~m}$ 时, $\mathrm{B}$ 铁之间的距离 $\mathrm{d}$ 和束线距离 $\mathrm{L}$ 随弯转角的变化

设置偏转角 $\theta$ 、偏转半径 $\mathrm{R}$ 半径为变量, 图 3.15 研究了 $\mathrm{B}$ 铁之间的距离 $\mathrm{d}$ 和束线距离 $\mathrm{L}$ 变化趋势。 $\mathrm{d}$ 决定束线的长度, $\mathrm{L}$ 决定束线的宽度。考虑实际因素, 如返航束线和注入束线磁铁之间相互影响和束线安装要求, 束线之间的距离 $\mathrm{L}$ 不能太小, 对一定的 $\mathrm{L}, \theta$ 越小, $\mathrm{d}$ 越大, 束线越长。综合考虑, 偏转角 $\theta$ 选择 20 度, 弯转半径 $\mathrm{R}$ 选为 $0.4 \mathrm{~m}$, 相应的 $\mathrm{d}$ 为 $1.028 \mathrm{~m}$, 对应的磁铁弧长是 $0.139626 \mathrm{~m}$, 电子能量 $5 \mathrm{MeV}$ 时, 磁铁强度是 $0.457 \mathrm{kG}$, merger 结构横向尺寸 $\mathrm{d} 1$ 是 $0.44 \mathrm{~m}$, 纵向尺寸 $\mathrm{d} 2$ 是 $2.45 \mathrm{~m}$, 对应图 3.16a, 注入器束线和主束线夹角是 20 度。 


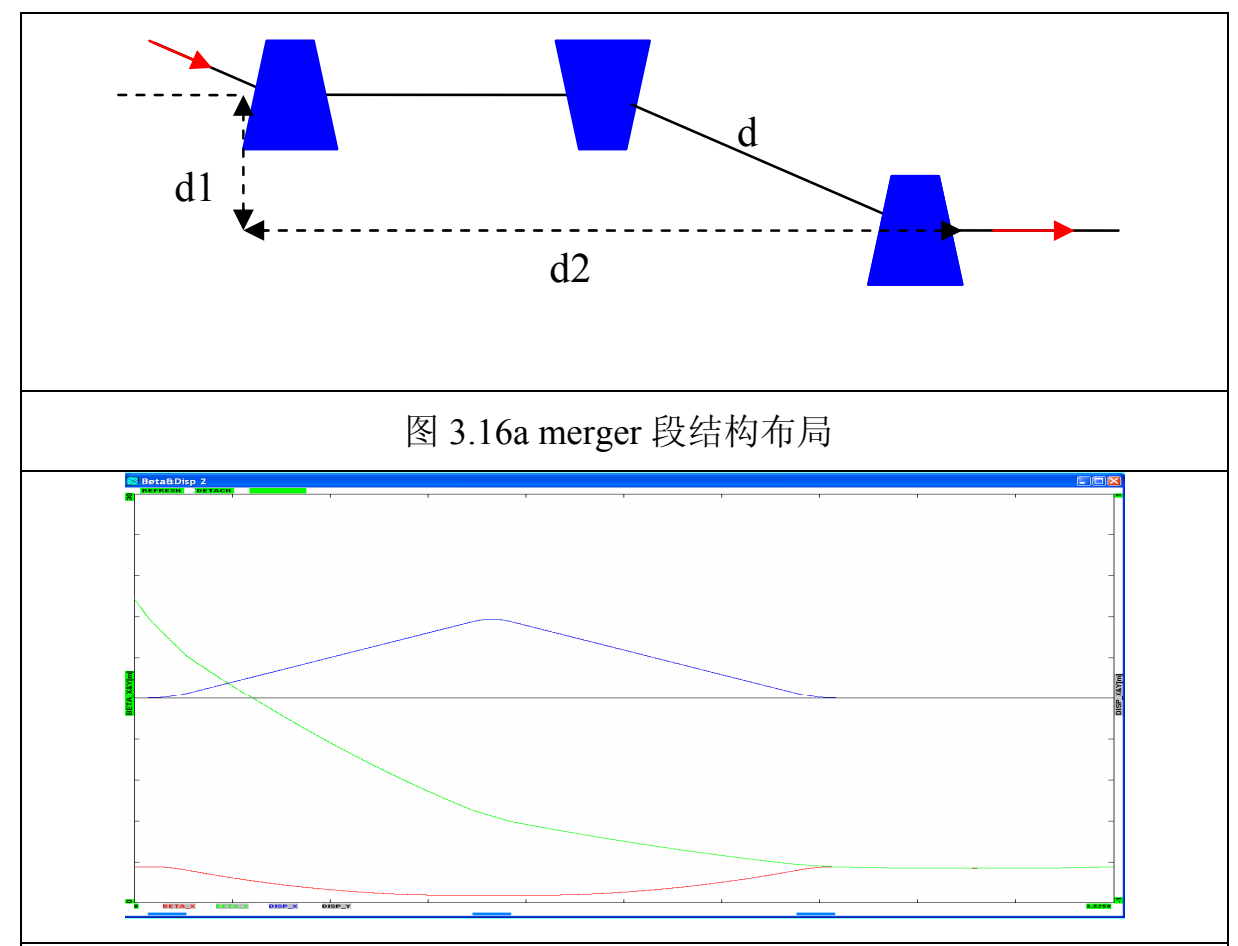

图 3.16b merger 段横向 $\beta$ 函数和色散曲线

merger 传输矩阵是

$$
\left(\begin{array}{cccccc}
-1 & 0.978 & 0 & 0 & 0 & 0 \\
0 & -1 & 0 & 0 & 0 & 0 \\
0 & 0 & 2.34 & 3.19 & 0 & 0 \\
0 & 0 & 1.45 & 2.41 & 0 & 0 \\
0 & 0 & 0 & 0 & 1 & -0.15 \\
0 & 0 & 0 & 0 & 0 & 1
\end{array}\right)
$$

$\mathrm{y}$ 方向受到散焦力作用, 这是因为考虑磁铁边缘场效应, 边缘场积分常数 $\mathrm{K} 1^{[62]}$ 是 $0.5, \mathrm{x}$ 方向虽然总的聚焦项 $M_{21}$ 是 0 , 但是每块磁铁对束流作用都是聚 焦的。图 3.16b 是 merger 段横向 $\beta$ 函数和色散曲线, 横轴表示束线长度, 下面三 个蓝色矩形标志对应磁铁位置, 红色曲线表示 $\mathrm{x}$ 方向的 $\beta$ 函数, 绿色曲线表示 $\mathrm{y}$ 方向的 $\beta$ 函数, 蓝色是色散函数, 最大色散位于中间磁铁位置, 是 $0.21 \mathrm{~m}$, 最大 $\beta$ 函数是 $23 \mathrm{~m}$ 。

\section{4 匹配段结构研究}

前终端匹配段连接注入器出口到主加速器入口, 用来控制横向束包络, 保证 束流顺利传输, 为了避免影响返航束流传输, 前终端匹配段选在注入器和 merger 
之间。常用的匹配元件有 $\mathrm{Q}$ 铁和螺线管, 不考虑空间电荷效应的影响, 它们只 改变横向束包络形状, 不改变束流发射度, 对束流纵向相空间传输与直线段相同, 因此，束流纵向相空间不受匹配段影响。

注入器出口束流 twiss 参数由注入器运行参数和初始束流参数决定, 可变参 数多, twiss 参数变化范围大; 受实际元件孔径的限制, 主加速器本身有一定的 束流接受度, 这两者共同决定匹配段束线工作参数, 匹配参数包括 $\mathrm{x}$ 和 $\mathrm{y}$ 平面的 $\beta 、 \alpha$ 和 $\gamma$, 不考虑 $\mathrm{x}$ 和 $\mathrm{y}$ 平面的耦合情况, 每个平面的 twiss 参数分别满足

$$
\beta \gamma-\alpha^{2}=1
$$

因此, 匹配参数实际上只有 4 个独立, $\beta_{x} 、 \alpha_{x} 、 \beta_{y}$ 和 $\alpha_{y}$, 相应的要求匹配段可 调元件自由度至少有 4 个。在传输系统设计中, 原则上可以把透镜长度、磁场梯 度和各透镜之间的距离等参数都当作独立变数来加以选择, 使之满足发射度的匹 配条件方程。但是, 这些参数分为两类, 一类是 “硬参数” , 如透镜长度和透镜 间距等结构参数, 在传输系统一旦制造和安装好之后, 就不能再随意变动; 另一 类是 “软参数” , 如透镜梯度等电磁参数, 在传输系统造好后还可以通过调节电 源的电压或电流来改变。在传输系统的设计中, 束流的初始形状及匹配要求都是 理论上预计的, 这种预计值同将来的实际运行值有区别。另一方面, 在以后运行 过程中, 束流的初始条件和匹配要求还可能因实验或应用任务的改变而变动。因 此, 除了在选择设计参数时对 “软”、“硬” 参数一起加以选择和优化, 使之满 足预计的匹配条件外, 系统中至少要包括四个独立可调的 “软参数” , 以便在运 行中随时校正各种因素引起的失配。这就是说, 同时调节 $\mathrm{x}$ 方向和 $\mathrm{y}$ 方向匹配的 传输段, 至少需要安排四个独立可调的透镜。硬参数的选择主要取决于工程上的 要求, 如安装方便、插入诊断元件和真空系统等。

注入器出口的参数在 3.2 节已经模拟给出不同条件下的 $\beta$ 和 $\alpha$, 下面研究主 加速器的束流接受度。

对 $\pi$ 模驻波加速腔, 峰值加速时, 它的横向传输矩阵是 $[63,64]$

$$
\left(\begin{array}{c}
x_{f} \\
x_{f}^{\prime}
\end{array}\right)=\left(\begin{array}{cc}
\cos (\alpha)-\sqrt{2} \sin (\alpha) & \sqrt{8} \frac{\gamma_{f}}{\gamma^{\prime}} \sin (\alpha) \\
-\frac{3}{\sqrt{8}} \frac{\gamma^{\prime}}{\gamma_{f}} \sin (\alpha) & \cos (\alpha)+\sqrt{2} \sin (\alpha)
\end{array}\right)
$$


其中, $\alpha=\frac{1}{\sqrt{8}} \ln \frac{\gamma_{f}}{\gamma_{i}}, \gamma_{i} 、 \gamma_{f}$ 和 $\gamma^{\prime}$ 分别表示粒子在加速腔入口的相对论因子、加 速腔出口的相对论因子和加速场梯度相对论因子, $\gamma_{f}=\gamma_{i}+\gamma^{\prime} L$, 它包含了加速 腔入口 (出口) 的聚焦 (散焦) 效果。注意为了和程序输出对比, (3.22) 式对 加速腔传输矩阵进行归一化。

北京大学的主加速器包含两个 9cell TESLA 型加速腔, 加速腔加速长度约 $1 \mathrm{~m}$, 两端的束管长度 $t_{L}$ 是 $0.155 \mathrm{~m}$, 加速腔之间的长度是 $0.035 \mathrm{~m}$, 因此加速腔之 间的传输矩阵漂移长度 $d_{L}$ 是 $0.346 \mathrm{~m}$ （包含束管长度），总长度约 $2.73 \mathrm{~m}$ 。主加 速器的总传输矩阵 $M$ 表示为

$$
M_{t o t}=M_{t_{L}} * M_{a c c 2} * M_{d_{L}} * M_{a c c 1} * M_{t_{L}}
$$

其中, $M_{t_{L}}$ 是长度为 $t_{L}$ 的束管传输矩阵, $M_{d_{L}}$ 是加速腔之间的漂移段传输矩 阵, $M_{a c c 1}$ 和 $M_{a c c 2}$ 是第一个加速腔和第二个加速腔对应的传输矩阵。

根据 (3.22) 和 (3.23) 对加速器传输矩阵量级进行估算: 注入器出口的束 流能量约 $5 \mathrm{MeV}$, 主加速器运行梯度 $13 \mathrm{MV} / \mathrm{m}$, 第一个 $9 \mathrm{cell}$ 之后束流能量约 $18 \mathrm{MeV}$ ，第二个 $9 \mathrm{cell}$ 之后束流能量约 $31 \mathrm{MeV}$, 第一个加速腔 $M(12)$ 是 $1.77 \mathrm{~m}$, 第二个加速腔 $M(12)$ 是 $1.29 \mathrm{~m}$, 可与加速器长度相比较。Optim 程序计算峰值加 速时, $M_{t o t}(12)$ 是 $2.046 \mathrm{~m}$, 偏离峰值-10 度加速时, $M_{t o t}(12)$ 是 $2.044 \mathrm{~m}$, 可见, 改变相位对 $M_{t o t}(12)$ 影响很小, 与文献[65]实验测量结果一致。

传输矩阵的另一种表示方式是 ${ }^{[66]}$

$$
M(i \rightarrow f)=\left(\begin{array}{cc}
\sqrt{\frac{\beta_{f}}{\beta_{i}}}\left(\cos \Delta \psi+\alpha_{i} \sin \Delta \psi\right) & \sqrt{\beta_{i} \beta_{f}} \sin \Delta \psi \\
\frac{\alpha_{i}-\alpha_{f}}{\sqrt{\beta_{i} \beta_{f}}} \cos \Delta \psi-\frac{1+\alpha_{i} \alpha_{f}}{\sqrt{\beta_{i} \beta_{f}}} \sin \Delta \psi & \sqrt{\frac{\beta_{i}}{\beta_{f}}}\left(\cos \Delta \psi-\alpha_{f} \sin \Delta \psi\right)
\end{array}\right)
$$

$\alpha_{i} 、 \alpha_{f} 、 \beta_{i}$ 和 $\beta_{f}$ 分别是传输矩阵起点和终点的 $\alpha$ 和 $\beta$ 函数, $\Delta \psi=\int \frac{d s}{\beta(s)}$ 是 经传输矩阵后的相位超前。

$$
M_{12}(i \rightarrow f)=\sqrt{\beta_{i} \beta_{f}} \sin \Delta \psi
$$

把加速器看成周期传输结构, 则加速器入口和出口的 $\beta$ 函数相同, 并且 $\alpha=0$, 即加速腔入口束流成腰。 
综合以上, 加速器接受度要求束流横向包络函数满足 $\beta \sim$ 加速器长度 $2.7 \mathrm{~m}$, $\alpha \sim 0$ 。

下面的计算是采用 OPTIM ${ }^{[67]}$ 程序, 它的主要优点是输出界面相比 DIMAD、 ELEGANT 等更加友好, 能直接观测束线上所有参数对束流传输的影响, 主要做 一阶光学计算, 做粒子追踪时包含高阶项影响。

图 3.17 是 OPTIM 计算的加速器束包络曲线, 加速器工作参数是 $13 \mathrm{MV} / \mathrm{m}$, 加速相位 -10 度, 图 a 对应初始参数 $\beta=2.7 \mathrm{~m}$, 不同 $\alpha$ 下的束包络变化, 图 $\mathrm{b}$ 是 初始 $\alpha=0, \beta$ 分别是 $1.35 \mathrm{~m} 、 2.7 \mathrm{~m}$ 和 $4 \mathrm{~m}$ 时束包络变化。从图 a 可以看出 $\alpha=0$ 时 加速器出口的束流相对 $\alpha=-0.2$ 时发散更快, $\alpha=0.2$ 时出口束流发散的最厉害, 不利于后面的传输; 从图 $\mathrm{b}$ 得到 $\beta=2.7 \mathrm{~m}$ 时 $\beta$ 函数在加速器中基本保持不变; 从 图 $\mathrm{c}$ 和图 $\mathrm{d}$ 中可以看出, 初始 $\beta=2.7 \mathrm{~m}, \alpha=0$ 时, 改变主加速器平均场梯度或 $\mathrm{RF}$ 运行相位, 束包络都能很好的控制。因此, 北京大学的 $2 * 9$ cell 主加速器接受度 参数是 $\beta \sim 2.7 m, \alpha$ 稍小于 0 。

\begin{tabular}{|c|c|}
\hline $\begin{array}{llllllll}3.5 & \\
\end{array}$ & 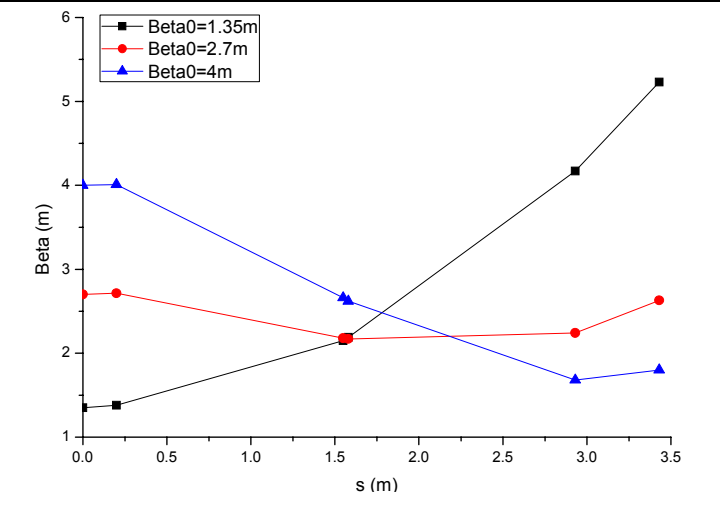 \\
\hline $\begin{array}{c}3.17 \mathrm{a} \text { Eacc }=13 \mathrm{MV} / \mathrm{m}, \quad \beta=2.7 \mathrm{~m} \text {, 不同 } \alpha \\
\text { 下, 加速器束中包络曲线 }\end{array}$ & $\begin{aligned} 3.17 \mathrm{~b} \text { Eacc } & =13 \mathrm{MV} / \mathrm{m}, \alpha=0, \text { 不同初始 } \beta \text { 下, } \\
& \text { 加速器中束包络曲线 }\end{aligned}$ \\
\hline 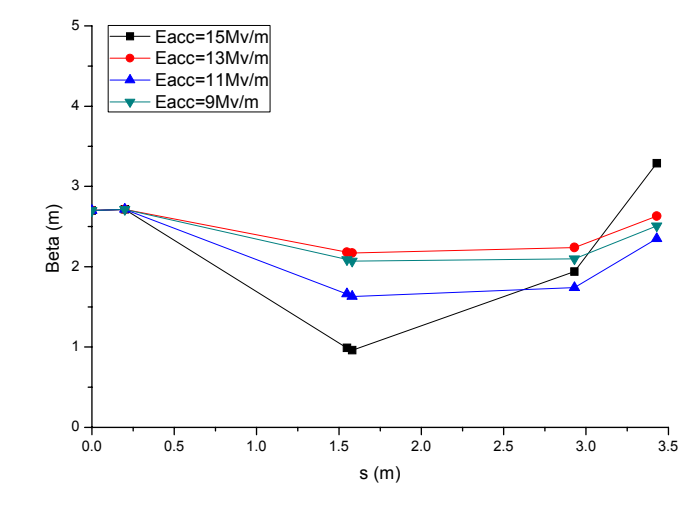 & 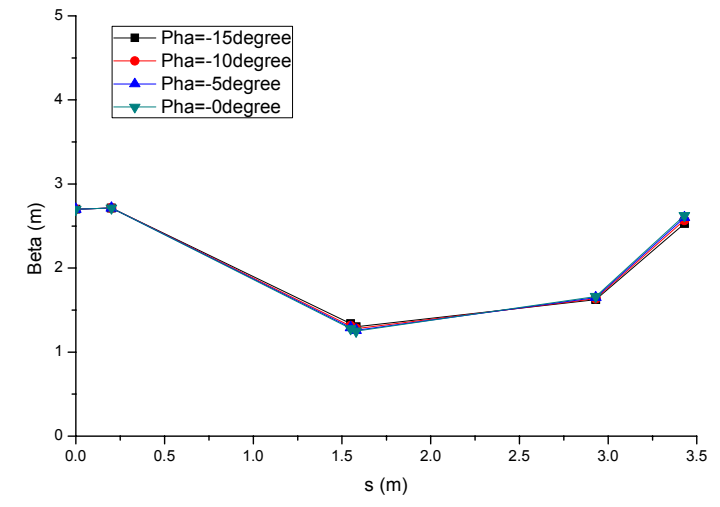 \\
\hline $\begin{array}{c}3.17 \mathrm{c} \mathrm{Pha}=-10^{\circ}, \quad \beta=2.7 \mathrm{~m}, \alpha=0 \text {, 不同场 } \\
\text { 梯度下, 加速器中束包络曲线 }\end{array}$ & $\begin{array}{c}3.17 \mathrm{~d} \mathrm{Eacc}=13 \mathrm{MV} / \mathrm{m}, \quad \beta=2.7 \mathrm{~m}, \alpha=0 \text {, 不 } \\
\text { 同加速相位下, 加速器中束包络曲线 }\end{array}$ \\
\hline
\end{tabular}


匹配段设计除了要能够保证各种条件下, 注入器提供的束流传输到主加速器 时, 满足主加速器的接受度要求外, 还要考虑实际调节过程中 $\mathrm{x}$ 和 $\mathrm{y}$ 两个方向进 行控制的方便性, 希望改变 $\mathrm{x}$ 方向参数 $\beta_{x}$ 和 $\alpha_{x}$ 时调节元件自由度参数不影响 $\mathrm{y}$ 方向参数 $\beta_{y}$ 和 $\alpha_{y}$, 反正亦然, 这样可以减少机器调节时的工作量。

根据 3.2 节模拟输出参数, 注入器出口的束流在有些情况发散很厉害, 对应 的束斑也很大, 是造成前终端匹配段设计的难点。根据匹配条件数, 匹配段至少 需要四块 $\mathrm{Q}$ 铁, 但当 $\alpha$ 很小时（如-20）, $\mathrm{Q}$ 铁在 $\mathrm{x}$ 和 $\mathrm{y}$ 方向聚焦性质相反, 决 定了第一块 $\mathrm{Q}$ 铁后一个方向的束斑长大很快, 很难实现匹配。下面提出两种可 能的方案：第一种是采用螺线管和四块 $\mathrm{Q}$ 铁结合; 第二种是采用六块 $\mathrm{Q}$ 铁, 前 三块之间的距离很短, 组成一组, 保证 $\mathrm{x}$ 和 $\mathrm{y}$ 方向的束包络在很短距离内都得到 聚焦。

\subsection{1 匹配段结构方案一}

注入器和主加速器具有轴对称性, $\mathrm{x}$ 和 $\mathrm{y}$ 方向传输性能相同。螺线管在横向 传输上也具有对称性, 实现两个方向同时聚焦, 因此, 可以同时控制两个方向束 流的发散问题，但 merger 段 $\mathrm{x}$ 方向和 $\mathrm{y}$ 方向传输性能不同，因此，只采用螺线 管不能满足加速器入口的接受度要求, 必须结合 $\mathrm{Q}$ 铁。束线结构如图 3.18, 包 括四块 $\mathrm{Q}$ 铁和一个螺线管, 螺线管是把注入器出口的束流两个方向同时聚焦, 所有 $\mathrm{Q}$ 铁长度都是 $15 \mathrm{~cm}$, 螺线管长度是 $30 \mathrm{~cm}$, 漂移段几何参数是 $\mathrm{d} 1=\mathrm{d} 5=20 \mathrm{~cm}$, $\mathrm{d} 2=\mathrm{d} 3=\mathrm{d} 4=45 \mathrm{~cm}$ ， 匹配段束线总长度是 $2.7 \mathrm{~m}$ 。

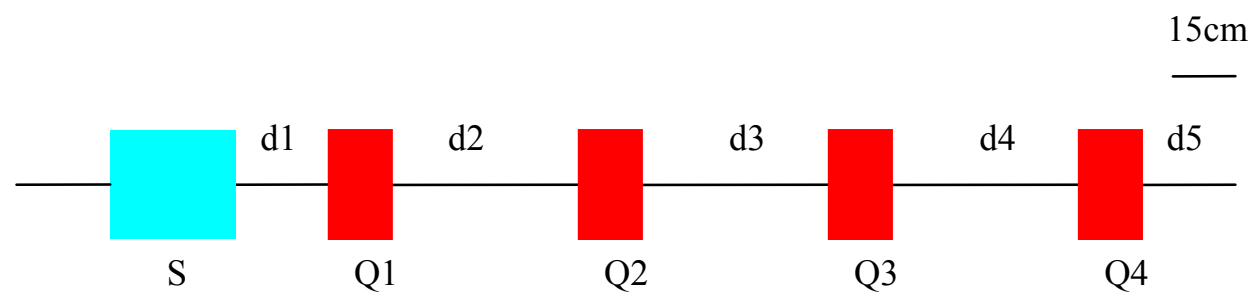

图 3.18 匹配段方案一结构示意图

注入器输出参数变化范围很大, 这里选择了 $20 \mathrm{pC}$ 下改变场梯度对应的 7 组 数据作为匹配优化的参考值, 采用 OPTIM 优化, 优化后的束包络曲线如图 3.19, 束线是从注入器出口到主加速器入口, 图(1)-(7)是对应的 7 组不同初始参数, 图 (8) 是标示元件在束线上的相对位置, 从图中可以看出螺线管是用来很快聚焦 $\mathrm{x}$ 和 $\mathrm{y}$ 方向的束流, 使发散束变成汇聚束, 限制束斑变大, 第一块 $\mathrm{Q}$ 铁打破 $\mathrm{x}$ 和 $\mathrm{y}$ 
方向传输对称性, 使束流 $\mathrm{x}$ 方向在第二块 $\mathrm{Q}$ 铁成腰, $\mathrm{y}$ 方向发散最大, 这样调节 第二块 $\mathrm{Q}$ 铁对 $\mathrm{x}$ 方向束流基本不影响, $\mathrm{Q} 2$ 功能独立, 控制 $\mathrm{y}$ 方向束包络, 类似 的, Q3 控制 $\mathrm{x}$ 方向束包络。

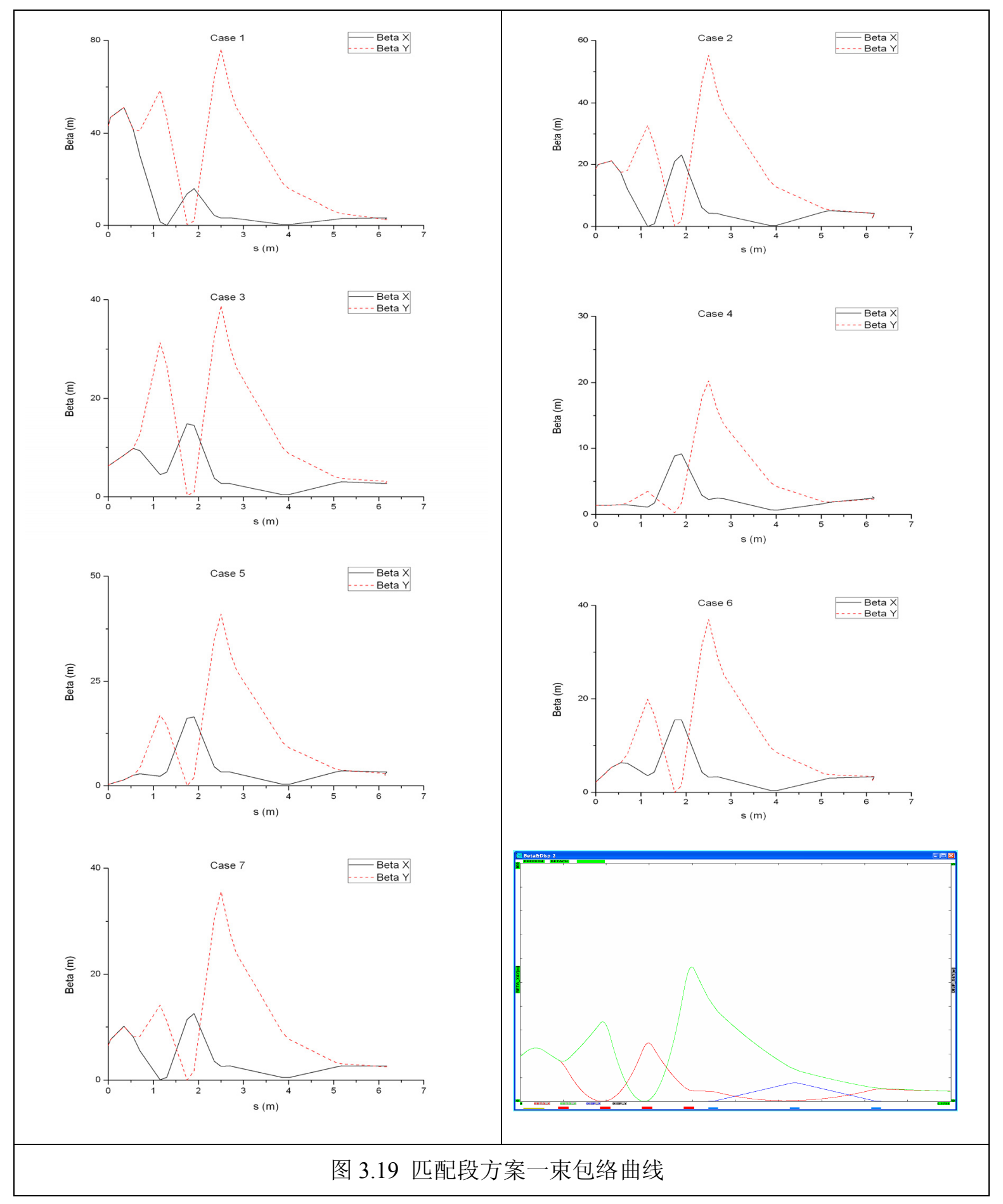

表 3.3 是对应每组数据所需要的螺线管强度和四极铁强度。可调参数有 5 个, 螺线管强度和 $\mathrm{Q}$ 铁强度。匹配后的最大 $\beta$ 函数约 $80 \mathrm{~m}$, 假设几何发射度是 $0.6 \mu$ $\mathrm{m}$ 时, 对应的最大束斑 $\sigma$ 不超过 $7 \mathrm{~mm}$, 考虑误差以及真空管道厚度等因素, 束 
流偏离轨道位置实际机器一般可以控制到 $2 \mathrm{~mm}$ 以下, 真空管道厚度 $1.5 \mathrm{~mm}$, 束 管内半径设置 $3 \sigma+2 \mathrm{~mm}=2.3 \mathrm{~cm}$, 束管外半径或透镜孔径是 $2.45 \mathrm{~cm}$, 这样可以保 证束流在传输过程中基本无损失，对应的四极铁磁极面场强度不超出 100Gauss, 离注入器出口最近的螺线管强度在有些情况下需要工作到 1000 Gauss, 为避免失 超, 这对超导注入器的磁屏蔽要求很高。

另一方面考虑, 螺线管对发射度影响很大, 当束流在注入器出口处于发射度 补偿区时, 使用螺线管将补偿束流发射度, 模拟结果表明, 补偿后的束流若没有 加速结构的限制, 发射度会很快增长。在这种前终端结构下, 螺线管后的束线很 长, 使用四极铁破坏发射度补偿条件, 因此, 此束线上螺线管无法完成发射度补 偿, 反而会加快发射度增长。

表 3.3 匹配段方案一优化所需要的螺线管和四极铁强度

\begin{tabular}{|l|c|c|c|c|c|}
\hline \multicolumn{1}{|c|}{ case } & $\mathrm{S}(\mathrm{kG})$ & $\mathrm{Q} 1(\mathrm{kG} / \mathrm{cm})$ & $\mathrm{Q} 2(\mathrm{kG} / \mathrm{cm})$ & $\mathrm{Q} 3(\mathrm{kG} / \mathrm{cm})$ & $\mathrm{Q} 4(\mathrm{kG} / \mathrm{cm})$ \\
\hline $\begin{array}{l}\beta_{1}=43.2 \mathrm{~m} \\
\alpha_{1}=-36.3\end{array}$ & 0.744 & 0.012 & -0.027 & 0.038 & -0.028 \\
\hline $\begin{array}{l}\beta_{2}=18.6 \mathrm{~m} \\
\alpha_{2}=-13.1\end{array}$ & 0.704 & 0.005 & -0.024 & 0.016 & -0.027 \\
\hline $\begin{array}{l}\beta_{3}=6.3 \mathrm{~m} \\
\alpha_{3}=-2.8\end{array}$ & 0 & 0.012 & -0.032 & 0.024 & -0.028 \\
\hline $\begin{array}{l}\beta_{4}=1.38 \mathrm{~m} \\
\alpha_{4}=-0.1\end{array}$ & 0 & 0.008 & -0.039 & 0.026 & -0.025 \\
\hline $\begin{array}{l}\beta_{5}=0.4 \mathrm{~m} \\
\alpha_{5}=-0.8\end{array}$ & 0.0 & 0.017 & -0.039 & 0.027 & -0.027 \\
\hline $\begin{array}{l}\beta_{6}=2.2 \mathrm{~m} \\
\alpha_{6}=-4.8\end{array}$ & 0.705 & 0.012 & -0.034 & 0.025 & -0.027 \\
\hline $\begin{array}{l}\beta_{7}=6.5 \mathrm{~m} \\
\alpha_{7}=-11.1\end{array}$ & 0.925 & 0.015 & -0.032 & 0.032 & -0.026 \\
\hline
\end{tabular}

\subsection{2 匹配段结构方案二}

这种方案中只用 $\mathrm{Q}$ 铁, 共 6 块, 透镜的排列如图 3.20, 所有 $\mathrm{Q}$ 铁长度都是 $15 \mathrm{~cm}$, 漂移段几何参数是 $\mathrm{d} 1=\mathrm{d} 2=15 \mathrm{~cm}, \mathrm{~d} 3=\mathrm{d} 4=\mathrm{d} 5=45 \mathrm{~cm}, \mathrm{~d} 6=20 \mathrm{~cm}$, 束线总长度 $2.8 \mathrm{~m}$, 与方案一基本相同, 前三块 $\mathrm{Q}$ 铁距离较短, 它们的功能和螺线管一样, 同时聚焦 $\mathrm{x}$ 和 $\mathrm{y}$ 方向的束流。 
$15 \mathrm{~cm}$

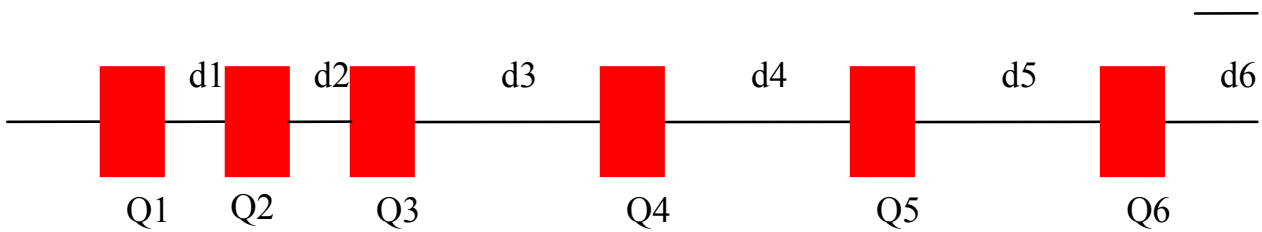

图 3.20 匹配段方案二结构示意图
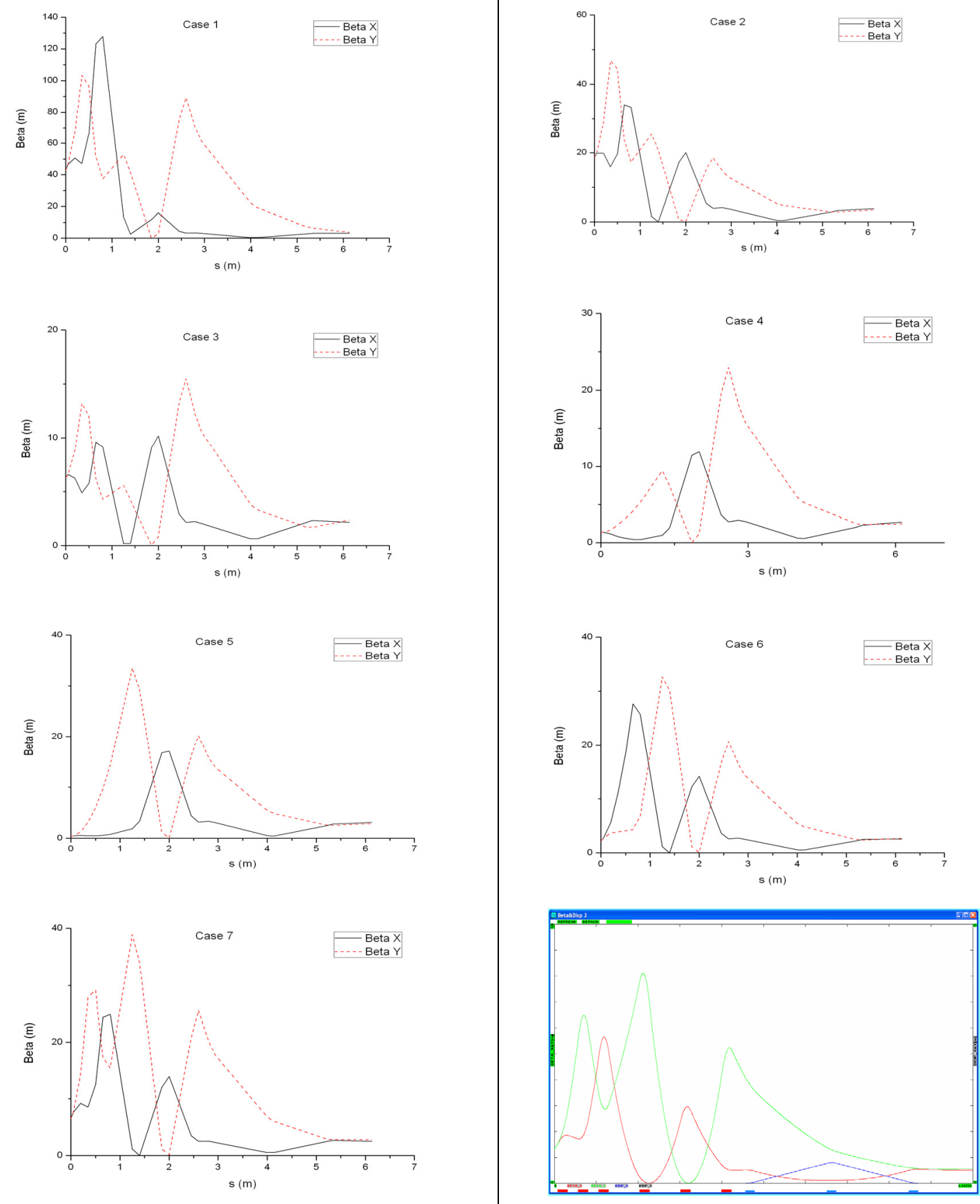

图 3.21 匹配段方案二束包络曲线 
匹配初始参数与方案一相同, 优化后的束包络如图 3.21, 对应的 $\mathrm{Q}$ 铁强度如表 3.4, 匹配后的最大 $\beta$ 函数约 $150 \mathrm{~m}$, 与上节估计方法一样, 对应的最大束斑 $\sigma$ 不 超过 $10 \mathrm{~mm}$, 考虑误差以及真空管道厚度等因素, 束流偏离轨道位置一般可以限 制到 $2 \mathrm{~mm}$ 以下，真空管道厚度 $1.5 \mathrm{~mm}$ ，束管内半径设置 $3 \sigma+2 \mathrm{~mm}=3.2 \mathrm{~cm}$ ，束 管外半径或透镜孔径是 $3.35 \mathrm{~cm}$ ，这样可以保证束流在传输过程中无损失，对应

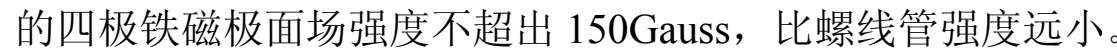

表 3.4 匹配段方案二优化所需要的四极铁强度

\begin{tabular}{|l|c|c|c|c|c|c|}
\hline \multicolumn{1}{|c|}{ case } & $\begin{array}{c}\mathrm{Q} 1 \\
(\mathrm{kG} / \mathrm{cm})\end{array}$ & $\begin{array}{c}\mathrm{Q} 2 \\
(\mathrm{kG} / \mathrm{cm})\end{array}$ & $\begin{array}{c}\mathrm{Q} 3 \\
(\mathrm{kG} / \mathrm{cm})\end{array}$ & $\begin{array}{c}\mathrm{Q} 4 \\
(\mathrm{kG} / \mathrm{cm})\end{array}$ & $\begin{array}{c}\mathrm{Q} 5 \\
(\mathrm{kG} / \mathrm{cm})\end{array}$ & $\begin{array}{c}\mathrm{Q} 6 \\
(\mathrm{kG} / \mathrm{cm})\end{array}$ \\
\hline $\begin{array}{l}\beta_{1}=43.2 \mathrm{~m} \\
\alpha_{1}=-36.3\end{array}$ & 0.013 & -0.039 & 0.041 & -0.03 & 0.052 & -0.030 \\
\hline $\begin{array}{l}\beta_{2}=18.6 \mathrm{~m} \\
\alpha_{2}=-13.1\end{array}$ & 0.016 & -0.041 & 0.043 & -0.030 & 0.043 & -0.029 \\
\hline $\begin{array}{l}\beta_{3}=6.3 \mathrm{~m} \\
\alpha_{3}=-2.8\end{array}$ & 0.016 & -0.039 & 0.043 & -0.031 & 0.037 & -0.028 \\
\hline $\begin{array}{l}\beta_{4}=1.38 \mathrm{~m} \\
\alpha_{4}=-0.1\end{array}$ & 0.016 & 0 & 0 & -0.035 & 0.030 & -0.028 \\
\hline $\begin{array}{l}\beta_{5}=0.4 \mathrm{~m} \\
\alpha_{5}=-0.8\end{array}$ & 0.041 & 0 & 0 & -0.032 & 0.030 & -0.033 \\
\hline $\begin{array}{l}\beta_{6}=2.2 \mathrm{~m} \\
\alpha_{6}=-4.8\end{array}$ & -0.021 & 0 & 0.038 & -0.038 & 0.041 & -0.033 \\
\hline $\begin{array}{l}\beta_{7}=6.5 \mathrm{~m} \\
\alpha_{7}=-11.1\end{array}$ & 0.023 & -0.043 & 0.046 & -0.033 & 0.041 & -0.032 \\
\hline
\end{tabular}

综合考虑，前终端匹配段选择第二种方案。

\section{5 前终端束线结构和束流动力学模拟}

总结匹配段和 merger 段设计, 前终端束线结构如图 3.22, 包括三部分: 注 入器、6 块 $\mathrm{Q}$ 铁组成的匹配段和三块磁铁 merger 段。注入器部分从光阴极到 $3+1 / 2$ cell 出口总长度为 $0.59 \mathrm{~m}$, 考虑光阴极传输室、注入器出口后连接部件等, 注入器束线总长考虑为 $2 \mathrm{~m}$, 匹配段长度 $2.8 \mathrm{~m}$, merger 后到主加速器入口的距离 是 $1 \mathrm{~m}$, 放置诊断元件和真空器件, 前终端尺寸是长度约 $7.8 \mathrm{~m}$, 宽约 $2 \mathrm{~m}$, 束管 
外孔径要求 $3.35 \mathrm{~cm}$ 以上。

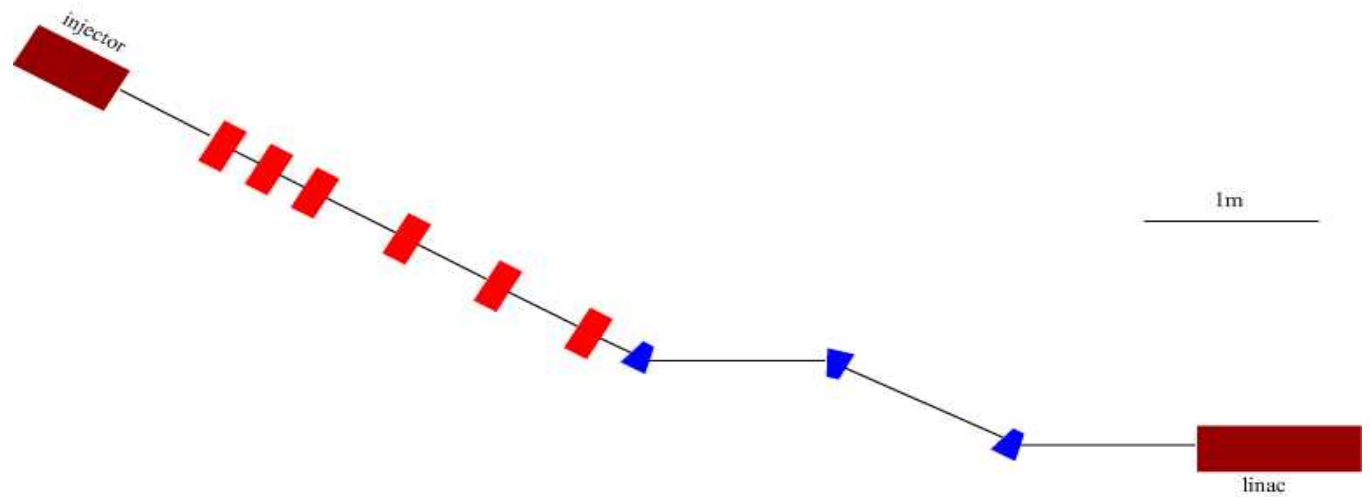

图 3.22 前终端束线结构图

上节用光学程序设计匹配传输段时, 没有考虑空间电荷效应, 而在低能段空 间电荷效应较为明显, 光学程序计算有较大的不准确性, PARMELA ${ }^{[68]}$ 程序能够 计算空间电荷效应, 但采用的是粒子追踪方法, 不能进行束线元件参数优化, 因 此 OPTIM 优化的磁铁参数可以作为 PARMELA 程序输入的参考值。下面用 PARMELAR 程序计算束团电荷为 $20 \mathrm{pC}$ 时前终端的束流品质, 输入文件见附录 1 。

束流初始条件见表 3.5 , 模拟时候采用的粒子数目是 20000 个, 初始束流是 Gauss 分布, 根据 3.2 节优化结构, 超导腔平均场梯度选在 $10 \mathrm{MV} / \mathrm{m}$, 考虑纵向 束流品质, 激光相对加速腔的入射相位是 233 度。
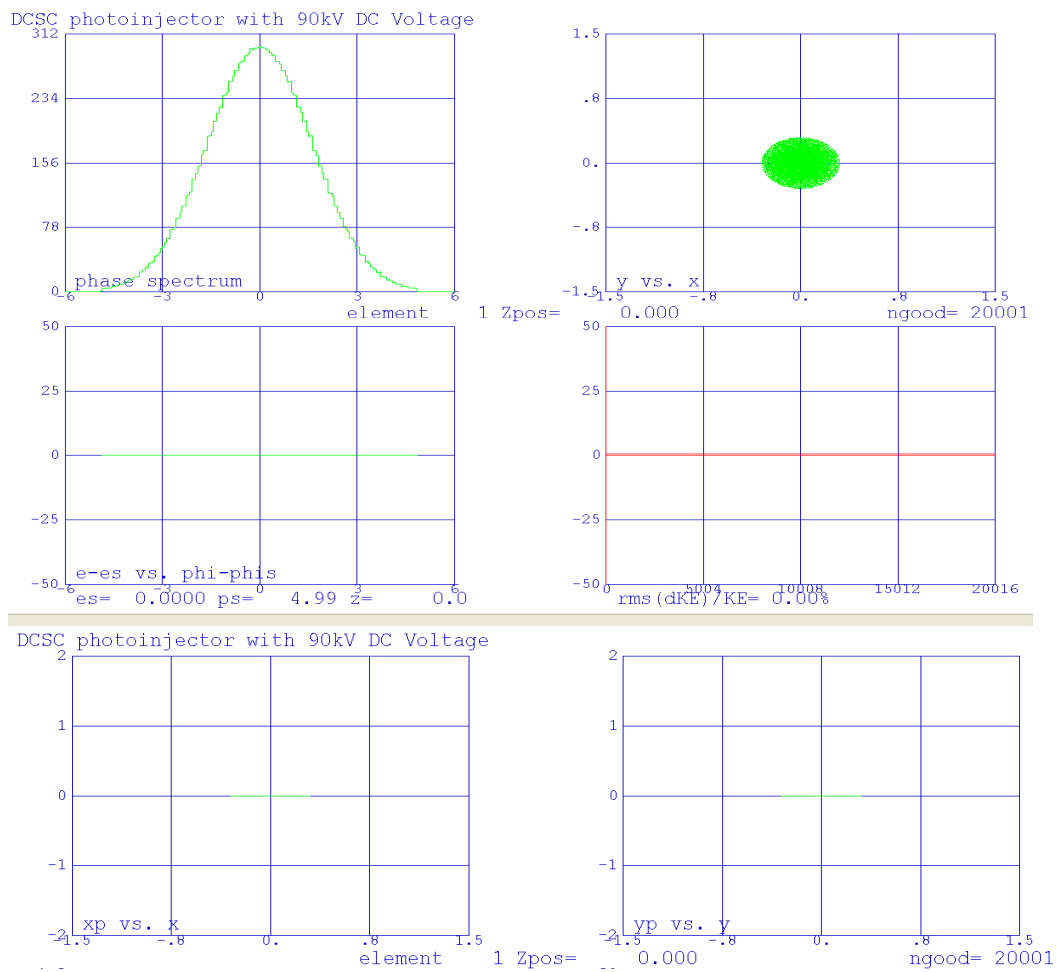

图 3.23 光阴极处初始束流品质 

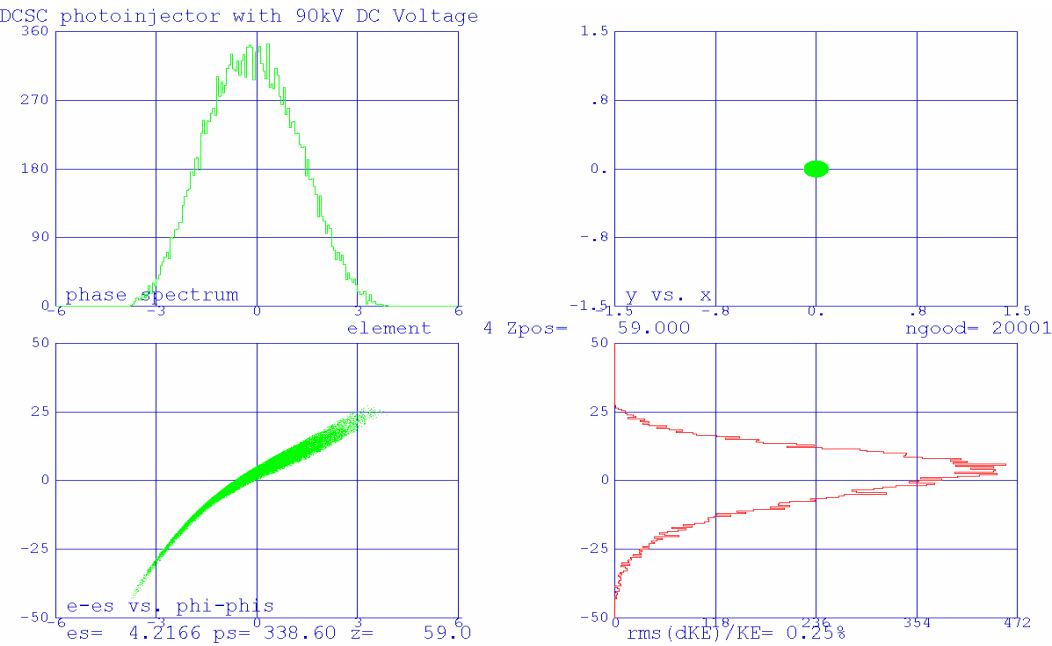

DCSC photoinjector with $90 \mathrm{kV}$ DC Voltage

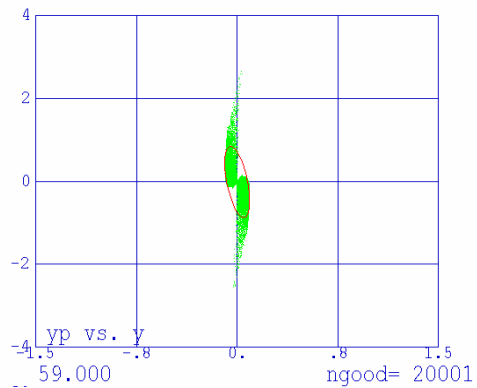

图 3.24 注入器出口束流品质
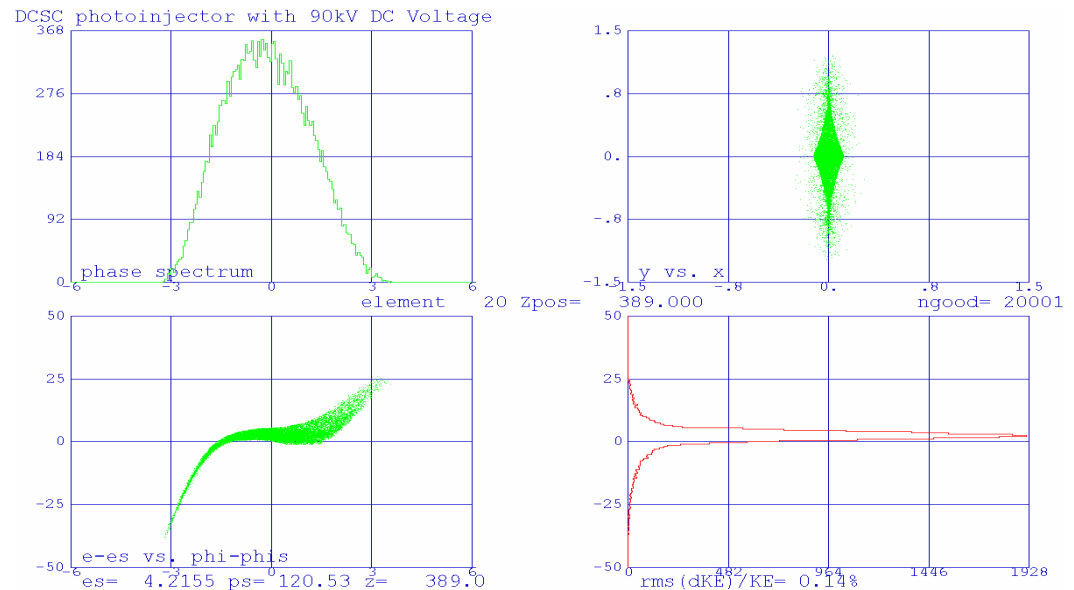

DCSC photoinjector with gokv

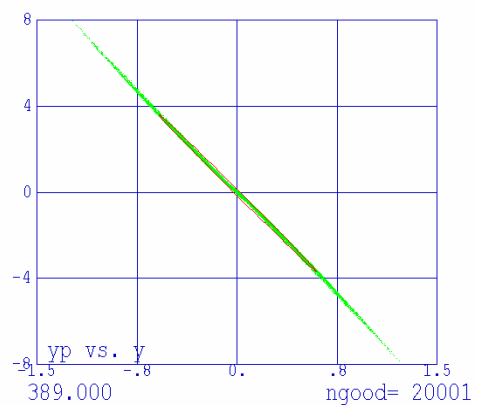

图 3.25 匹配段后束流品质 

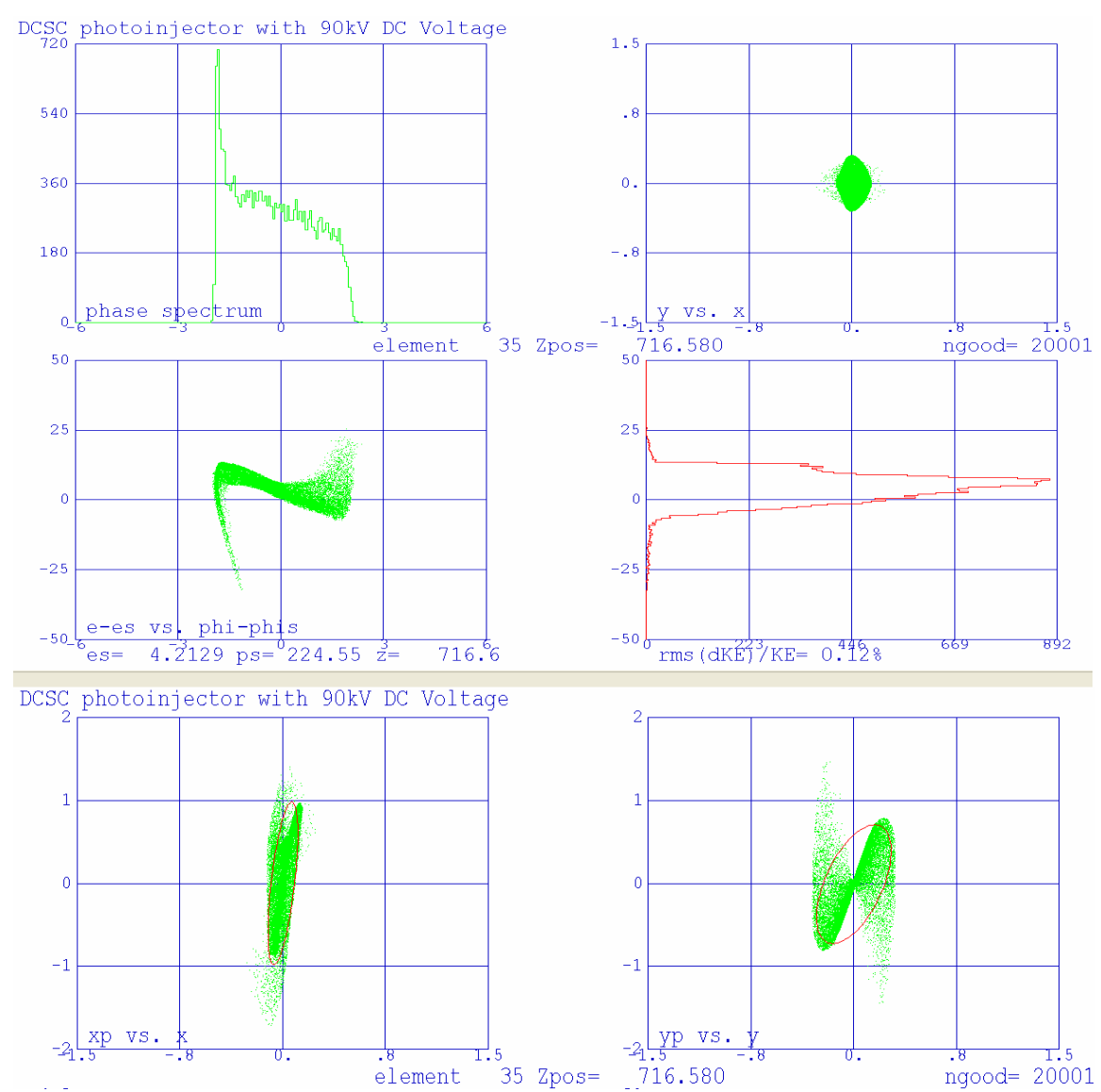

图 3.26 Merger 后 $1 \mathrm{~m}$ 处束流品质

表 3.5 模拟计算的初始条件

\begin{tabular}{|c|c|c|}
\hline \multirow{4}{*}{ 电子束团 } & RMS 半径 $(\mathrm{mm})$ & 1.5 \\
\cline { 2 - 3 } & RMS 长度 $(\mathrm{ps})$ & 3.4 \\
\cline { 2 - 3 } & 电荷量 $(\mathrm{pC})$ & 20 \\
\cline { 2 - 3 } & 初始发射度 $(\mathrm{mm}-\mathrm{mard})$ & 0 \\
\hline 超导腔 & 平均加速电场强度 $(\mathrm{MV} / \mathrm{m})$ & 10 \\
\hline
\end{tabular}

图 3.23、3.24、3.25、3.26 表示束线上光阴极处、注入器出口、匹配段后和 merger 后 $1 \mathrm{~m}$ 处的束流品质, 各图的含义是, 左上图是束流的脉冲分布图; 右上 图是束流横截面图; 左中图是处在不同相位的电子能量分布图; 右中图是束流能 散分布图; 左下图是束流 $\mathrm{x}$ 方向相空间图; 右下图是束流 $\mathrm{y}$ 方向相空间图。从图 中可以看出, 由于空间电荷效应, 从注入器出口到匹配段后, 束团头部电子能量 增大, 束团尾部电子能量降低, 尤其是靠近中心部分的电子, 空间电荷效应表现 更为明显, 这是因为空间电荷力与线密度梯度 $\lambda^{\prime}(z)$ 成正比, 对纵向是 Guass 分 布的束流, 电荷力沿 $\mathrm{z}$ 分布曲线如图 3.27, 束团头部粒子受到空间电荷力加速, 得到能量, 束团尾部粒子受到空间电荷力减速, 失去能量, 能量变化与位置有关, 
这样便不难理解经匹配段纵向相空间变化; 从 3.25 纵向相图还可以看出, 虽然 集中在中部的粒子能量位移关联很小, 但头部和尾部的粒子能量位移关联很好, 经 merger 后, 从 3.26 图可以看到头部和尾部的粒子都被压缩。注入器后空间电 荷效应不可忽视。

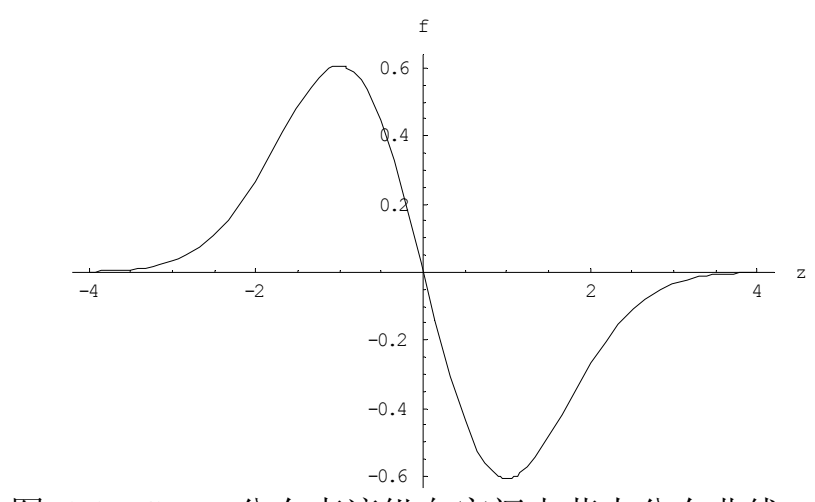

图 3.27 Gauss 分布束流纵向空间电荷力分布曲线

表 3.6 是模拟计算各点的束流品质参数, 注入器后横向束流横向归一化和纵 向归一化发射度由于空间电荷效应都增大。

表 $3.620 \mathrm{pC}$ 时束流品质参数

\begin{tabular}{|c|c|c|c|c|c|c|}
\hline & $\begin{array}{c}\mathrm{E} \\
(\mathrm{MeV})\end{array}$ & $\begin{array}{c}\Delta \mathrm{E} / \mathrm{E} \\
(\%)\end{array}$ & $\begin{array}{c}\varepsilon_{\mathrm{rms}, \mathrm{n}, \mathrm{x}} \\
(\mathrm{mm} \cdot \mathrm{mrad})\end{array}$ & $\begin{array}{c}\varepsilon_{\mathrm{rms}, \mathrm{n}, \mathrm{y}} \\
(\mathrm{mm} \cdot \mathrm{mrad})\end{array}$ & $\begin{array}{c}\varepsilon_{\mathrm{rms}, \mathrm{n}, \mathrm{z}} \\
(\mathrm{ps}-\mathrm{keV})\end{array}$ & $\begin{array}{c}\mathrm{L}_{\mathrm{RMS}} \\
(\mathrm{ps})\end{array}$ \\
\hline 注入器出口 & 4.217 & 0.25 & 1.54 & 1.54 & 6.795 & 2.861 \\
\hline 匹配段后 & 4.217 & 0.13 & 1.44 & 2.03 & 10.214 & 2.673 \\
\hline merger 后 $1 \mathrm{~m}$ 处 & 4.217 & 0.12 & 1.94 & 3.71 & 11.367 & 2.447 \\
\hline
\end{tabular}

$120 \mathrm{pC}$ 时, 加速场梯度运行在 $13 \mathrm{MV} / \mathrm{m}$, 注入器出口束流能量到 $5.48 \mathrm{MeV}$, 横向归一化 $\mathrm{rms}$ 发射度是 $2.79 \mathrm{~mm}-\mathrm{mrad}, \mathrm{rms}$ 束团长度是 $5.7 \mathrm{ps}$, 能散是 $0.44 \%$, 纵向归一化发射度是 $40 \mathrm{ps}-\mathrm{keV}$, merger 后 $1 \mathrm{~m}, \mathrm{x}$ 方向归一化 $\mathrm{rms}$ 发射度增长到 $4.68 \mathrm{~mm}-\mathrm{mrad}, \mathrm{y}$ 方向归一化 $\mathrm{rms}$ 发射度增长到 $4.85 \mathrm{~mm}-\mathrm{mrad}$, 束团长度是 $4.5 \mathrm{ps}$, 能散到 $0.17 \%$, 纵向归一化发射度是 $30 \mathrm{ps}-\mathrm{keV}$, 横向最大 $\mathrm{rms}$ 束斑是 $2.7 \mathrm{~mm}$ 。

\section{6 本章小结}

本章设计优化了前终端束线, 包括三部分, $3+1 / 2$ cell DC-SC 光阴极注入器、 匹配段和 merger 段。

研究了 $3+1 / 2$ cell DC-SC 光阴极注入器在低电荷下所能提供的束流品质, 研 
究结果表明目前注入器结构对低电荷束流有过聚焦效果。除了根据发射度变化曲 线外, 还可以根据注入器出口的 twiss 参数判断注入器是否工作在过聚焦区。改 变 $\mathrm{DC}$ 电压、 $\mathrm{RF}$ 相位以及束团长度对过聚焦影响不大。通过增大束团电荷量、 降低加速场梯度或减小驱动激光束斑尺寸可以避免过聚焦。

对四种不同的 merger 结构进行比较, 包括误差敏感和空间电荷效应, 研究 表明: dog-leg 结构对误差要求很高, 并且使用磁铁个数最多; zigzag 结构在误 差敏感分析和发射度增长上都给出最优结果, 但目前该结构还没有使用; zig-zag 结构、chicane 结构和三块磁铁结构模拟的最坏横向发射度都满足 FEL 系统的要 求; 由于三块磁铁结构使用磁铁个数最少, 并且所占空间最小, 该结构被采用。 匹配段提出两组束线方案, 都可以处理注入器出口 twiss 参数大范围变化问 题, 第一组是用螺线管聚焦, 螺线管在控制束流发散上有很大优势, 但考虑到螺 线管强度很大时, 超导注入器屏蔽问题以及它对束流发射度影响, 最终选择第二 种方案, 它的结构是在注入器出口用三块距离很近的 $\mathrm{Q}$ 铁实现 $\mathrm{x}$ 和 $\mathrm{y}$ 方向同时 聚焦。

优化设计后前终端束线横向长约 $7.8 \mathrm{~m}$, 宽约 $2 \mathrm{~m}$, 束管外孔径 $3.5 \mathrm{~cm}$ 。用 PARMELA 程序研究了 $20 \mathrm{pC}$ 和 $120 \mathrm{pC}$ 下, 束流品质变化情况, 模拟结果表明, 空间电荷效应对横向和纵向影响都不可忽略, 到前终端末, 横向发射度增长到 $5 \mathrm{~mm}-\mathrm{mrad}$, 仍然满足 FEL 的要求, 纵向上, 纵向空间电荷力改变相空间分布, 经过 merger 后纵向相空间头部和尾部束团被压缩。 


\section{第四章 返航装置设计}

根据第二章总体设计, 本章从理论上分析返航装置相空间匹配要求, 重点优 化可调路径长度结构和 arc 结构, 设计了满足 FEL 和能量回收的返航束线, 最后 研究高阶项对束流传输的影响。

\section{1 返航束线总体要求}

返航束线是指束流经主加速器加速后传输到扭摆器, 产生 FEL, 然后返回主 加速器减速, 最后到垃圾靶。返航电子束再注入主加速器的注入点有两种选择: 主加速器入口和主加速器出口, 前者是返航束流和注入束流在加速器中同方向传 输, 后者是返航束流和注入束流在加速器中反方向传输。这里考虑束流同方向传 输, 即返航束流由主加速器入口注入, 返航束线布局图如 4.1 所示。

从设计目的上考虑，它必须分别满足 FEL 和能量回收对束流的要求; 从几 何结构上看, 加速后的高能束流经应用后返回到再注入点需要改变传输方向 360 度, 设计中选择两个 180 度偏转结构 $\operatorname{arc}$ 段, 这样连接 $\operatorname{arc}$ 段之间两条束线中心 相互平行, 考虑北京大学加速器实验室建筑面积是 $20 \mathrm{~m} \times 7 \mathrm{~m}$, 束线的长度受限制, 把扭摆器放置在主加速器对面, 它的核心部分有主加速器、merger、 arc1、扭摆 器、 $\operatorname{arc} 2$ 。

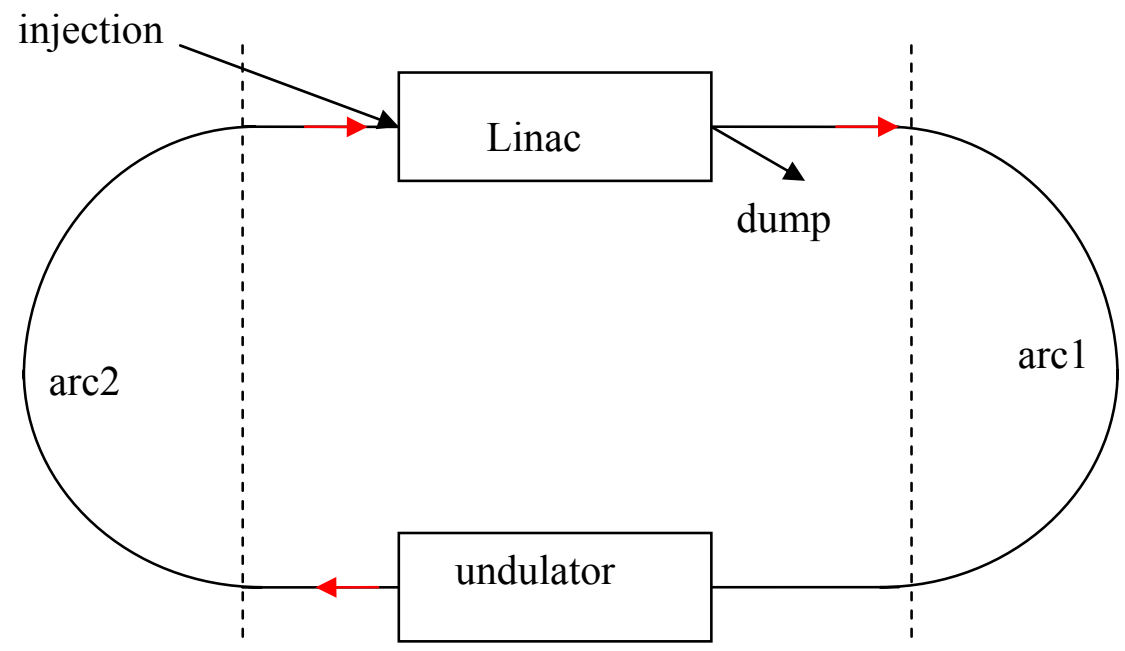

图 4.1 返航束线布局图

\subsubsection{FEL 对束流要求}

FEL 对电子束流的要求除了能量和流强之外, 还包括对横向相空间和纵向相 
空间的严格要求。

横向相空间上, 要求扭摆器中电子束和光束相空间匹配, 使电子束在空间上 与光腔的基模基本重合, 以获得高的充满因子, 即电子束斑与激光束腰满足 $\sigma_{e} \sim w_{0}=\sqrt{\frac{Z_{R} \lambda_{R}}{\pi}}$, 该条件下, 电子束和光束的作用最有效, 这要求电子束横向 几何发射度不得超过光衍射极限下, 对应电子束的几何发射度满足 ${ }^{[69]}$,

$$
\varepsilon_{r, r m s} \leq \lambda_{R} /(4 \pi)
$$

光斑的大小与瑞利长度有关, 瑞利长度 $Z_{R}$ 的选取以作用区（即扭摆器的长 度) 的平均光电场最大为准, 以获得最大的增益, 模拟计算增益与 $Z_{R} / L_{u}$ 关系 ${ }^{[70]}$ 如图 4.2, 图中假定电子束是高斯分布, $\eta$ 为电子束在光模内的有效填充因子: $\eta=\sqrt{\lambda L_{u} / 2 \pi \sigma_{e}^{2}}=\frac{\omega_{0}}{\sigma_{e}} \sqrt{L_{u} / 2 Z_{R}}, \sigma_{e}$ 为电子束的横向尺寸。由图可见增益随瑞利 长度 $Z_{R}$ 与扭摆器长度 $L_{u}$ 之比变化, 最大增益区相应的 $Z_{R}$ 为:

$$
Z_{R} \approx(1 / 5 \sim 1 / 2) L_{u}
$$

极大值对应的 $Z_{R}=L_{u} / 2.96 \sim L_{u} / 3$ 。

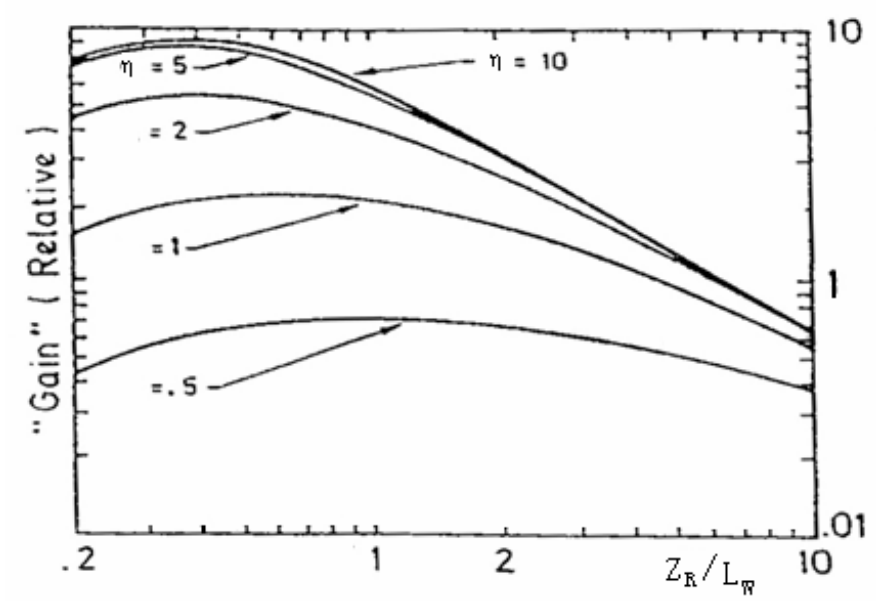

图 4.2 增益与 $Z_{R} / L_{W}$ 关系

由 4 块永磁铁组成 1 个周期的扭摆器对束流的横向传输可以近似处理为周期 chicane 结构, 等效 chicane 每块磁铁的投影长度是 $1 / 2$ 扭摆器周期, 偏转角度是 $\theta$, 其最大值是 $K / \gamma \sim 1 / \gamma^{[71]}$, 电子在扭摆器的能量约几十 $\mathrm{MeV}$, 因此 $\theta$ 很小。 chicane 结构设定偏转平面是 $\mathrm{x}$, 则 $\mathrm{x}$ 平面束流无聚焦, $\mathrm{y}$ 方向有边缘角聚集, 其传输矩阵分别是 


$$
\begin{gathered}
M_{x}=\left[\begin{array}{cc}
1 & \lambda_{u} / \cos (\theta) \\
0 & 1
\end{array}\right] \sim\left[\begin{array}{cc}
1 & \lambda_{u} \\
0 & 1
\end{array}\right] \\
M_{y} \sim\left[\begin{array}{cc}
1-8 \theta \operatorname{Tan}(\theta)+8(\theta \operatorname{Tan}(\theta))^{2} & \frac{\lambda_{u} \theta(1-\theta \operatorname{Tan}(\theta))(1-2 \theta \operatorname{Tan}(\theta))}{\sin (\theta)} \\
\frac{16 \operatorname{Tan}(\theta) \sin (\theta)(2 \theta \operatorname{Tan}(\theta)-1)}{\lambda_{u}} & 1-8 \theta \operatorname{Tan}(\theta)+8(\theta \operatorname{Tan}(\theta))^{2}
\end{array}\right]
\end{gathered}
$$

因此, 扭摆器 $\mathrm{x}$ 平面的束流传输矩阵可以近似为:

$$
\left(\begin{array}{cc}
1 & L_{u} \\
0 & 1
\end{array}\right)
$$

束包络函数在直线段的传输方程是

$$
\begin{gathered}
\beta(z)=\beta_{w}+\frac{\left(z-Z_{w}\right)^{2}}{\beta_{w}} \\
\alpha(z)=-\frac{z-Z_{w}}{\beta_{w}}
\end{gathered}
$$

$Z_{w}$ 是束腰的位置, $\beta_{w}$ 是束腰处的 $\beta$ 值。电子束和光束同时在扭摆器中心成腰, $Z_{w}=0$, 当 $\beta_{w}=Z_{R}$, 并且束流发射度满足 FEL 要求时, 电子束和光束在扭摆器 中传输可以重合的最好, 匹配最优。得到 $\mathrm{x}$ 平面, 电子束在扭摆器入口束包络要 求是

$$
\begin{gathered}
\beta_{e n, x}=Z_{R}+\frac{L_{u}^{2}}{4 Z_{R}} \\
\alpha_{e n, x}=\frac{L_{u}}{2 Z_{R}}
\end{gathered}
$$

在 $\mathrm{y}$ 平面, 扭摆器对束流聚焦有自然聚焦力。定义匹配 Beta 函数

$$
\beta_{\text {match }}=\gamma \lambda_{u} /(2 \pi K)
$$

它表明扭摆器对束流聚焦的强弱, 化简得到 $\beta_{\text {match }}$ 即是束流在扭摆器磁场中的曲 率半径。根据 (4.4) 式, 如果电子束的初始相空间与扭摆器里的 $\beta_{\text {match }}$ 匹配, 即

$$
\begin{gathered}
\beta_{e n, y}=\beta_{\text {match }} \\
\alpha_{e n, y}=0
\end{gathered}
$$

则在扭摆器里束流包络保持恒定, 等于 $\beta_{\text {match }}$ 。 
若 $\beta_{\text {match }}<Z_{R}$, 扭摆器对束流 $\mathrm{y}$ 平面是强聚焦。当扭摆器入口的束包络满足

(4.11) 和 (4.12) 式时, 电子束在扭摆器中被激光包围, 匹配最优。

若 $\beta_{\text {match }}>Z_{R}$, 扭摆器对束流弱聚焦。电子束和光束匹配最优, 要求扭摆器 入口束流汇集, 使得在扭摆器中心束流成腰, 并且束腰处的 $\beta_{y}$ 与瑞利长度 $Z_{R}$ 相 等。

结合第二章扭摆器选取的参数, 当 $K>1.33$ 时, $\beta_{\text {match }}<Z_{R}$, 此时, $\mathrm{y}$ 平面 是强聚焦, 扭摆器中 $\mathrm{y}$ 平面束包络近似恒定, 扭摆器入口 $\beta_{e n, y}=\beta_{\text {match }}, \alpha_{e n, y}=0$; 当 $K<1.33$ 时, 扭摆器入口要求 $\mathrm{y}$ 束流汇聚。

设 $Z_{R}=L_{u} / 3$, 根据公式 (4.8) 、（4.9）, 扭摆器入口 $\mathrm{x}$ 平面的包络函数是 $\beta_{e n, x}=13 L_{u} / 12, \alpha_{e n, x}=1.5$ 。

对纵向相空间, FEL要求尽可能高的峰值电流或短束团长度, 并且束流能散 达到扭摆器的要求。对Gauss分布的束流, 峰值流强

$$
I_{p}=\frac{Q}{\sqrt{2 \pi} \tau_{\mu}} \approx \frac{Q}{2.5 \tau_{\mu}}
$$

其中, $\mathrm{Q}$ 是单束团电荷量, $\tau_{\mu}$ 为束团脉冲宽度的 $r m s$ 值, 峰值流强与激光增 益G相关, 振荡器型FEL要求激光增益大于激光传输中的损耗, 保证光在腔镜中一 直被放大, 因此, 增益对峰值流强或束团长度有一个最低要求。

在扭摆器中, 电子束在扭摆器磁场和辐射场作用下最后形成辐射波长内的群 聚, 电子束的能量转换为辐射场能量, 电子束能散变大, FEL达到功率饱和。电 子束初始能散决定了FEL饱和的快慢, 即决定了实现饱和所需的扭摆器长度。振 荡器型自由电子激光要求

$$
\Delta \gamma / \gamma<1 /\left(4 N_{u}\right)
$$

自由电子激光对束团长度和能散的要求决定电子束的纵向归一化发射度的 上限, 它对注入器纵及传输段纵向发射度控制提出要求。

$$
\varepsilon_{z}<\sigma_{t}(\Delta \gamma / \gamma) E_{e}
$$

\subsection{2 能量回收对束流要求}

能量回收的优势是节约功率源的微波功率。根据第二章分析, 在理想运行条 件下, 加速束流和返航束流平均流强相等, 并且二者相对的 RF 相位差 $360 n+180$ 
度时( $\mathrm{n}$ 是整数), 返航电子束转换为微波加速场与功率源在加速结构内所建立的 微波加速场完全一样, 这时功率源除了补充腔壁的热损耗外, 需要供给束流的功 率是 0 。因此, 能量回收对束流的要求包括返航时束流注入主加速器的相位、返 航的流强（输运过程束流的流失可忽略不计）和束团重复频率（重复频率决定了 加速和减速束团之间的时间间隔 $\Delta \tau$, 它需要满足在 $\Delta \tau$ 内, 腔内微波场基本保持 不变）。

加速束流和返航束流是和同一个加速腔作用, 当加速电子束相对 RF 的相位 确定后, 返航束流相对 RF 的相位是由束流再次经过加速腔同一点时所经历的时 间 $T_{r}$ 决定，它与相对论电子束在返航线上所走的路径长度 $L_{r}$ 关系是

$$
T_{r}=L_{r} / c
$$

因此要求

$$
T_{r}=(n+1 / 2) / f_{R F}
$$

或

$$
L_{r}=(n+1 / 2) \lambda_{R F}
$$

$f_{R F}$ 是 $\mathrm{RF}$ 腔的频率 $1.3 \mathrm{GHz}, \lambda_{R F}$ 是对应的波长 $23.077 \mathrm{~cm}$ 。实际机器中, 由于准 直误差或者 FEL 作用束流中心能量发生变化等, 束流在返航束线上所走路径长 度与设计值有偏离, 返航束线要具有调整束流路径长度的能力, 所调节的 RF 相 位范围大于这些因素引起的相位变化。

$\mathrm{JLAB}$ 的 $6 \mathrm{GeV}$ 束线长约 $5 \mathrm{~km}$, 束线误差引起的束流路径长度变化可以控制 到 $5 \mathrm{~mm}$ 以下, 对北京大学能量回收装置, 电子能量为几十 $\mathrm{MeV}$, 束线长约几十 米, 类比 JLAB 的系统, 误差引起路径长度变化比 $5 \mathrm{~mm}$ 要小, 这里假设是 $5 \mathrm{~mm}$, 对应的 RF 相位改变是 7.8 度; FEL 引起的相位改变与电子束转化到 FEL 的功率 有关, JLAB 的 $10 \mathrm{~kW}$ 红外 FEL 运行经验表明, 自由电子激光在开和关两种状态

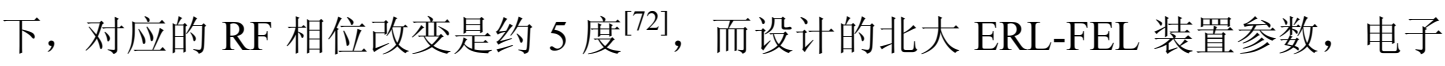
束转换 FEL 的效率比 JLAB 的装置低, 预计 FEL 过程改变 RF 相位不大于 5 度。 北京大学的能量回收装置 $R F$ 相位调节范围要在 \pm 13 度以上。

能量回收的另一个要求是回收流强与加速流强相等, 这要求束流传输中不丢 失。经过 FEL 之后, 束流能散变大, 在大的色散段, 如 $\operatorname{arc2}$ 部分, 色散引起的 束斑增大 $\eta^{*}(\delta p / p)$ 相比 Betatron 振荡对应的束斑 $\sqrt{\beta \varepsilon}$ 大很多, 因此, FEL 之后, 
系统要能够传输大能散束流，保证束流不丢失，即 FEL 之后的传输线具有大动 量接收度。

返航束线上，不同部分如加速器、 $\operatorname{arc} 1 、 \operatorname{arc} 2$ 对束流有一定的接收度，扭摆 器对横向束包络也有要求，这些要通过加入横向匹配段来实现。

能量回收之后, 束流能量从 $30 \mathrm{MeV}$ 到 $5 \mathrm{MeV}$, 降为原来 $1 / 6$, 如果不考虑能 散压缩, 束流的相对能散将增大 6 倍, 这对主加速器出口到垃圾靶传输要求很高, 当色散为 $0.1 \mathrm{~m}$ 时, 对应的束斑到 $6 \mathrm{~cm}$, 为了控制这部分束管尺寸, 避免束流打 到管壁上造成的危害，不仅要控制色散，还要考虑束流能散的压缩。

综合以上，能量回收自由电子激光对返航束线的要求总结如下:

(1)束团路径长度可调，调节范围相当于 $R F$ 相位 \pm 13 度以上。

(2)横向束包络匹配, 满足 $\operatorname{arc} 1 、 \operatorname{arc} 2$ 、扭摆器以及主加速器对束流横向相空 间要求。

(3)FEL 之前, 束团长度压缩。

(4)能量回收时，束团能散压缩。

设计顺序先考虑对束线影响因素最多的部分，依次到因素最少，如纵向相空 间匹配优先横向相空间匹配，因为调整纵向相空间时会影响横向相空间，而调整 横向相空间一般不会影响纵向相空间。

首先考虑路径长度调节装置, 再考虑纵向相空间设计要求, 最后设计了匹配 段形成返航束线。

\section{2 束流纵向相空间调控}

这部分介绍了束流纵向相空间调控理论, 在束线上实现束团长度压缩和束团 能散压缩, 结合北大装置, 给出相应的工作参数要求。

\subsection{1 束流纵向相空间调控条件}

束流纵向相空间分布是用纵向位置 $l$ 和能散 $\delta p / p$ 描述，对比横向相空间， 以 $\mathrm{x}$ 平面为例, 纵向相空间的纵向位置和能散调控过程类似横向相空间 $x$ 和 $x$ 经 直线段或者薄透镜后的变化, 纵向位置等同于位置偏离 $x$, 能散等同于发散角 $x^{\prime}$, 束团长度压缩/拉伸结构类比直线段传输, 加速器改变束流能散类比薄透镜传输。 为了更清楚描述纵向相空间的调控，这里先介绍横向相空间的调控。 
假设粒子有初始的位置偏离 $\pm x_{i}$, 发散角 $x_{i}^{\prime}$ 是 0 , 则经过直线传输段后, 粒 子的相空间表示

$$
X(f)=\left(\begin{array}{l}
x_{f} \\
x_{f}^{\prime}
\end{array}\right)=M(i \rightarrow f) X(i)=\left(\begin{array}{cc}
1 & M_{12} \\
0 & 1
\end{array}\right)\left(\begin{array}{c} 
\pm x_{i} \\
0
\end{array}\right)=\left(\begin{array}{c} 
\pm x_{i} \\
0
\end{array}\right)
$$

可以看出, 发散角为 0 的粒子, 经直线传输段, 相空间分布保持不变。

若粒子初始的位置偏离 $x_{i}$ 是 0 , 发散角是 $\pm x_{i}^{\prime}$, 则经过直线传输段后, 粒子 的相空间表示

$$
\left(\begin{array}{c}
x_{f} \\
x_{f}^{\prime}
\end{array}\right)=\left(\begin{array}{cc}
1 & M_{12} \\
0 & 1
\end{array}\right)\left(\begin{array}{c}
0 \\
\pm x_{i}^{\prime}
\end{array}\right)=\left(\begin{array}{c} 
\pm M_{12} x_{i}^{\prime} \\
\pm x_{i}^{\prime}
\end{array}\right)
$$

其相空间分布变化的逆过程是初始相空间分布为 $\left(\begin{array}{c} \pm M_{12} x_{i}^{\prime} \\ \pm x_{i}^{\prime}\end{array}\right)$, 终端相空间分 布是 $\left(\begin{array}{c}0 \\ \pm x_{i}^{\prime}\end{array}\right)$, 传输矩阵是 $\left(\begin{array}{cc}1 & M_{12} \\ 0 & 1\end{array}\right)^{-1}$, 即

$$
\left(\begin{array}{c}
0 \\
\pm x_{i}^{\prime}
\end{array}\right)=\left(\begin{array}{cc}
1 & M_{12} \\
0 & 1
\end{array}\right)^{-1}\left(\begin{array}{c} 
\pm M_{12} x_{i}^{\prime} \\
\pm x_{i}^{\prime}
\end{array}\right)
$$

即若终端相空间粒子的位置偏离为 0 , 粒子的初始相空间位置偏离 $x_{i}$ 和发散角 $x_{i}^{\prime}$ 必须关联, 并且线性关联满足 $d x / d x^{\prime}=M_{12}$ 。

图 4.3 显示了两种不同初始条件下, 经直线段束流相空间的变化, 绿色表示 初始相空间分布, 红色表示终点相空间分布, 左图是初始相空间粒子发散角为 0 , 右图初始位置偏离是 0 。根据以上粒子相空间在直线段的传输分析, 左图粒子相 空间分布保持不变, 粒子的位置偏离不会影响发散角, 而要改变位置偏离, 束流 必须有初始的发散角; 在 4.3 右图, 初始发散角为 $\pm x_{i}^{\prime}$ 的束流经过直线 $M_{12}$ 后, 束流的相空间分布关联, 相空间分布从初始绿色变成红色, 它的逆过程是初始相 空间是有一定关联的分布, 经过 “长度” $-M_{12}$ 后, 束流位置偏离变成 0 , 相空 间分布变化从红色变成绿色。 


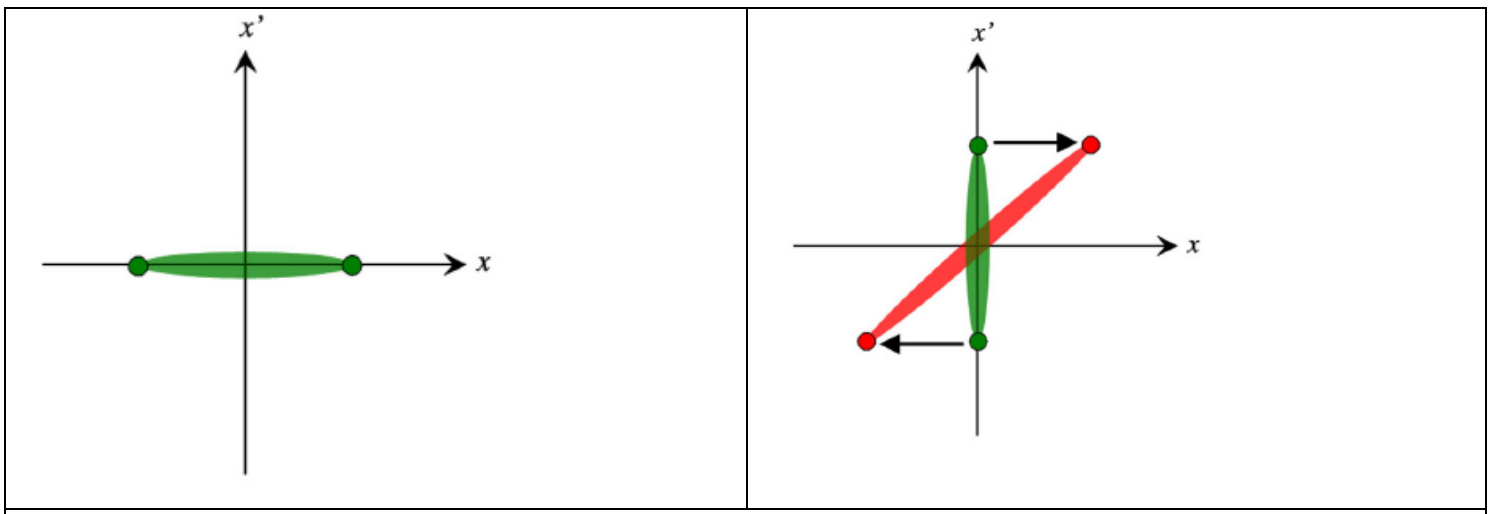

图 4.3 直线传输段, 粒子初始发散角 0（左）/位置偏离 0（右）对应相空间的变化

在薄透镜中, 若初始发散角 $x_{i}^{\prime}$ 是 0 , 位置偏离 $\pm x_{i}$, 束流传输是

$$
\left(\begin{array}{l}
x_{f} \\
x_{f}^{\prime}
\end{array}\right)=\left(\begin{array}{cc}
1 & 0 \\
M_{21} & 1
\end{array}\right)\left(\begin{array}{c} 
\pm x_{i} \\
0
\end{array}\right)=\left(\begin{array}{c} 
\pm x_{i} \\
\pm M_{21} x_{i}
\end{array}\right)
$$

相空间分布变化的逆过程是

$$
\left(\begin{array}{c} 
\pm x_{i} \\
0
\end{array}\right)=\left(\begin{array}{cc}
1 & 0 \\
M_{21} & 1
\end{array}\right)^{-1}\left(\begin{array}{c} 
\pm x_{i} \\
\pm M_{21} x_{i}
\end{array}\right)
$$

即若终端相空间粒子的发散角为 0 , 粒子的初始相空间位置偏离 $x_{i}$ 和发散角 $x_{i}^{\prime}$ 必 须关联, 并且线性关联满足 $d x / d x^{\prime}=1 / M_{21}$ 。

若粒子初始的位置偏离 $x_{i}$ 是 0 , 发散角是 $\pm x_{i}^{\prime}$, 则经过薄透镜后, 粒子的相 空间

$$
\left(\begin{array}{l}
x_{f} \\
x_{f}^{\prime}
\end{array}\right)=\left(\begin{array}{cc}
1 & 0 \\
M_{21} & 1
\end{array}\right)\left(\begin{array}{c}
0 \\
\pm x_{i}^{\prime}
\end{array}\right)=\left(\begin{array}{c}
0 \\
\pm x_{i}^{\prime}
\end{array}\right)
$$

相空间分布经透镜后保持不变。

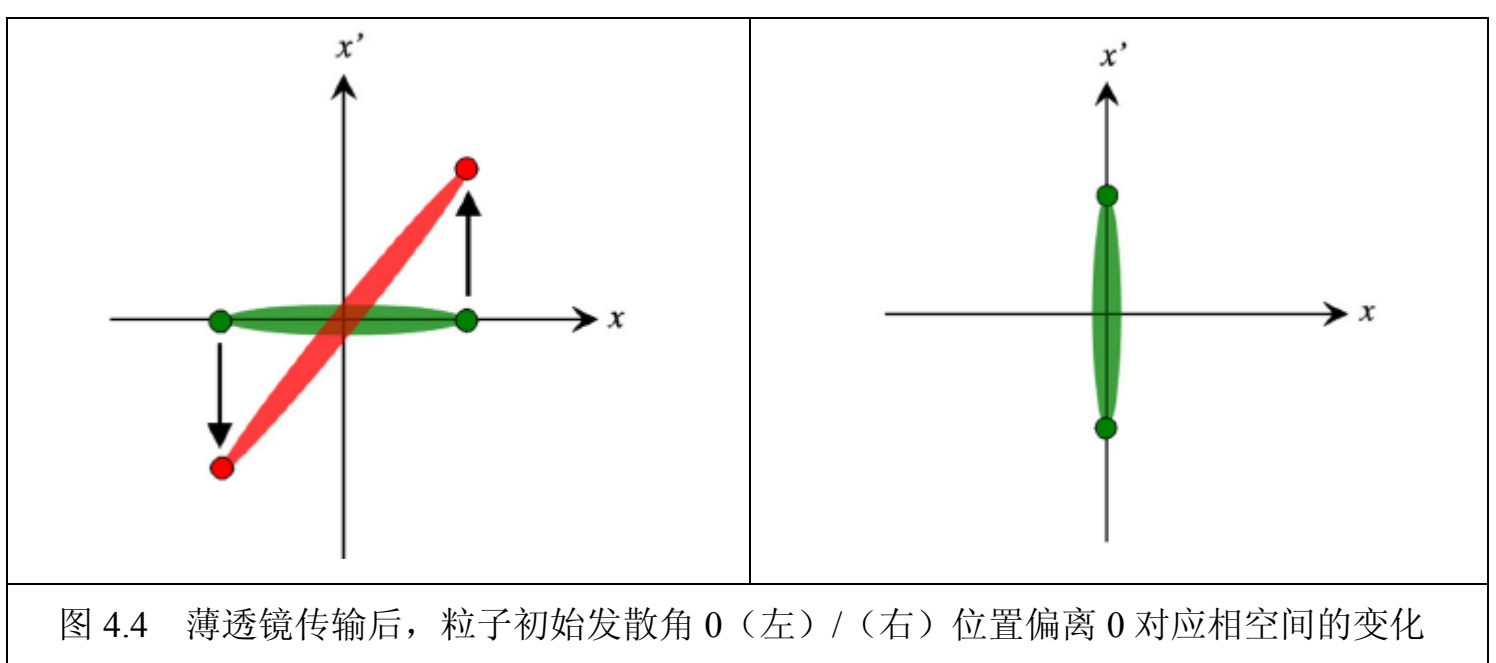


图 4.4 显示了两种不同初始相空间分布（绿色）下，经薄透镜后束流相空间 分布 (红色) 的变化, 从图中可以得到, 粒子的发散角不会影响位置偏离, 束流 必须有初始的位置偏离才能改变发散角; 初始位置偏离为 $\pm x_{i}^{\prime}$ 的束流经过透镜 $M_{21}$ 后, 束流的相空间分布关联, 如图 4.4 左图, 相空间分布从初始绿色变成红 色, 逆过程是初始相空间分布是有一定关联, 经过聚焦是 $-M_{21}$ 的透镜后, 束流 角发散变成 $0,4.4$ 左图从初始红色分布变成终端绿色分布。

以上介绍了横向相空间经过直线段和薄透镜后, 束流横向相空间改变。纵向 相空间上, 经过磁压缩/拉伸结构, 传输矩阵中包含 $M_{56}$, 与直线传输类似, 若压 缩束团, 束流的纵向相空间分布必须关联, 关联相对 $M_{56}$ 的大小决定束团压缩的 程度。

低能段, 为了减小空间电荷效应造成束流品质变坏, 要求前终端传输的束流 能散很小, 束团长度很长, 类似 4.3 左图绿色分布。

FEL 要求束团长度很短。根据以上分析为了得到所需的束团长度, 相空间分 布首先形成关联, 它是通过束流在加速器中偏离峰值相位加速得到, 类似横向薄 透镜的功能, 如图 4.4 左图; 再通过磁压缩结构, 合理选择 $M_{56}$, 束团长度得到 最大压缩, 类似 4.3 右图红色分布到绿色分布。

经过 FEL 后束团长度最短, 束流能散很大。能量回收后, 束流能量降低到 几 $\mathrm{MeV}$, 为了控制束流相对能散, 纵向相空间要求相空间从最短束团长度、最 大能散变成束团长度最长、能散最小。类比横向相空间, 为了得到最小能散, 相 空间分布要形成关联, 束团首先经过磁压缩结构, 如 4.3 右图, 然后经过加速器 偏离峰值减速, 如 4.4 左图逆过程, 这样完成束团能散和束团长度的交换。

\subsubsection{ERL-FEL 中束团长度和能散调控理论}

以上是假设不同粒子的相空间分布线性关联完全一样时, 定性分析纵向相空 间上一阶光学传输如何实现能散和束团长度之间的调控。实际束团有一定的发射 度, 束团长度不能无限制的压缩, 能散也同样不能调控到非常小, 并且当能散较 大时二阶或更高阶效应的影响是不可忽略的。 


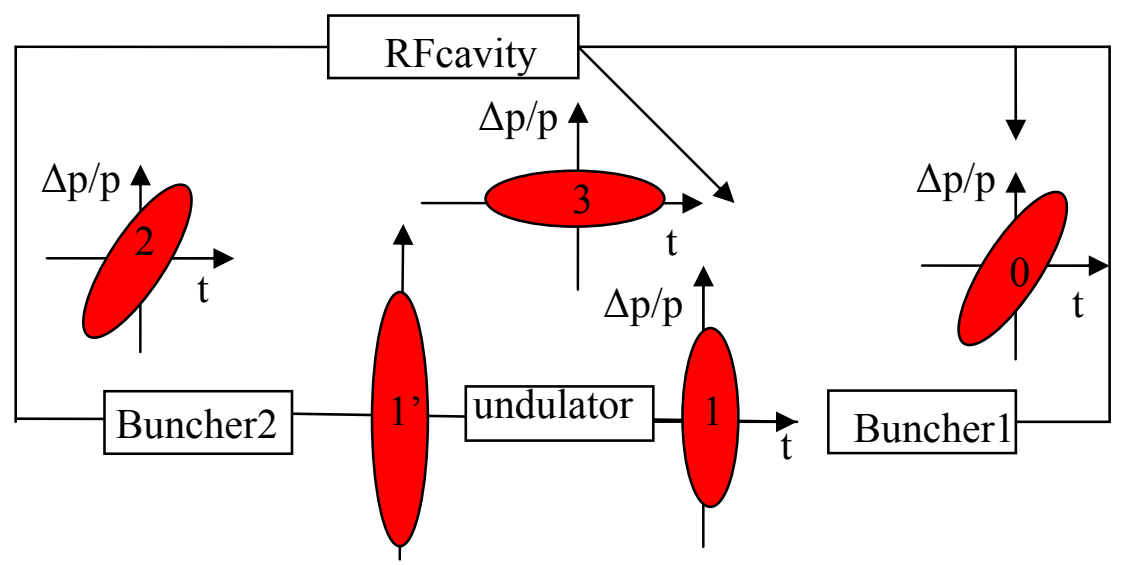

图 4.5 ERL-FEL 纵向相空间的调控示意图

图 4.5 显示 ERL-FEL 中束流的纵向相空间调控过程: 主加速器入口的相空 间分布类似 3, 0 是经主加速器偏离峰值加速后高能粒子相空间分布; 1 表示经 过磁结构 Buncher1 后的相空间, Buncher1 与 Buncher2 之间有扭摆器装置, Buncher 2 之前的相空间与分布 1 类似, 表示成 1 , 能散因为 FEL 过程变大, 发 射度增大; 2 是经过 Buncher2 后的相空间; 3 是能量回收后的相空间。束团长度 $\sigma_{t}=\sqrt{\sigma_{55}(i)}=\sqrt{\beta_{z}(i) \varepsilon_{z}}$, 能散 $\sigma_{\delta_{p / p}}=\sqrt{\sigma_{66}(i)}=\sqrt{\gamma_{z}(i) \varepsilon_{z}}, \quad \sigma_{56}(i)=-\alpha_{z}(i) \varepsilon_{z}$, rms 发射度 $\varepsilon_{z}=\sqrt{\sigma_{55}(0) \sigma_{66}(0)-\sigma_{56}^{2}(0)}, \quad \beta_{z} \gamma_{z}-\alpha_{z}{ }^{2}=1$ 。定义常 数 $f_{56}=-\sigma_{55}(0) / \sigma_{56}(0)=\beta_{z} / \alpha_{z}$, 它反映束流相空间分布关联的大小或相空间倾斜程 度, $f_{56}$ 越小, 相空间倾斜越厉害, 束流关联越好。

横向相空间经过矩阵 $M=\left(\begin{array}{ll}M_{11} & M_{12} \\ M_{21} & M_{22}\end{array}\right)$ 后, twiss 参数前后的变化关系是

$$
\begin{aligned}
& \beta(f)=\left(M_{12}\right)^{2} \gamma_{0}-2 M_{12} M_{11} \alpha_{0}+\left(M_{11}\right)^{2} \beta_{0} \\
& \gamma(f)=\left(M_{22}\right)^{2} \gamma_{0}-2 M_{22} M_{21} \alpha_{0}+\left(M_{21}\right)^{2} \beta_{0}
\end{aligned}
$$

类比横向的 twiss 参数, 从主加速出口到扭摆器入口纵向相空间的传输矩阵 $M=\left(\begin{array}{cc}1 & M_{56} \\ 0 & 1\end{array}\right)$, 从 0 到 1 ,

$$
\beta_{z}(1) \varepsilon_{z}=\left(M_{56}\right)^{2} \gamma_{z}(0) \varepsilon_{z}-2 M_{56} \alpha_{z}(0) \varepsilon_{z}+\beta_{z}(0) \varepsilon_{z}
$$

或

$$
\sigma_{55}(1)=\sigma_{55}(0)\left(1-M_{56} / f_{56}\right)^{2}+\left(M_{56} \varepsilon_{z}\right)^{2} / \sigma_{55}(0)
$$


从 (4.27) 式得到, 当 $f_{56}=R_{56}$ 时, 束团压缩到最短, 即束团相空间关联与 磁压缩匹配。相空间匹配时, 最短束团长度

$$
\left(\sigma_{t}\right)_{\min }=M_{56} \varepsilon_{z} / \sigma_{t}(0)
$$

它正比于发射度, 若得到足够短的束团, 必须控制束流纵向发射度。进一步 研究, $\mathrm{RF}$ 加速前后纵向归一化发射度保持不变, 几何发射度 $\varepsilon_{z}$ 随加速前后的能 量之比值而变化, 假设 $\mathrm{RF}$ 之前 $\alpha$ 或 $\langle\delta p / p \cdot t\rangle$ 是 0 , 则 $\varepsilon_{z} / \sigma_{t}(0)=\sigma_{\delta p / p}(i n j)$, 它 是非相关能散, 主要来源于注入器, 从 (4.28) 式得到注入器非相关能散限定了 最短束团长度, 换句话说, 束团最短压缩长度对注入器出口的非相关能散和纵向 归一化发射度提出相应的要求。

从 2 到 3 的相空间变化类似以上分析, $\mathrm{RF}$ 加速腔的传输矩阵 $M=\left(\begin{array}{cc}1 & 0 \\ M_{65} & 1\end{array}\right)$, 根据（4.26）式

$$
\gamma_{z}(3) \varepsilon_{z}=\gamma_{z}(2) \varepsilon_{z}-2 M_{65} \alpha_{z}(2) \varepsilon_{z}+\left(M_{65}\right)^{2} \beta_{z}(2) \varepsilon_{z}
$$

或

$$
\sigma_{66}(3)=\sigma_{66}(2)\left(1-M_{65} \alpha_{z}(2) / \gamma_{z}(2)\right)^{2}+\left(M_{65} \varepsilon_{z}\right)^{2} / \sigma_{66}(0)
$$

当 $M_{65}=\gamma_{z}(2) / \alpha_{z}(2)$ 时, 经主加速器后, 束团能散压缩到最小, $\left(\sigma_{\delta p / p}\right)_{\min }=\left(M_{65} \varepsilon_{z}\right) / \sigma_{\delta p / p}(0)$, 其中 $\varepsilon_{z} / \sigma_{\delta p / p}(0)$ 表示 FEL 后的束团长度, 与主加 速器后的最小能散成正比。

下面介绍电子束在 RF 场偏离峰值加速/减速束流形成相空间的线性关联以 及相空间二阶修正。这里先注明以下字母的含义, $i n j$ 表示前端粒子的参数, $a c c$ 表示经过主加速后的参数, $b$ 表示束流完全压缩后或扭摆器之前的参数, $F E L$ 表 示出光之后的束流参数, $r e$ 表示扭摆器之后到能量回收的参数。

假设前端, 粒子偏离束团中心的位置是 $l_{i n j}\left(l_{i n j} \approx c t_{i n j}=\frac{\lambda_{R F}}{2 \pi} \phi_{i n j}, t_{i n j}\right.$ 大于 0 表 示束团尾部, 小于 0 表示束团头部）, 能量 $E_{i n j}$, 与参考粒子的能量差是 $\Delta E_{i n j}$, 束团能量位置无关联。经过主加速后, 参考粒子能量 $E_{a c c}\left(l_{i n j}=0\right)=E_{i n j}+V \cos \phi_{0} \equiv E_{f}$, 粒子的位置偏离和能量偏离分别是

$$
l_{a c c}=l_{i n j}
$$




$$
\Delta E_{a c c}=\Delta E_{i n j}+\Delta E_{R F}
$$

其中, $\Delta E_{R F}=V\left[\cos \left(\phi_{0}+2 \pi l_{i n j} / \lambda_{R F}\right)-\cos \phi_{0}\right], \phi_{0}$ 是中心粒子偏离峰值加速的相 位, $V$ 是粒子处于峰值相位得到的最大能量。

粒子相对能散是 $\frac{\Delta E_{a c c}}{E_{f}}=\frac{V\left[\cos \left(\phi_{0}+2 \pi l_{i n j} / \lambda_{R F}\right)-\cos \phi_{0}\right]+\Delta E_{i n j}}{E_{f}}$, 一般, 注入 器引起的粒子能量偏移 $\Delta E_{i n j}$ 比加速器中粒子偏离参考相位引起的能量偏移小很 多, 并且 $\Delta E_{i n j}$ 是非相关能散。忽略注入能散, 当粒子位置偏离所引起的加速相 位 $2 \pi l_{i n j} / \lambda_{R F}$ 改变是小量时, 上式展开到二阶项

$$
\frac{\Delta E_{a c c}}{E_{f}} \approx \frac{\Delta E_{R F}}{E_{f}}=-\frac{V \sin \phi_{0}}{E_{f}} 2 \pi l_{i n j} / \lambda_{R F}-\frac{V \cos \phi_{0}}{E_{f}} \frac{\left(2 \pi l_{i n j} / \lambda_{R F}\right)^{2}}{2}
$$

一次项表示粒子偏离参考相位引起的能量位置线性关联, 平方项表示由于 $\mathrm{RF}$ 加 速场非线性造成的二阶关联。

粒子从主加速器出口到扭摆器, 能散保持不变; 相对参考粒子的位置偏离是

$$
l_{b}=l_{i n j}+M_{56} \frac{\Delta E_{R F}}{E_{f}}+T_{566}\left(\frac{\Delta E_{R F}}{E_{f}}\right)^{2}
$$

代入 (4.31) 式,

$$
\begin{aligned}
& l_{b} \approx l_{i n j}\left(1-M_{56} \frac{V \sin \phi_{0}}{E_{f}} 2 \pi / \lambda_{R F}\right) \\
& +l_{i n j}^{2}\left(-M_{56} \frac{V \cos \phi_{0}}{E_{f}} \frac{\left(2 \pi / \lambda_{R F}\right)^{2}}{2} \frac{\Delta E_{R F}}{E_{f}}+T_{566}\left(\frac{V \sin \phi_{0}}{E_{f}} 2 \pi / \lambda_{R F}\right)^{2}\right) \\
& +l_{i n j}^{3}\left(4 \pi^{2} T_{566} V^{2} \sin 2 \phi_{0} /\left(E_{f}^{2} \lambda_{R F}^{3}\right)\right)+l_{i n j}^{4} \ldots
\end{aligned}
$$

当 $\left|\frac{V \sin \phi_{0}}{E_{f}} 2 \pi l_{i n j} / \lambda_{R F}\right|>>\left|\frac{V \cos \phi_{0}}{E_{f}} \frac{\left(2 \pi l_{i n j} / \lambda_{R F}\right)^{2}}{2}\right|$, 或 $\left|\tan \phi_{0}\right|>>\pi l_{i n j} / \lambda_{R F}$ 时, 即二阶 项以上的效应可以忽略, 为了压缩束团到最短,

$$
\begin{gathered}
l_{a c c}-M_{56} \frac{V \sin \phi_{0}}{E_{f}} 2 \pi l_{i n j} / \lambda_{R F}=0 \\
-M_{56} \frac{V \cos \phi_{0}}{E_{f}} \frac{\left(2 \pi l_{i n j} / \lambda_{R F}\right)^{2}}{2}+T_{566}\left(-\frac{V \sin \phi_{0}}{E_{f}} 2 \pi l_{i n j} / \lambda_{R F}\right)^{2}=0
\end{gathered}
$$


从（4.34）、（4.35）式得到

$$
\begin{gathered}
\tan \phi_{0}=\frac{E_{f}}{\left(E_{f}-E_{i n j}\right) M_{56}} \frac{\lambda_{R F}}{2 \pi} \\
T_{566}=\frac{M_{56}}{2} \frac{E_{f}}{\left(E_{f}-E_{i n j}\right)}\left(\frac{\cos \phi_{0}}{\sin \phi_{0}}\right)^{2} \\
T_{566}=\frac{\pi}{\lambda_{r f}}\left(\frac{\cos \phi_{0}}{\sin \phi_{0}}\right) M_{56}^{2}
\end{gathered}
$$

或者

以上两式给出 $\mathrm{RF}$ 相位与磁压缩结构对应的匹配参数。

束流在扭摆器入口的 rms 能散

$$
\left(\frac{\Delta E_{a c c}}{E_{f}}\right)_{F E L} \approx-\frac{V \sin \phi_{0}}{E_{f}} 2 \pi \sigma_{a c c} / \lambda_{R F}
$$

所以

$$
\tan \phi_{0}=-\left(\frac{\Delta E_{a c c}}{E_{f}}\right)_{F E L} \frac{E_{f}}{\left(E_{f}-E_{i n j}\right)} \frac{\lambda_{R F}}{2 \pi \sigma_{a c c}}
$$

其中, $\sigma_{a c c}$ 是束团 $\mathrm{rms}$ 长度。

根据 FEL 要求的能量、能散以及注入能量, （4.36）、（4.38）式共同决定 束流的加速相位、主加速器出口到扭摆器之间的 $M_{56}$ 和 $T_{566}$ 。

下面研究能散压缩过程 ${ }^{[73]}$ 。经 FEL 后, 束团很短, 能散最大, 粒子位置偏 离参考中心的很小, 但能量偏离最大。经过 FEL 到束团拉伸、能量回收的推导 过程与以上类似, 扭摆器出口到主加速器入口的纵向传输参数是 $M_{56}^{r e}$ 和 $T_{566}^{r e}$, 则 主加速器入口，偏离参考粒子的位置是

$$
l_{r e}=M_{56}^{r e}\left(\frac{\Delta E}{E_{f}}\right)_{F E L}+T_{566}^{r e}\left(\frac{\Delta E}{E_{f}}\right)_{F E L}^{2}
$$

$\left(\frac{\Delta E}{E_{f}}\right)_{F E L}$ 是 FEL 之后的束流能散。

能量回收后, 相对中心粒子, 能散是

$$
\Delta E_{r e}=\Delta E_{F E L}+V\left[\cos \left(\phi_{r e}+2 \pi l_{r e} / \lambda_{R F}\right)-\cos \left(\phi_{r e}\right)\right]
$$

$\phi_{r e}$ 是能量回收时, 粒子相对 RF 的相位。将（4.39）式代入 (4.40) 展开, 


$$
\begin{aligned}
& \Delta E_{r e}=\Delta E_{F E L}\left(1+\frac{\left(E_{f}-E_{\text {dump }}\right)}{E_{f}} \frac{2 \pi}{\lambda_{R F}} \tan \phi_{r e} M_{56}^{r e}\right) \\
& +\Delta E_{F E L}^{2}\left(-\frac{\left(E_{f}-E_{\text {dump }}\right)}{2 E_{f}^{2}}\left(\frac{2 \pi}{\lambda_{R F}} M_{56}^{r e}\right)^{2}+\frac{\left(E_{f}-E_{\text {dump }}\right)}{E_{f}^{2}} \frac{2 \pi}{\lambda_{R F}} T_{566}^{r e} \tan \phi_{r e}\right) \\
& +\Delta E_{F E L}^{3} \ldots
\end{aligned}
$$

当 $M_{56}^{r e} \gg T_{566}^{r e}\left(\frac{\Delta E}{E_{f}}\right)_{F E L}$ 时, 忽略二阶项以上的效应, 能散得到最大压缩时, 得到

$$
\begin{gathered}
\tan \phi_{r e}=-\frac{E_{f}}{\left(E_{f}-E_{d u m p}\right) M_{56}^{r e}} \frac{\lambda_{R F}}{2 \pi} \\
T_{566}^{r e}=-\frac{\pi}{\lambda_{R F}} \frac{\cos \phi_{r e}}{\sin \phi_{r e}}\left(M_{56}^{r e}\right)^{2}=-\frac{\lambda_{R F}}{4 \pi \tan ^{3} \phi_{r e}}\left(\frac{E_{f}}{E_{f}-E_{\text {dump }}}\right)^{2}
\end{gathered}
$$

回收后的束流能量是

$$
E_{\text {dump }}=E_{f}+V \cos \phi_{r e}
$$

功率源控制要求 $\phi_{r e}$ 与 $\phi_{0}$ 差 180 度。对比（4.36）、（4.42）、（4.43）式, 得到

$$
\begin{gathered}
M_{56}^{r e}+M_{56}=0 \\
T_{566}^{r e}+T_{566}=0
\end{gathered}
$$

北京大学的束流参数是注入束流能量 $5 \mathrm{MeV}$, 加速后的能量是 $30 \mathrm{MeV}$, 注入 束团 $\mathrm{rms}$ 长度约是 $3.4 \mathrm{ps}$, 扭摆器入口要求的能散到 $0.4 \%$, 代入以上（4.36）和 (4.38), 得到束流在主加速器加速相位是-10 度, 扭摆器之前的磁压缩系统 $M_{56}=-0.25 m$, 修正二阶项 $T_{566}=-5.13 m ; \mathrm{FEL}$ 之后的束团拉伸系统 $M_{56}^{r e}=0.25 m$, 束流 $T_{566}^{r e}=5.13 m$, 减速相位是 170 度。

检验二阶项效应以上的影响, 代入以上参数, 可以得到, 主加速器出口到扭 摆器之间 $\left|\tan \phi_{0}\right|>>\pi l_{i n j} / \lambda_{R F}$ 成立; 扭摆器出口到主加速器入口高阶项影响忽略条 件 $M_{56}^{r e}>>T_{566}^{r e}\left(\frac{\Delta E}{E_{f}}\right)_{F E L}$ 要求 $\left(\frac{\Delta E}{E_{f}}\right)_{F E L}<<5 \%$, 否则, 二阶项以上的影响不可忽略, 能散压缩空间将畸变, 需要考虑三阶修正。 


\section{3 路径长度调节段设计}

能量回收要求束流在返航束线上所走的路径长度 $L=(n+1 / 2) \lambda_{R F}$, 此时, 加 速束流相位相对减束束流差 180 度, 实现这个条件有两种方法: 第一是保持 RF 系统工作频率不变, 改变束流在返航束线上所走的路径长度; 第二是返航束线不 变, 改变 RF 系统频率, $\delta L=c(n+1 / 2)\left(\delta f / f^{2}\right)$ 。用北大的束线进行估算, $\mathrm{n}=173.5$, 若改变 RF 相位 10 度, 第二种方法需要改变 RF 频率 $1 \mathrm{MHz}$, 频率改变太大, 而 且会影响加速相位, 没有被考虑(而且会影响加速束流相位), 该方法在束线较长 即 $\mathrm{n}$ 很大时是一种可考虑的办法。这里只介绍改变束流返航束线长度。

路径长度调节的目的是保证返航电子束以最佳相位注入主加速器, 可以通过 机械移动束线或使用磁铁系统实现。机械移动束线可调范围大, 需要配套装置来 精确控制移动距离, 如 JAERI FEL 装置和 ERLP 移动整个 arc 段; 磁铁系统是改 变束流在系统中所走的路径, 如 JLAB FEL 装置是改变束流进入 $\operatorname{arc}$ 中 180 度二 极铁的角度, 从而改变束流的弯转角度和在磁铁中所走的路程。

这里选用磁铁系统实现, 如图 4.6 所示, 采用由四块矩形二极铁组成的对称 束团磁压缩 chicane 结构 ${ }^{[74]}$ 。通过改变磁铁系统的强度, 改变弯转角, 从而改变 束团经过该装置的总路径, 由于结构的对称性, 改变磁铁的弯转角, 消色散依然 满足, 它可以实现小范围调节; 另外, 机械平行移动 B2 和 B3（该方法在 LCLS 装置上使用), 可以实现路径长度粗调, 调节范围大。下面主要考虑细调。

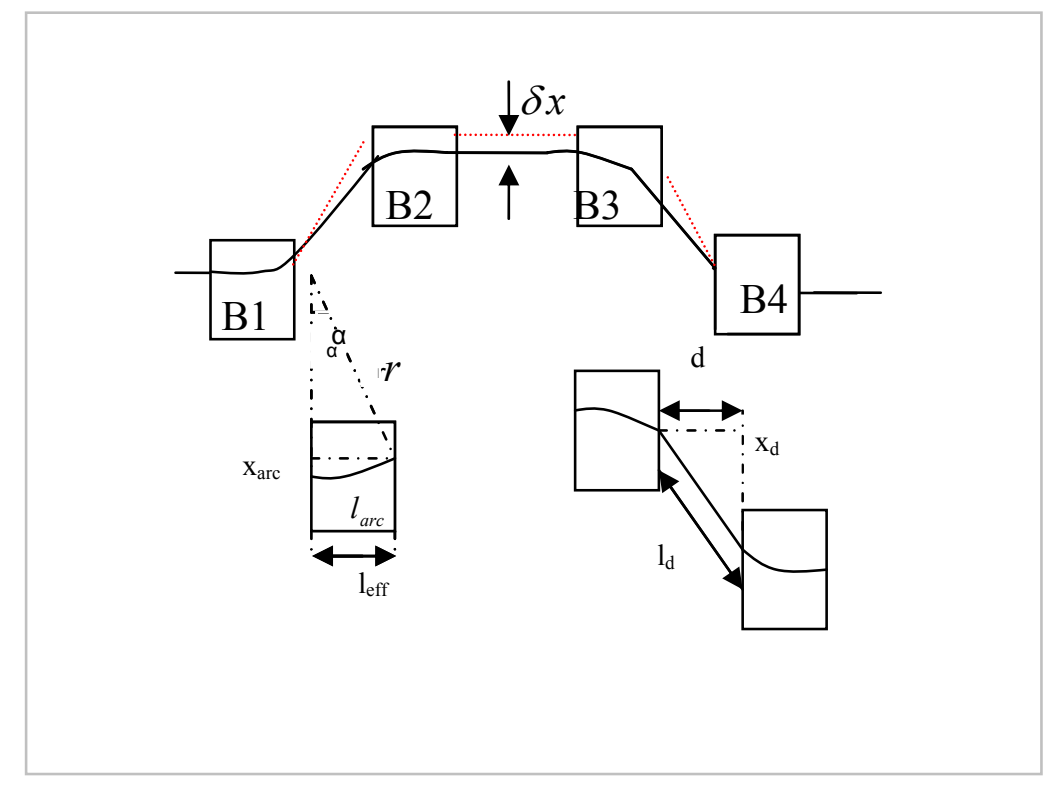

图 4.6 束团路径长度调节装置

它的几何结构是: 磁铁的有效长度为 $l_{\text {eff }}$; 弯转半径为 $r$; 偏转角度为 $\alpha$; 束 
团经过每个二极铁的轨迹长度为 $l_{a r c}$; 横向位移为 $x_{a r c} ; d$ 为第一块磁铁到第二块 磁铁之间的投影的长度，即 $\mathrm{B} 1$ 和 $\mathrm{B} 2$ 间的长度（与 $\mathrm{B} 3$ 和 $\mathrm{B} 4$ 间的长度相同）; $l_{d}$ 为漂移区的路径长度; $\delta x$ 是实际束流相对参考束线的水平位移。

根据图 4.3 所示的几何关系有

$$
\begin{gathered}
l_{\text {eff }}=r \sin \alpha \\
l_{a r c}=r \alpha
\end{gathered}
$$

因此有

$$
l_{\text {arc }}=l_{\text {eff }} \cdot \frac{\alpha}{\sin \alpha}
$$

电子的在漂移区的路径长度为

$$
l_{d}=\frac{d}{\cos \alpha}
$$

因此，束团通过整个磁压缩装置后所走的轨迹与直线轨迹的差值为

$$
\Delta l=4\left(l_{\text {arc }}-l_{\text {eff }}\right)+2\left(l_{d}-d\right)
$$

利用前面得到的关系式, 得到

$$
\Delta l=4 l_{e f f}\left(\frac{\alpha}{\sin \alpha}-1\right)+2 d \cdot\left(\frac{1}{\cos \alpha}-1\right)
$$

因此, 改变偏转角 $\alpha$, 束团经过此结构的路径长度也跟着改变。

以束流进入系统的轴即 B1 所在的轴为参考轴, 束流在系统中心相对参考轴 的水平位移是

$$
x=2 l_{\text {eff }} \frac{(1-\cos \alpha)}{\sin \alpha}+d \tan \alpha
$$

改变偏转角时, 水平位移会改变 $\delta x$, 这部分改变贡献在 $\mathrm{B} 2$ 和 $\mathrm{B} 3$ 之间的束 线上。

此结构的对束团有压缩功能

$$
R_{56}=\frac{4 l_{e f f}}{\sin \alpha}(\tan \alpha-\alpha)+\frac{2 d}{\cos \alpha} \tan ^{2} \alpha
$$

改变偏转角时, $M_{56}$ 也会改变。

通过优化参数几何参数 $d 、 l_{\text {eff }}$ 和偏转角 $\alpha$, 控制 $\delta x$ 尽可能小, 束流在 $\mathrm{B} 2$ 和 B3 中所走的路径尽量控制在中心场区, 并且该结构所能涵盖的路径长度变化 能够满足 \pm 13 度以上。 
优化后 $d=1.5 \mathrm{~m}, l_{\text {eff }}=0.4 \mathrm{~m}$, 中心弯转角 $\alpha=20^{\circ}$, 改变弯转角 \pm 1 度时, 对 应的束线参数变化如表 $4.1, \mathrm{dl}$ 是相对中心弯转角的路径长度变化, $\mathrm{d} \psi$ 是等效 $\mathrm{RF}$ 相位变化, $\mathrm{M}_{16}$ 是束线上对应的最大色散。

表 4.1 路径调节装置结构参数表

\begin{tabular}{|c|c|c|c|c|c|}
\hline Bend angle & 19 & 19.5 & 20 & 20.5 & 21 \\
\hline $\mathrm{dl}(\mathrm{cm})$ & -2.29 & -1.16 & 0 & 1.2 & 2.43 \\
\hline $\mathrm{d} \psi(\mathrm{degree})$ & -35.7 & -18.1 & 0 & 18.74 & 37.97 \\
\hline$\delta x(\mathrm{~cm})$ & -3.67 & -1.84 & 0 & 1.847 & 3.71 \\
\hline $\mathrm{R}_{56}(\mathrm{~cm})$ & -43.8 & -46.5 & -49.3 & -52.1 & -55.1 \\
\hline $\mathrm{R}_{16}(\mathrm{~cm})$ & 71.9 & 74.4 & 76.8 & 79.37 & 81.9 \\
\hline
\end{tabular}

从表中可以看出弯转角改变 \pm 0.5 度时, 涵盖的 $R F$ 相位改变到 \pm 18 度, 这足 以满足路径长度调节要求, 对应的最大色散约 $0.8 \mathrm{~m}$, 另外, $\mathrm{R}_{56}$ 在弯转角改变中 从- $0.46 \mathrm{~m}$ 变化到 $-0.52 \mathrm{~m}$, 从控制束管尺寸和束团压缩考虑, 该结构被安置在扭摆 器之前, 束流能散小。路径调节装置不仅改变返航束流相对 RF 的相位, 伴随相 位调整时, 束团的压缩也会改变, 因此, 主加速器到扭摆器之间除了该结构外, 还需要有 $R_{56}$ 可变的磁系统, 满足束团到达扭摆器时处于完全压缩。路径调节装 置 $R_{56}$ 大于束团压缩所需要的 $R_{56}=-0.25 m$, 要求磁系统的 $R_{56}$ 变化范围是 $0.21 \mathrm{~m}$ 到 $0.27 \mathrm{~m}$ 。

arc 是由磁铁系统组成, 设计中考虑用两个 $\operatorname{arc}$ 结构分别实现主加速器出口 到扭摆器入口和扭摆器出口到主加速器入口的纵向相空间要求, $\operatorname{arc} 1$ 能够保证束 团在扭摆器入口完全压缩, $\operatorname{arc} 1$ 结构的 $R_{56}$ 调节范围是 $0.21 \mathrm{~m}$ 到 $0.27 \mathrm{~m}$, $\operatorname{arc} 2$ 用 来满足能散压缩, $\mathrm{R}_{56}$ 是 $0.25 \mathrm{~m}$, 下面介绍 $\operatorname{arc}$ 结构设计。

\section{4 arc 段设计}

$\operatorname{arc}$ 结构如图 4.7 所示, 由四块完全相同的矩形 B 磁铁和五块 Q 铁组成, 每 块 B 磁铁的弯转角是 45 度, 具有中心对称性, 是对称消色散系统。 $\operatorname{arc}$ 几何尺 寸如表 4.2 , 宽 $4.3 \mathrm{~m}$, 长 $1.2 \mathrm{~m}$ 。磁铁偏转半径是 $0.5 \mathrm{~m}, 30 \mathrm{MeV}$ 时, 磁场强度是 $2.03 \mathrm{kG}$ 。

磁铁系统中, 


$$
R_{56}=\int \frac{D(s)}{\rho} d s
$$

其中, $D$ 是色散, $\rho$ 是磁铁弯转半径。

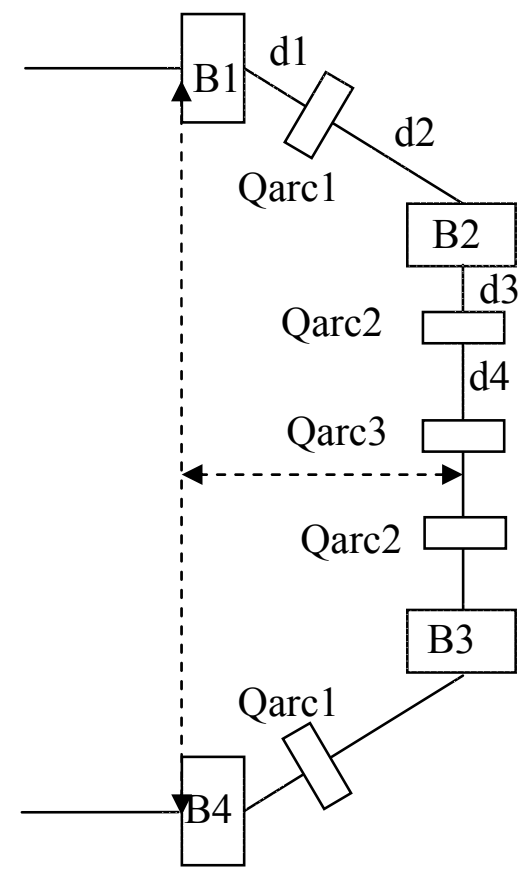

图 4.7 arc 结构示意图

表 $4.2 \mathrm{arc}$ 的几何结构

\begin{tabular}{|c|c|c|}
\hline \multirow{2}{*}{ 弯转磁铁 } & 弯转角 & 45 度 \\
\cline { 2 - 3 } & 弯转半径 & $0.5 \mathrm{~m}$ \\
\hline $\mathrm{Q}$ 铁 & 长度 & $0.15 \mathrm{~m}$ \\
\hline $\mathrm{d} 1$ & 长度 & $0.3 \mathrm{~m}$ \\
\hline $\mathrm{d} 2$ & 长度 & $0.55 \mathrm{~m}$ \\
\hline $\mathrm{d} 3$ & 长度 & $0.25 \mathrm{~m}$ \\
\hline $\mathrm{d} 4$ & 长度 & $0.45 \mathrm{~m}$ \\
\hline
\end{tabular}

由图 4.7 可以看出

$$
R_{56}=2\left(\int_{B 1} \frac{D(s)}{\rho} d s+\int_{B 2} \frac{D(s)}{\rho} d s\right)
$$

$\mathrm{B} 1$ 处的色散从 0 开始, 由磁铁本身决定, 不可调节, 对 $R_{56}$ 贡献很小, $R_{56}$ 主要 由第二块磁铁处的色散决定。色散项传输矩阵 ${ }^{[75]}$ 是 


$$
\left(\begin{array}{c}
D(f) \\
D^{\prime}(f) \\
1
\end{array}\right)=\left(\begin{array}{ccc}
M_{11} & M_{12} & M_{16} \\
M_{21} & M_{22} & M_{26} \\
0 & 0 & 1
\end{array}\right)\left(\begin{array}{c}
D(i) \\
D^{\prime}(i) \\
1
\end{array}\right)
$$

$D(i)$ 和 $D^{\prime}(i)$ 表示起点的色散函数和色散函数导数, $D(f)$ 和 $D^{\prime}(f)$ 表示终 点的色散函数和色散函数导数, $M$ 是起点到终点的传输矩阵。经过 $\mathrm{B} 1$ 后, 色 散函数和其导数由 B1 唯一决定, B2 处的色散是由 B1 到 B2 之间的传输线决定, 当束线的几何结构确定后, 改变 Q arc1 的强度, B2 处的色散改变, 从而实现 $\operatorname{arc}$ 系统的 $R_{56}$ 的调整。因此, Q arc1 功能独立, 可以控制 $\operatorname{arc}$ 系统的 $R_{56}$ 。

Q arc2 和 Q arc3 是用来实现 $\operatorname{arc}$ 系统的消色散, 不影响 $R_{56}$, 根据第三章分析, 对称系统中, 只需要一个自由参数就能满足消色散条件, 这里有两个自由度, Q arc2 和 Q arc3 的强度有很多种组合, 可以调整横向束包络。

设计的 $\operatorname{arc}$ 结构其色散项调节和 $R_{56}$ 调节由不同 $\mathrm{Q}$ 铁分别控制, Q arc1 决定 $\operatorname{arc}$ 系统的 $R_{56}, \mathrm{Qarc} 2$ 和 Q $\operatorname{arc} 3$ 控制 $\operatorname{arc}$ 系统的消色散, 每块 $\mathrm{Q}$ 铁功能独立, 避 免调节困难。系统设计中 $\operatorname{arc} 1$ 和 $\operatorname{arc} 2$ 几何结构完全相同, 由于 $R_{56}$ 要求不同, $\mathrm{Q}$ 铁强度有差别。除此之外, $\operatorname{arc} 1$ 传输低能散束流, 主要要求保持束流品质, 并且 $R_{56}$ 大范围可调, 满足扭摆器入口束团压缩到最短; $\operatorname{arc} 2$ 传输大能散束流, 要求 束流传输中不丢失, 大能散下需要考虑高阶传输对束流相空间分布的影响, 同时 $\operatorname{arc} 2$ 调控束流纵向相空间, 实现减速后束流能散压缩。下面对 $\operatorname{arc}$ 结构的 $R_{56}$ 可 调范围和能散接受度进行研究。

图 4.8 是 $R_{56}=0.25 m$ 对应的束包络函数和色散函数, 图中最下行红色方块对 应四极铁位置, 蓝色方块对应偏转磁铁位置, 最大色散约 $0.45 \mathrm{~m}$, 色散的峰值在 Q arc1 和 Q arc3 处, 三块 $\mathrm{Q}$ 铁的强度分别是 $K(\operatorname{Qarc1})=21.187\left(1 / \mathrm{m}^{2}\right)$, $K(\operatorname{Qarc} 2)=0.186\left(1 / \mathrm{m}^{2}\right), K(\operatorname{Qarc3})=11.124\left(1 / \mathrm{m}^{2}\right)$ 。矩形 B 铁对束流 $\mathrm{x}$ 方向无 聚焦, 但三块 $\mathrm{Q}$ 铁在 $\mathrm{x}$ 方向都是聚焦, 尤其是 $\mathrm{Qarc} 1$ 聚焦较强, $\mathrm{y}$ 方向的聚焦力 来源于 $\mathrm{B}$ 铁很弱, 为了避免 $\mathrm{y}$ 方向束包络发散过大, 在 $\mathrm{Q} \operatorname{arc} 1$ 处 $\beta_{y}$ 到最小, $\operatorname{arc}$ 结构对束流横向包络有一定的接受度, 这里为了束包络对称, $\operatorname{arc} 入 口$ 的 $\beta_{x}=100 \mathrm{~cm}, \beta_{y}=700 \mathrm{~cm}, \alpha_{x}=2.5, \alpha_{y}=-1.5$ 。 


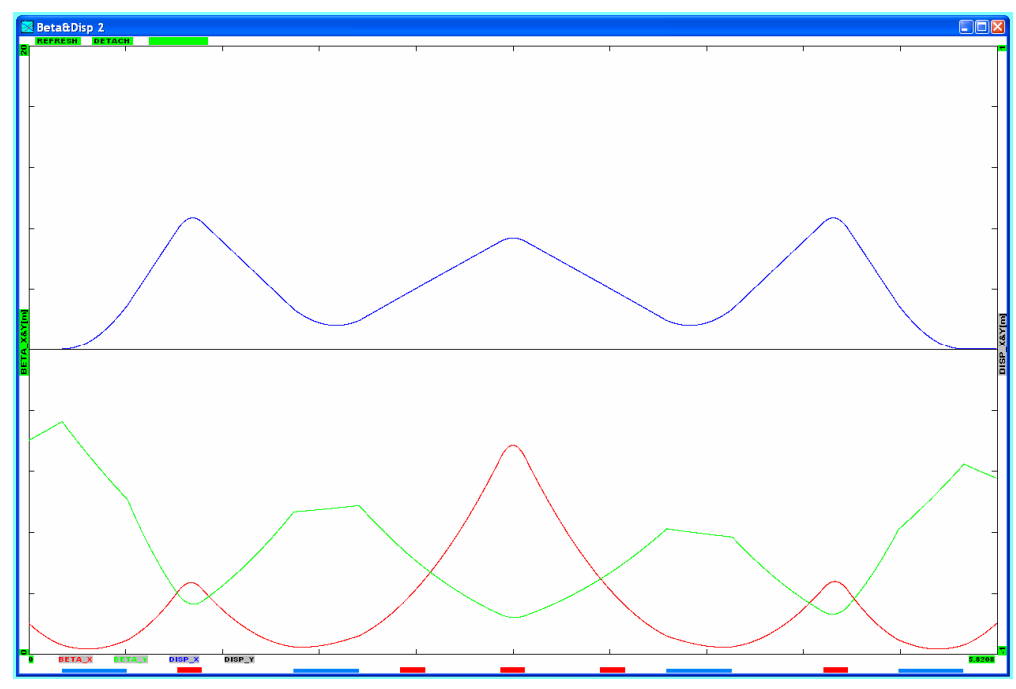

图 4.8 arc 段束包络曲线和色散函数 红色: $\beta_{x}$; 绿色: $\beta_{y}$; 蓝色: 色散

图 4.9 研究了不同 $R_{56}$ 时, Q arc1、Qarc2 和 Q arc3 磁铁调节强度范围, 图中 $R_{56}$ 从 $0.15 \mathrm{~m}$ 变化到 $0.4 \mathrm{~m}$ 时, Q $\operatorname{arc} 1$ 的 $K$ 从 $18\left(1 / \mathrm{m}^{2}\right)$ 变化到 $22\left(1 / \mathrm{m}^{2}\right)$, Q arc2 的 $K$ 从 $-2\left(1 / m^{2}\right)$ 变化到 $2\left(1 / m^{2}\right), \mathrm{Qarc} 3$ 的 $K$ 从 $10\left(1 / m^{2}\right)$ 变化到 $12\left(1 / m^{2}\right), \mathrm{Q}$ 铁强度变 化范围不是很大, 意味着束包络函数在调节 $R_{56}$ 时, 不会出现很多的增长, 横向 束包络较稳定。因此, 设计的 $\operatorname{arc}$ 结构能够实现 $R_{56}$ 大范围调节。

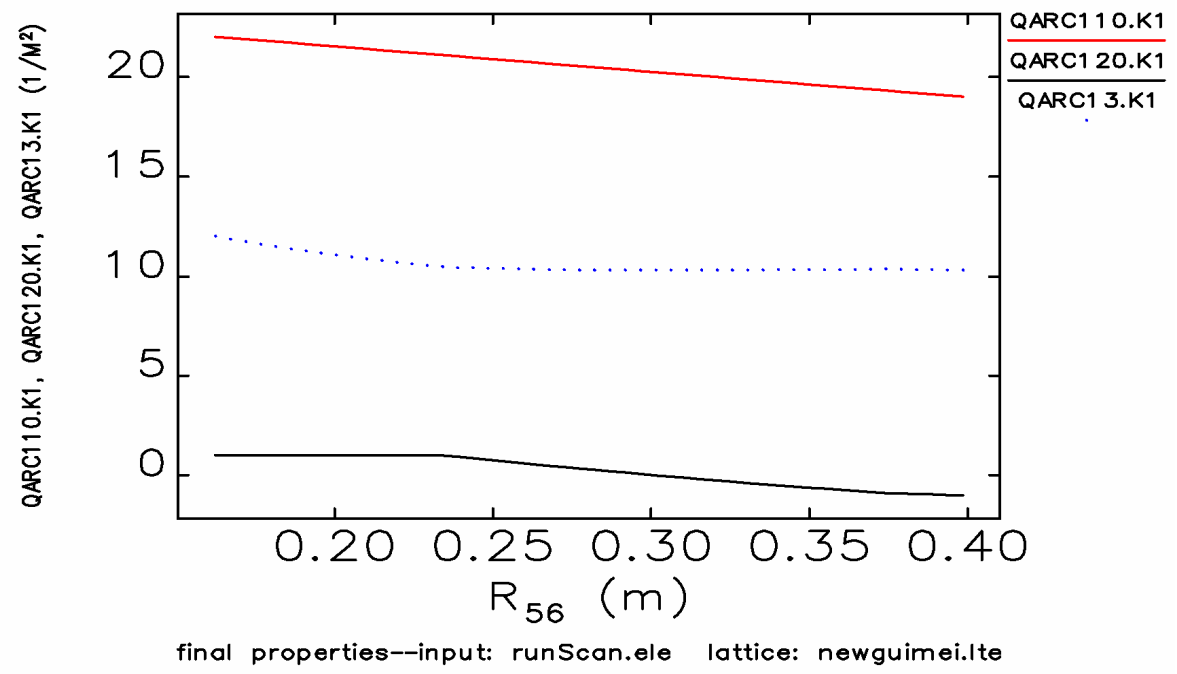

图 $4.9 \operatorname{arc}$ 段的 $R_{56}$ 调节范围研究

图 4.10 研究了不同 $R_{56}$ 时, $\operatorname{arc}$ 段的束包络曲线和色散曲线变化范围, 分别研 究取 $R_{56}=0.19 m$ （红色）, $R_{56}=0.27 m$ （蓝色）和 $R_{56}=0.33 m$ （黑色）, 结果 
表明不同 $R_{56}$ 对应最大色散值不超过 $0.6 \mathrm{~m}$, 并且束包络曲线在 arc 内随色散调节 也能够保持很好。

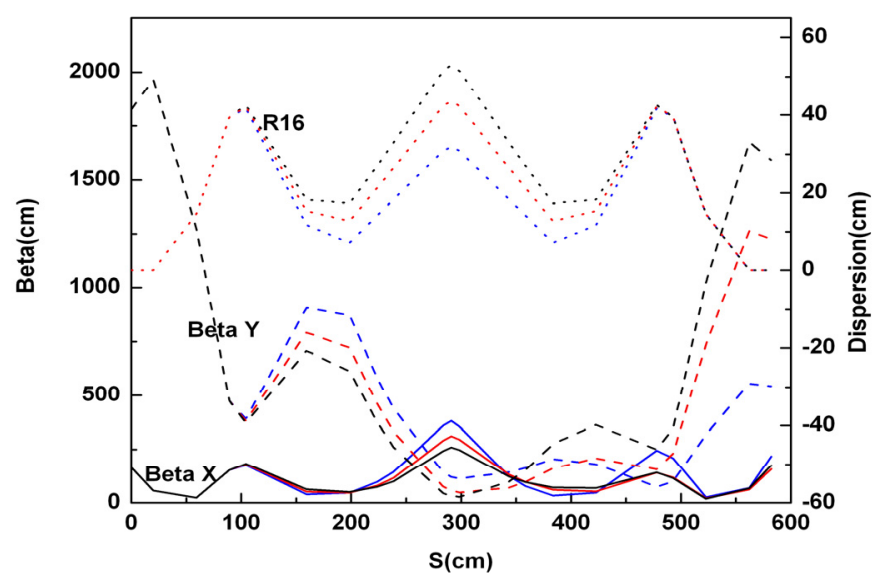

图 4.10 不同 $R_{56}$ 时, $\operatorname{arc}$ 段束包络曲线和色散函数 红色: $R_{56}=0.19 m$; 蓝色: $R_{56}=0.27 m$; 黑色: $R_{56}=0.33 m$

在 $\operatorname{arc} 2$ 处, 束流能散很大, 图 4.11 研究了束流能散从-5\%变化到 $5 \%$, 束流 中心轨道的变化范围, 从图中可以看出最大中心轨道偏离不超过 $3 \mathrm{~cm}, \operatorname{arc}$ 内 $\mathrm{x}$ 方向束包络曲线从图 4.9 得到最大约 $5 \mathrm{~m}$, 由于 beta 震荡对应的束斑不超过 $1 \mathrm{~mm}$, 因此, $\operatorname{arc} 2$ 处束管半径设计到 $4 \mathrm{~cm}$ 能够传输能散到 $5 \%$ 的束流。

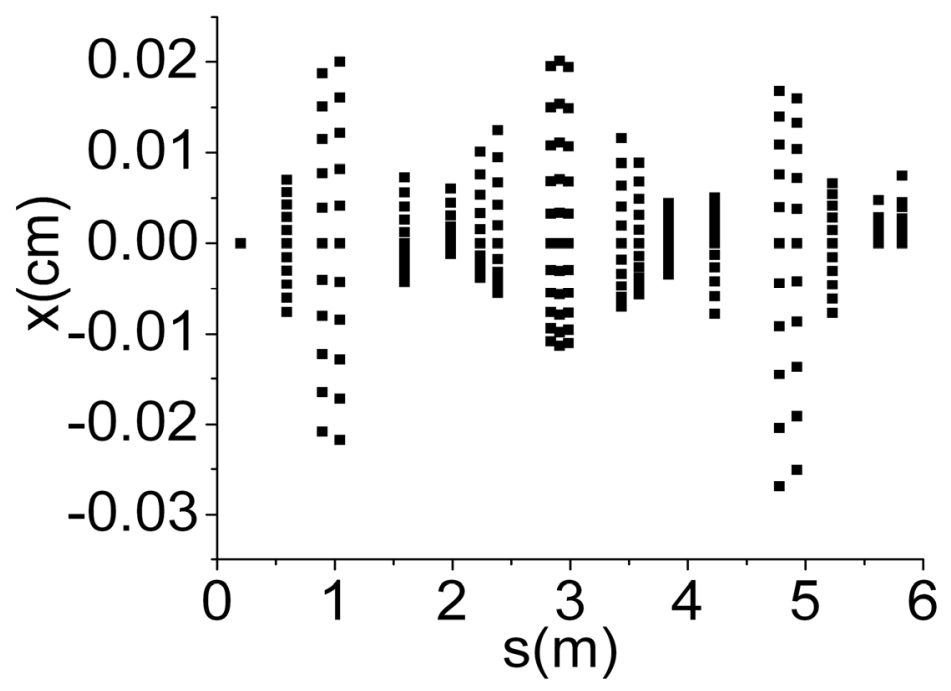

图 4.11 arc 段的动量接收度研究 


\section{5 返航束线设计}

以上研究了返航装置上束流纵向相空间的调控要求和实现的相空间调控的 束线结构, 为了同时满足横向相空间要求, 不同的调控段结构之间需要有匹配段。 图 4.12 是北京大学能量回收自由电子激光装置的束线布局图, 依次是主加速器 出口的三块磁铁结构, 匹配段 1 , $\operatorname{arc} 1$, 路径调节段, 匹配段 2 , 扭摆器、匹配 段 3, $\operatorname{arc2}$, 匹配段 4 和主加速器入口的三块磁铁结构。主加速器入口的三块磁 铁结构是合并返航的高能束流和注入的低能束流与 merger 段共用一块 B 铁, 中 间的 $\mathrm{B}$ 铁长度是两边的两倍, 偏转方向相反, 偏转角分别是 3.71 度、-7.42 度、 3.71 度, 它对束流纵向相空间传输影响较小, 其 $R_{56}=-0.007 \mathrm{~m}$; 主加速器出口 的三块磁铁结构与入口的三块磁铁结构完全相同, 它是分离加速的高能束流和能 量回收后的低能束流, 经过第一块 B 铁, 减速束流偏转 20 度, 传输到垃圾靶; 匹配段 1 和匹配段 3 是控制束流横向包络满足 $\operatorname{arc}$ 段的横向接受度要求, 匹配段 2 满足扭摆器对束流横向相空间要求, 匹配段 4 是满足主加速器的横向接受度要 求。返航束线周长是 $40.04 \mathrm{~m}$ 或 $173.5 \mathrm{RF}$ 周期, 束线长 $16.9 \mathrm{~m}$, 宽 $4.26 \mathrm{~m}$ 。表 4.3 是电子束能量是 $30 \mathrm{MeV}$ 时, 对应的返航束线上磁铁系统参数。

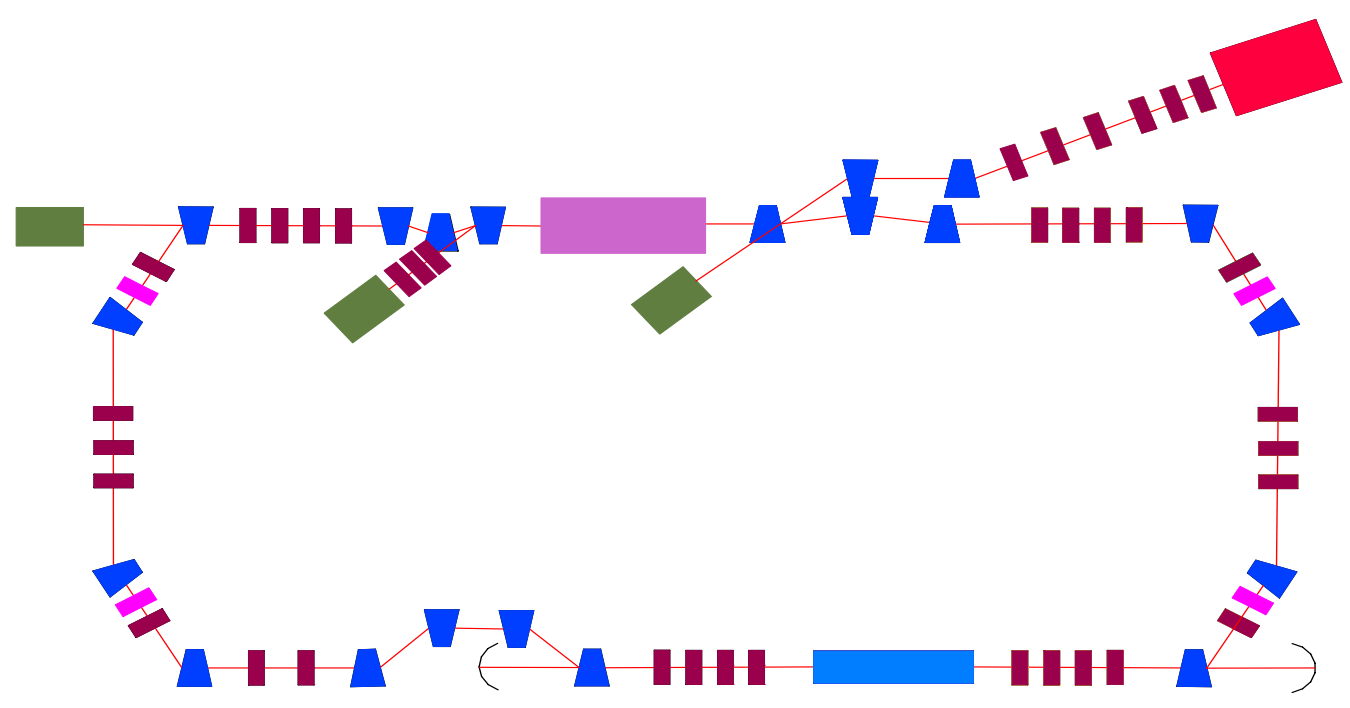

\section{DC-SCGun Quads $\triangle$ Bend Sextupole $2 \times 9$ cell Cavity Wiggler Dump Layout of PKU-ERL-FEL Lattice}

图 4.12 北京大学能量回收自由电子激光装置的束线布局图 
表 $4.330 \mathrm{Mev}$ 时返航束线磁铁系统参数

\begin{tabular}{|c|c|c|c|c|}
\hline \multicolumn{5}{|c|}{ 二极铁参数 } \\
\hline 类别 & B1 & B2 & & B3 \\
\hline 弯转角（度） & $3.71(7.42)$ & 45 & & 20 \\
\hline 个数 & $4(2)$ & 8 & & 4 \\
\hline 强度（kG） & 0.457589 & 2.03519 & & 0.870095 \\
\hline 边缘场积分常数 K1 & 0.5 & 0.5 & & 0.5 \\
\hline 束管孔径（cm） & 3.7 & $\begin{array}{l}5 @ \operatorname{arc} 1 \\
10 @ \operatorname{arc} 2\end{array}$ & & 10@chicane \\
\hline \multicolumn{5}{|c|}{ 四极铁参数 } \\
\hline 长度（cm） & 15 & \multicolumn{2}{|l|}{ 个数 } & 28 \\
\hline 场梯度范围（kG/cm） & $-0.3<\mathrm{G}<0.3$ & \multicolumn{2}{|c|}{ 束管孔径 $(\mathrm{cm})$} & $\begin{array}{c}\text { 3.7@非色散 } \\
\text { 5@arc1 } \\
10 @ \operatorname{arc2}\end{array}$ \\
\hline \multicolumn{5}{|c|}{ 最大色散参数和束包络参数 } \\
\hline $\operatorname{BetaX}(\mathrm{m})$ & 40 & Betay $(\mathrm{m})$ & \multicolumn{2}{|c|}{25} \\
\hline 色散 Dx（cm） & $\begin{array}{l}<60 @ \text { arc } \\
<80 @ \text { chicane }\end{array}$ & $\mathrm{R} 56(\mathrm{~cm})$ & & $\begin{array}{l}\text { R56<40@arc } \\
\text { K556-52@chicane }\end{array}$ \\
\hline
\end{tabular}

图 4.13 是返航装置上束包络曲线和色散曲线, 起始点是主加速器入口, 束 流能量是 $5 \mathrm{MeV}$, 加速后到 $30 \mathrm{MeV}$, 终点是主加速器出口, 束流被减速到 $5 \mathrm{MeV}$, 坐标轴单位是 $\mathrm{m}$, 束线上最大 Beta 函数约 $40 \mathrm{~m}$, 最大色散函数是 $0.8 \mathrm{~m}$, 位于扭 摆器之前, 该处能散较小, $0.4 \%$, 因此由于色散束斑增大约 $3.2 \mathrm{~mm}$ 。

下面对束斑大小进行估算。返航束线上，束流能量约 $30 \mathrm{MeV}$, 束流几何发 射度小于 $0.25 \mu \mathrm{m}$ 或归一化发射度小于 $15 \mu \mathrm{m}$, Beta 振荡对应的 $\mathrm{rms}$ 束斑不超 过 $3 \mathrm{~mm}$; 色散引起束斑的增大是在 $\operatorname{arc}$ 段和路径长度调节段, $\operatorname{arc} 1$ 和路径长度调 节段, 能散 $0.4 \%$ 时, 束斑增大分别到 $2 \mathrm{~mm}$ 和 $3.2 \mathrm{~mm}$, $\operatorname{arc} 2$ 处, 能散到 $5 \%$ 时束 斑增大到 $2.5 \mathrm{~cm}$ 。 

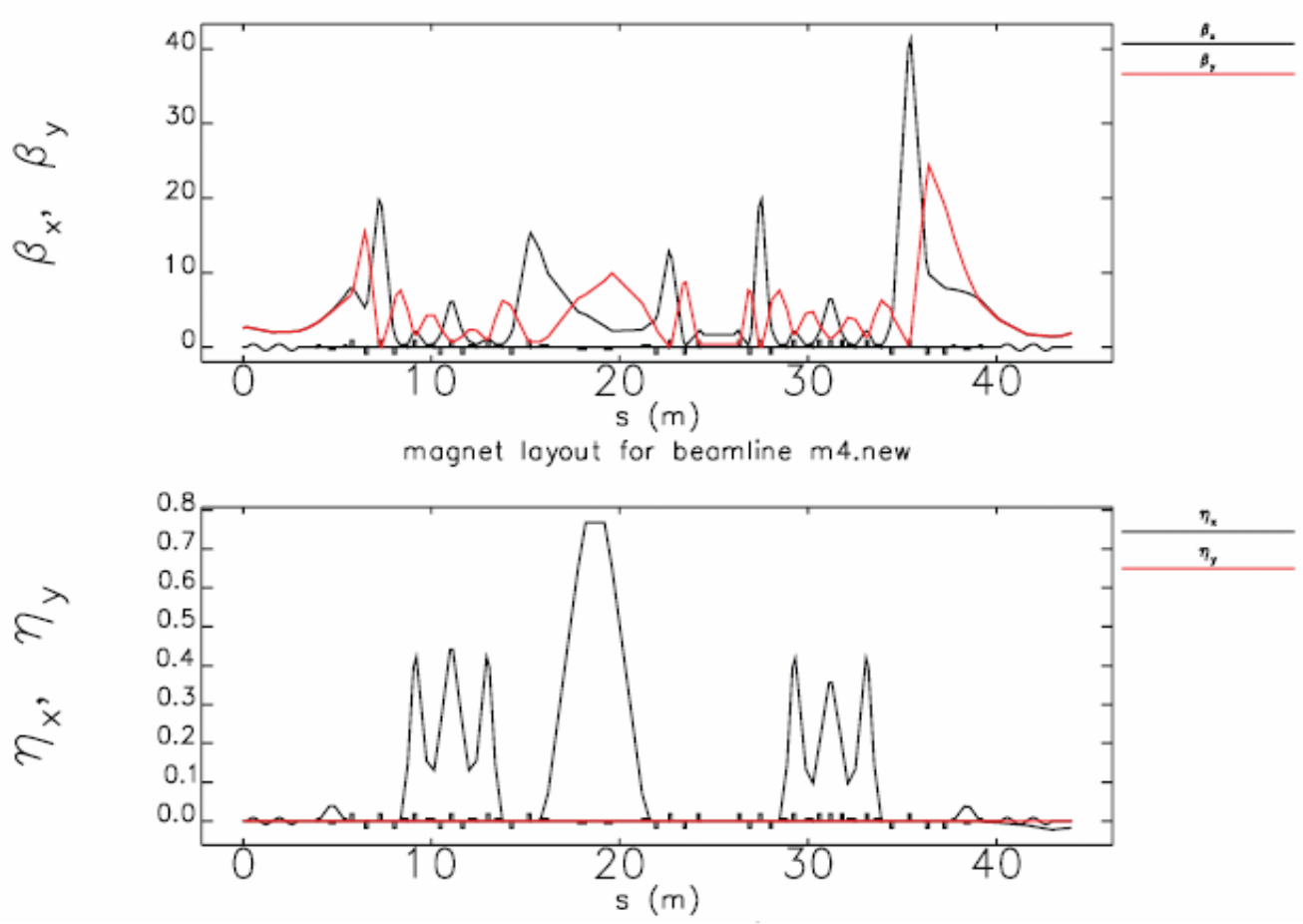

图 4.13 返航装置束包络曲线和色散曲线

\subsection{S-2-E 模拟计算}

上面完成了返航束线的光学设计，它不考虑粒子分布。

下面是用 ELEGANT 程序追踪粒子, 计算分两部分: 从主加速器入口到扭摆 器入口的束流相空间变化和扭摆器出口到主加速器出口的束流相空间变化。前者 是依据 PARMELA 输出给出粒子初始相空间分布, 后者是假设扭摆器出口的粒 子分布。

\subsection{1 主加速器到扭摆器入口的模拟计算}

束流从主加速器入口传输到扭摆器入口, 要求保持束流品质, 在扭摆器入口 束团压缩到最短。该传输段束流能散小, 能量高, 影响束流品质变坏的最重要因 素是束团压缩到很短时的相干同步辐射。 


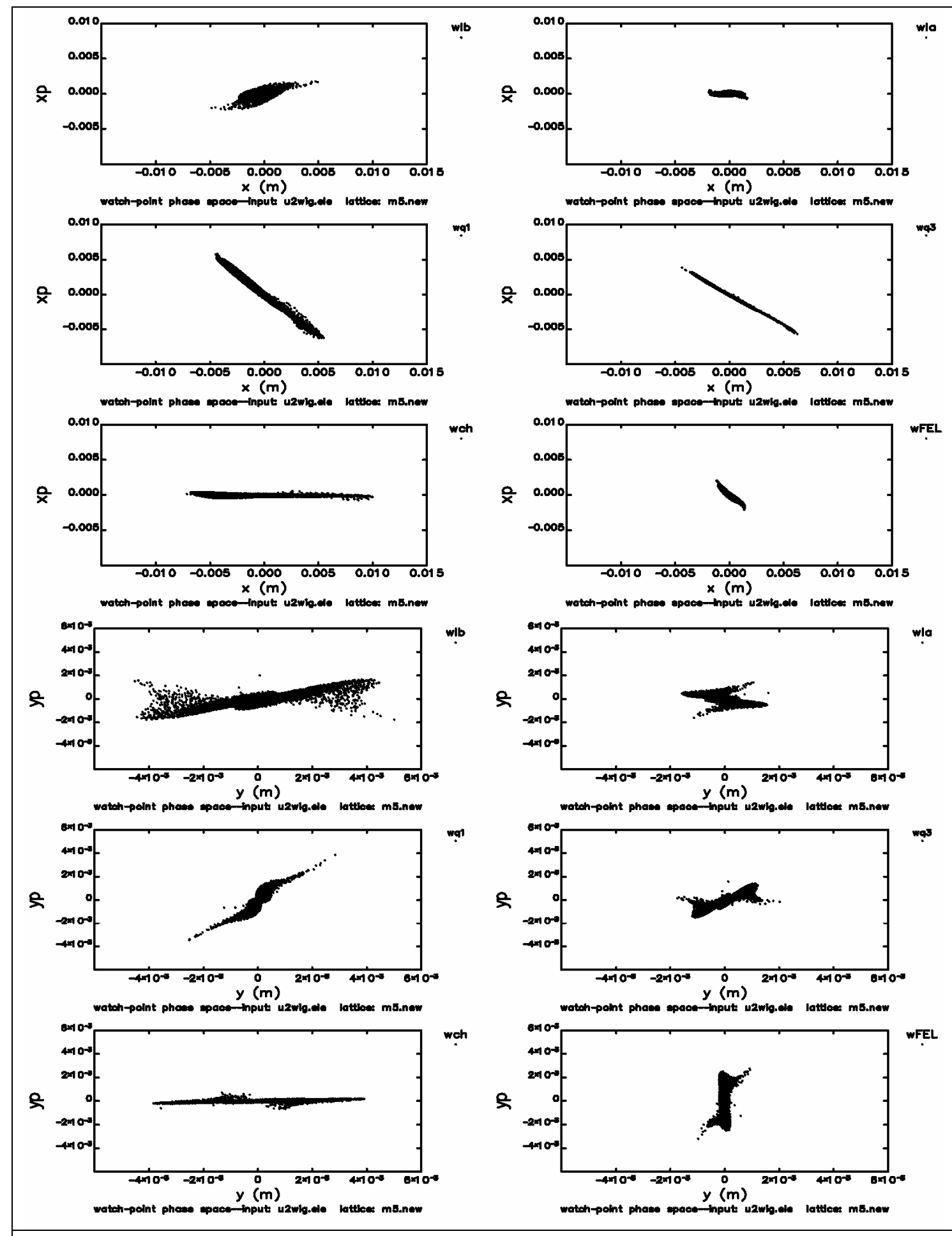

图 4.14 主加速器到扭摆器之间横向相空间变化

(wlb: 主加速器入口, wla: 主加速器之后, wq1: $\operatorname{arc1}$ 中的 Qarc1, wq3: $\operatorname{arc1}$ 中的 Qarc3, wch: chicane 中心, wFEL: 扭摆器入口)

这段传输线的 ELEGANT 输入文件见附录 2, 图 4.14 是束流横向相空间粒子 分布, 图 4.15 是束流纵向相空间粒子分布, 图中只给出几个关键点的粒子分布, wlb 表示主加速器入口, wla 表示主加速器出口, wq1 表示 $\operatorname{arc1}$ 中的 Qarc1, wq3 
表示 $\operatorname{arc1}$ 中的 Qarc3, wch 表示扭摆器之前的 chicane 中心点, wFEL 表示扭摆器 入口。

主加速器入口束流分布是 PARMELA 程序模拟计算给出的, 对应图 4.14 和 图 4.15 的 wlb, 图 4.16 给出横向 $\mathrm{rms}$ 束斑和束团长度沿束线变化曲线。 $\mathrm{x}$ 方向 $\operatorname{arc} 1$ 部分和路径长度调节段束斑较大, $\mathrm{rms}$ 值到 $4 \mathrm{~mm}$, 非色散段横向 $\mathrm{rms}$ 束斑不 超过 $2 \mathrm{~mm}$, arc1 内色散最大点对应束斑 FWHM 约 $15 \mathrm{~mm}$, 路径长度调节段最大 点对应束斑 FWHM 约 $20 \mathrm{~mm}$, 束团长度在扭摆器入口压缩到最小, $\mathrm{rms}$ 值是 $0.65 \mathrm{ps}$ 。

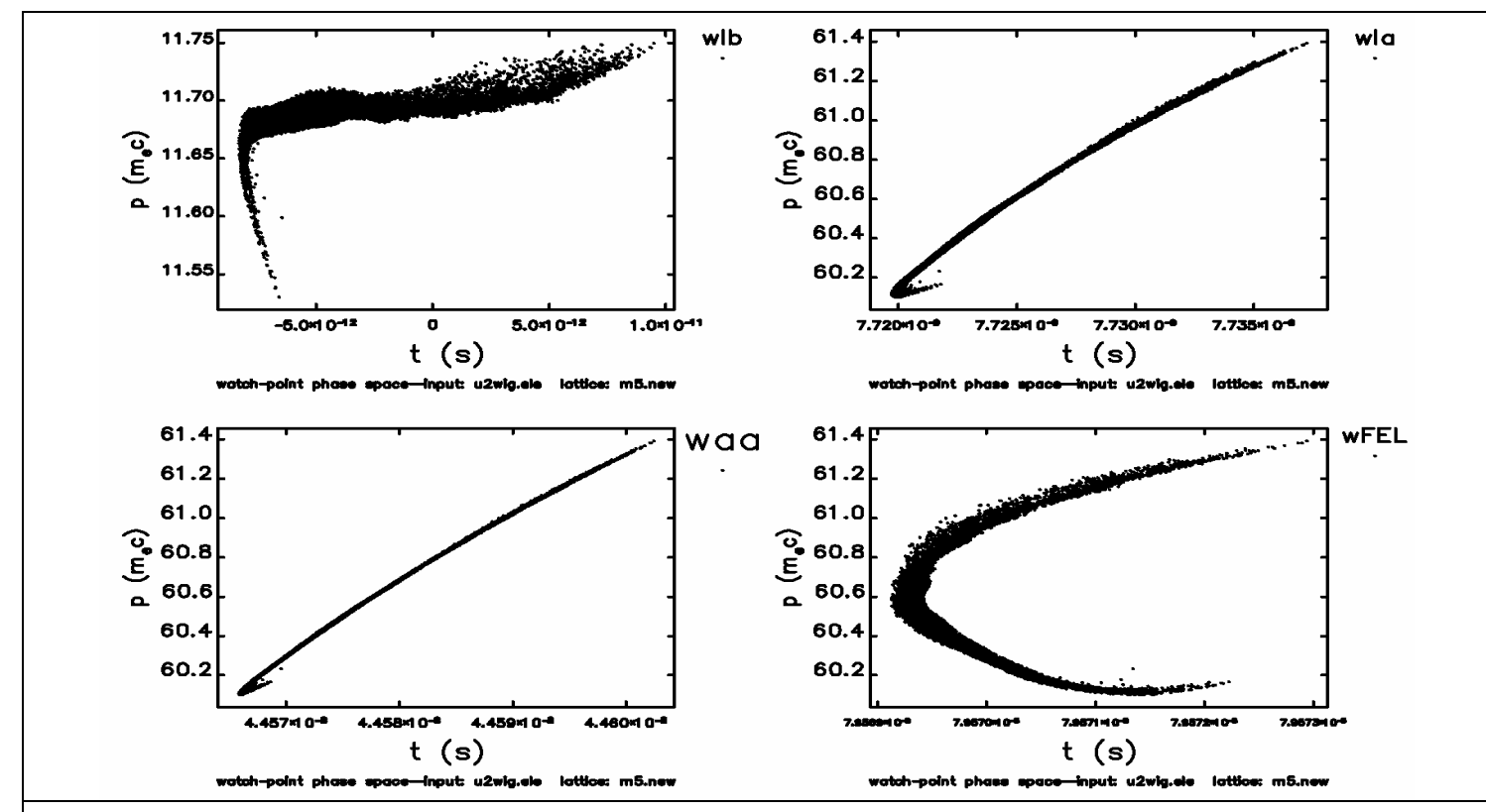

图 4.15 主加速器到扭摆器之间纵向相空间追踪

(wlb: 主加速器入口, wla: 主加速器之后, waa: arc1 出口, wFEL: 扭摆器入口)

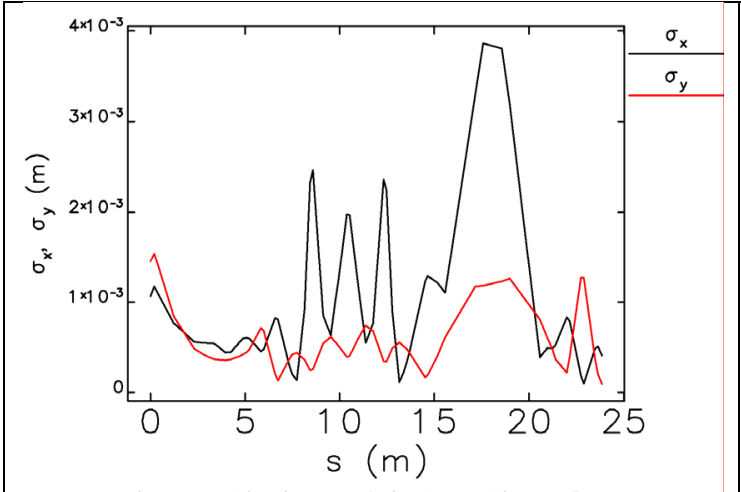

sigma matrix--input: u2wig.ele lattice: m5.new

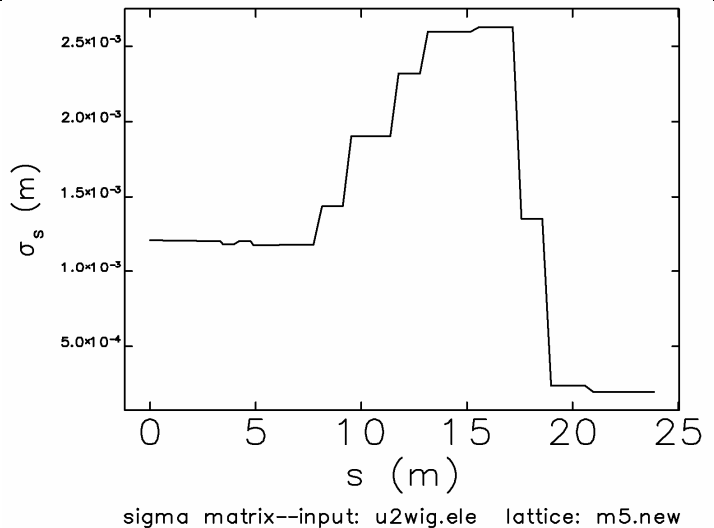

sigma matrix--input: u2wig.ele lattice: m5.new

图 4.16 主加速器到扭摆器之间束斑变化曲线和束团长度变化曲线

扭摆器之前的相干同步辐射是用程序 CSRtrack $^{[76]}$ 计算, 模拟结果表明相干 
同步辐射对能散和束团长度的影响约 $1 \%, \mathrm{x}$ 方向发射度变化小于 $5 \%, \mathrm{y}$ 方向发 射度变化小于 $1 \%$, 相干同步辐射对束流的影响可以接受。

\subsection{2 扭摆器出口到主加速器的模拟计算}

扭摆器出口束流能散较大, 高阶像差引起束流相空间畸变, 束流品质变坏。 这里考虑高阶修正, 扭摆器出口到主加速器出口的束流追踪考虑三种情况:

（1） $\mathrm{R}_{56}=0$, 即不修正 RF 减速束流引起的能散; （2） $\mathrm{R}_{56}=0.25 \mathrm{~m}, \mathrm{~T}_{566}=0 \mathrm{~m}$, 只 修正 $\mathrm{RF}$ 减速束流时引起的一阶能散变化; (3) $\mathrm{R}_{56}=0.25 \mathrm{~m}, \mathrm{~T}_{566}=5 \mathrm{~m}$, 修正 $\mathrm{RF}$ 减速束流引起的一阶和二阶能散变化。 $\mathrm{R}_{56}$ 的改变是调节 $\mathrm{Qarc} 1$ 实现, $\mathrm{T}_{566}$ 的改 变是通过调节 $\operatorname{arc} 2$ 内部的六极铁强度实现, 六极铁位于 $\operatorname{arc} 2$ 内部色散最大处。

三种情况下，扭摆器出口的粒子分布相同， RMS 能假设是 $1 \%$, FWHM 能 散约 7\%, 图 4.17 是对应的束流纵向相空间粒子分布。从图中可以看出, $\operatorname{arc} 2$ 调 控纵向相空间 $\mathrm{R}_{56}=0$ 时 (4.17 上图), 主加速器出口的能散最大, FWHM 能散 到 $40 \%$; 当 $\operatorname{arc} 2$ 匹配 RF 线性项的引起能散增大时 (4.17 中图), 主加速器出口 纵向相空间分布是抛物线形, 它是粒子减少相位不同时 RF 场引起能散增大, 此 时, 二阶效应引起的能散增大最重要, FWHM 能散到 $10 \%$; 当 $\operatorname{arc} 2$ 匹配 RF 线 性项和二阶项引起的能散时 (4.17 下图), 主加速器出口能散增大主要表现是三 阶效应, FWHM 能散到 $25 \%$ 。

扭摆器出口到主加速器出口纵向相空间调控, 必须匹配 RF 减速引起的线性 能散增大, 要求 $\mathrm{R}_{56}=0.25 \mathrm{~m}$, 控制主加速器出口的能散; 对高阶效应的考虑, 若 匹配二阶项引起的能散, 则三阶项效应相比二阶项修正为 0 时主加速器出口的剩 余 FWHM 能散更大, 这里不考虑使用十极铁修正三次项, 回收后最小能散对应 的二阶修正 $\mathrm{T}_{566}=0 \mathrm{~m}$ 。二阶修正是在 $\operatorname{arc} 2$ 内色散较大处对称放置一对六极铁, 这 里是在 Qarc1 之后。 

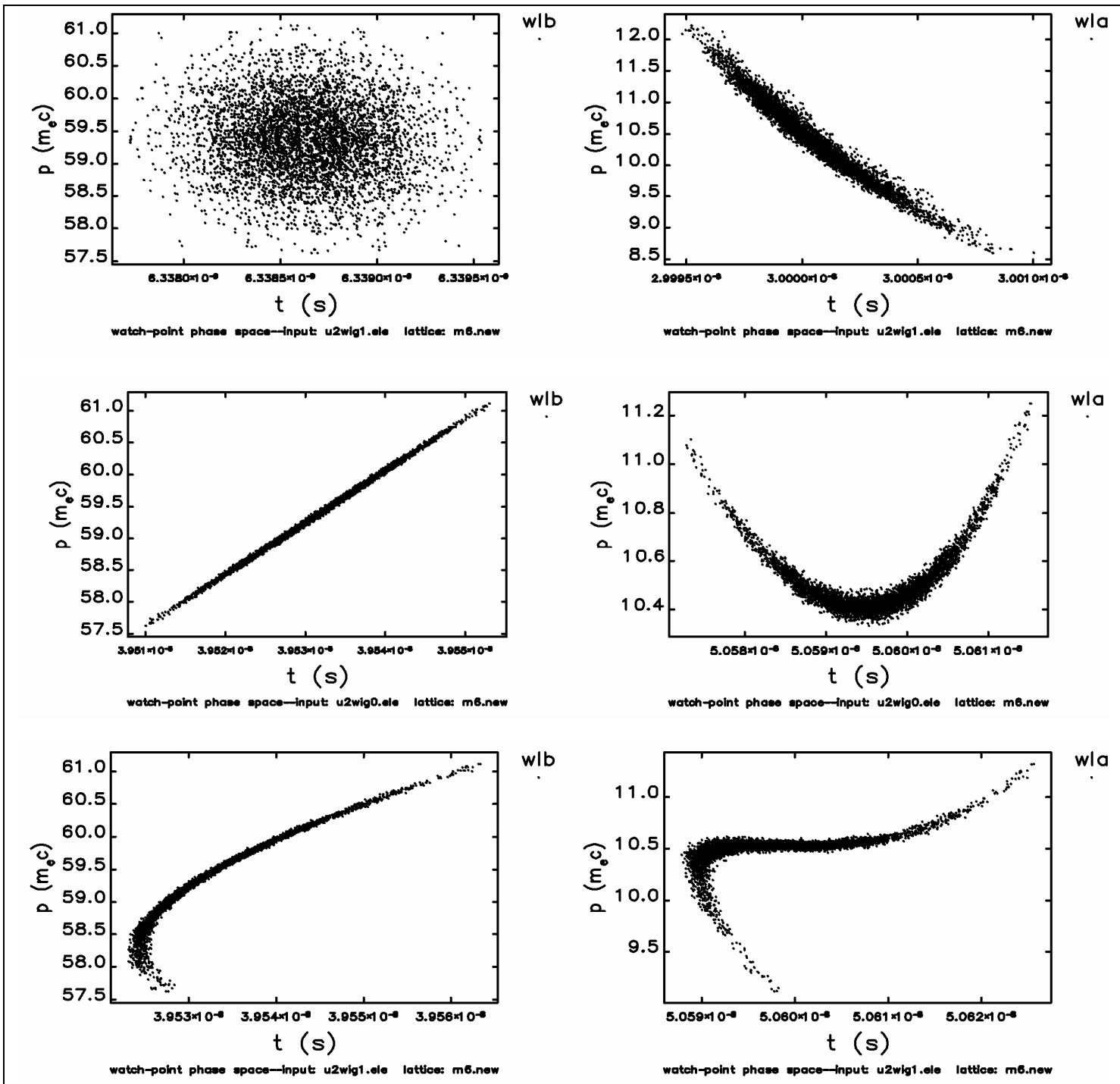

图 4.17 扭摆器到主加速器出口纵向相空间追踪

上图: $\mathrm{R}_{56}=0, \mathrm{~T}_{566}=0 \mathrm{~m}$; 中图: $\mathrm{R}_{56}=0.25 \mathrm{~m}, \mathrm{~T}_{566}=0 \mathrm{~m}$; 下图: $\mathrm{R}_{56}=0.25 \mathrm{~m}, \mathrm{~T} 566=5 \mathrm{~m}$ (wlb: 主加速器之前, wla: 主加速器之后)

图 4.18 是 $\mathrm{R}_{56}=0.25 \mathrm{~m}, \mathrm{~T}_{566}=0 \mathrm{~m}$ 时束流横向相空间粒子分布，对应的图中几 个关键点的粒子分布分别是: wFEL 表示扭摆器之后, wq1 表示 $\operatorname{arc2}$ 中的 Qarc1, wq3 表示 $\operatorname{arc} 2$ 中的 Q arc3, wm5 表示 arc2 出口, wlb 表示主加速器入口, wla 表 示主加速器出口。图 4.19 是相应横向束斑 $\mathrm{rms}$ 值和束团能散沿束线变化曲线, 束斑最大值是在 $\operatorname{arc} 2$ 内, $\mathrm{rms}$ 值是 $4 \mathrm{~mm}$ 。从相空间分布可以看出高阶效应引起 的相空间畸变不严重，色散最大处对应的束斑 FWHM 值是 $4 \mathrm{~cm}$ 。 


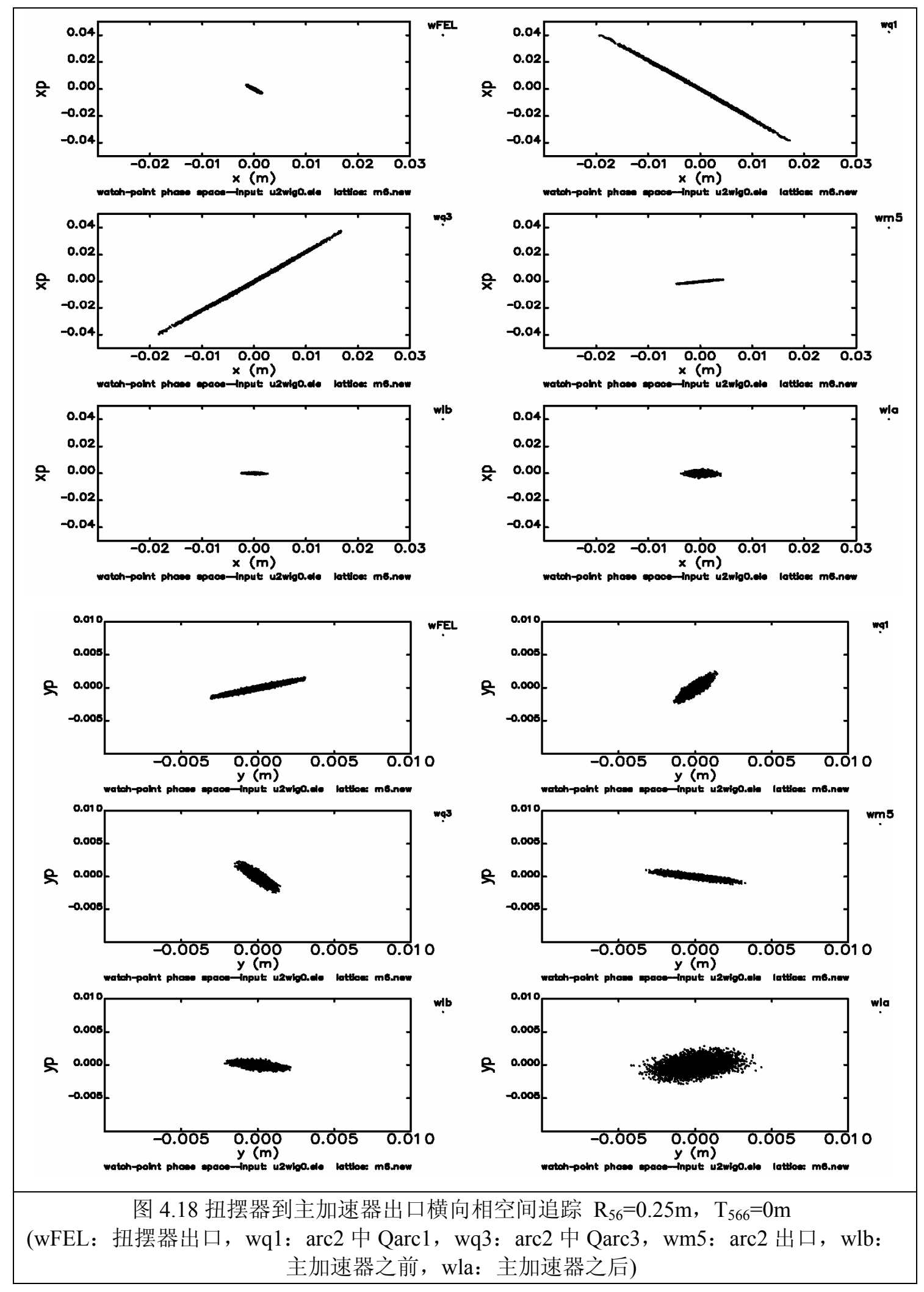

扭摆器之后束流能散大, 高阶色散项如 $\mathrm{T}_{166} 、 \mathrm{~T}_{266}$ 等对横向相空间上束流 分布的影响不可忽略, 模拟结果表明 $\mathrm{x}$ 方向归一化发射度增大 $6 \%$, y 方向归一 化发射度增大 $4 \%$ 。 


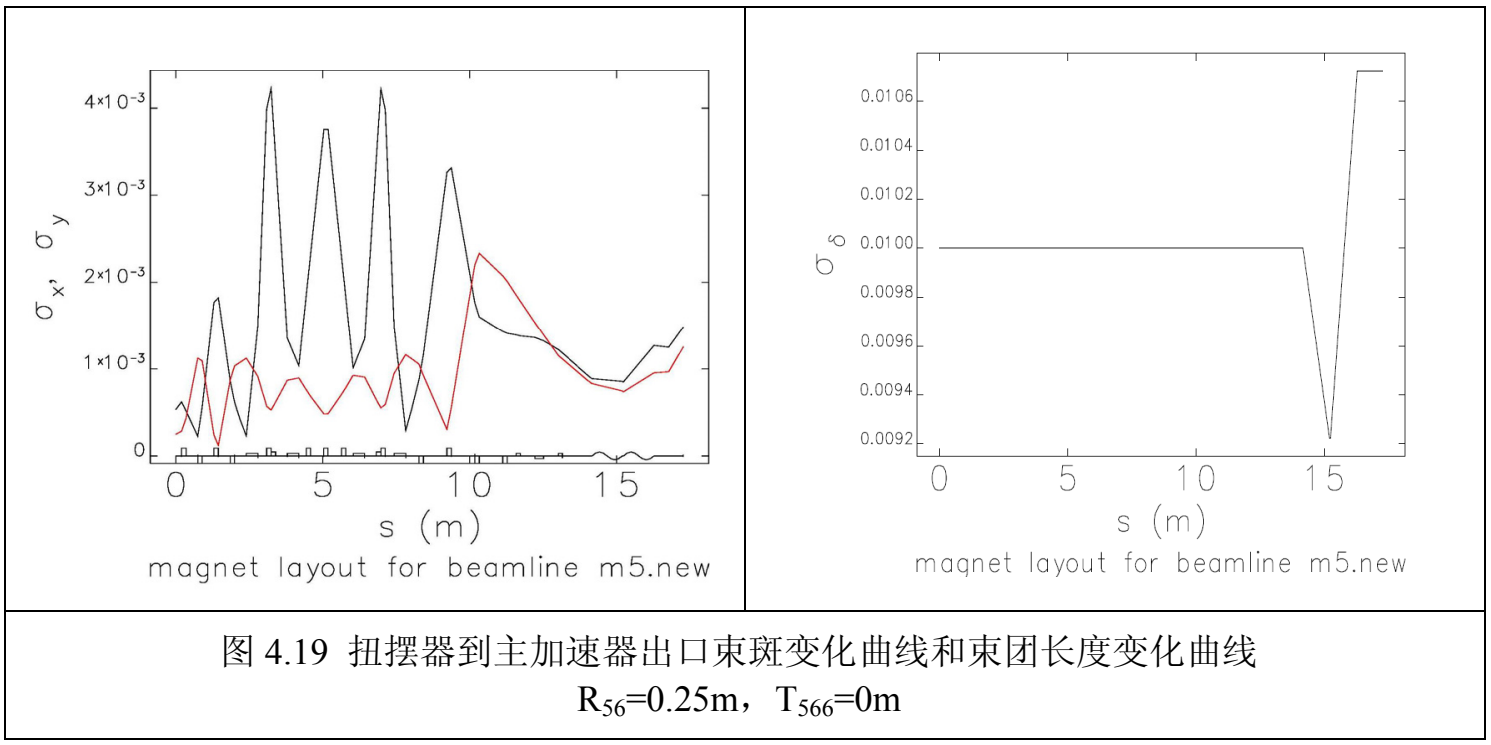

\section{7 本章小结}

本章首先研究能量回收和自由电子激光对返航束线的结构要求, 理论分析扭 摆器入口电子束与光腔激光基模匹配时束流横向相空间分布, 结合机器参数, 给 出具体要求, 并对返航束线路径长度调节范围进行分析, 考虑准直误差和 FEL 作用，返航束线路径可调范围要大于 \pm 13 度的 $R F$ 相位。

推导了纵向相空间的调控理论, 研究主加速器出口到扭摆器之间实现的束团 压缩条件, 给出加速相位与磁压缩系统参数的关系; 研究了扭摆器之后到主加速 器之间的束输运在主加速器实现能散压缩条件以及减速相位与磁压缩系统参数 的关系, 并对 RF 场引起的能量-位置高阶关联进行研究, 给出相应的匹配关系。

结合机器参数, 粒子在主加速器中加速相位是-10 度; 匹配纵向相空间线性 关联要求主加速器到扭摆器之间的 $R_{56}=-0.25 m$, 使扭摆器入口束团长度压缩到 最短; 能量回收要求束流在主加速器中的减速相位是 170 度, 为匹配纵向相空间 线性关联, 实现主加速器中能散的压缩, 要求扭摆器出口到主加速器之间 $R_{56}=0.25 \mathrm{~m}$ 。

根据上述理论结果，设计了路径长度可调的磁结构，调整范围到 \pm 18 度。 提出了对称消色散 $\operatorname{arc}$ 结构设计，它的优点是色散调节与 $R_{56}$ 调节由不同的四极 铁分别控制, 实现 $R_{56}$ 大范围可调, 满足了上述要求。 $\operatorname{arc} 1$ 和 $\operatorname{arc} 2$ 采用相同的几 何结构, 束线在满足的路径调节的同时, 通过改变 $\operatorname{arc} 1$ 的 $R_{56}$, 与扭摆器前的 chicane 结合可以实现扭摆器之前获得最短的束团, 结合 PARMELA 程序计算, 用 elegant 程序追踪返航束线粒子的相空间分布表明：扭摆器之前束团压缩长度 
最短到 $0.65 \mathrm{ps}$, 束斑最大点是在 $\operatorname{arc} 1$ 内和扭摆器之前的 chicane 磁结构内, FWHM 约 $2 \mathrm{~cm}$; 调节 $\operatorname{arc} 2$ 的 $R_{56}$ 能够在主加速器中对能量回收束团实现能散压缩; 分析 了偏离峰值减速时 RF 引起的能散变化, 对比一阶不修正、一阶修正和二阶修正 时加速出口对应的能散, 结果表明加速器出口能散最小时扭摆器出口到主加速器 入口束线满足 $\mathrm{R}_{56}=0.25 \mathrm{~m}, \mathrm{~T}_{566}=0 \mathrm{~m}$, 束斑最大在 $\operatorname{arc} 2, \mathrm{FWHM}$ 约 $4 \mathrm{~cm}$, 主加速 器出口的束流能散 FWHM 约 $10 \%$, 扭摆器之后束斑最大在 $\operatorname{arc} 2$, FWHM 约 $4 \mathrm{~cm}$ 。 束流动力学的研究包括扭摆器前后的 CSR 和高阶像差的影响, 结果表明这些效 应的影响都在可接受范围。 



\section{第五章＼cjkstart轨道校正系统优化设计和系统稳健性研究}

本章将优化设计返航束线的轨道校正系统, 并对返航系统的稳健性 （robustness）进行研究。轨道校正系统优化的目标是把由于各种误差引起的束 流轨道偏离控制在可接受范围。主要工作包括误差的理论分析及 kick 的位置和 大小对束流光学的影响。使用解析计算方法优化校正磁铁（Corrector）和束流位 置监测计 (BPM) 的位置和个数, 使得轨道校正系统的安排最有效, 最经济; 用 elegant 程序追踪计算, 进一步验证解析计算方法设计轨道校正系统的可靠性。 本章第二部分对系统的稳健性进行研究, 考虑实际机器各种误差的影响, 它包括 三部分: 研究有束流光学失配和电源抖动误差时, 传输线的光学敏感度, 这类误 差是随机的, 不可校正; 研究磁铁有系统安装误差时, 匹配段四极铁和调控色散 和 $R_{56}$ 的四极铁需要调节的范围, 这类误差可校正, 四极铁的调节范围反映系统 应对各种误差的能力; 研究四极铁的准直误差和二极铁绕纵轴旋转误差对色散的 影响，这类误差在设计中没有可调节磁铁，不可校正。

\section{1 误差简介}

束线上的元件误差根据磁场阶数划分为二极场误差、四极场误差、六极场误 差等, 其中对线性光学有影响的是二极场误差和四极场误差, 即 kick 误差和场 梯度误差，六极场误差影响系统的高阶光学。

二极场误差引起束团的横向偏角整体改变, 中心位置瞬间没有改变, 即束团 瞬间感受到横向冲击（kick），但在接下来的束线上，横向偏角和中心位置的变 化遵从束流光学矩阵传输, 横向偏角的改变使得束流中心偏离系统中心轨道。 kick 误差的来源有二极铁磁场强度误差和四极铁准直误差。二级铁电源抖动直 接反应二级铁磁场的改变 $\delta B$; 对四极铁, 若准直误差为 $\delta x$, 束团中心在 $\delta x$ 处 感受到横向 kick, 对应的二极场误差为 $\delta B=G^{*} \delta x, G$ 是四级铁场梯度。磁场 误差 $\delta B$ 对束流的 kick 引起发散角的改变是 $\delta x^{\prime}=\delta B l /(B \rho), l$ 为元件长度, $B \rho$ 是磁刚度, 对单电子或电荷量为 $\mathrm{Ze}$ 的粒子, 常表示为 $B \rho[\mathrm{Tm}]=\frac{m v}{Z e}=\left\{\begin{array}{l}3.3357 p[\mathrm{GeV} / \mathrm{c}] \\ \frac{3.3357}{Z} p[\mathrm{GeV} / \mathrm{c}]\end{array}, \quad \mathrm{p}\right.$ 是粒子的动量。 
单个二极场误差对束流横向位置的影响可以由 kick 到束线尾部的传输矩阵 $M_{12}$ 表示为 $^{[77]}$

$$
x=M_{12}^{k i c k \rightarrow \text { end }} x^{\prime}
$$

假如束线上 $N$ 个位置有很小的 kick 误差, 它们对束流影响的累计效果可以 线性叠加

$$
x=\sum_{n=1}^{N} M_{12}^{n \rightarrow \text { end }} x_{n}^{\prime}
$$

其中 $M_{12}^{n \rightarrow \text { end }}=\sqrt{\beta_{n} \beta_{\text {end }}} \sin \varphi^{n \rightarrow \text { end }}$ 。 kick 误差对束线的影响效果取决于误差所在点 和观测点的束包络以及它们之间的相位超前, 束包络较小或 $\sin \varphi^{n \rightarrow e n d}$ 接近 0 时, 误差对观测点的影响不明显。

束线上, 校正磁铁是改变束流轨道的偏角, 与 kick 误差对束流影响相同。 根据以上分析, 系统中使用 corrector 校正束流轨道和 BPM 测量束流轨道时, BPM 和 corrector 都会选择在 Beta 值较大处，校正磁铁和位置监测计之间的相位超前 选择也尽量接近 90 度, 使得 $\sin \varphi^{n \rightarrow \text { end }}$ 接近 1 , 这样, 校正磁铁的校正效果最好, BPM 对校正磁铁的监测最敏感，这是 BPM 和 corrector 在束线上的放置原则。

若束线上有 $N$ 个误差，它们对束流的影响可以平均得到

$$
<x>=\sqrt{\frac{N}{2}}-\beta<x>
$$

$\bar{\beta}$ 是束线上束包络函数的平均值。通过以上表达式可以粗略估算二极场误差引起 的束斑增大。

场梯度误差会引起聚焦的变化, 导致束包络函数和色散函数 $\eta$ 的改变。场梯 度误差 $\delta B^{\prime}$ 对聚焦长度的影响为 $\delta(1 / f)=\delta B^{\prime} l /(B \rho)$ 。

以下计算场梯度误差对各个参数的影响。理想束线, 从元件 $\mathrm{n}$ 到观测点 $\mathrm{end}$ 的传输矩阵为

$$
M_{\text {design }}^{n \rightarrow \text { nd }}=\left[\begin{array}{cc}
\sqrt{\frac{\beta_{\text {end }}}{\beta_{n}}\left(\cos \varphi+\alpha_{n} \sin \varphi\right)} & \sqrt{\beta_{n} \beta_{\text {end }}} \sin \varphi \\
-\frac{1+\alpha_{n} \alpha_{\text {end }}}{\sqrt{\beta_{n} \beta_{\text {end }}}} \sin \varphi+\frac{\alpha_{n}-\alpha_{\text {end }}}{\sqrt{\beta_{n} \beta_{\text {end }}}} \cos \varphi & \sqrt{\frac{\beta_{n}}{\beta_{\text {end }}}}\left(\cos \varphi-\alpha_{\text {end }} \sin \varphi\right)
\end{array}\right]=\left[\begin{array}{ll}
M_{11} & M_{12} \\
M_{21} & M_{22}
\end{array}\right]
$$


其中, $\varphi$ 是 $\mathrm{n}$ 到束线尾部的 phase advance, $\alpha$ 和 $\beta$ 分别是对应元件 $\mathrm{n}$ 点和 end 点的 twiss 参数。

若元件 $\mathrm{n}$ 处有场梯度误差, 则传输矩阵变成

$$
M_{\text {error }}^{n \rightarrow \text { end }}=M_{\text {design }}^{n \rightarrow \text { end }}\left[\begin{array}{ll}
1 & 0 \\
\delta & 0
\end{array}\right]=\left[\begin{array}{ll}
M_{11}+M_{12} \delta & M_{12} \\
M_{21}+M_{22} \delta & M_{22}
\end{array}\right]
$$

Twiss 参数的传输方程是

$$
\begin{gathered}
\beta=M_{11}^{2} \beta_{0}-2 M_{11} M_{12} \alpha_{0}+M_{12}^{2} \gamma_{0} \\
\alpha=-M_{11} M_{21} \beta_{0}+\left(M_{11} M_{22}+M_{12} M_{21}\right) \alpha_{0}-M_{12} M_{22} \gamma_{0}
\end{gathered}
$$

公式 (5.5) 代入 (5.6) 和 (5.7) , 可以计算由于误差引起 twiss 参数的变化。 类似的根据色散传输矩阵

$$
\left(\begin{array}{c}
\eta \\
\eta^{\prime} \\
1
\end{array}\right)=\left[\begin{array}{ccc}
M_{11} & M_{12} & M_{16} \\
M_{21} & M_{22} & M_{26} \\
0 & 0 & 1
\end{array}\right]\left[\begin{array}{c}
\eta_{0} \\
\eta_{0}^{\prime} \\
1
\end{array}\right]
$$

可以得到误差对色散的影响。

$$
\begin{aligned}
& \frac{\Delta \beta}{\beta^{\text {end }}}=-\delta(1 / f) \beta^{\text {error }} \sin 2 \varphi^{\text {error } \rightarrow \text { end }} \\
& \Delta \alpha=\delta(1 / f) \beta^{\text {error }}\left(\cos 2 \varphi^{\text {error } \rightarrow \text { end }}-\alpha^{\text {end }} \sin 2 \varphi^{\text {error } \rightarrow \text { end }}\right) \\
& \Delta \varphi=\frac{1}{2 \pi} \delta(1 / f) \beta^{\text {error }}\left(\sin \varphi^{\text {error } \rightarrow \text { end }}\right)^{2} \\
& \Delta \eta=-\delta(1 / f) \eta^{\text {error }} \sqrt{\beta^{\text {error }} \beta^{\text {end }}} \sin \varphi^{\text {error } \rightarrow \text { end }}
\end{aligned}
$$

从上式可以看出场梯度误差对束包络的影响大小与它所在点的 Beta 函数有关, Beta 函数越大, 影响越大。场梯度误差对色散的影响大小除了与 Beta 函数有关 外, 还与它所在点的色散函数有关, 色散函数越大, 色散的改变也越大。

$\mathrm{N}$ 个不同的误差叠加并平均可以得到

$$
\begin{aligned}
& <\frac{\Delta \beta}{\beta}>=\sqrt{\frac{N}{2}}-\bar{\beta}\langle\delta(1 / f)> \\
& <\Delta \alpha>=\sqrt{\frac{N}{2}}-\bar{\beta}<\delta(1 / f)> \\
& <\Delta \varphi>=\frac{1}{4 \pi} \sqrt{\frac{3 N}{2}}-\bar{\beta}\langle\delta(1 / f)> \\
& <\Delta \eta>=\sqrt{\frac{N}{2}}-\bar{\eta}<\delta(1 / f)>
\end{aligned}
$$


二极场误差影响束流轨道, 需要使用轨道校正系统。四极场误差影响束流光 学, 将研究系统对误差的敏感度分析等。

\section{2 轨道校正系统优化设计}

当传输元件有误差时, 束流横向偏角增长, 进而引起束流中心偏离、束包络 函数和色散函数变化, 因此, 必须加入轨道校正磁铁修正束流中心轨道, 限制束 流中心轨道在可接受范围, 同时, 还需要 BPM 测量束流中心位置, 它和校正系 统形成反馈系统, 用来监测校正系统的效果。轨道校正磁铁和束流位置监测计共 同组成轨道校正系统。

北京大学返航束线上使用的传输元件是二极铁和四极铁, 轨道校正系统考虑 的误差来源有束流注入轨道误差、四极铁误差、二级铁误差和束流位置监测计误 差, 表 5.1 列出各种误差的 RMS 值, 这是加速器系统所要求的一般指标。

表 5.1 北京大学传输系统误差要求

\begin{tabular}{|c|c|c|}
\hline \multirow{2}{*}{ 束流注入误差 } & 束流位置误差 & $0.5 \mathrm{~mm}$ \\
\cline { 2 - 3 } & 束流偏角误差 & $0.025 \mathrm{mrad}$ \\
\hline 四极铁误差 & 准直误差 & $0.2 \mathrm{~mm}$ \\
\hline \multirow{2}{*}{ 二极铁误差 } & 场强误差 $(\Delta B / B)$ & $0.02 \%$ \\
\cline { 2 - 3 } & 绕纵轴旋转误差 & $1 \mathrm{mrad}$ \\
\hline 束流位置监测计误差 & 准直误差 & $0.25 \mathrm{~mm}$ \\
\hline
\end{tabular}

根据这些指标，对返航束线的校正系统进行优化设计，优化的目标是保证经 过校正磁铁校正后束流中心轨道在可接受范围, 同时使用尽可能少的轨道校正磁 铁和束流位置监测计数目, 以降低束线成本, 这里设计要求束流中心轨道偏离系 统中心 $2 \mathrm{~mm}$ 以下。

常用的轨道校正系统优化方法有两种: 解析计算方法和粒子追踪方法, 这里 先采用 Yu-Chiu Chao 编写的解析计算方法 ${ }^{[78]}$ 设计并优化轨道校正系统（该解析 计算方法成功地设计了 CERN 的 Large Hardron Collider Project ${ }^{[79]}$ 和 Jefferson Lab 的 $6 \mathrm{GeV} \mathrm{CEBAF}^{[80]}$ 机器的轨道校正系统), 然后用 ELEGANT 程序追踪粒子, 验证用解析计算方法所设计的轨道校正系统的合理性和可靠性。

解析计算方法相比粒子追踪设计轨道校正系统的主要优势有以下几点：(1) 
粒子追踪方法单次追踪只能分析一种误差组合分布, 若要求轨道校正系统能涵盖 所有可能的误差组合, 需要追踪的次数很多, 计算时间很长, 而解析计算方法只 需要计算一次; （2）粒子追踪方法在回答校正系统是否合理很被动, 它不能清 楚的给出校正系统结构的缺陷以及如何改进, 但解析计算方法可以清楚分析校正 系统的结构的缺陷以及可能改进的措施, 如它能分析校正磁铁是否过多或过少以 及校正磁铁是否有效校正束流轨道, 能分析束流位置监测计位置是否合理, 是否 有束流中心轨道较大而没有观测到的情况或束流位置监测计所在位置处不能有 效的响应校正磁铁的校正效果，分析束流位置监测计是否过多或过少等; 解析计算方法能给出误差组合最坏情况下对应的束流中心轨道; (4) 解析计算 方法给出所有误差组合下校正磁铁的强度范围。图 5.1 是解析计算方法给出的校 正后的束流中心轨道, 从图中可以看出束线中部缺少束流位置监测计, 束流中心 轨道虽然偏离很大但 BPM 没有观测到, 这样的位置称为 “盲点” ，根据束流中 心轨道分布可以增加或移动 BPM，进一步优化校正系统。

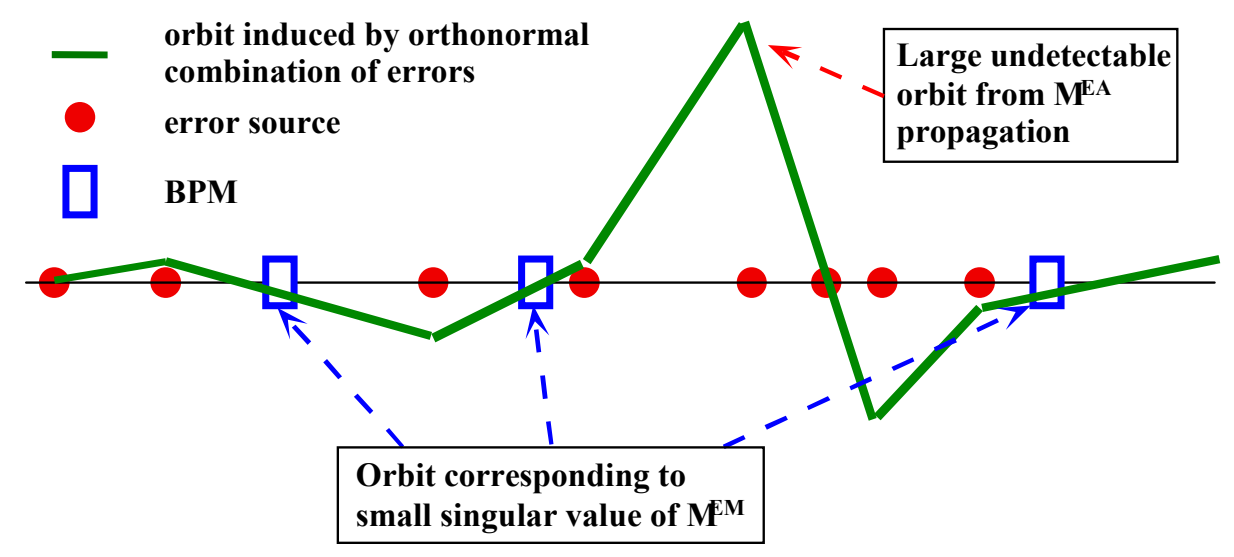

图 5.1 解析计算方法分析轨道校正系统结构缺陷

\subsection{1 解析计算方法及轨道校正系统优化设计}

实际机器运行时, 不能像模拟计算知道束线各点的中心轨道, 轨道校正系统 是通过放置有限个校正磁铁和束流位置监测计, 实现束线各点束流中心轨道偏离 系统中心的范围可接收。

束线元件误差或校正磁铁沿束线改变束流中心轨道的大小是由它们之间的 传输矩阵决定，束流轨道改变的来源称为激励源 A ( “actuators”)，束流中 心轨道的监测称为响应点 R ( “responders”) , “actuators” 和 “responders” 之间的关联传输矩阵称为响应矩阵 “response matrix”，即 


$$
\left(\begin{array}{c}
R^{1} \\
R^{2} \\
\vdots \\
R^{n}
\end{array}\right)=\left(\begin{array}{cccc}
C^{11} & C^{12} & \cdots & C^{1 m} \\
C^{21} & C^{22} & \ddots & C^{2 m} \\
\vdots & \ddots & \ddots & \vdots \\
C^{n 1} & C^{n 2} & \cdots & C^{n m}
\end{array}\right) \cdot\left(\begin{array}{c}
A^{1} \\
A^{2} \\
\vdots \\
A^{m}
\end{array}\right)
$$

激励源有元件误差和校正磁铁, 响应点有 BPM 或束线任意点。当激励源是 correctors, 响应点是 BPMs 时, 响应矩阵就是轨道校正系统传输矩阵, 利用该矩 阵可以优化 corrector 的强度, 使得 BPM 观察到的束流中心轨道限制在可接受范 围内。

束线上的激励源分为三类: (1) correctors; (2) 束线误差, 如注入束流位 置偏离、准直误差、磁铁误差; (3) 束线上所有元件, 它们将改变和决定传输 矩阵。响应点分为两类: (1) BPM; (2) 束线所有元件。用 $\mathrm{E}$ 表示准直误差, $\mathrm{C}$ 表示 corrector、二极铁或二极导向磁铁等改变轨道偏角的激励源, $\mathrm{A}$ 表示所有 元件, $\mathrm{M}$ 表示 BPM。

在 BPM 上观测到准直误差的影响可以表示为

$$
R^{M}=M^{E M} \cdot A^{E}
$$

在束线所有元件上观测到准直误差的影响可以表示为

$$
R^{A}=M^{E A} \cdot A^{E}
$$

在 BPM 上观测到 corrector 的影响可以表示为

$$
R^{M}=M^{C M} \cdot A^{C}
$$

在束线所有元件上观测到 corrector 的影响可以表示为

$$
R^{A}=M^{C A} \cdot A^{C}
$$

轨道校正所需要的 corrector 的强度是满足 $\left|R^{A}-M^{C A} \cdot A^{C}\right|^{2}$ 极小。

通过响应矩阵 $M^{C M}$ 的伪逆矩阵 $M_{C M}^{\dagger},(5.14)$ 表示为

$$
A^{C}=M_{C M}^{\dagger} \cdot R^{M}
$$

$M_{C M}^{\dagger}=\left(M_{C M}^{T} M_{C M}\right)^{-1} M_{C M}^{T}$, 该方程要求 corrector 的个数小于 BPM 的个数, 即未 知数小于条件数, corrector 的强度不是唯一确定, 假设 $M^{C M}$ 是 $M \times N$ 矩阵, 则 $M>N$, 伪逆矩阵 $M_{C M}^{\dagger}$ 是 $N \times M$ 矩阵, 通过 SVD( singular value decomposition) ${ }^{[81,82]}$ 方法分解矩阵 $M^{C M}$ 到 corrector 矢量向空间和 BPM 的矢量向空间 


$$
\begin{aligned}
& M_{C M}=U \Sigma V^{T} \\
& =\left(\begin{array}{cccc}
u_{1}^{1} & u_{1}^{2} & \cdots & u_{1}^{N} \\
u_{2}^{1} & u_{2}^{2} & \cdots & u_{2}^{N} \\
\vdots & \vdots & & \vdots \\
u_{M}^{1} & u_{M}^{2} & \cdots & u_{M}^{N}
\end{array}\right)\left(\begin{array}{llll}
\delta_{1} & & & \\
& \delta_{2} & & \\
& & \ddots & \\
& & & \delta_{N}
\end{array}\right)\left(\begin{array}{cccc}
v_{1}^{1} & v_{2}^{1} & \cdots & v_{N}^{1} \\
v_{1}^{2} & v_{2}^{2} & \cdots & v_{N}^{2} \\
\vdots & \vdots & & \vdots \\
v_{1}^{N} & v_{2}^{N} & \cdots & v_{N}^{N}
\end{array}\right)
\end{aligned}
$$

其中, $U$ 是 $M \times N$ 矩阵, 它的 $N$ 个行向量 $\overrightarrow{u^{i}} \quad(i=1, \cdots, N)$ 是正交单位矢量, $\Sigma$ 是 $N \times N$ 斜对角矩阵, $V^{T}$ 是 $N \times N$ 矩阵 $V$ 的转置矩阵, 它的 $N$ 个列向量 $\vec{v}^{i}$

$(i=1, \cdots, N)$ 是正交单位矢量, 即 $U^{t} U=I$ 和 $V^{t} V=V V^{t}=I$ 。上式满足以下关系

$$
\begin{gathered}
M_{C M} \vec{v}^{i}=\delta_{i} \vec{u}^{i}, \quad\left(M_{C M}\right)^{T} \vec{u}^{i}=\delta_{i} \vec{v}^{i} \\
\left(M_{C M}\right)^{T} M_{C M} \vec{v}^{i}=\delta_{i}^{2} \vec{v}^{i}, \quad M_{C M}\left(M_{C M}\right)^{T} \vec{u}^{i}=\delta_{i}^{2} \vec{u}^{i}
\end{gathered}
$$

代入方程（5.16）可以得到

$$
\begin{aligned}
& A^{C}=\left(M_{C M}^{T} \cdot M^{C M}\right)^{-1} \cdot M_{C M}^{T} \cdot R^{M} \\
& =\left(\begin{array}{cccc}
v_{1}^{1} & v_{1}^{2} & \cdots & v_{1}^{N} \\
v_{2}^{1} & v_{2}^{2} & \cdots & v_{2}^{N} \\
\vdots & \vdots & & \vdots \\
v_{N}^{2} & v_{N}^{2} & \cdots & v_{N}^{N}
\end{array}\right)\left(\begin{array}{cccc}
1 / \delta_{1} & & & \\
& 1 / \delta_{2} & & \\
& & \ddots & \\
& & & 1 / \delta_{N}
\end{array}\right)\left(\begin{array}{cccc}
u_{1}^{1} & u_{2}^{1} & \cdots & u_{N}^{1} \\
u_{1}^{2} & u_{2}^{2} & \cdots & u_{N}^{2} \\
\vdots & \vdots & & \vdots \\
u_{1}^{N} & u_{2}^{N} & \cdots & u_{M}^{N}
\end{array}\right)\left(\begin{array}{c}
R_{1} \\
R_{2} \\
\vdots \\
R_{M}
\end{array}\right)
\end{aligned}
$$

在矢量空间 $\overrightarrow{v^{i}}$ 中，分解 $A^{C}$ 可以得到系统可校正性（correctability）的性质; 在矢量空间 $u^{i}$ 分解 $R^{M}$ 可以得到系统的可观察性（observability）的性质; 根据矩 阵 $\Sigma$ 对角元素的特点可以得到系统是否 singularity, 各对角元素的大小反映 corrector（或 BPM）在观察空间 BPM（或 corrector）的校正效果, 对角元素值 越大, 表明 corrector 校正效果越明显（BPM 响应越灵敏）。解析计算方法就是 通过分析响应矩阵 $M$ 的特性分析校正系统的各种特性, 实现轨道校正系统的优 化设计。

根据表 5.1 系统误差参数, 图 5.2 是无校正系统时束流中心轨道沿束线变化 曲线, 可以看出 $\mathrm{x}$ 和 $\mathrm{y}$ 平面轨道偏离最大到 $8 \mathrm{~cm}$, 因此, 必须加入轨道校正系统。 下面对北京大学返航束线校正系统进行优化, 初始时 BPM 和 Corrector 位置选择 是放在最有效的校正位置和最灵敏的监测位置, 即 Beta 较大处, 它们之间的相 位差尽量远离 $180 \mathrm{n}$ 度 $(\mathrm{n}$ 是整数), 优化后束线上共需要 BPM 个数是 26 个, 它同 时监测 $\mathrm{x}$ 和 $\mathrm{y}$ 两个方向的束流轨道, $\mathrm{x}$ 方向需要 corrector 个数是 15 个, $\mathrm{y}$ 方向 
corrector 个数是 17 , 它们的位置分布如图 5.3 所示。

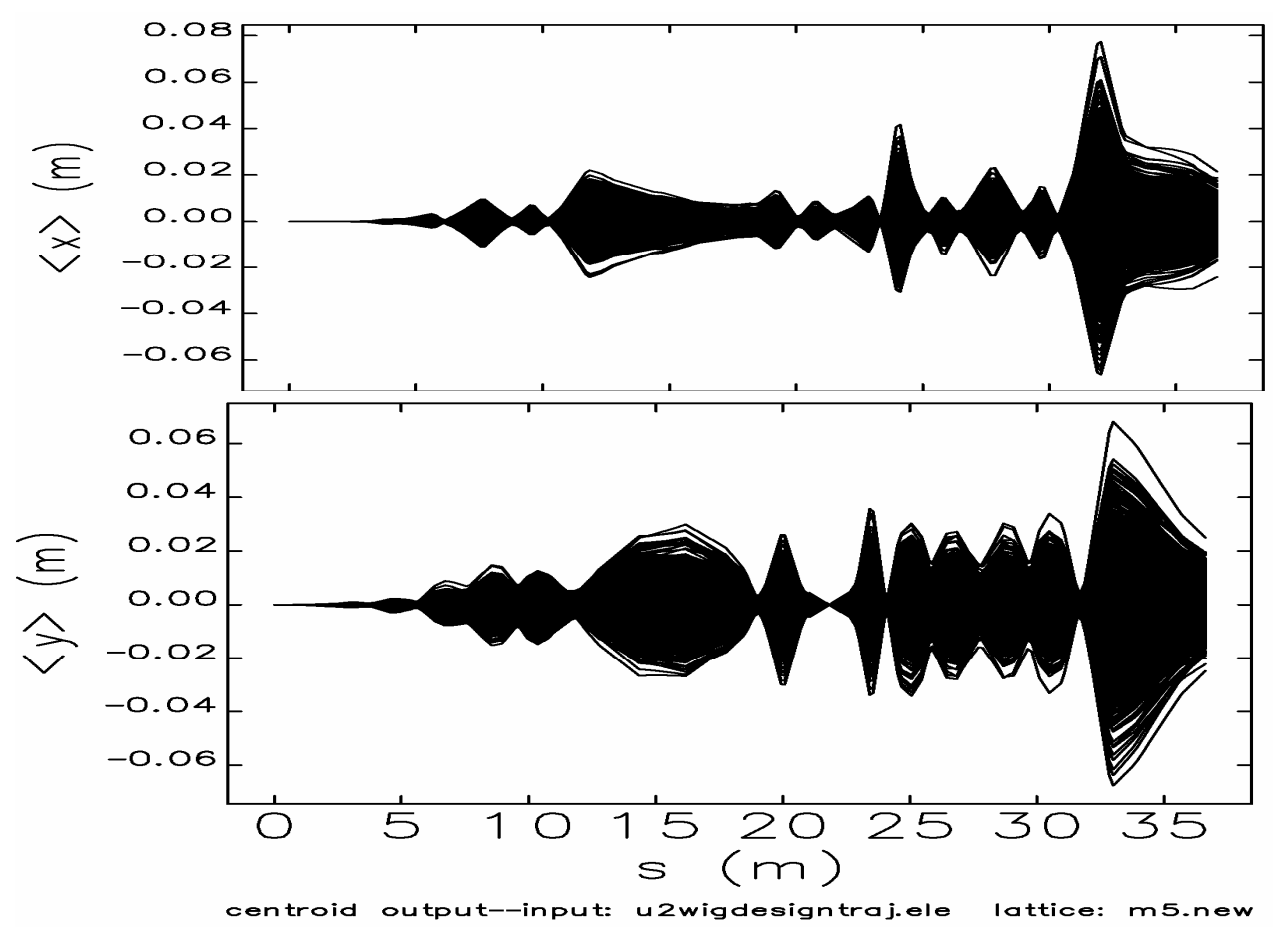

图 5.2 校正之前的束流中心轨道

校正后的束流中心轨道偏离如图 5.4, 横轴表示束线长度, 横轴上的绿色圆 点表示 BPM 所在的位置, 纵轴表示校正后的束流中心轨道偏离的 $3 \sigma$ 值, 从图中 可以看出中心轨道偏离系统中心最大 $3 \sigma$ 值是 $1.5 \mathrm{~mm}$, 这是对应注入点处（注入 位置偏离误差 $\sigma$ 是 $0.5 \mathrm{~mm}$ ），校正后束线末尾束流散角是 $0.13 \mathrm{mrad}$ 。图 5.5 表示 校正磁铁上限是 500G-cm 时, 校正磁铁所能校正轨道误差的范围, 其单位是 $\sigma$, 绿线对应 $3 \sigma$ 值, 从图中可以看出校正磁铁可以校正 $4 \sigma$ 以上的误差, 意味着该校 正系统能处理 $99.9937 \%$ 的误差概率组合。表明该校正系统足以处理返航束线各 种可能的误差组合, 校正后的中心轨道偏离在 $1.5 \mathrm{~mm}$ 以下, 校正磁铁强度上限 是 $500 \mathrm{G}-\mathrm{cm}$ 。 


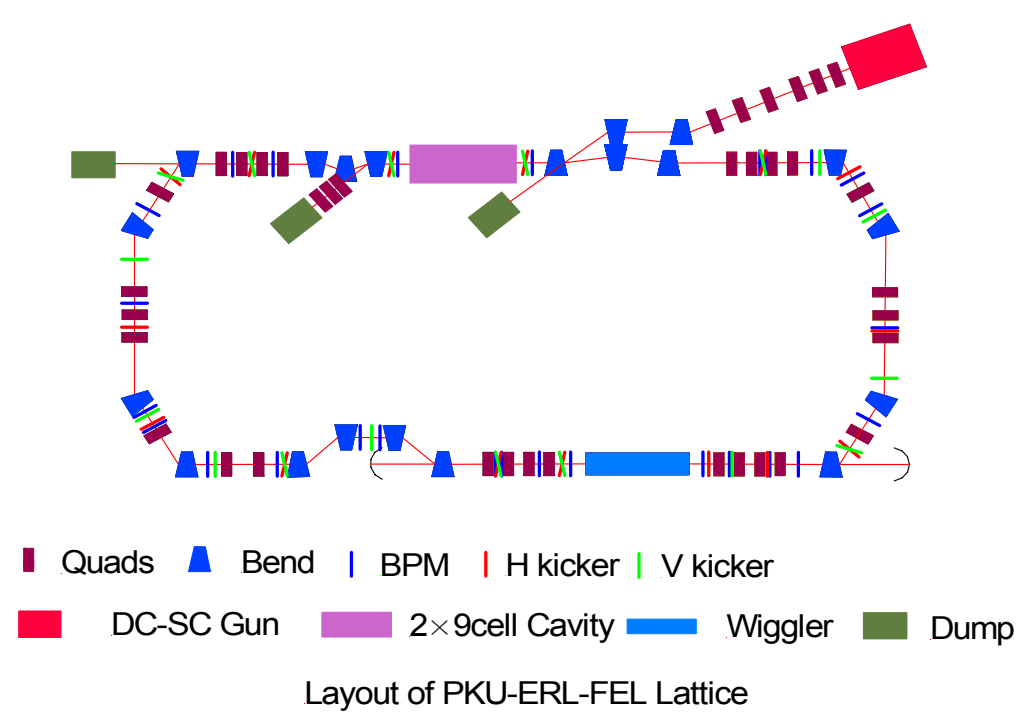

图 5.3 北京大学轨道校正系统分布图

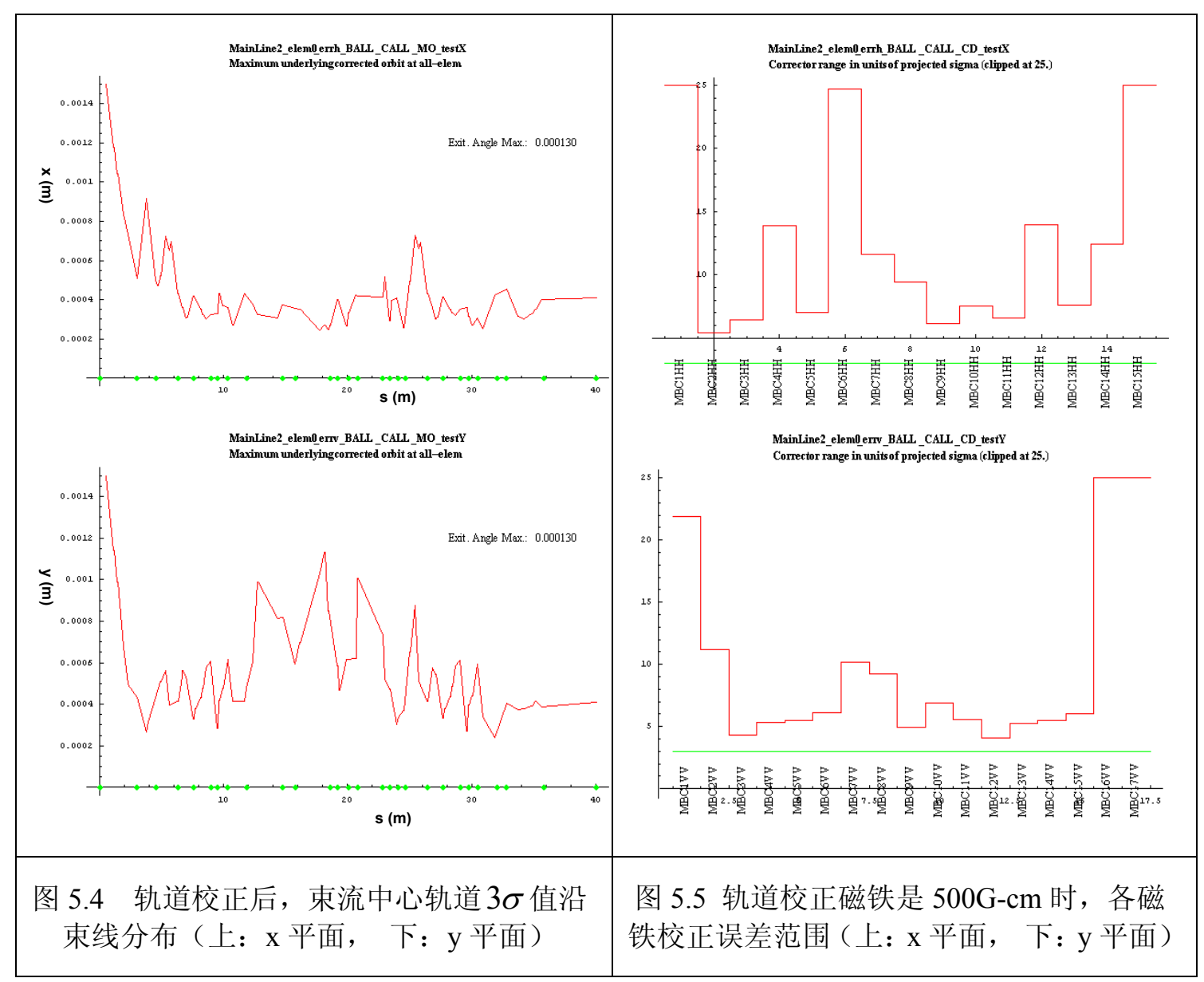

\subsection{2 粒子追踪研究轨道校正系统}

为了研究上述设计的轨道校正系统的可靠性, 这里用 ELEGANT 程序研究了 $\mathrm{s}$ 返航束线, BPM 和 Corrector 位置分布以及误差范围与上面完全相同, 它追踪 
的次数对应误差可能组合的种类数, 为了涵盖 $99.99 \%$ 以上的可能误差组合, 这 里共研究 10 万种组合, 它的计算统计结果如图 5.6, 图 5.6a 是校正后的束流中 心轨道偏离, 结果表明中心轨道偏离 $3 \sigma$ 不超过 $1.5 \mathrm{~mm}$, 最大轨道偏离约 $2 \mathrm{~mm}$, 与解析计算方法结论一致, 图 $5.6 \mathrm{~b}$ 是对应的校正磁铁的强度分布统计, 单位是 $\operatorname{mrad}$, 最大校正范围是 $5 \mathrm{mrad}$, 它和 G-cm 的换算关系是 $B l[G-c m]=0.33557 \theta[\mathrm{mrad}] \cdot \frac{P}{e}[\mathrm{GeV} / \mathrm{c}], P$ 是粒子的动能, 单位是 $[\mathrm{GeV} / \mathrm{c}]$, $30 \mathrm{MeV}$ 时, $100 \mathrm{G}-\mathrm{cm}$ 等效为 $1 \mathrm{mrad}$, 因此, corrctor 范围与解析计算方法结论也 是一致。

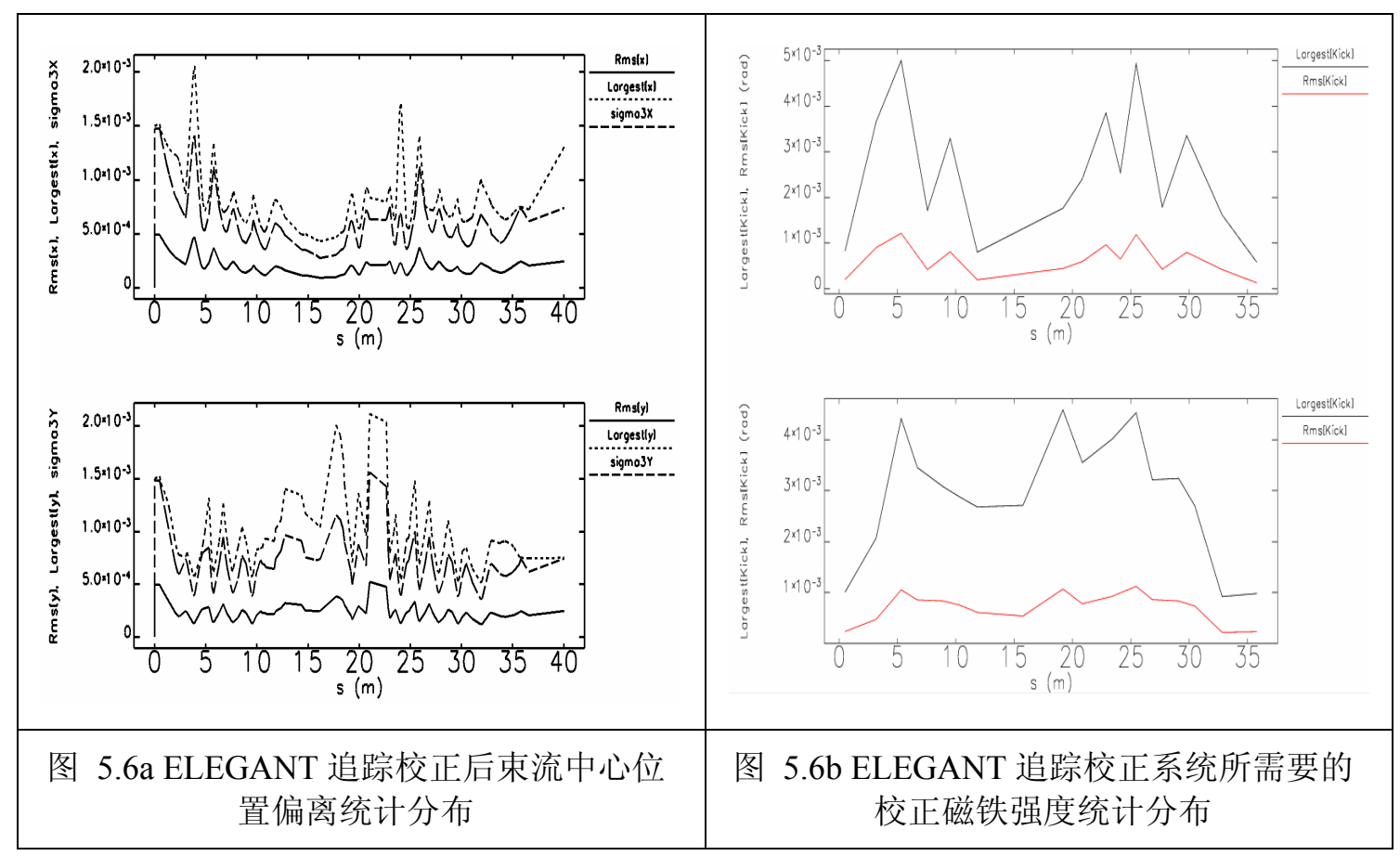

以上计算验证了轨道校正系统的可靠性, 它足以处理各种误差分布组合所造 成的束流中心位置偏离, 校正后的中心位置 $3 \sigma$ 偏离最大不超过 $2 \mathrm{~mm}$, 所需要的 校正磁铁强度 $500 \mathrm{G}-\mathrm{cm}$ 。

\section{3 系统稳健性研究}

这节将用 ELEGANT 程序研究返航束线对各种非理想情况的处理能力, 包括 束流光学传输对磁铁系统运行抖动误差和非理想束注入的敏感程度分析; 注入束 流失配或磁铁系统有安装误差时, 研究匹配段四级铁和 $\operatorname{arc}$ 段四极铁的调节校正 能力; 四极铁准直误差或二极铁绕纵轴旋转误差将会改变系统的消色散特性, 但 这种误差引起的消色散没有多余的磁铁可以校正, 研究返航系统对磁铁系统这类 
误差的容忍程度。

设计中，返航束线对束流横向相空间有一定的接收度，上面计算是假设横向 twiss 参数等于设计值, 机器运行中, 束流 twiss 参数可能偏离设计值, 横向束包 络失配。描述束流相空间参数是 $\beta 、 \alpha$ 和 $\gamma, \beta \gamma-\alpha^{2}=1$ 表明相空间描述参数只 有两个就可以完整描述相空间的信息, 表述失配大小的参数也是两个[83]: CS （Courant-Snyder）和角度 $\psi$, 它是在理想束流归一化相空间定义的, 相空间归 一化的优点在于它不考虑理想束流在不同情况下的相空间的区别, 如图 5.7 所示, 左图是实际测量束流的相空间, 黑色表示匹配的相空间, 蓝色是失配的相空间, 右图是对相空间坐标系进行变换，在新的坐标系下，匹配束流相空间是单位圆， 失配束流的相空间用参数 $\lambda$ 和 $\psi$ 描述, $\lambda$ 表示椭圆相空间长轴的长度, $\psi$ 表示椭 圆相空间的长轴与横坐标的夹角, 从 0 变化到 180 度, 定义 $C S=(\lambda+1 / \lambda) / 2$, 是椭圆相空间长轴和短轴之和的一半; 当 $C S=1$ 表示束流匹配。

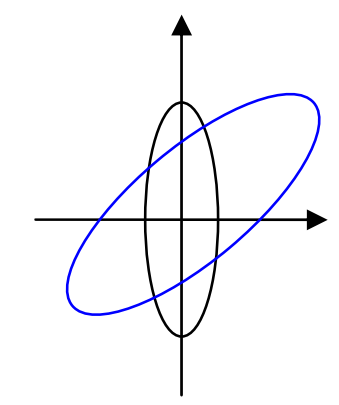

设计束流相空间归一化

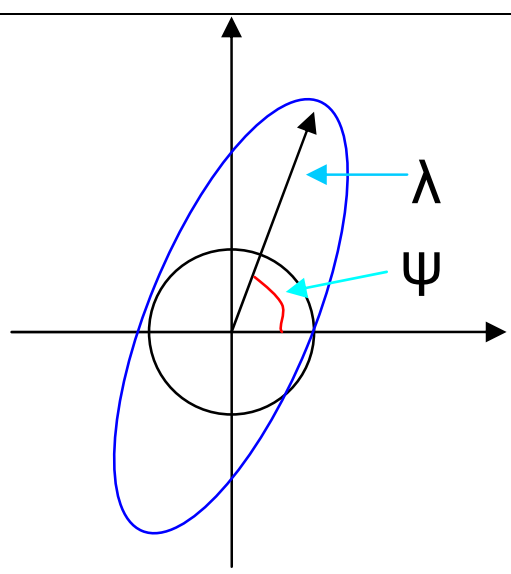

图 5.7 束流相空间失配定量表示示意图（左：真实相空间，右：归一化相空间）

机器运行时, 磁铁电源抖动误差造成束包络函数和色散函数的改变, 采用加 速器系统的一般指标, 磁铁电源抖动误差 RMS 值是 $0.1 \%$, 图 5.8 是注入束流匹 配和失配时束包络函数对抖动误差的响应, 红色曲线是磁铁电源无抖动误差时的 束包络曲线, 绿色是各种磁铁误差组合下的束包络曲线。注入束流匹配时, 如图 5.8 左上图, 电源抖动误差对束包络影响不是很大, 最大 Beta 从设计的 $40 \mathrm{~m}$ 到 $50 \mathrm{~m}$; 考虑注入束流失配时, 选择 $C S=1.2, \psi$ 值取从 0 到 180 度之间的某些值, 尽可能涵盖各种失配, 这里取 0 度、 45 度、90 度、135 度和 157 度。从图 5.8 可 
以看出, 各种不同的失配情况下, 最大 Beta 值约 $80 \mathrm{~m}$, 这意味着束斑比原来大 1.4 倍。

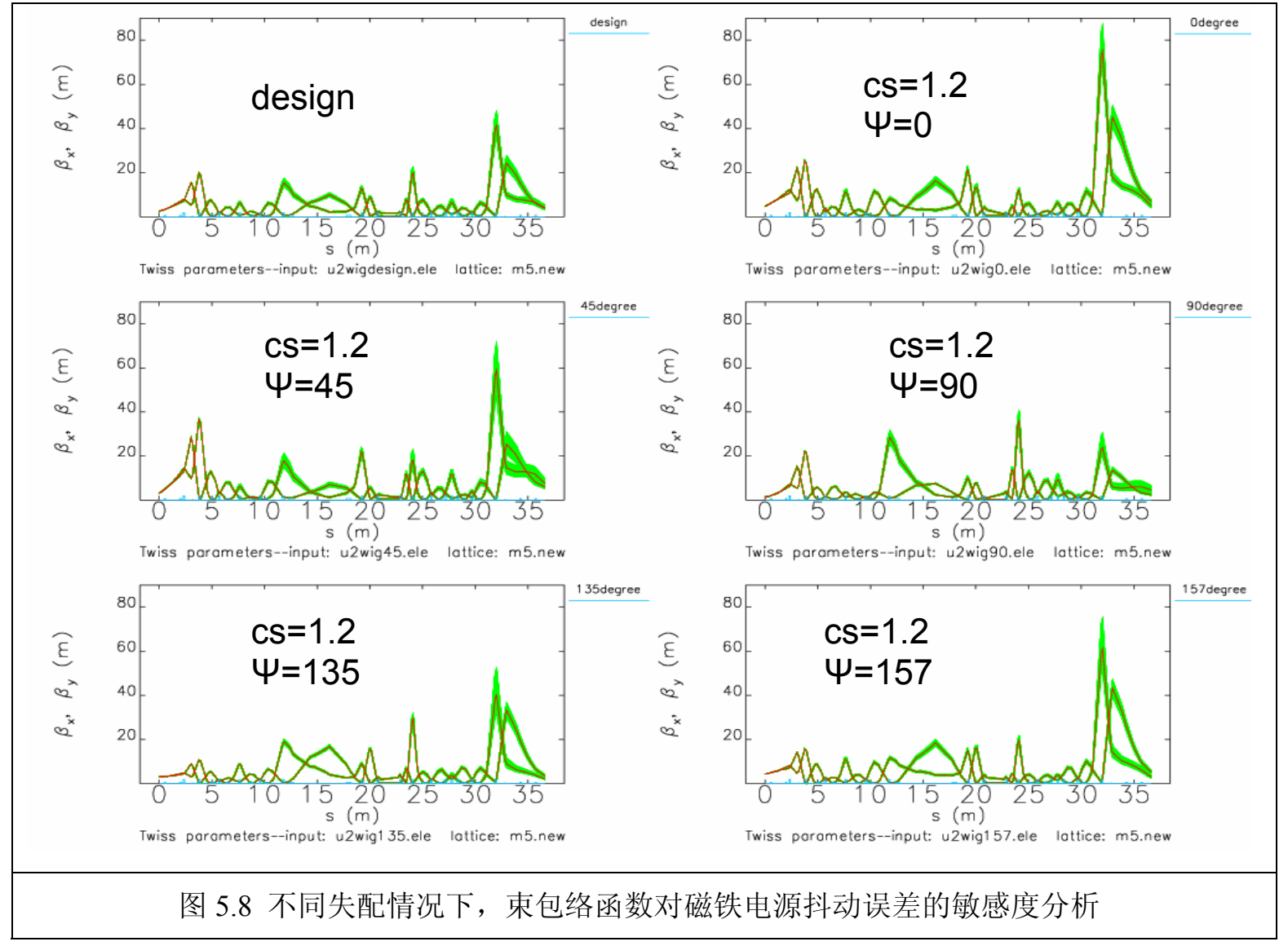

图 5.9 是研究返航束线的色散函数 $R_{16}$ 和 $R_{56}$ 对磁铁电源抖动误差的敏感度分 析, $R_{16}$ 和 $R_{56}$ 的值是以束线起点为参考点, 红色曲线表示磁铁电源无抖动误差时 各函数变化曲线, 绿色是磁铁抖动误差 RMS 值是 $0.1 \%$ 时各种可能组合下函数变 化曲线, 结果表明色散函数 $R_{16}$ 偏离设计值最大是 $0.06 \mathrm{~m}$, 它表明对 $0.4 \%$ 能散的 束流, 色散引起的束斑增大是 $0.24 \mathrm{~mm}$, 占束斑大小的 $5 \%$; 扭摆器入口, $R_{56}$ 偏 离设计值最大约 $3 \mathrm{~mm}$, 对 $0.4 \%$ 能散的束流, 束团长度压缩改变是 $0.04 \mathrm{ps}$, 小于 束团长度的 $1 \%$, 主加速器入口 $R_{56}$ 偏离设计值最大约 $4 \mathrm{~mm}$, 能量回收后束流能 散增大 $0.1 \%$, 表明磁铁电源抖动误差对色散以及束团纵向相空间分布影响很小。

图 5.10 是研究 $0.1 \%$ 磁场抖动误差对束流发射度的影响, 可以看出束流发射 度在色散段变化较大, 这主要是因为横向和纵向相空间耦合, 但是在束线非色散 段, 束流发射度变化很小, $\mathrm{x}$ 平面增长约 $1.4 \%, \mathrm{y}$ 平面增长约 $1.2 \%$, 磁场抖动 误差对束流发射度影响较小。 
返航束线有 $0.1 \%$ 磁场抖动误差, 并且失配参数 $C S=1.2$ 时, 考虑不同失配相 空间, 传输线的束包络函数仍能保持的很好, 束斑增大最大值是设计的 1.4 倍, 这是可以接收的; $0.1 \%$ 磁场抖动误差改变束线的色散特性和 $R_{56}$, 由于色散引起 的束斑增大最大不超过 $1 \mathrm{~mm}, R_{56}$ 的改变对束流最短束团长度和能量回收的能散 变化影响很小; 对横向发射度增长影响不超过 $2 \%$ 。返航束线的束流光学对 $0.1 \%$ 磁铁抖动误差敏感程度可以接收。
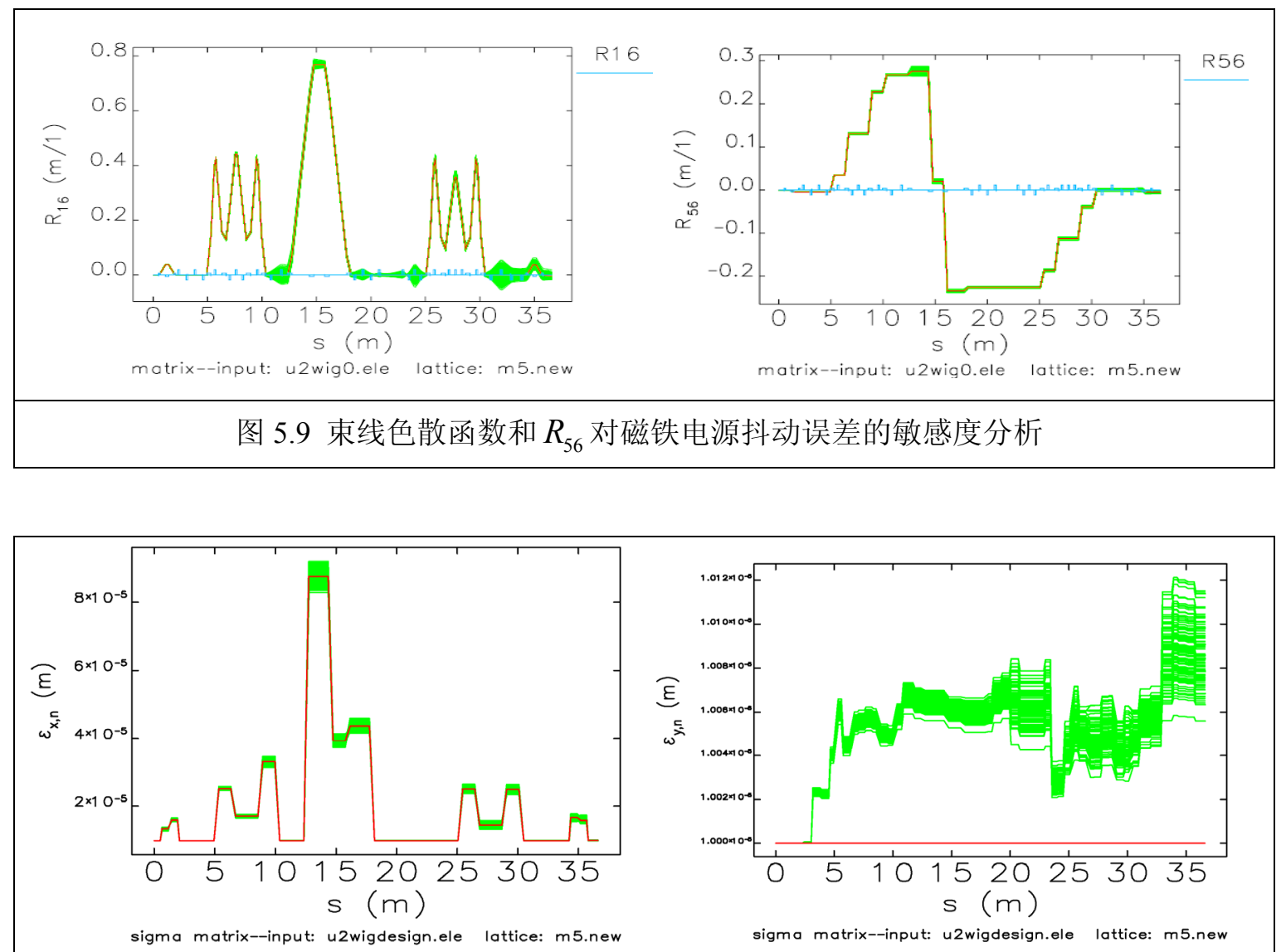

图 5.10 磁铁电源抖动误差对束流发射度的影响

磁铁系统有加工误差, 在 ARC 段, 这种误差将导致束线偏离消色散射计; 在传输段, 误差将导致束包络失配。假设系统加工误差 RMS 值是 $1 \%$, 调节 ARC 段四级铁 Q arc1 和 Q arc3, 使得 $\mathrm{ARC}$ 段束线满足消色散特性, 并且保证 $R_{56}$ 等 于设计值。图 5.11 是各种误差组合下, 四极铁调谐后强度统计分布, 红色是无 系统误差时四极铁强度, 从图中可以看出四极铁强度变化 $\pm 1\left(1 / \mathrm{m}^{2}\right)$, 足以保证 $\mathrm{ARC}$ 段色散特性以及 $R_{56}$ 的要求。 

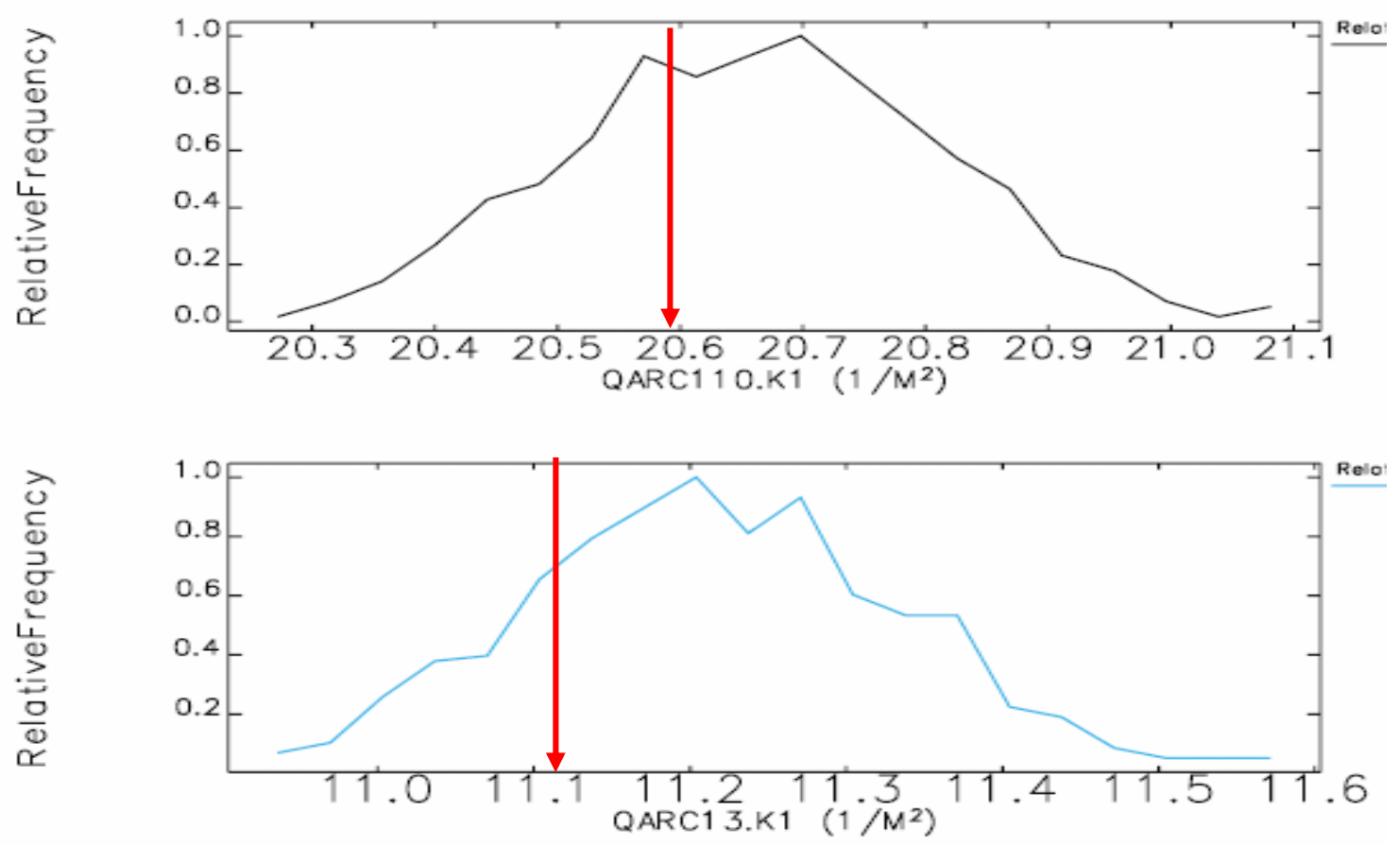

图 5.11 磁铁系统加工误差是 $1 \%$ 时, $\mathrm{ARC}$ 段四极铁运行范围统计分布

$\mathrm{ARC}$ 段磁场强度的改变会改变后面的束包络, 尤其是扭摆器对横向束包络 匹配要求较高, 为了满足扭摆器的要求, 需要改变 $\operatorname{arc}$ 段和扭摆器之间的四极铁 强度, 重新匹配束包络, 图 5.12 研究系统加工误差 RMS 值是 1\%时, 匹配六种 不同注入束流所对应的四极铁强度统计分布, 对应 5.13 图所用的束线参数, 红 色直线是匹配段四极铁强度的设计值, 四极铁强度变化 $\pm 5\left(1 / \mathrm{m}^{2}\right)$ 时可以校正束线 安装误差以及注入束流失配对束包络的影响。图 5.13 是经再次匹配后 ARC 到扭 摆器之间的束包络曲线分布, 红色曲线表示无系统误差时的束包络函数分布, 绿 色是各种误差组合下的束包络函数分布, 匹配后 $\mathrm{x}$ 和 $\mathrm{y}$ 方向的束包络都能控制的 很好, 最大不超过 $40 \mathrm{~m}$, 扭摆器入口的束包络函数都达到设计值要求。 

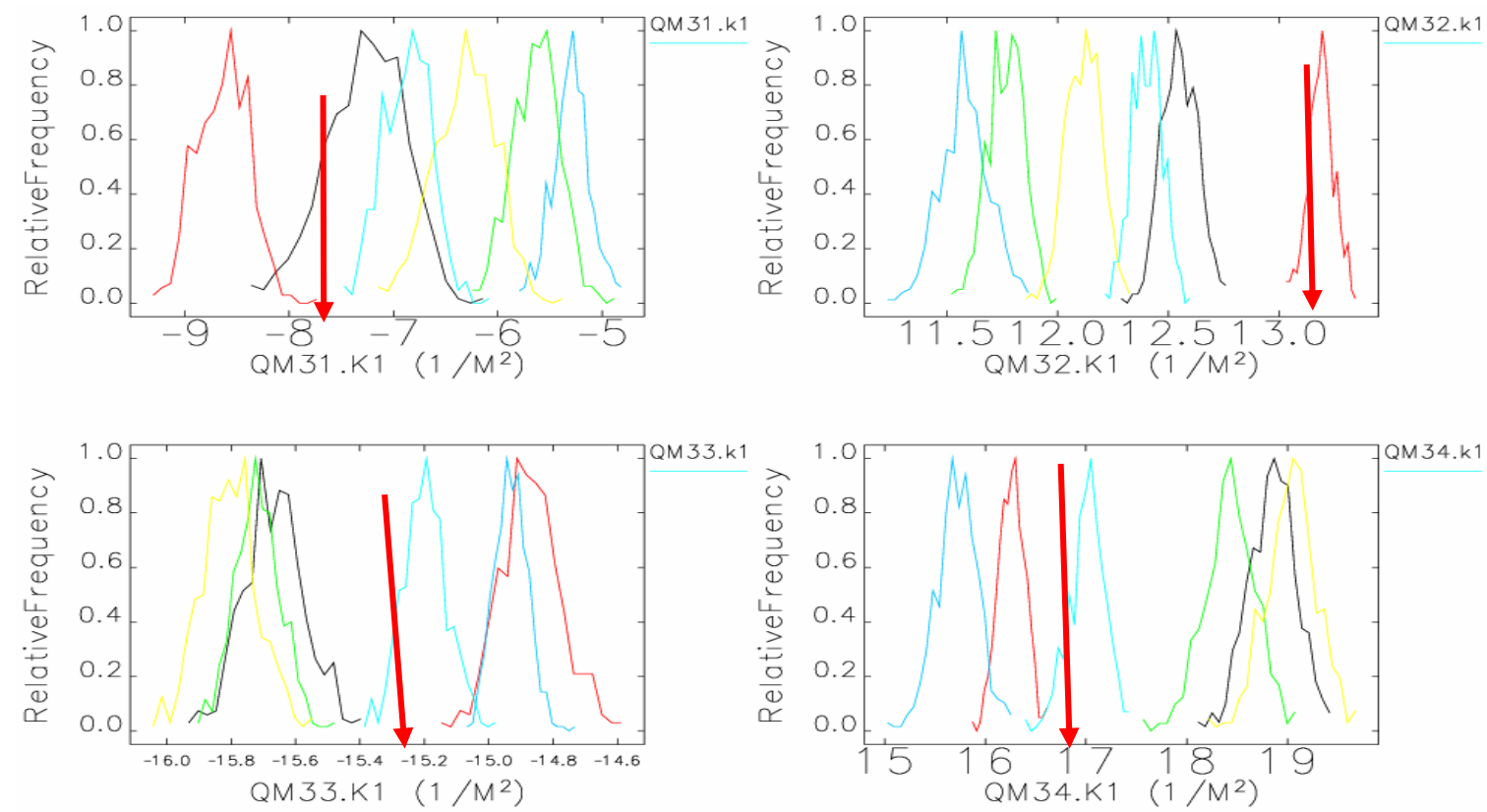

图 5.12 磁铁系统误差是 $1 \%$ 时, 扭摆器之前的匹配段在不同注入相空间下四极铁强度统计 分布
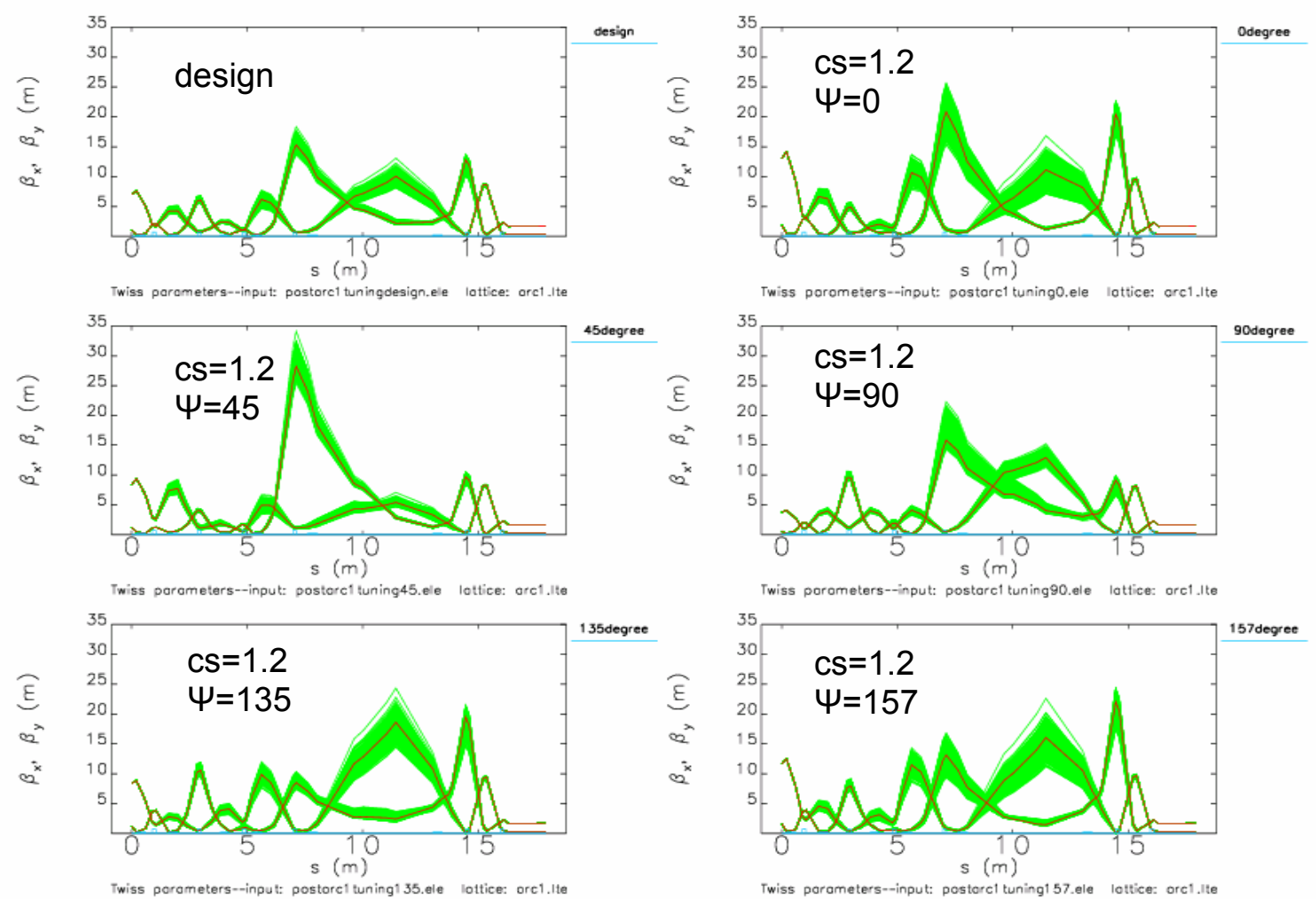

图 5.13 磁铁系统误差是 $1 \%$ 时, 重新匹配后, $\operatorname{arc}$ 到扭摆器之间的束包络分布曲线

返航束线有 $1 \%$ 的系统加工误差时, 通过调谐 ARC 内部的四极铁强度, 能 够保持束线的消色散特性和纵向相空间 $R_{56}$ 的要求, 四极铁强度调谐范围与设计 
值差 $\pm 1\left(1 / m^{2}\right)$ 。系统误差和注入束流失配对束包络的影响通过四极铁再次匹配来 满足扭摆器的要求, 四极铁变化范围与设计值差 $\pm 5\left(1 / \mathrm{m}^{2}\right)$, 各种情况下, 束包络 函数都能控制的很好, beta 值在 $40 \mathrm{~m}$ 以下。

除了电源抖动误差和磁铁加工误差外, 磁铁系统还有安装误差, 这里考虑准 直误差和绕纵轴旋转误差, 在色散段, 安装误差使束线偏离消色散, 安装系统精 度要求: 四极铁横向准直误差 $\mathrm{rms}$ 值是 $0.2 \mathrm{~mm}$, 二极铁绕纵轴旋转误差 $\mathrm{rms}$ 值是 $1 \mathrm{mrad}$, 下面研究它们对束线色散的影响。

图 5.14 是四极铁 $\mathrm{x}$ 方向准直误差是 $0.2 \mathrm{~mm}$ 时, 色散函数和 $R_{56}$ 的变化曲线, 它只影响 $\mathrm{x}$ 方向的色散, 不改变 $\mathrm{y}$ 方向的色散, 红色曲线是无准直误差时各函数 变化曲线, 绿色是各种误差组合下对应各函数变化曲线, 从图中可以得到, 对能 散为 $0.4 \%$ 的束流, 由于四极铁 $\mathrm{x}$ 方向 $0.2 \mathrm{~mm}$ 准直误差, $\mathrm{x}$ 方向的色散引起的束 斑增大不超过 $0.4 \mathrm{~mm}$, 扭摆器之前的 $R_{56}$ 与设计值差别最大约 $2 \mathrm{~mm}$, 主加速器入 口的 $R_{56}$ 与设计值差别最大约 $6 \mathrm{~mm}$, 这对束团长度和能散都影响很小。

图 5.15 是四极铁 $\mathrm{y}$ 方向准直误差是 $0.2 \mathrm{~mm}$ 时, 色散函数和色散函数导数变 化曲线。无准直误差时, $\mathrm{y}$ 方向是色散恒为 0 , 四极铁 $\mathrm{y}$ 方向的准直误差只影响 $\mathrm{y}$ 方向的色散, 不改变 $\mathrm{x}$ 方向的色散, 由于 $\mathrm{y}$ 平面无束流偏转, 因此, 四极铁 $\mathrm{y}$ 方向准直误差不影响 $R_{56}$, 对能散为 $0.4 \%$ 的束流, 由于四极铁 $\mathrm{y}$ 方向 $0.2 \mathrm{~mm}$ 准 直误差, $\mathrm{y}$ 方向的色散引起的束斑增大不超过 $0.06 \mathrm{~mm}$ 。

图 5.16 是二极铁绕纵轴旋转误差是 $1 \mathrm{mrad}$ 时, 色散函数和色散函数导数变 化曲线, 它只影响 $\mathrm{y}$ 方向的色散特性, 不改变 $R_{56}$, 对能散为 $0.4 \%$ 的束流, 二极 铁绕轴旋转误差引起束斑增大在 $0.04 \mathrm{~mm}$ 以下。

准直误差和绕轴旋转误差对束流发射度的影响在使用轨道校正系统之前计 算结果如下: 四极铁 $\mathrm{x}$ 方向的准直误差使得发射度在扭摆器入口 $\mathrm{x}$ 方向增长 $30 \%$, $\mathrm{y}$ 方向增长 $1 \%$; 四极铁 $\mathrm{y}$ 方向的准直误差使得发射度在扭摆器入口 $\mathrm{x}$ 方向增长 $1 \%$, y 方向增长 $40 \%$; 二极铁铁绕轴旋转误差使得发射度在扭摆器入口 $\mathrm{x}$ 方向 增长 $1 \%, \mathrm{y}$ 方向增长 $60 \%$ 。采用轨道校正系统后, 四极铁 $\mathrm{x}$ 方向的准直误差引 起发射度在 $\mathrm{x}$ 方向增大 $1 \%$, $\mathrm{y}$ 方向增大 $0.015 \%$; 四极铁 $\mathrm{y}$ 方向的准直误差引起 发射度在 $\mathrm{x}$ 方向增大 $0.5 \%, \mathrm{y}$ 方向增大 $0.4 \%$; 二极铁铁绕轴旋转误差引起发射 度在 $\mathrm{x}$ 方向增大 $0.5 \%, \mathrm{y}$ 方向增大 $3 \%$ 。校正后各种安装误差对发射度增大不超 
过 $5 \%$ 。
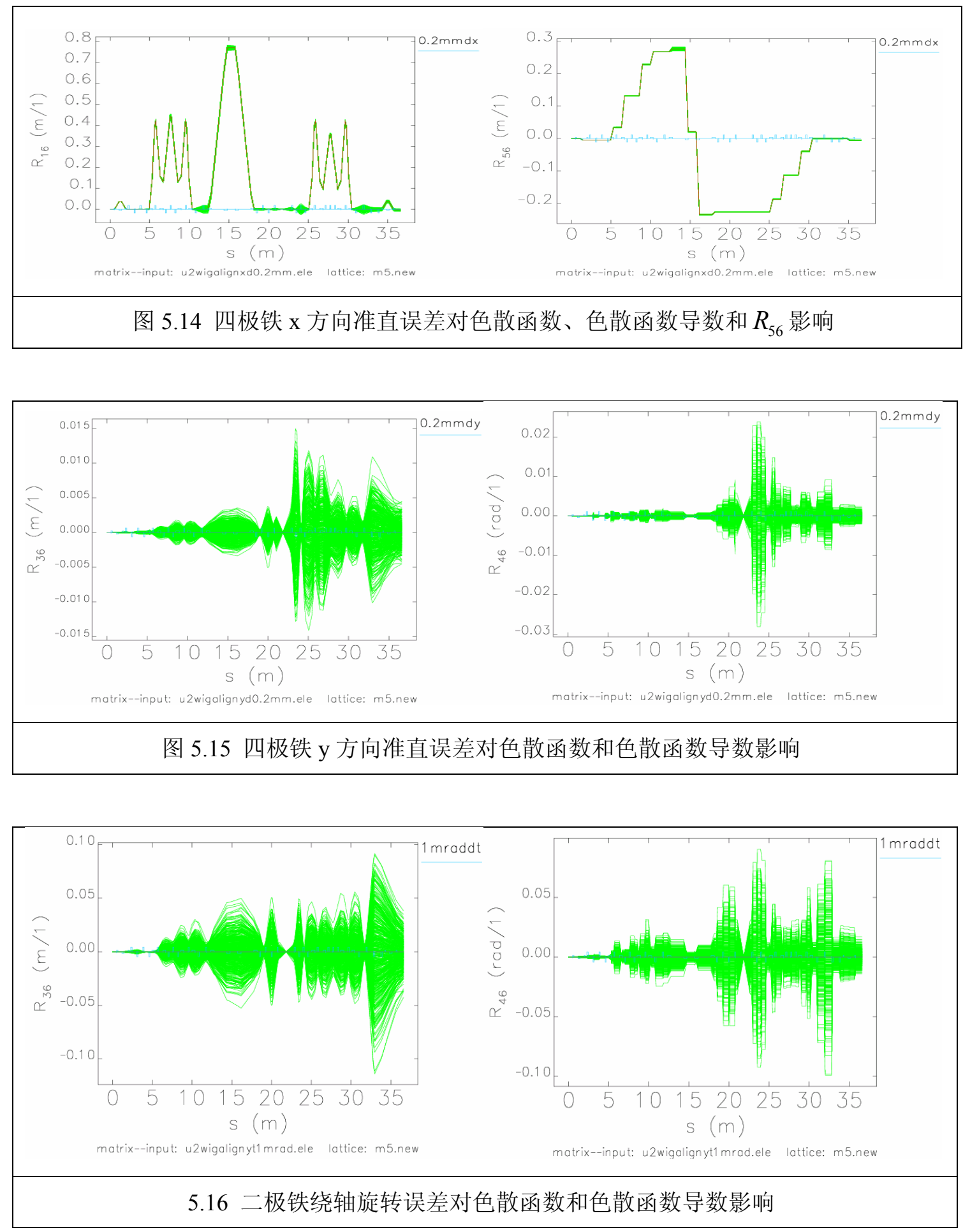

安装误差改变束线的消色散特性，若控制四极铁准直误差 $0.2 \mathrm{~mm}$ 以下和二 极铁绕纵轴旋转误差 $1 \mathrm{mrad}$ 以下, 对 $0.4 \%$ 能散的束流, 色散引起束斑的增长都 可以控制在 $0.5 \mathrm{~mm}$ 以下。系统安装误差引起束流发射度增长不超过 $5 \%$, 这是可 以接受的。 


\section{4 本章小结}

本章使用解析计算方法优化设计北京大学返航束线轨道校正系统, 优化后使 用的 BPM 是 26 个, $\mathrm{x}$ 方向 corrector 个数是 15 个, $\mathrm{y}$ 方向 corrector 个数是 17, 校正之前束流中心轨道偏离系统中心到 $8 \mathrm{~cm}$, 校正后束流中心轨道偏离系统 中心 $3 \sigma$ 值不超过 $2 \mathrm{~mm}$, 校正磁铁强度上限是 $500 \mathrm{G}-\mathrm{cm}$ 时, 校正磁铁可以处理 $4 \sigma$ 以上的轨道误差。此外, 还用 ELEGANT 程序研究轨道校正系统, 结果与解析计算 方法结论一致。

分析了系统稳健性, 研究注入束流匹配和失配时, $0.1 \%$ 的电源抖动误差对束 包络、色散以及发射度的影响, 结果表明束包络仍然保持的很好, 束斑增大到设 计值的 1.4 倍, 横向发射度增长不超过 2\%; 磁铁加工误差为 $1 \%$ 时, 通过调节 arc 段内部的四极铁强度, 能够保持束线的消色散特性和束团压缩对 $R_{56}$ 的要求, 四 极铁强度 $\mathrm{k}$ 的调谐范围与设计值差 $\pm 1\left(1 / \mathrm{m}^{2}\right)$; 系统加工误差和注入束流失配对束 包络的影响通过调节四极铁可实现对扭摆器的匹配注入要求, 四极铁 $\mathrm{k}$ 的变化范 围与设计值差 $\pm 5\left(1 / \mathrm{m}^{2}\right)$, 各种情况下, 束包络函数都能控制的很好, beta 值在 40m 以下;

研究了系统的四极铁准直误差和二极铁绕纵轴旋转误差对束线色散以及发 射度的影响。在 $0.2 \mathrm{~mm}$ 的准直误差和 $1 \mathrm{mrad}$ 旋转误差下, 束线消色散特性改变, 引起束斑的增长都可以控制在 $1 \mathrm{~mm}$ 以下; 在使用轨道校正系统前, 准直误差引起 的发射度增长约 $40 \%$, 绕轴旋转误差引起的发射度增长到 $60 \%$; 使用校正系统后, 系统安装误差引起束流发射度增长不超过 5\%。因此, 轨道校正系统对控制束流 中心轨道偏离和发射度增长是可靠有效的。 


\section{第六章＼cjkstart多圈束流崩溃效应理论与模拟计算}

带电束团进入加速腔加速的同时, 束团通过束-腔相互作用在加速腔内会激 励起其它谐振模式一高阶模, 在腔中建立起相应的感应电磁场, 高阶模场的能量 与束流偏离加速腔的横向位移有关, 横向位移越大, 激励的高阶模场能量越高; 另一方面, 加速腔中的高阶模电磁场（特别是偶次模）对束流的作用, 使得束流 横向获得动量, 偏离理想轨道。在高重复频率束流加速模式下, 束团之间存在尾 场效应 ${ }^{[84]}$, 前一束团激励的高阶模场在很短时间内得不到充分衰减, 对后续的束 团产生影响, 各束团激发的高次模在腔体内累积, 影响束流品质, 甚至引起束流 崩溃效应（Beam Break Up）。CW 模式加速时, 常用束流脉冲重复频率通常高 达几十兆赫兹, 相应的束团时间间隔约 $10^{-8} \mathrm{~s}$, 而加速腔高模式场衰减时间常数 $\tau_{L}=2 \frac{Q_{L}}{\omega_{n}}$, 其中 $\omega_{n}$ 是各高阶模的角频率, $10^{9} \mathrm{~Hz}$ 量级, 因此, $\tau_{L}$ 主要取决于 $Q_{L}$, 超导加速器中, $Q_{L}$ 一般很高, 经高阶模耦合器衰减后约 $10^{4}, \tau_{L} \sim 10^{-5} \mathrm{~S}$, 高阶 模场衰减时间远大于束团间隔时间, 因此, 前面束团激励的高阶模电磁场将影响 后续束流的加速与传输。能量回收时, 束流多次通过同一个加速器, 同一束团连 续两次通过加速腔的时间间隔由返航束线长度决定, 对北大的装置, 束团所走路 径长度设计是 $173.5 \mathrm{RF}$ 周期, 即 $1.3^{*} 10^{-7} \mathrm{~s}$, 也比高阶模的衰减时间小两个量级, 因此, 束团第一次激励的高阶模不仅对后续的束团有影响, 返航再次进入加速腔 的同一个束团同样也会受到影响, 并且若高阶模电磁场继续从束流得到能量, 则 将激励起更强的高阶模, 直到束流打到束管上而丢失, 即产生束流崩溃效应。根 据束流与高阶模作用过程划分束流崩溃, 主要有再生束流崩溃效应 (regenerative BBU) 、累积束流崩溃效应（cumulative BBU）和多圈束流崩溃效应（Multipass $\mathrm{BBU}$ )。再生束流崩溃效应 ${ }^{[55,86,87]}$ 是指在一个加速腔中, 束流受到高阶模电磁场 作用, 横向有动量, 随后转化成横向位移; 当束团有位移时, 将与高阶模纵向电 场交换能量, 束流动能转变成高阶模电磁场能量, 后续束团将感受到更强的电磁 场, 从而引起更大的横向位移, 高阶模激励与束流横向偏离形成一个自放大反馈 系统, 直到束流丢失, 阈值电流是 $I_{t h}=\frac{\pi^{3} E}{2 e R_{a} k_{n} L}$, 其中 $E$ 是束流能量, $R_{a}$ 是高阶 模分路阻抗, $L$ 是加速结构的长度, $k_{n}$ 是高阶模波数, $e$ 是电子电荷, 阈值电流 
含义是该流强下, 束团交给高阶模的能量与高阶模失去的能量相等, 北京大学装 置对应的该类阈值电流约 $30 \mathrm{~A}$ 。累积束流崩溃效应 ${ }^{[88,89,90]}$ 是束流与多个加速腔作 用, 前面加速腔中的高阶模场作用束流, 产生横向角偏离, 通过加速腔之间的传 输矩阵 $M_{12}$ 或 $M_{34}$, 横向角偏离转变成后面加速腔中的横向位移, 从而激励更强 的高阶模, 使得后续的束流感受到的场更强, 直到束流丢失, 阈值电流是该流强 下激励的高阶模引起束流横向位移在后面加速腔中放大, 直到束流打到管壁, 这 类不稳定性主要表现在加速结构很长的束线上, 北京大学主加速器只有两个 9 cell 腔, 累积束流崩溃效应不显著。多圈束流崩溃效应是同一加速腔中, 同一个束团 再次激励高阶模, 返航束线的传输矩阵 $M_{12}$ 或 $M_{34}$ 决定了束流再次通过加速腔的 位移, 也决定了激励的高阶模场能量, 因此阈值电流取决于束流参数、高阶模和 返航束线光学传输, 阈值电流含义与再生束流崩溃效应类似。

相比前两种束流不稳定性, 多圈束流崩溃效应限制了能量回收装置最大加速 电流。束流崩溃效应除了有横向不稳定外, 还有纵向不稳定, 通常, 纵向阈值电 流比横向阈值电流高一个量级以上, 因此, 本文只考虑多圈横向束流崩溃效应。

束流崩溃效应与加速高阶模场直接相关, 本章首先介绍束流崩溃效应的原理 和阈值电流理论推导, 再分析哪类高阶模对束流影响最大, 并根据 TESLA 超导 腔的高阶模分布, 模拟计算了北京大学 ERL 装置上的阈值电流, 最后探讨可能 提高阈值电流的方法。

\section{1 多圈束流崩溃效应及单模阈值电流理论推导}

图 6.1 给出束流两次通过加速腔的示意图 ${ }^{[91]}$, 其过程是: 束流沿加速腔轴线 进入, 其动量是 $p_{i}$, 第一次通过加速腔后, 动量是 $p_{r}$, 角偏离是 $\theta_{c}^{(1)}(t)$, 第二 次通过加速腔时, 束流横向有位移 $x_{c}^{(2)}(t)$, 通过加速腔后动量变成 $p_{f}$, 图中的 实线表示无高阶模影响时的理想束流轨道, 虚线表示受到高阶模力作用后的束流 轨道, 第二次通过加速腔的横向位移与 $\theta_{c}^{(1)}(t)$ 和返航束线传输相关, 横向位移 $x_{c}^{(2)}(t)$ 越大, 第二次激励的高阶模场也越强, 束流第二次通过加速腔时受到前面 束流激发 (包括束流第一次激发的场) 的高阶模场偏转角更大, 束流的横向偏离 和高阶模的激励形成正向反馈放大, 直到束流打到腔壁上而丢失, 这是多圈束流 崩溃效应。 


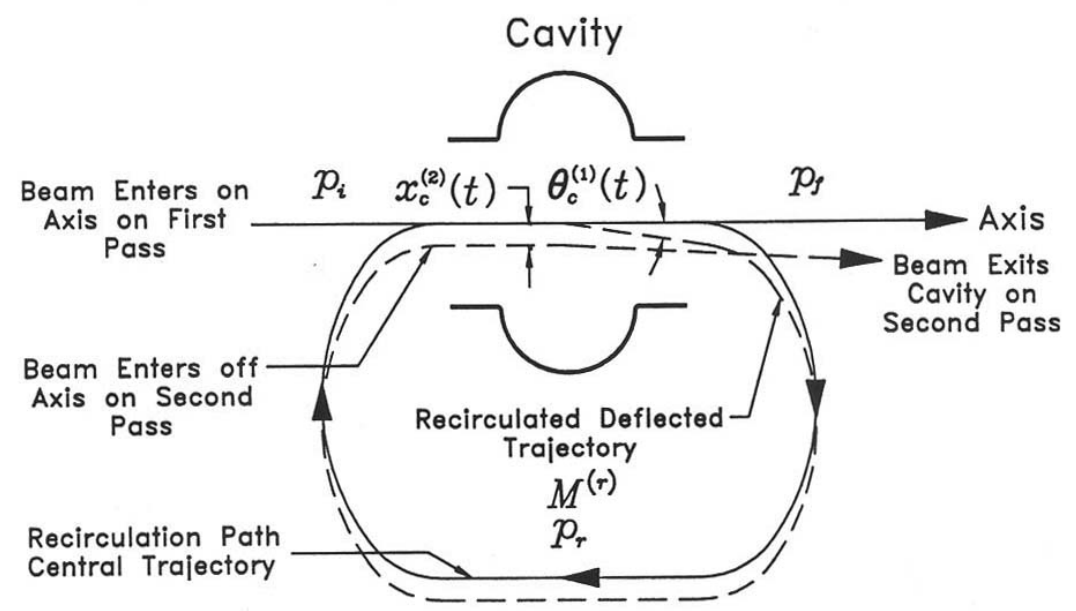

图 6.1 多圈束流崩溃效应示意图

假设高阶模场的加速电压在半径 $\mathrm{a}$ 处是 $V_{a}$, 其对应的加速场与束流的位移在 同一方向上, 在点电荷近似下, 离轴 $\mathrm{r}$ 处的束流交给高阶模交换的能量 $\Delta U$ 是

$$
\Delta U=-q V_{a} \cos (\phi) \frac{r}{a}
$$

其中, $q=I_{0} / f_{b}$ ( $I_{0}$ 是束流平均流强, $f_{b}$ 是束团重复频率) 是束团电荷量, $\phi$ 是 电荷相对高阶模峰值电场相位。

高阶模 $E_{z}$ 是随 $\varphi$ 变化, 具有方向性, 假设高阶模相对 $\mathrm{x}$ 轴极化角是 $\alpha$, 则 高阶模的单位矢量是 $\vec{n}=\cos (\alpha) \hat{x}+\sin (\alpha) \hat{y}$, 束流相对高阶模的位移

$$
r=\vec{r} \cdot \vec{n}=x \cos (\alpha)+y \sin (\alpha)
$$

其中, $\vec{r}$ 表示束流的位移矢量。

束流第一次和第二次通过加速腔交给高阶模的能量是

$$
\begin{array}{r}
\Delta U_{1}=-q \frac{V_{a}}{a} \cos (\phi)\left[x_{1} \cos (\alpha)+y_{1} \sin (\alpha)\right] \\
\Delta U_{2}=-q \frac{V_{a}}{a} \cos \left(\phi+\omega T_{r}\right)\left[x_{2} \cos (\alpha)+y_{2} \sin (\alpha)\right]
\end{array}
$$

其中, $T_{r}$ 是束流再次返回到加速腔中所经历的时间, $\omega$ 是对应的高阶模角频 率， $x_{1} 、 y_{1} 、 x_{2} 、 y_{2}$ 分别是束流第一次和第二次通过加速腔的坐标。

束流第一次通过加速腔与高阶模作用, 受到的横向角偏离是 $V_{\perp} /(p c / e)$, 其 中, $p$ 是束流对应的动量, $V_{\perp}=-\frac{c}{\omega} \frac{V_{a}}{a} \sin (\phi)$ 。横向角偏离是 


$$
\begin{aligned}
& x^{\prime}=-\frac{e V_{a}}{\omega a p} \sin (\phi) \cos (\alpha) \\
& y^{\prime}=-\frac{e V_{a}}{\omega a p} \sin (\phi) \sin (\alpha)
\end{aligned}
$$

$x_{2} 、 y_{2}$ 可以用高阶模场引起的角偏离表示:

$$
\begin{aligned}
& x_{2}=m_{11} x_{1}+m_{12} x_{1}^{\prime}+m_{13} y_{1}+m_{14} y_{1}^{\prime}-q \frac{V_{a}}{\omega a p} \sin (\phi)\left[m_{12} \cos (\alpha)+m_{14} \sin (\alpha)\right] \\
& y_{2}=m_{31} x_{1}+m_{32} x_{1}^{\prime}+m_{33} y_{1}+m_{34} y_{1}^{\prime}-q \frac{V_{a}}{\omega a p} \sin (\phi)\left[m_{32} \cos (\alpha)+m_{34} \sin (\alpha)\right]
\end{aligned}
$$

假设束团激励的高阶模场不随时间变化, 即第二圈时高阶模的激励对高阶模 电压影响可以忽略, 束流交给高阶模场的平均功率或高阶模场增加的功率是

$$
\dot{U}_{\text {beam }}=\left\langle\Delta U_{1}+\Delta U_{2}\right\rangle \cdot f_{b}
$$

束团电荷量反应束团与高阶模单次交换能量的多少, 重复频率是交换能量的 累计快慢。

高阶模丢失的总功率 ${ }^{[92]}$ 是

$$
P_{t o t}=\frac{V_{a}^{2}}{\left(\frac{\omega}{c}\right)^{2} a^{2}\left(\frac{R_{d}}{Q}\right) Q_{L}}
$$

高阶模总功率的变化:

$$
\dot{U}=\dot{U}_{\text {beam }}-P_{\text {tot }}=\left\langle\Delta U_{1}+\Delta U_{2}\right\rangle \cdot f_{b}-P_{\text {tot }}
$$

化简后的得到，

$$
\begin{aligned}
& \dot{U}=I_{0} \frac{e V_{a}^{2}}{\omega a^{2} p_{b}} M_{12}^{*}\left\langle\sin \phi \cos \left(\phi+\omega T_{r}\right)\right\rangle-\frac{V_{a}^{2}}{a^{2}(\omega / c)^{2}\left(R_{d} / Q\right) Q_{L}} \\
& =-I_{0} \frac{e V_{a}^{2}}{\omega a^{2} p_{b}} M_{12}^{*} \frac{\sin \left(\omega T_{r}\right)}{2}-\frac{V_{a}^{2}}{a^{2}(\omega / c)^{2}\left(R_{d} / Q\right) Q_{L}}
\end{aligned}
$$

其中 $m_{12}^{*}=m_{12} \cos ^{2}(\alpha)+\left(m_{14}+m_{32}\right) \sin (\alpha) \cos (\alpha)+m_{34} \sin ^{2}(\alpha)$ 。

当束团交给高阶模的能量与高阶模丢失的能量相等时, 对应的电流是阈值电 流，得到

$$
\left\langle\Delta U_{1}+\Delta U_{2}\right\rangle \cdot f_{b}=P_{c}
$$

化简后得到 ${ }^{[93]}$ 


$$
I_{t h}=-\frac{2 p c}{e\left(\frac{\omega}{c}\right)\left(\frac{R_{d}}{Q}\right) Q m_{12}^{*} \sin \left(\omega T_{r}\right)}
$$

可以看出, 阈值电流与束流参数、返航束线光学矩阵以及高阶模有关。它正 比于束流动量, 表明束流能量越高, 高阶模引起的横向角偏离越小, 因此, 低能 部分更容易发生束流崩溃效应; 它与返航束线的矩阵 $m_{12}^{*}$ 成反比, 反映高阶模对 第一圈的角偏移经返航束线后对应的横向位移大小, $m_{12}$ 或 $m_{34}$ 越大, 横向位移 越大, 当返航相对相位 $\omega T_{r}$ 合适时, 激励的高阶模场放大; 它与高阶模分路阻抗 成反比, 其中 $R_{d} / Q$ 是由加速腔的几何决定, 因此, 衰减高阶模、降低 $Q$ 可以提 高阈值电流; 此外它与高阶模的极化方向有关。

阈值电流恒正, 要求 $m_{12}^{*} \sin \left(\omega T_{r}\right)$ 是负值。当 $m_{12}^{*} \sin \left(\omega T_{r}\right)>0$ 时, 束流是稳 定的, 但对高束团电荷量, 束流第二次通过加速腔对高阶模场的影响不能忽略, 对应的最大阈值电流需要用程序模拟计算。

\section{2 加速腔中的高阶模}

粒子与高阶模场交换能量的过程是高阶模横向磁场 $H_{\varphi}$ 对束流有横向偏转, 随后有横向位移, 当高阶模纵向电场方向 $E_{z}$ 与粒子运动方向相反时, 粒子把能 量交给高阶模场, $H_{\varphi}$ 决定束流偏转角的大小, 进而产生横向位移, $E_{z}$ 决定能量 交换的多少, 因此最关键的场是 $E_{z}$ 和 $H_{\varphi}$ 。 以下分析哪些模式对 BBU 效应影响 最大。

实际加速腔几何结构复杂, 各高阶模很难通过解析办法得到, 但它是由圆柱 形谐振腔演变来的, 因此它的谐振模式场分布和圆柱谐振腔特点很相似, 可以通 过分析圆柱形谐振腔的电磁场分布研究超导腔中高阶模的电磁场分布。

\subsection{1 圆柱形谐振腔}

圆柱形谐振腔如图 6.2 所示, 半径为 a, 腔长 1 。根据电磁场的特点, 把 $H_{z}=0$ 的模称为 $T M$ 模, $E_{z}=0$ 的模称为 $T E$ 模。 $T E$ 模没有纵向电场分量, 束流在 $E_{z}$ 方 向上无能量交换，不容易被加速的带电粒子所激励; 此外, 束流横向角偏离来源 于束流与横向磁场作用, 因此, $T M$ 模相比 $T E$ 模更危险。 


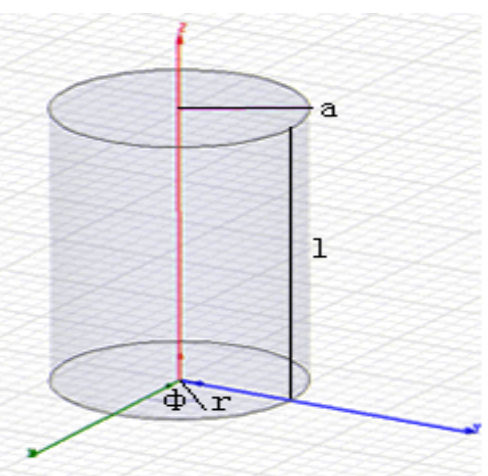

图 6.2 圆柱形谐振腔

对于 $T M_{m n p}$ 模式 ${ }^{[94]}$, 相应的场分布是:

$$
\begin{gathered}
E_{r}=-\frac{2}{k_{c}}\left(\frac{p \pi}{l}\right) E_{0} J_{m}^{\prime}\left(k_{c} r\right) \cos (m \varphi) \sin \left(\frac{p \pi}{l} z\right) \\
E_{z}=2 E_{0} J_{m}\left(k_{c} r\right) \cos (m \varphi) \cos \left(\frac{p \pi}{l} z\right) \\
E_{\varphi}=\frac{2 m}{k_{c} r}\left(\frac{p \pi}{l}\right) E_{0} J_{m}\left(k_{c} r\right) \sin (m \varphi) \sin \left(\frac{p \pi}{l} z\right) \\
H_{r}=-j \frac{2 m \omega \varepsilon}{k_{c} r} E_{0} J_{m}\left(k_{c} r\right) \sin (m \varphi) \cos \left(\frac{p \pi}{l} z\right) \\
H_{\varphi}=-j \frac{2 \omega \varepsilon}{k_{c}} E_{0} J_{m}^{\prime}\left(k_{c} r\right) \cos (m \varphi) \cos \left(\frac{p \pi}{l} z\right) \\
H_{z}=0 \\
\omega=c \sqrt{k_{c}^{2}+\left(\frac{p \pi}{l}\right)^{2}}
\end{gathered}
$$

$m=0,1,2, \cdots \cdots ; n=1,2,3, \cdots \cdots ; p=0,1,2, \cdots \cdots$; 其中 $k_{\mathrm{c}}=V_{\mathrm{m}} / \mathrm{a}, V_{\mathrm{m}}$ 是第一 类 $m$ 阶贝塞尔函数 $J_{m}(x)$ 的第 $n$ 个根, $J_{m}^{\prime}(x)$ 是第 $m$ 阶贝塞尔函数的一阶微分, $\mathrm{r}$ 是束流离轴线 $Z$ 的距离。

对于偶极模(即 $\mathrm{m}=1$ ), 当 $|x|<<1, J_{1}(x) \approx x / 2$, 纵向电场 $E_{z}$ 随 $\rho$ 线性增加, 决定了束流与高阶模交换能量的多少, 偶极模对束流影响最大, 是决定崩溃效应 最主要的模式。当 $\mathrm{p}=0$ 时, 横向磁场 $H_{\varphi}$ 不随 $\mathrm{z}$ 变化, 图 6.3 显示 $T M_{110}$ 模的电 磁场分布:

$$
\begin{gathered}
E_{z}=E_{0} J_{1}\left(k_{c} r\right) \cos (\varphi) \\
H_{\varphi}=-j \frac{\omega \varepsilon}{k_{c}} E_{0} J_{1}^{\prime}\left(k_{c} r\right) \cos (\varphi)
\end{gathered}
$$


束流离轴越远, 它与高阶模交换的能量越多, 束流沿加速腔运动受到的横向磁偏 转力不随 $\mathrm{z}$ 变化。
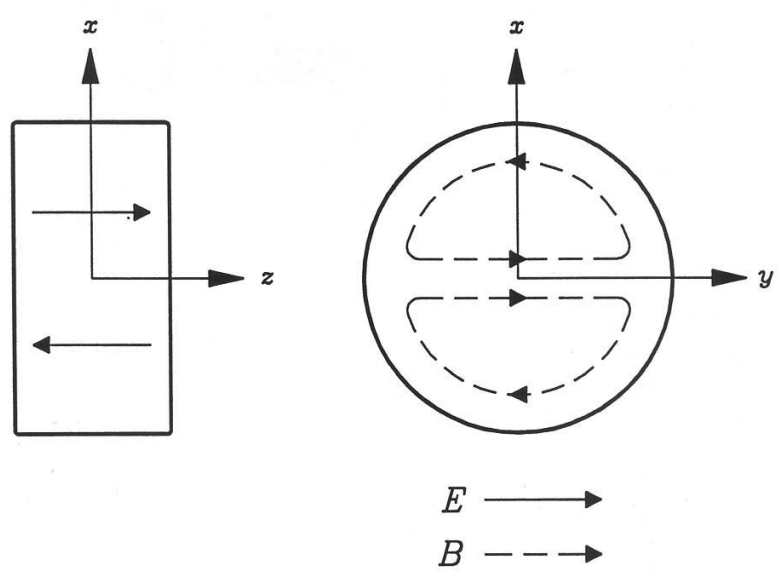

图 $6.3 T M_{110}$ 模的电磁场分布

多圈加速时, 束流第一次通过加速腔, 横向磁场力使得束流获得横向角偏离, 通过返航束线再次通过加速腔, 这个角偏离转化成横向位移, 离轴的束流通过电 场 $E_{z}$ 交换能量。可以看出, 不管束流第一次通过加速腔时有没有横向位移, 第 二圈时都很容易激励高阶模场。

\subsection{2 圆柱形波导的截止频率}

加速腔两端是圆柱形束管, 它限制了加速基模, 对加速腔内的某些高阶模也 有截止作用。

根据圆波导波动方程可求出各模式的截止波长 $\lambda_{c}$ 或截止频率 $f_{c}$ $\left(f_{c}=c / \lambda_{c}\right)$, 当电磁波频率 $f>f_{c}$ 时, 电磁波以行波的方式传播出去, 当电磁 波频率 $f<f_{c}$, 电磁波在波导内成截止状态, 从而束缚在加速腔内, 影响束流。

对于 $T M_{m n}$ 模, 截止波长:

$$
\left(\lambda_{c}\right)_{T M_{m n}}=\frac{2 \pi a}{\mu_{m n}}
$$

$\mathrm{m}=0,1,2, \cdots \cdots ; \mathrm{n}=1,2,3, \cdots \cdots, \mu_{m n}$ 是第一类 $\mathrm{m}$ 阶贝塞尔函数的第 $\mathrm{n}$ 个根, $\mathrm{a}$ 是 圆柱形波导的半径。前边分析影响 BBU 最大的模是偶极模, $T M_{11}$ 对应的截止波 长是 $1.64 \mathrm{a}, T M_{12}$ 对应的截止波长是 $0.90 \mathrm{a}, T M_{13}$ 对应的截止波长是 $0.62 \mathrm{a}$, 因 此, $T M_{11}$ 是截止频率最低的 $T M$ 模。TESLA 9 cell 超导腔的束管半径 $\mathrm{a}=0.039 \mathrm{~m}$, 
对应的截止频率是 $4.690 \mathrm{GHz}$ 。所需要研究 $T M$ 类型的高阶模主要是频率低于

4. $690 \mathrm{GHz}$ 的偶极模。

对于 $T E$ 类型的偶极模, 束管半径 $\mathrm{a}=0.039 \mathrm{~m}$ 最低截止频率约是 $2.26 \mathrm{GHz}$ 。

TESLA 超导腔模拟结果表明高阶模场不能严格划分为 TM 模或 TE 模, 多数情 况下, 它是两种模式的混合, 对这种类型的高阶模, 当频率高于 $2.26 \mathrm{GHz}$ 时, 高 阶模场都会通过束管传播出去, 后面考虑的高阶模最高频率到 $2.3 \mathrm{GHz}$ 。

\section{3 阈值电流}

以上分析了哪些高阶模对束流崩溃效应影响最大和需要考虑的高阶模频率 范围, 并且推导了一个加速腔内只有一个高阶模时对应的阈值电流。实际情况下, 加速器是多个加速腔组成, 每个加速腔又由多个加速单元组成 (北京大学主加速 器是由 2 个加速腔组成, 每个加速腔包含 9 个加速单元）, 每个加速单元高阶模 不止一个, 如果不同高阶模频率差别不大, 它们还会相互影响（如高阶模频率 $2 \mathrm{GHz}, \mathrm{Q}$ 值 $10^{5}-10^{6}$, 则高阶模带宽是 1-10kHz, 若其他高阶模频率偏离 $2 \mathrm{GHz}$ 小于 高阶模带宽, 它们之间会相互影响), 并且同一频率的高阶模还会出现模式极化, 它们有相同的频率、 $\mathrm{Q}$ 以及 $\mathrm{R} / \mathrm{Q}$, 只是极化角不同, 图 6.4 显示同一高阶模不同 极化方向的电场强度分布, 这种情况下必须借助程序来计算阈值电流。但这不意 味以上理论计算所给出的國值电流没有意义, 它可以快速找出最有害的高阶模, 直观分析各参数的重要性, 对如何进一步提高阈值电流有指导意义。
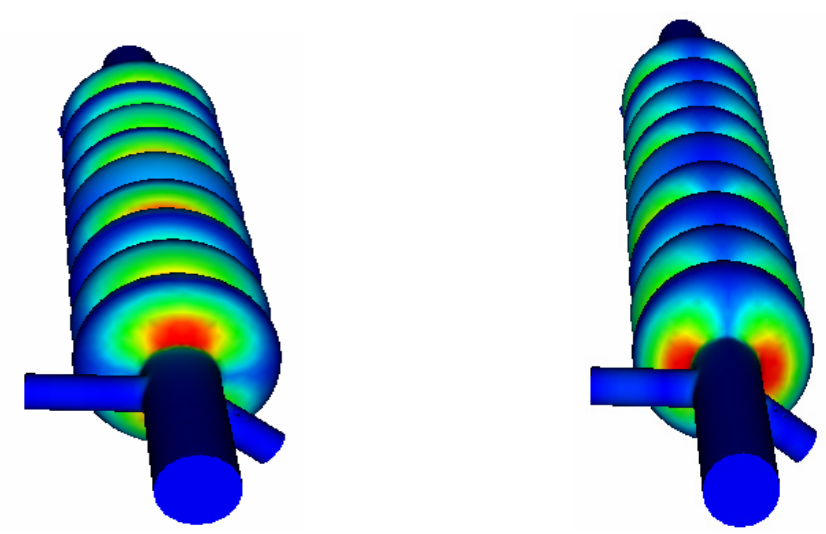

图 6.4 同一高阶模不同极化方向对应电场相对强度分布 


\subsubsection{TESLA 加速腔高阶模}

北京大学 ERL-FEL 装置上使用的加速器是 TESLA 9ce11 超导加速器, 它包括 两个高阶模耦合器, 高阶模耦合器的位置如图 6.5 所示, 位于 9ce11 腔两端, 优 化后高阶模耦合器的夹角是 $115^{\circ}$ 。

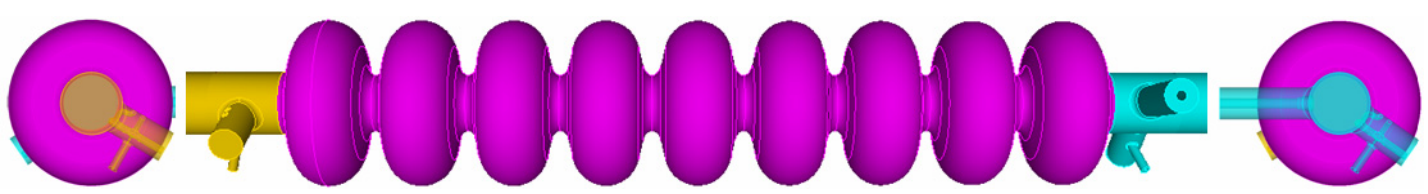

图 6.5 TESLA 9cell 超导加速器结构图

在 TTF 装置上, 计算和测量了 TESLA 9cel1 超导腔的偶极模 ${ }^{[95,96,97]}$, 主要是 高阶模的 $\mathrm{Q}_{\mathrm{ext}}$ 和频率，但是都没有提供关于高阶模极化角信息，并且由于制造的 工艺, 实际加速腔高阶模不完全相同, $\mathrm{Q}_{\mathrm{ext}}$ 和频率是离散分布。程序 $0 \mathrm{mega3} \mathrm{P}^{[98]}$ 模拟计算与多个超导腔测量值结果 ${ }^{[99]}$ 对比表明： $Q_{\text {ext }}$ 离散对应的最大值和最小值 差约 10 倍，高阶模频率与模拟值最大差 $10 \mathrm{MHz}$ 。

表 6.1 TESLA 9cell 偶极模参数 ${ }^{*}$

\begin{tabular}{|c|c|c|c|c|c|}
\hline Model ID & $\mathrm{f}(\mathrm{MHz})$ & $\begin{array}{l}\text { a_major } \\
(\mathrm{V} / \mathrm{mm})\end{array}$ & $\begin{array}{l}\text { polarization } \\
\text { angle (deg) }\end{array}$ & $\begin{array}{c}\mathrm{R} / \mathrm{Q}(\Omega / \\
\left.\mathrm{mm}^{2} / \text { cavity }\right)\end{array}$ & $\mathrm{Q}_{\text {ext }}$ \\
\hline 0 & 1620.898 & 0.00155 & 1.56 & 0.00005 & 502241.00 \\
\hline 1 & 1620.942 & 0.00152 & 94.09 & 0.00005 & 463673.00 \\
\hline 2 & 1628.904 & 0.00741 & -37.33 & 0.00121 & 98099.00 \\
\hline 3 & 1628.925 & 0.00740 & 52.21 & 0.00121 & 168667.00 \\
\hline 0 & 1642.049 & 0.00239 & 111.92 & 0.00013 & 45623.50 \\
\hline 1 & 1642.111 & 0.00239 & 19.27 & 0.00012 & 75262.10 \\
\hline 2 & 1659.987 & 0.01839 & 101.94 & 0.00733 & 26211.90 \\
\hline 3 & 1660.109 & 0.01855 & 11.58 & 0.00745 & 43235.10 \\
\hline 4 & 1682.052 & 0.00596 & 97.01 & 0.00076 & 16676.50 \\
\hline 5 & 1682.211 & 0.00641 & 8.72 & 0.00088 & 28878.60 \\
\hline 6 & 1707.256 & 0.07065 & 99.54 & 0.10517 & 11467.20 \\
\hline 7 & 1707.422 & 0.07177 & 9.01 & 0.10849 & 21076.70 \\
\hline 8 & 1734.321 & 0.08595 & 116.17 & 0.15322 & 8432.30 \\
\hline 9 & 1734.385 & 0.08580 & 25.92 & 0.15266 & 16456.50 \\
\hline 10 & 1755.804 & 0.01277 & -2.18 & 0.00334 & 41269.70 \\
\hline
\end{tabular}




\begin{tabular}{|c|c|c|c|c|c|}
\hline 11 & 1761.770 & 0.03241 & 90.04 & 0.02144 & 6860.55 \\
\hline 12 & 1763.127 & 0.03032 & 0.17 & 0.01875 & 12318.30 \\
\hline 13 & 1788.641 & 0.02659 & 93.72 & 0.01422 & 3834.84 \\
\hline 14 & 1789.414 & 0.02780 & 2.38 & 0.01554 & 6109.69 \\
\hline 15 & 1798.877 & 0.01803 & 94.06 & 0.00650 & 5822.13 \\
\hline 16 & 1799.365 & 0.01930 & 2.91 & 0.00745 & 9602.86 \\
\hline 17 & 1837.059 & 0.01563 & 98.22 & 0.00478 & 20529.20 \\
\hline 0 & 1873.727 & 0.06737 & 104.52 & 0.08713 & 33527.90 \\
\hline 1 & 1873.758 & 0.06674 & 15.03 & 0.08551 & 42679.90 \\
\hline 2 & 1879.973 & 0.03148 & 106.57 & 0.01896 & 49015.40 \\
\hline 3 & 1879.993 & 0.03101 & 17.42 & 0.01840 & 61090.90 \\
\hline 4 & 1884.065 & 0.00607 & 107.46 & 0.00070 & 77576.90 \\
\hline 5 & 1884.079 & 0.00593 & 17.29 & 0.00067 & 95211.30 \\
\hline 6 & 1886.527 & 0.00952 & 106.85 & 0.00173 & 148502.00 \\
\hline 7 & 1886.538 & 0.00929 & 18.01 & 0.00164 & 183939.00 \\
\hline 8 & 1887.789 & 0.00184 & 106.29 & 0.00006 & 516671.00 \\
\hline 9 & 1887.800 & 0.00180 & 15.25 & 0.00006 & 644600.00 \\
\hline 10 & 1929.762 & 0.01408 & -36.88 & 0.00369 & 6.59 \\
\hline 11 & 1930.722 & 0.01313 & 45.60 & 0.00321 & 6.48 \\
\hline 12 & 2270.482 & 0.00711 & -9.31 & 0.00080 & 129.13 \\
\hline 13 & 2283.688 & 0.00733 & 95.81 & 0.00085 & 4588.13 \\
\hline 14 & 2294.319 & 0.00724 & -23.05 & 0.00082 & 188.72 \\
\hline
\end{tabular}

* 感谢 SLAC 的 LI Zenghai 博士提供的 HOM 数据

这里以程序 0mega3P 模拟计算的高阶模参数作为标准。Omega3P 是 SLAC Advanced Computations Department 开发的, 该程序也被用到 JLAB 7-cel1 超 导加速腔和 ILC 加速腔高阶模计算。

表 6.1 列出计算的所有偶极模信息, 包括频率 $\mathrm{f}$ 、离轴激发对应的电压 a_major、极化角和 $\mathrm{Q}_{\mathrm{ext}}$, 激发时, 腔内储存的能量是 $4.427093909 \times 10^{-12} \mathrm{~J}$, 根据 这些参数得到 $\mathrm{R} / \mathrm{Q}\left(R / Q=V^{2} /(\omega U)\right)$ 。 
这里需要注意的是 $\mathrm{R} / \mathrm{Q}$ 的定义, 对基模, 定义 $R / Q=V^{2} /(\omega U), \mathrm{V}$ 是轴线上 对应的电压, 偶次模电压在轴上为 0 , 因此, 实验或模拟给出的电压是离轴一定 距离的电压, 常用场梯度表示场的相对电压, 为了与基模定义统一, 并直接用到 程序和 6.1 理论估算中, 各高阶模场梯度除以对应的波数 $\mathrm{k}$ 定义为高阶模电压, $\mathrm{R} / \mathrm{Q}$ 定义是 $R / Q=V^{2} /(\omega U) / k^{2}$ 。

\subsubsection{BBU 模拟程序}

模拟多圈束流崩溃效应的程序可分成两类: 粒子追踪和分析计算。其中,

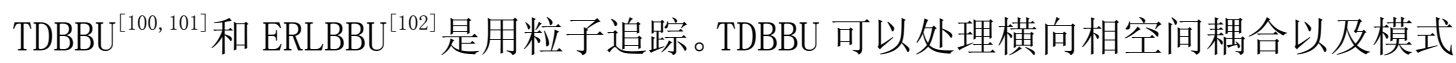
极化问题, 是时域空间粒子追踪, 所需要时间较长, 用 FORTRAN 编写, 运行在 unix 环境下。ERLBBU 是用 $\mathrm{C}++$ 编写, 运行在 windows 下, 可以处理横向相空间 耦合以及模式极化问题，运行时间比 TDBBU 或 $\mathrm{MATBBU}^{[103,104]}$ 快很多，可以很快给 出阈值电流, 输出窗口友好。MATBBU 是用 FORTRAN 编写, 它是在频域空间计算 矩阵的本征值, MATBBU 看到的是一定频域范围内的高阶模, TDBBU 和 ERLBBU 看 到的是全部的高阶模。此外, cornel1 大学还发展了 $\mathrm{BI}^{[105]}$ 程序。

JLAB 的红外 FEL 升级装置上采用这四个程序分别计算阈值电流，结果吻合 很好, 与实验测量对比 ${ }^{[106]}$, 误差在 $10 \%$ 以下，与公式 (6.13) 计算结果相符合的 也很好。因此, 本文用 ERLBBU 计算 PKU ERL-FEL 的阈值电流, 并用公式 (6.13) 找出危害最大的高阶模。

\subsection{3 阈值电流计算}

根据方程（6.13），阈值电流与束流能量、高阶模频率、 $\mathrm{R} / \mathrm{Q} 、 \mathrm{Q} 、 \mathrm{~m}_{12}$ 以及 返航时间有关。在束管截止频率以下，不同高阶模频率没有量级差别，束流能量 近似对应束流第一圈通过加速腔中心的能量, 主加速器是由两个 9cell 加速腔组 成，对应的能量分别是 $11.11 \mathrm{MeV}$ 和 $23.6 \mathrm{MeV}, \mathrm{ERL}$ 返航束线上, $\mathrm{x}$ 和 $\mathrm{y}$ 相空间 没有耦合, 耦合矩阵元素 $m_{32}=0$ 和 $m_{14}=0$, 因此, $m_{12}^{*}=m_{12} \cos ^{2} \alpha+m_{34} \sin ^{2} \alpha$, $m_{12}$ 和 $m_{34}$ 是从加速腔中心经返航线到同一加速腔中心的传输矩阵， $\alpha$ 是高阶模 极化角。程序 OPTIM 或 DIMAD 给出的传输矩阵都是在传输元件的起点或者终 点, 理论估算中矩阵取近似, $m_{12}$ 和 $m_{34}$ 值的对应点是加速腔出口, 第一个加速 腔出口, $m_{12}=1.22 m$ 和 $m_{34}=1.23 m$, 第二个加速腔出口, $m_{12}=1.86 m$ 和 
$m_{34}=2.98 m, m_{12}$ 与 $m_{34}$ 差别不是很大, 因此 $m_{12}^{*} \sim m_{12} \sim m_{34} \sim 1 m$ 。 $T_{r}$ 是束流在返 航束线上所经历的时间, 是 $173.5 \mathrm{RF}$ 周期, 相应的高阶模频率改变 $1 \mathrm{MHz}$ 等效 $\mathrm{RF}$ 相位改变 48 度, 因此, 高阶模频率精确度要求保留 $10 \mathrm{kHz}$ 以下, 除 $\sin \left(\omega T_{r}\right)$ 接近 0 的情况外, 其他的阈值电流精度估算都可以控制在 $10 \%$ 以内; 对 $\sin \left(\omega T_{r}\right)$ 接近 0 的高阶模, 可以看出阈值电流一般会很大, 因此, 不会影响阈值电流估算 的结论, 对阈值电流取决定性的高阶模 $\sin \left(\omega T_{r}\right)$ 都在 0.1 量级。第一个加速腔对 应的阈值电流 $I_{t h}^{a} \sim 5.31^{*} 10^{6} /\left(\frac{R_{d}}{Q}\right) Q$, 第二个加速腔对应的阈值流强 $I_{t h}^{b} \sim 1.13 * 10^{7} /\left(\frac{R_{d}}{Q}\right) Q$, 可以看出限制阈值流强的高阶模是 $\left(\frac{R_{d}}{Q}\right)$ 和 $Q$ 都很大的 高阶模, 实验和测量表明 TESLA 高阶模的 $Q$ 值最高到在 $10^{6}$, 因此, 本文重点考 虑的高阶模 $\left(\frac{R_{d}}{Q}\right)$ 取 10 以上, 并且 $Q$ 较大。

表 6.2 各高阶模阈值电流分析计算

\begin{tabular}{|c|c|c|c|c|c|c|c|}
\hline $\begin{array}{c}\text { Frequency } \\
(\mathrm{MHz})\end{array}$ & $\begin{array}{c}\mathrm{R} / \mathrm{Q} \\
(\Omega / \text { cavity })\end{array}$ & $\mathrm{Q}_{\mathrm{ext}}$ & $\sin (\omega \mathrm{Tr})$ & $m_{12}{ }^{* a}$ & $m_{12}{ }^{* b}$ & $\mathrm{I}_{\mathrm{th}} \mathrm{a}(\mathrm{A})$ & $\mathrm{I}_{\text {th }} \mathrm{b}(\mathrm{A})$ \\
\hline 1788.641 & 10.14303 & 3834.84 & -0.98 & 1.23 & 2.98 & 12.71 & 11.15 \\
\hline 1789.414 & 11.07233 & 6109.69 & -0.91 & 1.22 & 1.86 & 7.90 & 11.00 \\
\hline 1879.994 & 11.88166 & 61090.9 & -0.55 & 1.22 & 1.96 & 1.15 & 1.53 \\
\hline 1879.974 & 12.24483 & 49015.4 & -0.57 & 1.23 & 2.90 & 1.35 & 1.22 \\
\hline 1763.128 & 13.76286 & 12318.3 & 0.93 & 1.22 & 1.86 & -3.13 & -4.36 \\
\hline 1761.771 & 15.76478 & 6860.55 & 0.72 & 1.23 & 2.99 & -6.26 & -5.48 \\
\hline 1873.759 & 55.5781 & 42679.9 & 0.45 & 1.22 & 1.94 & -0.43 & -0.58 \\
\hline 1873.728 & 56.63595 & 33527.9 & 0.43 & 1.23 & 2.92 & -0.57 & -0.51 \\
\hline 1707.257 & 82.33743 & 11467.2 & -0.80 & 1.23 & 2.96 & 0.67 & 0.59 \\
\hline 1707.422 & 84.9278 & 21076.7 & -0.71 & 1.22 & 1.89 & 0.40 & 0.55 \\
\hline 1734.385 & 115.8141 & 16456.5 & 0.16 & 1.22 & 2.08 & -1.60 & -2.00 \\
\hline 1734.321 & 116.2445 & 8432.3 & 0.22 & 1.23 & 2.77 & -2.34 & -2.21 \\
\hline
\end{tabular}

表 6.2 计算 $\left(\frac{R_{d}}{Q}\right)$ 在 10 以上每个高阶模对应的阈值电流, 最小的正的阈值电 流是 $0.4 \mathrm{~A}$, 对应的频率是 $1707.42 \mathrm{MHz}$, 频率为 $1707.25 \mathrm{MHz}$ 对应的阈值与它同 
一个量级。对阈值电流为负的情况, 公式计算不再有效, 需要用程序计算。

表 6.3 是用 ERLBBU 程序模拟计算的每个高阶模对应的阈值电流, 最有害 的高阶模与分析计算结论一致; 在分析计算有效的情况下 $\left(m_{12}^{*} \sin \left(\omega T_{r}\right)<0\right)$, 对 应的國值电流差别约 $10 \%$, 误差的来源之一是分析计算所用的传输矩阵; 分析计 算不适用的情况下 $\left(m_{12}^{*} \sin \left(\omega T_{r}\right)>0\right)$, ERLBBU 计算的阈值电流都在 $1 \mathrm{~A}$ 以上, 危害不大。
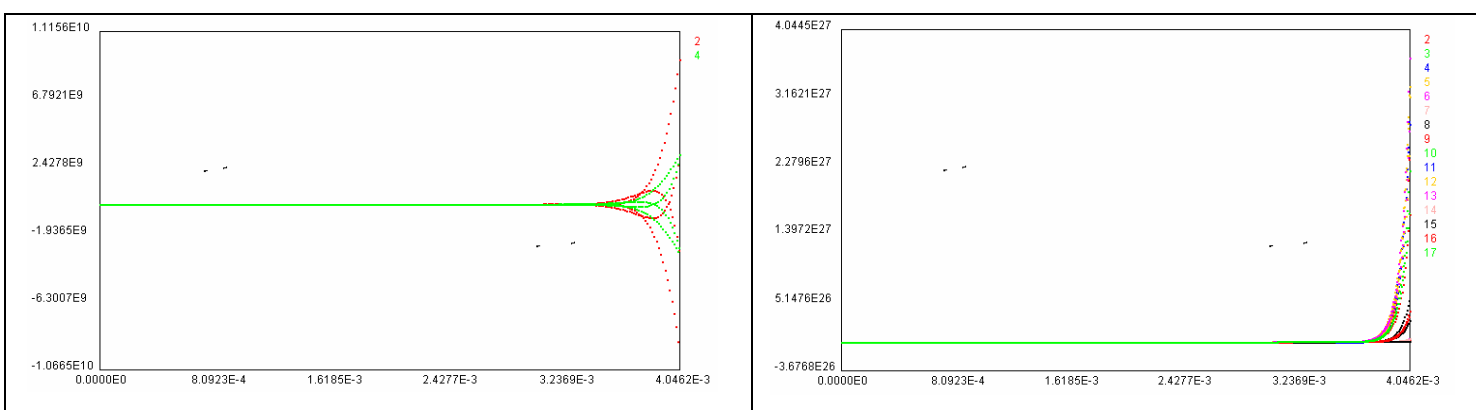

图 6.6a 横向位移随时间变化 ( 2 为 $\mathrm{x}, 4$ 位 $\mathrm{y}$, $\mathrm{I}=0.311 \mathrm{~A}$ )

图 6.6b 高阶模电压随时间变化（I=0.311A）
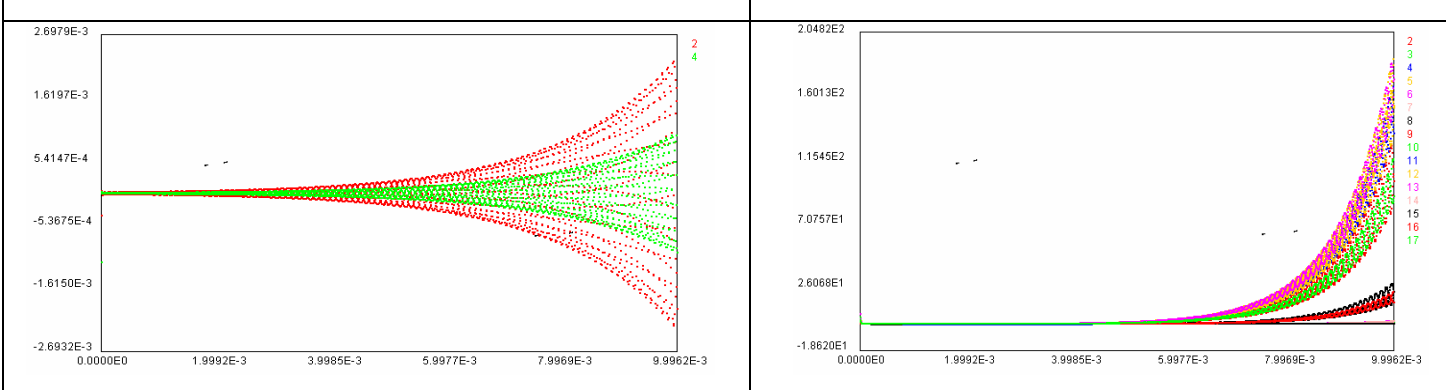

图 6.6c 横向位移随时间变化 (2 为 $\mathrm{x}, 4$ 位 $\mathrm{y}$, $\mathrm{I}=0.301 \mathrm{~A}$ ）

图 6.6d 高阶模电压随时间变化 $(\mathrm{I}=0.301 \mathrm{~A})$

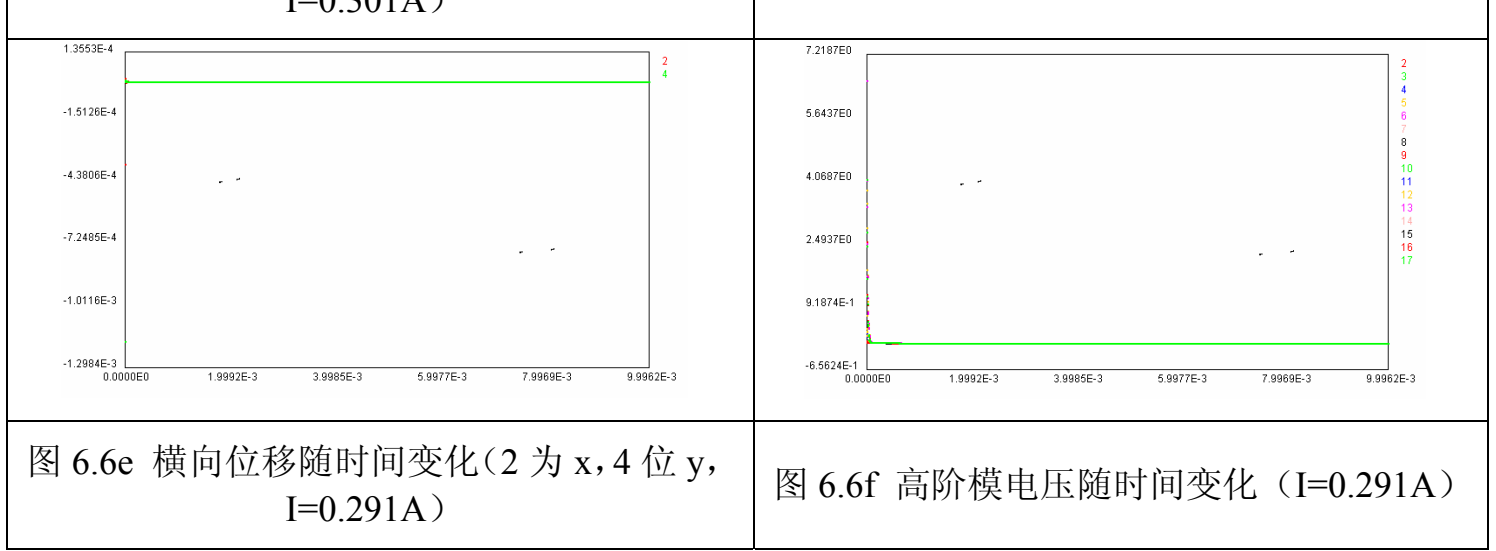

以上给出的是单个高阶模只在一个加速腔中存在的情况, 考虑两个加速腔包 含所有的高阶模, 模拟计算给出设计的束线阈值电流是 $0.30012 \mathrm{~A}$, 它考虑了不 同高阶模之间的相互影响以及两加速腔之间的影响, 比单个高阶模对应的阈值电 
流稍小。考虑实际加速腔高阶模参数 $\mathrm{Q}_{\mathrm{ext}}$ 以及频率的离散分布 ${ }^{[107]}$, 进一步估算 它们对阈值电流的最低限制范围:（1） Q ext 差 10 倍, 表明阈值电流可能降低到 原来的 $1 / 10$ 或增大 10 倍。（2）频率离散 $10 \mathrm{MHz}$, 对应 $\omega T_{r}$ 变化范围是 480 度, $\sin \left(\omega T_{r}\right)$ 从-1 变化到 1 , 当 $\sin \left(\omega T_{r}\right)=-1$ 时, 阈值电流最小。从表 6.2 可以估算, 对阈值电流影响最大的两个高阶模, 其 $\sin \left(\omega T_{r}\right)$ 限制阈值电流最小到原来的 0.7 。 总结这两项对高阶模的影响, 该设计对应的阈值电流最小到 $21 \mathrm{~mA}$, 能够保证设 计的 $3 \mathrm{~mA}$ 运行流强。

图 6.6 给出 ERLBBU 模拟不同流强下, 粒子横向位移随时间变化曲线以及 $\mathrm{R} / \mathrm{Q}$ 最大的四个高阶模电压 (对应第一个加速腔和第二个加速腔的第一圈和第二 圈）随时间变化。流强大于阈值电流时（0.311A）, 如图 6.6a, 粒子很快发散丢 失; 流强小于阈值电流时 (0.291A), 如图 6.6e, 粒子可以传输的很好; 流强在 阈值电流附近时 (0.301A), 横向位移 $(\mathrm{x} / \mathrm{y})$ 随时间震荡, 如图 6.6c。对比不 同流强下的高阶模电压, 高于阈值电流时, 高阶模电压增长很快, 表明束流传给 高阶模的能量远大于高阶模消耗的能量; 低于阈值电流, 高阶模电压无累积, 表 示高阶模损耗的能量大于与束流交给高阶模的能量。

表 6.3 ERLBBU 计算各高阶模的阈值电流

\begin{tabular}{|c|c|c|c|c|}
\hline Frequency(MHz) & $\mathrm{R} / \mathrm{Q}(\Omega /$ cavity $)$ & $\mathrm{Q}_{\text {ext }}$ & $\mathrm{I}_{\text {th }} \mathrm{a}(\mathrm{A})$ & $\mathrm{I}_{\mathrm{th}} \mathrm{b}(\mathrm{A})$ \\
\hline 1788.6410 & 10.14303 & 3834.840 & 11.71870 & 11.03000 \\
\hline 1789.4143 & 11.07233 & 6109.690 & 8.76870 & 12.71250 \\
\hline 1879.9938 & 11.88166 & 61090.900 & 1.22100 & 1.67340 \\
\hline 1879.9736 & 12.24483 & 49015.400 & 1.21400 & 1.16950 \\
\hline 1763.1278 & 13.76286 & 12318.300 & 52.75000 & 76.55000 \\
\hline 1761.7705 & 15.76478 & 6860.550 & 38.67500 & 36.37500 \\
\hline 1873.7585 & 55.57810 & 42679.900 & 14.46000 & 20.11000 \\
\hline 1873.7275 & 56.63595 & 33527.900 & 11.44000 & 10.95600 \\
\hline 1707.2567 & 82.33743 & 11467.200 & 0.60531 & 0.57383 \\
\hline 1707.4222 & 84.92780 & 21076.700 & 0.43400 & 0.61990 \\
\hline 1734.3854 & 115.81407 & 16456.500 & 1.82900 & 2.36700 \\
\hline 1734.3211 & 116.24448 & 8432.300 & 2.20460 & 2.20120 \\
\hline
\end{tabular}




\section{4 阈值电流测量和提高阈值电流的方法}

\subsection{1 阈值电流测量}

高阶模能量用电压表示 ${ }^{[108]}$

$$
U=\frac{V_{a}^{2}}{\omega a^{2}\left(\frac{\omega}{c}\right)^{2}\left(\frac{R}{Q}\right)}
$$

代入方程（6.11）

$$
\frac{d U}{d t}=-U \frac{\omega}{Q_{L}} \frac{I_{t h}-I_{0}}{I_{t h}}
$$

化简解方程（6.25），得到:

$$
U=U_{0} \exp \left(-t \frac{\omega}{Q_{L}} \frac{I_{t h}-I_{0}}{I_{t h}}\right)
$$

相应的高阶模电压随时间变化

$$
V=V_{0} \exp \left(-t \frac{\omega}{2 Q_{L}} \frac{I_{t h}-I_{b}}{I_{t h}}\right)
$$

根据电压变化曲线，定义有效品质因子和有效衰减时间，

$$
\begin{gathered}
Q_{\text {eff }}=Q_{L} \frac{I_{t h}}{I_{t h}-I_{0}} \\
\tau_{\text {eff }}=\tau_{0} \frac{I_{t h}}{I_{t h}-I_{0}}
\end{gathered}
$$

当加速电流为 0 时有效品质因子就是高阶模的固有 $Q_{L}$, 高阶模电压随时间 衰减, 衰减时间常数 $\tau_{0}=Q_{L} / \omega$; 当 $I_{t h}=I_{0}$ 时, $Q_{\text {eff }}$ 无穷大, 对应的高阶模 $\mathrm{s}$ 电压 不随时间变化; 当流强大于阈值电流，高阶模电压随时间指数增长。

阈值电流的测量有以下三种方法:

第一, 测量阈值电流可以根据阈值电流定义, 增加加速流强直到束流丢失, 从而确定阈值电流。

第二, 根据方程 (6.28), 加速腔和束线确定后, $Q_{\text {eff }}$ 只随流强变化。改变 流强, 测量相应的高阶模的有效品质因子 ${ }^{[109]}$ 。1/ $Q_{\text {eff }}=1 / Q_{L}\left(1-\frac{I_{0}}{I_{t h}}\right), 1 / Q_{\text {eff }}$ 随 $I_{0}$ 线性变化, 当 $I_{0}=I_{t h}$ 时, $1 / Q_{\text {eff }}=0$, 在阈值电流以下, 拟和直线, 并外延可以得 到 $I_{t h}$ 。

第三，根据方程（6.29），高阶模电压有效衰减时间常数随流强变化。改变 流强，测量高阶模功率/电压随时间变化，找到衰减时间，阈值电流确定方法与 
测量 $Q_{\text {eff }}$ 曲线类似, 即外延拟合曲线。

\subsection{2 提高阈值电流的方法}

6.1 节给出阈值电流随各参数的变化关系，根据表达式（6.13）, 得到四种 可能提高國值电流的方法。

第一, 增加电子束能量。因为阈值电流与电子能量成正比, 可以把较危险高 阶模加速腔放在电子能量较高处。

第二, 减小 $R / Q$ 。 $R / Q$ 由加速腔结构决定, 因此, 改变 $R / Q$ 需要改变加速腔 结构。

第三, 改变高阶模的性能, 包括降低 $\mathrm{Q}$ 和改变高阶模频率。降低 $\mathrm{Q}$ 值是用 高阶模耦合器尽可能衰减危险高阶模, 是高流强能量回收加速器设计重点考虑的 办法; 改变高阶模频率是改变 $\sin \left(\omega T_{r}\right)$ 项的符号, 使得 $m_{12}^{*} \sin \left(\omega T_{r}\right)>0$, 从而提 高阈值电流。

第四, 改变机器设计, 包括光学传输矩阵和返航时间。改变返航时间与改变 高阶模频率目的一样, 保证 $m_{12}^{*} \sin \left(\omega T_{r}\right)$ 大于 0 。改变 $m_{12}^{*}$ 接近 0 , 阈值流强趋近 无限大, 它是通过改变光学传输矩阵元素 $m_{12} 、 m_{14} 、 m_{32}$ 和 $m_{34}$ 。对 $\mathrm{x}$ 和 $\mathrm{y}$ 平面 不耦合的情况 ${ }^{[110]}, m_{14}=m_{32}=0$, 要求 $m_{12} 、 m_{34}$ 和极化角满足

$$
\alpha=\arctan \left(\sqrt{-\frac{m_{12}}{m_{34}}}\right)
$$

对高阶模极化角接近 0 度或 90 度情况, $\sin (2 \alpha) \sim 0$, 因此, 改变光学传输 矩阵, 耦合 $\mathrm{x}$ 和 $\mathrm{y}$ 平面, 使得 $m_{12}=m_{34}=0^{[111]}$, 此时

$$
m_{12}^{*}=\left(m_{14}+m_{32}\right) \sin (2 \alpha) / 2 \sim 0
$$

依赖于极化角。

对高阶模极化角远离 0 度或 90 度情况, 当 $m_{12}=m_{34}=0$ 时, 可能的办法是

或

$$
m_{14}+m_{32}=0
$$

它适用于任意极化角情况。

$$
m_{14}=-m_{32}
$$

$\mathrm{x}$ 和 $\mathrm{y}$ 平面的耦合是通过螺线管或者旋转四极铁实现, 螺线管实现办法最 直观，当 $K L=\pi / 2$ 时（其中 $K=B_{0} /(2 B \rho), L$ 是螺线管长度），对应的横向相 
空间的传输矩阵 $R=\left(\begin{array}{cc}0 & M \\ -M & 0\end{array}\right)$, 满足条件 $m_{12}=m_{34}=0$, 但是束流能量较高时, 所需要螺线管场强很高, 如 $30 \mathrm{MeV}, 75 \mathrm{~cm}$ 的螺线管长度, 要求场强到 $4.1 \mathrm{kG}$; 旋转四极铁需要多块组合才能实现 ${ }^{[112]}$ 。

若一个加速腔组成主加速器, 耦合 $\mathrm{x}$ 和 $\mathrm{y}$ 平面, 不难满足上面两种光学传输。 对多个加速腔组成的主加速器, 如两个加速腔, 保证每个加速腔的高阶模对应的 传输矩阵都能保持相应的要求, 加速腔之间的传输元件需要有特别要求。对前者, 要求加速腔之间的传输元件 $\mathrm{x}$ 和 $\mathrm{y}$ 平面不能有耦合; 对后者, 则要求加速腔部分 $\mathrm{x}$ 和 $\mathrm{y}$ 平面的传输矩阵完全相同, 加速腔之间不能包含四极铁元件。

改变光学传输矩阵或返航时间在提高特定高阶模阈值电流的同时, 也会影响 其他高阶模, 改变其对应的國值电流, 因此, 需要全面考虑。

\section{5 本章小结}

本章介绍了多圈束团崩溃效应的概念, 给出单腔单个高阶模情况下的阈值电 流, 它对理解限制阈值电流的因素有重要意义, 包括高阶模参数、返回束线光线 传输和束流参数; 在此基础上, 理论分析提高阈值电流的方法, 并介绍了测量阈 值电流的办法。针对北京大学 ERL-FEL 装置, 根据 Omega3P 模拟给出的 TESLA 型 9ce11 超导腔高阶模信息, 用理论分析和程序 ERLBBU 模拟计算分别找到最危 险的高阶模, 两种方法给出的结论一致, 最危险的高阶模对应的频率是 1707.42 $\mathrm{MHz}$ 和 $1707.25 \mathrm{MHz}$, 这两个模式极化角差别是 90 度, 频率差别不大, 很容易 相互影响, 两种办法计算的单模阈值电流值差别小于 $10 \%$, 因此, 用理论公式可 以最有效的找到危险高阶模。实际加速器有多个加速腔, 每个加速腔高阶模也很 多, 高阶模之间和加速腔之间相互影响, 必须用程序模拟计算阈值电流。北京大 学 ERL-FEL 装置阈值电流估算最小是 $21 \mathrm{~mA}$, 比设计的 $3 \mathrm{~mA}$ 运行流强高。 



\section{第七章 总结}

本论文是在北京大学在建装置的基础上, 研究了 ERL-FEL 的物理问题, 设 计了 ERL-FEL 传输束线, 对能量回收模式下的束流动力学进行研究, 对设计系 统的可靠性和稳定性进行分析, 并对 ERL 中多圈束团崩溃效应进行讨论和模拟 计算。

论文前两章综述了能量回收的历史、现状及发展趋势, 对机器总体参数进行 初步的优化, 研究了束团电荷、束团长度、束流横向和纵向发射度等参数对自由 电子激光功率的影响。在电子束品质满足 FEL 要求下, 对输出激光功率影响最 大的是束团电荷量和束团长度; PKU-ERL-FEL 的输出光波长范围是 $6 \sim 65 \mu \mathrm{m}$, $120 \mathrm{pC}$ 时输出激光的平均功率约 $900 \mathrm{~W}$ 。分析了能量回收和非能量回收两种模式 下系统对微波功率源的要求以及超导腔最佳工作参数: 能量回收下, 微波功率主 要由麦克风效应决定; 非能量回收模式下, 微波功率主要由束流流强决定。

在总体参数要求下, 论文第三章和第四章优化设计了系统前端传输系统和具 有 FEL 装置的返航束线传输系统。研究了原设计的 $300 \mathrm{pC}$ 电荷量的 $3+1 / 2$ cell DC-SC 光阴极注入器工作在低电荷下的束流品质, 结果表明原设计在低电荷、 高梯度下, 首腔对束流有过聚焦效应, 并对电子束的发射度带来严重影响。论文 运用模型分析过聚焦情况下, 空间电荷效应对发射度影响的变化趋势, 提出避免 过聚焦的办法，包括降低场梯度、增大束团电荷和减小束斑尺寸等。研究了不同 并束段结构的误差敏感度和空间电荷效应影响, 确定适合北京大学装置的三块磁 铁偏转并束段结构。返航束线上，分析了 FEL 和 ERL 对束流横向和纵向相空间 要求以及二阶校正理论, 提出可调的消色散对称 ARC 结构, 结合路径调节装置, 路径调控范围等效 RF 相位是可以涵盖由于 FEL 和准直误差对返航注入主加速器 相位的影响, 保证返航电子束正确地注入主加速器。对返航束线的动力学进行研 究, 结果表明 CSR 效应对束流品质影响较小; 大能散下, ARC2 的纵向相空间 高阶修正对能量回收后的能散有明显的影响,加入六极铁进行修正。

论文第五章和第六章是对所设计系统的进一步完善, 验证设计的稳定性和可 靠性。理论分析 corrector 和 BPM 在束线上的工作特点, 运用解析计算方法设计 优化了轨道校正系统, 使得校正后束流中心轨道在可接受范围, 同时优化 BPM 和 corrector 数目, 优化的 BPM 个数是 26 个, $\mathrm{x}$ 方向 corrector 个数是 $15, \mathrm{y}$ 方向 是 17 个, 校正后的轨道偏离值可以控制到 $2 \mathrm{~mm}$ 以下; 根据轨道校正系统, 研究 
了系统对运行误差、安装误差和加工误差等敏感程度以及容忍的误差范围, 确定 了系统设计的稳定性和可靠性。特别研究了高平均功率 ERL-FEL 的关键问题 ——多圈加速束流崩溃效应的影响, 确定了加速腔中最有害的高阶模, 获得本设 计的装置的阈值电流约为 $21 \mathrm{~mA}$, 大于设计的 $3 \mathrm{~mA}$ 运行流强。

下一步的工作建议有:

(1) 诊断系统的优化设计。该诊断系统不仅能测量束流参数（如能散、束团长 度、横向相空间参数、发射度等), 还要测量机器的运行参数 (如元件传输矩阵、 色散等), 使它能够监测和校正机器运行时各种可能出现的问题。建议应注意发 展无阻拦的探测技术。

(2) 进一步深入研究返航束流品质对其在加速腔内转换为电磁场的品质及对加 速束流品质的影响。 


\section{附录 1}

系统前终端束线输入文件 (PARMELA)

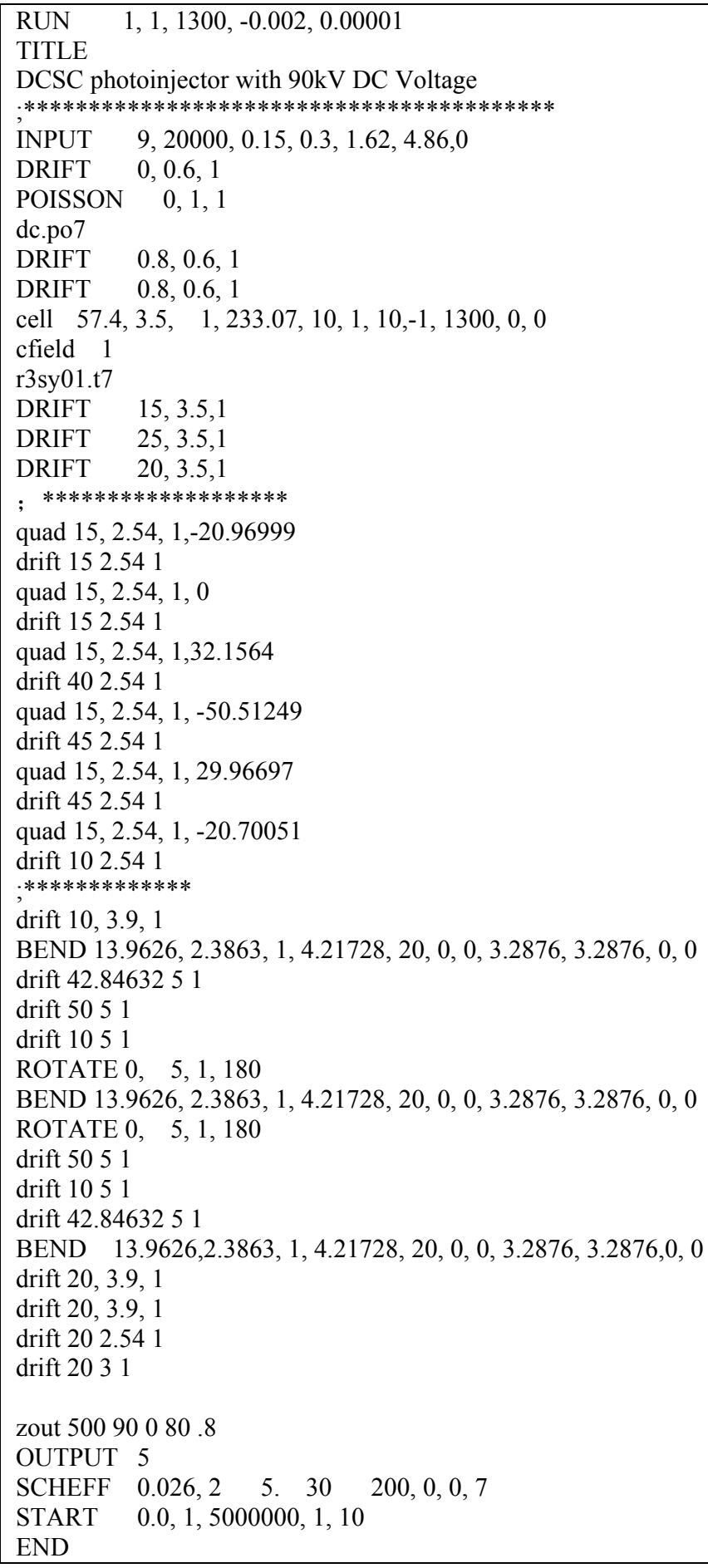




\section{附录 2}

返航束线 lattice 文件输入文件(elegant)

BARC11: $S B E N, L=0.392699, A N G L E=0.785398163397448, E 1=0.392699081698724, \&$ E2 $=0.392699081698724$, HGAP $=0.025$,EDGE_ORDER $=1$

BARC12: $\mathrm{SBEN}, \mathrm{L}=0.392699, \mathrm{ANGLE}=0.785398163397448, \mathrm{E} 1=0.392699081698724, \&$ $\mathrm{E} 2=0.392699081698724, \mathrm{HGAP}=0.025$,EDGE ORDER $=1$

BARC13: $\mathrm{SBEN}, \mathrm{L}=0.392699, \mathrm{ANGLE}=0.785398163397448, \mathrm{E} 1=0.392699081698724, \&$ $\mathrm{E} 2=0.392699081698724, \mathrm{HGAP}=0.025$,EDGE ORDER $=1$

BARC14: $\mathrm{SBEN}, \mathrm{L}=0.392699, \mathrm{ANGLE}=0.785398163397448, \mathrm{E} 1=0.392699081698724, \&$ $\mathrm{E} 2=0.392699081698724, \mathrm{HGAP}=0.025$,EDGE ORDER $=1$

BARC21: SBEN,L=0.392699,ANGLE $=0.785398163397448, E 1=0.392699081698724, \&$ $\mathrm{E} 2=0.392699081698724, \mathrm{HGAP}=0.025$,EDGE ORDER $=1$

BARC22: $\mathrm{SBEN}, \mathrm{L}=0.392699, \mathrm{ANGLE}=0.785398163397448, \mathrm{E} 1=0.392699081698724, \&$ $\mathrm{E} 2=0.392699081698724, \mathrm{HGAP}=0.025$,EDGE ORDER $=1$

BARC23: SBEN,L=0.392699,ANGLE $=0.785398163397448, E 1=0.392699081698724, \&$ $\mathrm{E} 2=0.392699081698724, \mathrm{HGAP}=0.025$,EDGE_ORDER $=1$

BARC24: $\mathrm{SBEN}, \mathrm{L}=0.392699, \mathrm{ANGLE}=0.785398163397448, \mathrm{E} 1=0.392699081698724, \&$ $\mathrm{E} 2=0.392699081698724, \mathrm{HGAP}=0.025$,EDGE_ORDER $=1$

$\mathrm{BCH} 1: \mathrm{SBEN}, \mathrm{L}=0.40824, \mathrm{ANGLE}=0.349065850398866, \mathrm{E} 2=0.349065850398866, \mathrm{HGAP}=0.025, \&$ EDGE ORDER $=1$

$\mathrm{BCH} 2: \overline{\mathrm{S} B E N}, \mathrm{~L}=0.40824, \mathrm{ANGLE}=-0.349065850398866, \mathrm{E} 1=-0.349065850398866, \&$ HGAP $=0.025$,EDGE ORDER $=1$

BCH3: $\mathrm{SBEN}, \mathrm{L}=0.40824, \mathrm{ANGLE}=-0.349065850398866, \mathrm{E} 2=-0.349065850398866, \&$

HGAP $=0.025$,EDGE ORDER $=1$

BCH4: $\mathrm{SBEN}, \mathrm{L}=0.40824, \mathrm{ANGLE}=0.349065850398866, \mathrm{E} 1=0.349065850398866, \mathrm{HGAP}=0.025, \&$ EDGE ORDER $=1$

BEXT1: SBEN,L=0.143996,ANGLE=0.06475171524898959,E2 $=0.06475171524898959, \&$ HGAP $=0.025$,EDGE_ORDER $=1$

BEXT2: $\mathrm{SBEN}, \mathrm{L}=0.287992, \mathrm{ANGLE}=-0.129503430497979, \mathrm{E} 1=-0.06475171524898959, \&$ $\mathrm{E} 2=-0.06475171524898959, \mathrm{HGAP}=0.025$,EDGE_ORDER $=1$

BEXT3: SBEN,L=0.143996,ANGLE $=0.06475171524898959, \mathrm{E} 1=0.06475171524898959, \&$ HGAP $=0.025$,EDGE_ORDER $=1$

BRINJ1: SBEN $, \mathrm{L}=0.14399, \mathrm{ANGLE}=0.06474892272218639, \mathrm{HGAP}=0.025, \mathrm{EDGE}$ ORDER $=1$ BRINJ2: $\mathrm{SBEN}, \mathrm{L}=0.28798, \mathrm{ANGLE}=-0.129498019977298, \mathrm{HGAP}=0.025, \mathrm{EDGE} \quad \mathrm{O} \mathrm{RDER}=1$ BRINJ3: SBEN,L=0.14399,ANGLE=0.06474892272218639,E1=-0.284314135149876,\& $\mathrm{HGAP}=0.025, \mathrm{EDGE}$ ORDER $=1$

CAV1: RFCA,L=1.3492, VOLT $=12.73320 \mathrm{e}$, PHASE=79,FREQ $=1300000000$, CHANGE_P0=1,\& END1 FOCUS $=1$,END2 FOCUS $=1$, BODY FOCUS MODEL $=" S R S "$

CAV11: RFCA,L=1.3492, VOLT=12.73320e 6 ,PHASE $=260$, FREQ $=1300000000$, CHANGE_P $0=1, \&$ END1 FOCUS $=1$, END2 FOCUS $=1$, BODY FOCUS MODEL $=" S R S "$

CAV2: $\bar{R} F C A, L=1.3492, \bar{V}$ OLT $=12.73320 \mathrm{e} 6, \bar{P} H A S E=79, F R E Q=1300000000, C H A N G E \_P 0=1, \&$ END1_FOCUS $=1$, END2_FOCUS $=1$,BODY_FOCUS_MODEL $=" S R S "$

CAV21: RFCA,L $=1.3492$, VOLT $=12.73320 \mathrm{e}$, ,PHASE $=260, \mathrm{FREQ}=1300000000$, CHANGE $\mathrm{P} 0=1, \&$ END1_FOCUS $=1$, END2_FOCUS $=1$,BODY_FOCUS_MODEL="SRS"

FEL: WIGGLER,L $=1.62, \overline{\mathrm{RADIUS}}=0.3666, \mathrm{~K}=0.7, \mathrm{POL} \overline{\mathrm{ES}}=121$

IIPM1: MONI

IIPM10: MONI

IIPM11: MONI

IIPM12: MONI

IIPM13: MONI

IIPM14: MONI

IIPM15: MONI

IIPM16: MONI

IIPM17: MONI

IIPM18: MONI

IIPM19: MONI

IIPM2: MONI

IIPM20: MONI

IIPM21: MONI

IIPM22: MONI

IIPM23: MONI

IIPM24: MONI

IIPM25H: MONI

IIPM25V: MONI

IIPM26: MONI 
IIPM27: MONI
IIPM3: MONI

IIPM4: MONI

IIPM5: MONI

IIPM6: MONI

IIPM7: MONI

IIPM8: MONI

IIPM9: MONI

INJERROR: MALIGN,ON PASS $=0$

KMBC10H: HKICK,L=1e-008

KMBC10V: VKICK,L=1e-008

KMBC11H: HKICK,L=1e-008

KMBC11V: VKICK,L=1e-008

KMBC12H: HKICK,L=1e-008

KMBC12V: VKICK,L=1e-008

KMBC13H: HKICK,L $=1 \mathrm{e}-008$

KMBC13V: VKICK,L=1e-008

KMBC14H: HKICK,L=1e-008

KMBC14V: VKICK,L=1e-008

KMBC15H: HKICK,L=1e-008

KMBC15V: VKICK,L=1e-008

KMBC16V: VKICK,L=1e-008

KMBC17V: VKICK,L $=1 \mathrm{e}-008$

KMBC1H: HKICK,L=1e-008

KMBC1V: VKICK,L=1e-008

KMBC2H: HKICK,L=1e-008

KMBC2V: VKICK,L=1e-008

KMBC3H: HKICK, $L=1 \mathrm{e}-008$

KMBC3V: VKICK,L $=1 \mathrm{e}-008$

KMBC4H: HKICK,L $=1 \mathrm{e}-008$

KMBC4V: VKICK,L=1e-008

KMBC5H: HKICK,L=1e-008

KMBC5V: VKICK,L=1e-008

KMBC6H: HKICK,L=1e-008

KMBC6V: VKICK,L=1e-008

KMBC7H: HKICK,L=1e-008

KMBC7V: VKICK,L $=1 \mathrm{e}-008$

KMBC8H: HKICK,L=1e-008

KMBC8V: VKICK,L=1e-008

KMBC9H: HKICK,L=1e-008

KMBC9V: VKICK,L=1e-008

LA: DRIF,L $=0.035$

LA1: DRIF, $\mathrm{L}=0.035$

LAA: DRIF, $\mathrm{L}=0.5$

LAA1: DRIF, $\mathrm{L}=0.5$

LAB: DRIF, $\mathrm{L}=0.2$

LAB1: DRIF, $\mathrm{L}=0.2$

OA4: DRIF, $\mathrm{L}=0.5$

OACC: DRIF,L $=3.4334$

OARC1: DRIF,L $=0.2$

OARC11: DRIF, $\mathrm{L}=0.3$

OARC12: DRIF, $\mathrm{L}=0.4$

s11: sextupole, $\mathrm{l}=0.15, \mathrm{k} 2=-0.94679014087144 \mathrm{E} 02$

OARC13: DRIF,L $=0.25$

OARC14: DRIF, $\mathrm{L}=0.45$

OARC2: DRIF, $\mathrm{L}=0.2$

OARC21: DRIF, $\mathrm{L}=0.3$

OARC22: DRIF, $\mathrm{L}=0.4$

s12: sextupole, $\mathrm{l}=0.15, \mathrm{k} 2=1.94679014087144 \mathrm{E} 02$

OARC23: DRIF, $\mathrm{L}=0.25$

OARC24: DRIF,L $=0.45$

OCH1: DRIF,L $=1.59627$

$\mathrm{OCH} 2:$ DRIF, $\mathrm{L}=1$

OEXT1: DRIF, $\mathrm{L}=0.5$

OM11: DRIF, $\mathrm{L}=0.2$

OM12: DRIF, $\mathrm{L}=0.6$

OM13: DRIF,L $=0.05$ 


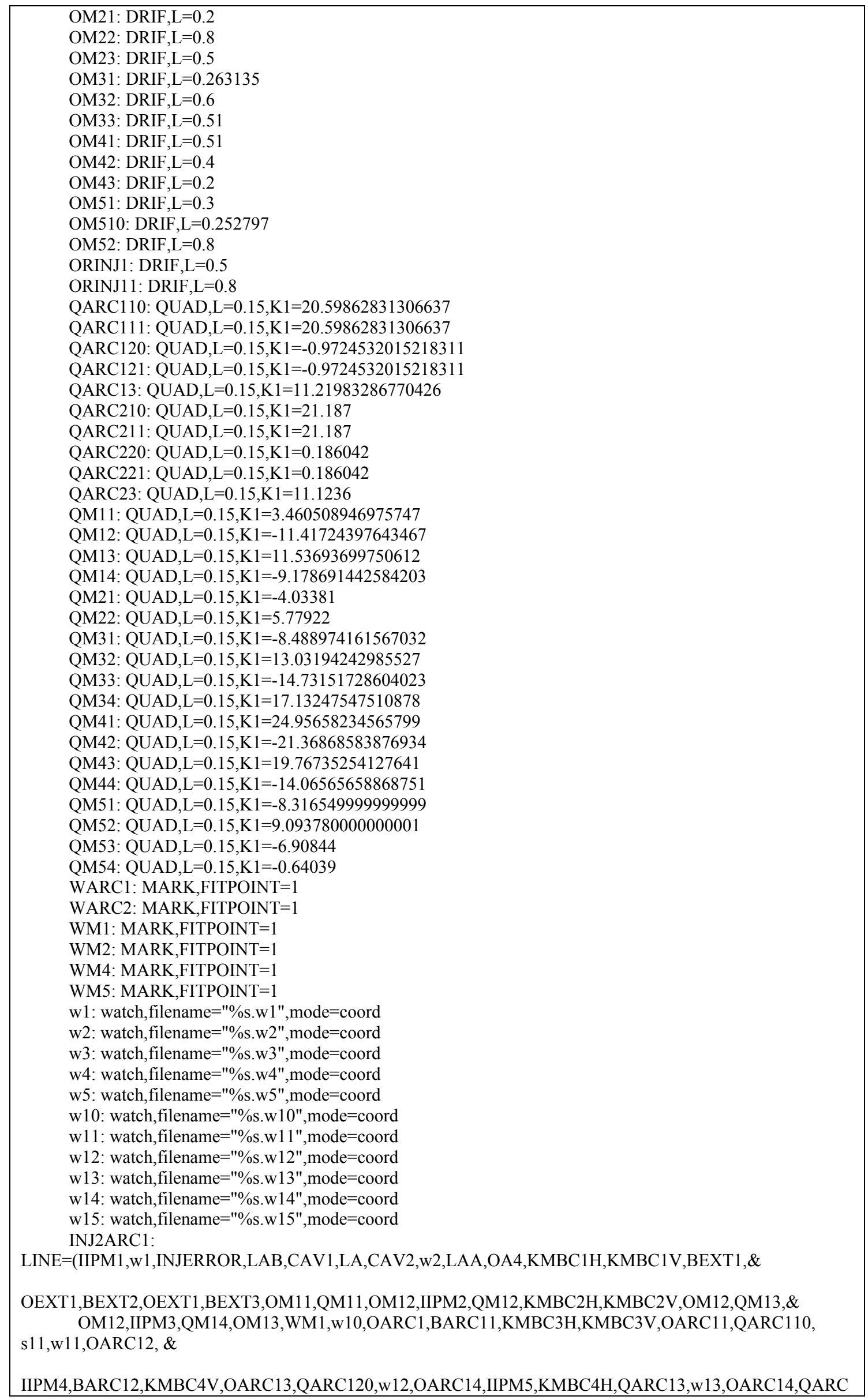




\section{$121, \&$}

OARC13,BARC13,IIPM6,KMBC5V, OARC12,IIPM7,KMBC5H,

S11,QARC111,OARC11,BARC14,IIPM8,\&

KMBC6V,OARC1,WARC1,w14,OM21,QM21,OM22,QM22,\&

IIPM9,KMBC7V,KMBC6H,OM23,BCH1,OCH1,BCH2,IIPM10,OCH2,IIPM11,KMBC8V,BCH3,OCH1,\& BCH4,OM31,QM31,IIPM12,OM32,IIPM13,KMBC9V,KMBC7H,QM32,OM32,QM33,IIPM14,OM32,\& QM34,IIPM15,KMBC10V,KMBC8H,OM33,WM2, w15)

FEL2REJ: LINE=(OM41,w1,IIPM16,KMBC9H,QM41,OM42,IIPM17,\&

KMBC11V,QM42,OM42,QM43,IIPM18,KMBC10H,OM42,QM44,IIPM19,OM43,WM4,OARC2,w2,BARC21,\&

KMBC11H,KMBC12V,OARC21,QARC210,s12,w3,OARC22,IIPM20,BARC22,KMBC13V,OARC23,QARC220 \&

OARC24,IIPM21,KMBC12H,w4,QARC23,OARC24,QARC221,OARC23,BARC23,IIPM22,KMBC14V,\&

OARC22,s12,QARC211,w5,IIPM23,KMBC13H,OARC21,BARC24,IIPM24,KMBC15V,w11,OARC2,WARC2, OM510,\&

QM51,OM52,QM52,IIPM25H,OM52,IIPM25V,KMBC14H,KMBC16V,QM53,OM52,QM54,w12,OM51,\& BRINJ1,ORINJ1,BRINJ2,w13,ORINJ1,BRINJ3,IIPM26,KMBC15H,KMBC17V,ORINJ11,WM5,\& LAB,CAV11,LA,w14, CAV21,LAA,OA4,IIPM27,w15)

主加速器入口到 FEL 的执行文件

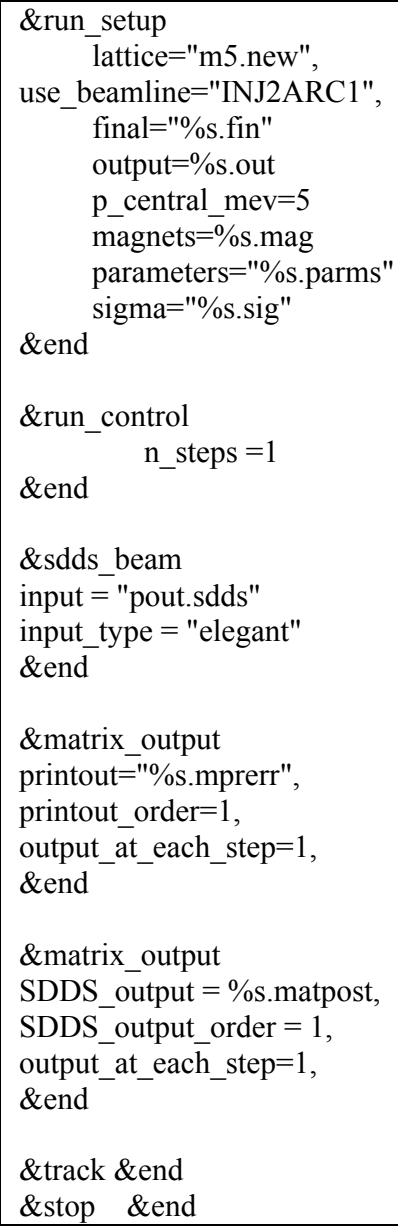




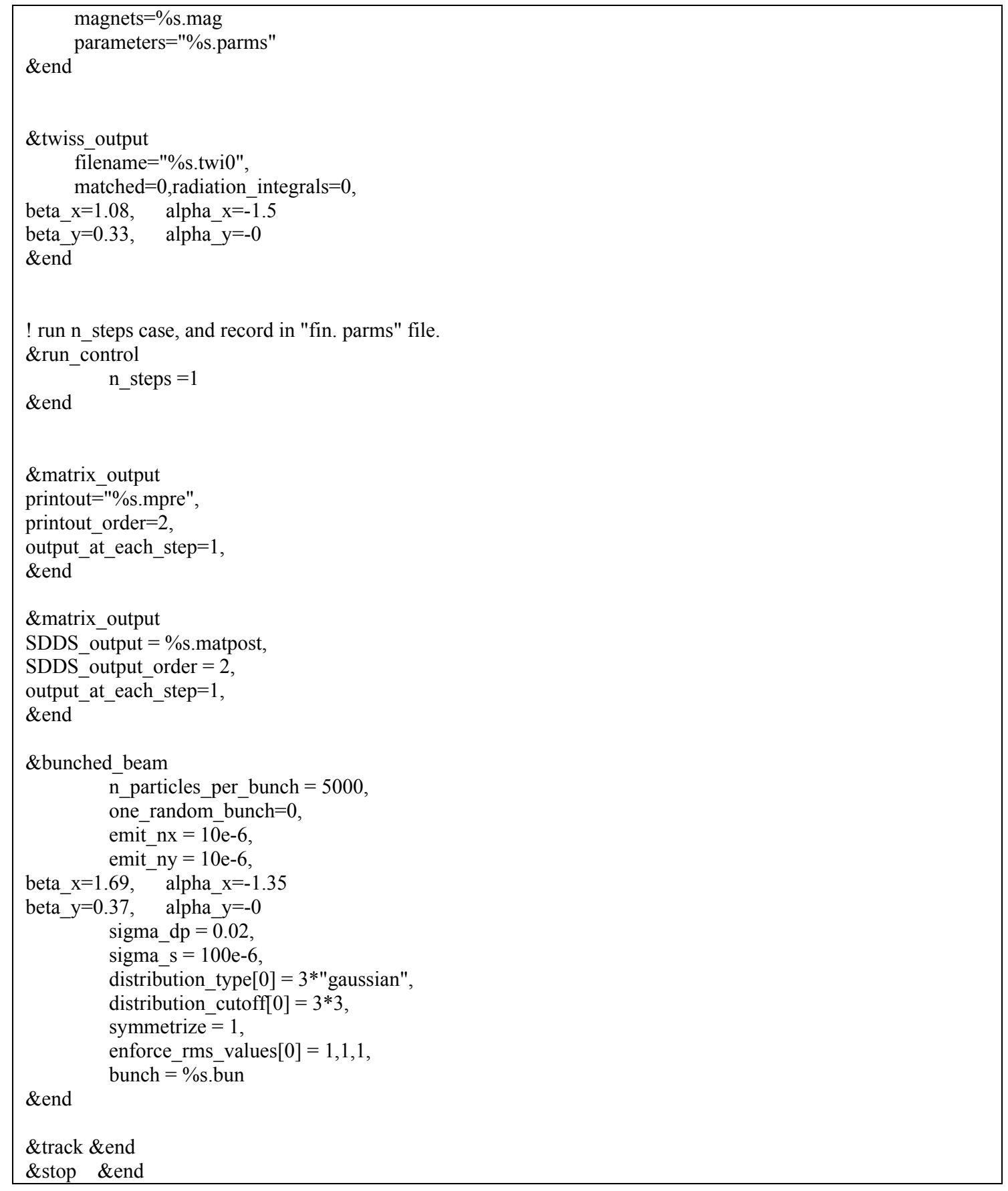




\section{参考文献}

[1] L. Merminga, D. Douglas, and G. Krafft, Annu. Rev. Nucl. Part. Sci. 53, 387 (2003).

[2] M. Tigner, A possible apparatus for clashing-beam experiments. Nuovo Cimento

$37: 1228,(1965)$

[3] S. Schriber et al., in Proceedings of the Particle Accelerator Conference, Chicago, IL, 1977 (IEEE, Piscataway, NJ, 1977), pp. 1061-1063.

[4] J. Flanz and C. Sargent, in Proceedings of the Particle Accelerator Conference, Vancouver, British Columbia, 1985 (IEEE, Piscataway, NJ, 1985), pp. 3213

3215.

[5] D.Douglas, et al., "Driver Accelerator Design for the 10kW Upgrade for the JLAB IR FEL",LINAC2001, Monterey, CA 2001, p.867.

[6] T. Shizuma, R. Hajima, E.J. Minehara, Simulated performance of the energy-recovery transport system for JAERI-FEL， NIMA475 (2001) 569-573

[7] N. Nishimori, R. Hajima, H. Iijima, FEL OSCILLATION WITH A HIGH EXTRACTION EFFICIENCY AT JAEA ERL FEL， FEL2006， 265-272

[8] N.A. Vinokurov, N.G. Gavrilov B.A. Knyazev, STATUS OF THE NOVOSIBIRSK HIGH POWER TERAHERTZ FEL， FEL2006，492-495

[9] D. J. Holder et al, 'The Status of the Daresbury Energy Recovery Prototype Project, EPAC 06,Edinburgh, p187.

[10] Vladimir N. Litvinenko, James Alduino, Dana Beavis, STATUS OF R\&D ENERGY RECOVERY LINAC AT BROOKHAVEN NATIONAL

LABORATORY, PAC07, 1347-1349

[11] V. Medjidzade, M. Liepe, S. Belomestnykh, DESIGN OF THE CW CORNELL ERL INJECTOR CRYOMODULE， PAC05，4290-4292

[12] Lee BC, et al. Proc. 2002 Linear Accel.Conf., p. 857

[13] Bazarov I, et al. CHESS Tech. Memo 01-003, JLAB-ACT-01-04 (2001)

[14] Gruner S, et al. Rev. Sci. Inst. 73:1402(2002)

[15] Ben-Zvi I, et al. Proc. 2001 Part. Accel.Conf., p. 350

[16] J. A. Clarke, FUTURE LIGHT SOURCES: INTEGRATION OF LASERS,

FELS AND ACCELERATORS AT 4GLS, FEL2007, 257-264

[17] Poole MW, Clarke JA, Seddon EA. Proc.2002 Euro. Part. Accel. Conf., p. 733

[18] Steffens E, Schindler U, eds. Proc. ERLSYN2002 Workshop (2002)

[19] Padmore HA, Schoenlein RW, ZholentsAA. Synchrotron Radiat. News

$14: 26(2001)$

[20] S. Sakanaka, R. Hajima, Status of the ERL Projects at KEK and JAEA, http://epaper.kek.jp/fls06/TALKS/WG205_TALK.PDF, FLS06

[21]J. Sekutowicz et al, Proposed continuous wave energy recovery operation of an x-ray FEL, PRST-AB 8, 010701(2005)

[22] MacKay W, Ben-Zvi I, et al. Proc. 2001Part. Accel. Conf., p. 3126;

[23] Parkhomchuk V, Ben-Zvi I. BNL CA/AP/47 (2001)

[24] Ben-Zvi I, Kewisch J, Murphy J, Peggs S.Nucl. Instrum. Methods A 463:94 (2001)

[25] Peggs S, Ben-Zvi I, Kewisch J, Murphy J.Proc. 2001 Part. Accel. Conf., p. 37

[26] Merminga L, et al. Proc. 2002 Eur. Part.Accel. Conf., p. 203

[27] http://conferences.jlab.org/ERL/ 
[28] 丁原涛, 北京大学 SASE FEL 的物理研究与优化设计, 博士学位毕业论文, 北京大学, 2004

[29] Kwang-Je Kim, Zhirong Huang, Synchrotron Radition and Free Electron Laser, USPAS Lecture Notes, Jan.2008, Part II, P46

[30] Kwang-Je Kim, Zhirong Huang, Synchrotron Radition and Free Electron Laser, USPAS Lecture Notes, Jan.2008, Part II, P45

[31] S.V.Benson, Spreadsheet for calculating the performance of a Free-electron Lasers, CEBAF TN 94-065

[32] Hasan Padamsee, Jens Knobloch, Tom Hays, A wiley-Interscience Publication, John Wiley \& Sons, Inc, 1998, 392

[33] G.A.Krafft, I.Bazarov, Recirculated and Energy Recovery Linear Accelerators, Lecture 10, USPAS Lecture notes, Jan 2008

[34] 吴文忠, 超导腔的高阶模及其衰减器的理论与实验研究, 硕士学位毕业论文, 北京大学, 2004, p10

[35] 鲁向阳, 金晓, 向蓉, 超导加速器 $\mathrm{CW}$ 模式的高阶模初步分析, 强激光与 粒子束, Vol17，3 (466-469)，2005

[36] Zhao Kui, Hao Jiankui et al. Research on DC-RF superconducting photocathode injector for high average power FELs, Nucl. Instr. Meth. Phys. Res. A 475 (2001) 564.

[37] Guimei Wang, Kui Zhao, Jiankui Hao, Xiangyang Lu, Yuantao Ding, Shengwen Quan, Senlin Huang, Jia'er Chen, EXPERIMENTL PROGRESS of DC-SC

PHOTOINJECTOR AT PEKING UNIVERSITY, fel2005, P161-163

[38] Zhu Feng et al, Updated design of the DC-SC photo-injector at Peking University, High power laser and particle beams, 2006(18):653-656

[39]丁原涛, 北京大学 SASE FEL 的物理研究与优化设计, 博士学位毕业论文, 北京大学, 2004

[40] B.E. Carlsten, New photoelectron injector design for the Los Alamos National Laboratory XUV FEL accelerator, Nucl. Instr. and Meth. A285 (1989) 313

[41] A.Chao, Physics of Collective Beam Instabilities in High Energy Accelerators, Wiley (1993)

[42] K.Floetmann,ASTRA, http://www.desy.de/ mpyflo/Astra_dokumentation/

[43] Martin Rinser, Theory and design of charged particle beams, John Wiley \& Sons, Inc, p469

[44] Martin Rinser, Theory and design of charged particle beams, John Wiley \& Sons, Inc, p65

[45] Martin Rinser, Theory and design of charged particle beams, John Wiley \& Sons, Inc, p57

[46] Martin Rinser, Theory and design of charged particle beams, John Wiley \& Sons, Inc, p469

[47] B.E. Carlsten, New photoelectron injector design for the Los Alamos National

Laboratory XUV FEL accelerator, Nucl. Instr. and Meth. A285 (1989) 313

[48] Martin Rinser, Theory and design of charged particle beams, John Wiley \& Sons, Inc, $\mathrm{p} 45$

[49] Alexander Wu Chao, Maury Tigner, Handbook of Accelerator Physics and Engineering, World Scientific, 3rd printing, p119

[50] K.-J.Kim, RF and space-charge effects in laser-driven RF electron guns,

Nucl.Instr. and Meth. A275,201 (1989) 
[51] 魏开煜, 带电束流传输理论, 现代物理学丛书, 科学出版社, 1986, p254

[52] D. Douglas, Technical Note 96-050, Jefferson Laboratory (1996).

[53] T. Shizuma, R. Hajima, E.J. Minehara, INJECTOR DESIGN FOR THE JAERI-FEL ENERGY-RECOVERY TRANSPORT, p1074-1076, EPAC2000.

[54] D.Kayran, V.N.Litvinenko, Novel method of emittance preservation in ERL merging system in presence of strong space charge forces, pac2005, p2512-2514

[55] V.N. Litvinenko, R. Hajima, D. Kayran, NIM A 557, (2006) pp 165-175

[56] 魏开煊, 带电束流传输理论, 现代物理学丛书, 科学出版社, 1986, p261-266

[57] R. Servranckx, K. Brown, L. Schachinger, D. Douglas, Users Guide to the

Program DIMAD, SLAC report 285 UC-28 May 1985.

[58] P.Piot et al., EPAC'98,pp.1447-1449,Stockholm, June 1998

[59] P.Piot et al.,"Emittances and Energy Spread srudies in Jefferson Lab

Free-Electron Laser",EPAC2000,Vienna,June2000

[60] D.Douglas, The Jefferson Lab 1kW IR FEL, Phyiscs, LINAC2000,P716-720

[61] Vladimir N.Litvinenko, Ryoichi Hajima, Dmitry Kayran, Merger design for ERLs, NIMA, 557,1 (165-175) , Feb. 2006

[62] L.Young, J.Billen, Parmela manual, p46

[63] I.V.Bazarov,G.A.Krafft,L.Merminga, Linac optics for energy recovery linac, PAC2001, p3347-3349

[64] J.Rosenzweig, L.Serafini, Transverse Particle motion in radio-frequency linear accelerators, Physical Review E, 49,2(1599-1602),Feb, 1994

[65] P.Piot, Y.-E. Sun, Note on the transport matrix measurement of a TESLA cavity, FNPL note

[66] Alex Chao, Lecture Notes on Accelerator Physics, USPAS2007, P54

[67] http://www-bdnew.fnal.gov/pbar/organizationalchart/lebedev/OptiM/optim.htm

[68] L.Young, J.Billen , PARMELA, laacg1.lanl.gov/laacg/services/parmela.html

[69] Kwang-Je Kim, Zhirong Huang, Synchrotron Radition and Free Electron Laser,

USPAS Lecture Notes, Jan.2008, Part II, P15

[70] 庄杰佳，自由电子激光理论与实验研究，书稿

[71] Kwang-Je Kim, Zhirong Huang, Synchrotron Radition and Free Electron Laser, USPAS Lecture Notes, Jan.2008, Part I, P27

[72] L. Merminga and J. Delayen, "On the Optimization of $Q_{\text {ext }}$ Under Heavy Beam Loading and in the Presence of Microphonics", CEBAF-TN\# 96-022

[73] D.Douglas, Longitudinal Phase Space Management in the IR Upgrade FEL

Driver, JLAB-TN-00-020, 2000

[74] 夏国兴, 北京大学 SASE FEL 磁压缩装置的研究, 博 士 后 研 究工 作 报 告, 北京大学, 2005

[75] Alex Chao, Lecture Notes on Accelerator Physics, USPAS2007

[76] M. Borland, "elegant: A flexible SDDS-Compilant Code for Accelerator

Simulation", APS LS-287, September 2000.

[77] D.Douglas, Error Estimates for the IR FEL Transport System,

JLAB-TN-96-035, 1996

[78] Y. Chao, Methods of Orbit Correction System Optimization, Proceedings of

1997 Particle Accelerator Conference, Vancouver, Canada.

[79] Y.-C. Chao, V.Mertens, "Analysis and Optimization of orbit correction configurations using Generalised response matrices and its application to the LHC injection transfer lines TI2 and TI8", LHC Project report 470 
[80] Y.-C.Chao, "Evaluation and Optimization of Orbit Correction System

Configuration of $12 \mathrm{GeV}$ CEBAF", JLAB-TN-06-015

[81] Alexander Wu Chao, Maury Tigner, "Handbook of Accelerator Physics and

Engineering", 3rd printing, World Scientific, P297-299

[82] http://en.wikipedia.org/wiki/Singular_value_decomposition

[83] G. Arduini, M. Giovannozzi, MEASUREMENT AND OPTIMISATION OF

THE PS-SPS TRANSFER LINE OPTICS，PAC1999，1999，1282-1284

[84] A.Chao, Physics of Collective Beam Instabilities in High Energy Accelerators, Wiley (1993)

[85] P.B.Wilson, AIP Conference Proceedings 87, 450 (1982)

[86] R. Helm, Proc. of the 1966 Linac Accelerator Conference, Los Alamos, 254

(1966).

[87] P.Lapostolle, A.Septier, Linear Accelerators, North Holland, Amsterdam, 175

(1970)

[88] O.H.Altenmueller et al., Proc. Of the 1966 Linear Accelerator Conference, Los Alamos, 267 (1966)

[89] W.K.H.Panofsky et al, Science 152(1966)

[90] J.J.Bisognano, Proceeding of the third workshop on RF superconducitivity, Argonne National Lab, ANL-PHY-88-1, 237(1988)

[91] N. R. Sereno, "Experimental Studies of Multipass Beam Breakup and Energy

Recovery using the CEBAF Injector Linac," Ph.D. Thesis, University of Illinois (1994)

[92] Hasan Padamsee, Jens Knobloch, Tom Hays, RF Superconductivity for

Accelerators, John Wiley \& Sons Inc., 1998, p341

[93] E. Pozdeyev, Phys. Rev. ST Accel. Beams 8, 054401 (2005).

[94] Hasan Padamsee, Jens Knobloch, Tom Hays, RF Superconductivity for

Accelerators, John Wiley \& Sons Inc., 1998, p41

[95] N. Baboi, M. Dohlus, C. Magne, et al, Proceedings of EPAC 2000, Vienna, Austria, 1107-1109

[96] StephaneFartoukh, CEA/DAPNIA/SEA-98-18, TESLA Report 1998-13, P13

[97] S. Fartoukh, M. Jablonka, J. M. Joly, et al, Proceedings of the 1999 Particle

Accelerator Conference, New York, 1999, 922-924

[98] https://mpi.slac.stanford.edu:8443/ext/index.php/Omega3P

[99] L. Xiao, C. Adolphsen, V. Akcelik, MODELING IMPERFECTION EFFECTS

ON DIPOLE MODES IN TESLA CAVITY, PAC07, 2454-2456

[100] K. Beard, Technical Note 02-045, Jefferson Laboratory (2002).

[101] B. Yunn, Phys. Rev. ST Accel. Beams 8, 104401 (2005).

[102] E. Pozdeyev, Phys. Rev. ST Accel. Beams 8, 054401 (2005).

[103] K .B. Beard, L. Merminga, B.Yunn, Jlab Tech. Note, JLAB-TN-02-044

[104] J.J. Bisognano and R.L. Gluckstern, 1987 PAC，Proceedings, 1078 (1987)

[105] I. Bazarov and G. Hoffstaetter, in Proceedings of the European Particle Accelerator Conference, Lucerne, Switzerland, 2004 (2004), pp. 2194-2196.

[106] Christopher D. Tennant, STUDIES OF ENERGY RECOVERY LINACS AT

JEFFERSON LABORATORY, Ph.D thesis, W\&M, P137, 2006

[107]L. Xiao, C. Adolphsen, et.al, MODELING IMPERFECTION EFFECTS ON

DIPOLE MODES IN TESLA CAVITY， PAC07，2454-2456 
[108] Hasan Padamsee, Jens Knobloch, Tom Hays 编著, RF Superconductivity for Accelerators, John Wiley \& Sons Inc., 1998, p341

[109] 吴文忠, 超导腔的高阶模及其衰减器的理论与实验研究, 硕士学位毕业论 文，北京大学，2004

[110] R. Rand and T. Smith, Part. Accel. 11, 1 (1980)

[111] E. Pozdeyev, Phys. Rev. ST Accel. Beams 8, 054401 (2005).

[112] D.Douglas, Operation of the FEL Upgrade with skew Quad Reflection and Rotation, JLAB-TN-04-016, JLAB-TN-04-023,JLAB-TN-04-25(2004) 



\section{致 谢}

本论文的完成得到了北京大学重离子物理研究所和美国 Jefferson 国家实 验室多位老师和同学的指导和帮助。

首先感谢我的导师赵酸教授, 感谢他在这五年多的时间里给予的悉心教导和 关怀, 在许多问题上给予的启迪, 并提供了大量机会, 使我的研究工作得以顺利 进行, 感谢他领导的射频超导组提供的良好实验条件和宽松的工作环境。赵老师 学识洣博, 思维敏锐, 经验丰富, 对科研追求严谨和不断创新的精神、为人处世 的坦荡和豁达将使我终身受益, 他的言传身教将是我一生的财富。我将谨遵恩师 的教诲, 孜孜以求, 不断进取, 以不辜负恩师对我的期望。

感谢我在美国 Jefferson Lab 的指导老师 Dr. Yu-Chiu Chao，感谢他对我 的论文工作的全心指导和帮助, 从具体小节到论文大局研究, 他都耐心指引, 赵 先生治学严谨, 知识洣博, 诲人不倦以及对工作的热爱和一丝不苟的态度, 都为 我做出了榜样。感谢他对我生活上的关心, 使我很快接受并适应新的环境, 安心 进行论文设计。论文的顺利进展和研究成果和赵先生倾注了大量的心血和时间密 不可分。

感谢北京大学客座教授庄杰佳先生对我五年多的指导, 庄老师渊博的学识、 丰富的经验和严谨的作风给我留下了深刻的印象。在论文的进展过程中，庄老师 提供了大量的指导和建议。从论文初稿到定稿, 庄老师不厌其烦，一审再审，大 到篇章布局的偏颇, 小到语句格式的瑕疵, 都一一予以指出。当我遇到困难的时 候, 庄老师总是耐心讲解, 帮我度过一个个难关。

感谢陈佳洱院士在百忙之中对论文工作的关心和支持, 他严谨的治学态度令 作者终身难忘。感谢鲁向阳老师几年来对作者无私的帮助, 还有他在学习生活、 实验工作和论文写作上提出的大量前瞻性的建议。感谢张保澄教授对论文工作的 支持和帮助, 对论文的完善提出宝贵的意见。感谢向蓉师姐、全胜文高工和林林 老师在光阴极实验中给予作者耐心的指导和大力的帮助。感谢丁原涛老师、黄森 林老师与作者的多次讨论和指导，感谢王莉芳老师、谢大㢷老师、郝建奎老师、 杨丽敏老师、朱风老师、吕德泉老师五年来在学习和生活上给予我很多的无私帮 助。 
感谢 JLAB 给我提供的研究机会。感谢 CASA 组成员给予无私的帮助和大量讨 论, 感谢 Lia Merminga 和 G. A. Krafft 给予工作上的大力支持和指导。感谢 Hari Areti 对作者工作和生活的安排。感谢 David Douglas 在束线设计上提供宝贵的 经验和理论指导, 感谢 S. V. Benson 在 FEL 上给予作者的指导和帮助, 感谢 George Neil 对作者工作的大量支持, 使作者有机会与各方面专家讨论, 感谢 FEL 组成 员多次给与有益的讨论和指导, 对论文设计提供大量宝贵的经验。感谢 Swapan Chat topadhyay 给作者提供的研究条件。

感谢 SLAC 的 Alex Chao 教授在作者工作中给予大量的指导和建议, 赵教授 思维缜密, 学识渊博, 经验丰富, 在多次讨论中, 他不拘一格的思路和循循善诱 的教导给予我无尽的启迪, 使作者对问题的认识更加深刻全面, 在此深深致谢。 感谢 SLAC 的 Zenghai Li 在高阶模研究上提供详细的资料和有益讨论, 使论文工 作更加完善。

感谢刘初玉同学五年来给予的大量帮助和支持。感谢吴文忠、储祥蓄、肖斌 平、王芳、刘振超、徐文灿等师兄师姐师弟师妹们, 感谢他们在学习和生活上给 予我的帮助。特别感谢幽默搞笑的焦飞师兄一直以来在学习和生活上照顾, 在我 遇到困难时给予的鼓励和帮助。

感谢我的先生郭全中陪伴我度过美好的大学和博士生活, 在人生的道路上为 我遮风挡雨, 在生活和工作中给我无限的支持和鼓励。感谢时刻牵挂我的父母和 哥哥, 还有那些不在我身边却时时关心我、爱护我的家人朋友们, 他们是我生命 中永远的依靠和支持, 他们无微不至的关怀, 是我前进的动力, 他们的殷殷希望, 激发我不断前行。

论文的完成远非终点, 文中的不足和浅显之处是我新征程的起点, 我将带着 你们的教导和期望继续前行, 努力做一个有用之人。

王 桂 梅 2008 年 5 月于北大技物楼 


\section{北京大学学位论文原创性声明和使用授权说明}

\section{原创性声明}

本人郑重声明: 所呈交的学位论文, 是本人在导师的指导下, 独立进行研 究工作所取得的成果。除文中已经注明引用的内容外, 本论文不含任何其他个人 或集体已经发表或撰写过的作品或成果。对本文的研究做出重要贡献的个人和集 体, 均已在文中以明确方式标明。本声明的法律结果由本人承担。

论文作者签名：日期：日年月日

\section{学位论文使用授权说明}

(必须装订在提交学校图书馆的印刷本)

本人完全了解北京大学关于收集、保存、使用学位论文的规定, 即:

- 按照学校要求提交学位论文的印刷本和电子版本;

- 学校有权保存学位论文的印刷本和电子版, 并提供目录检索与阅览服 务，在校园网上提供服务;

- 学校可以采用影印、缩印、数字化或其它复制手段保存论文;

- 因某种特殊原因需要延迟发布学位论文电子版, 授权学校 $\square$ 一年/ $\square$ 两年 $/ \square$ 三年以后，在校园网上全文发布。

（保密论文在解密后遵守此规定）

论文作者签名:

导师签名：

日期：年月日 